\title{
Maintenance treatment with antipsychotic drugs for schizophrenia (Review)
}

\author{
Leucht S, Tardy M, Komossa K, Heres S, Kissling W, Davis JM
}

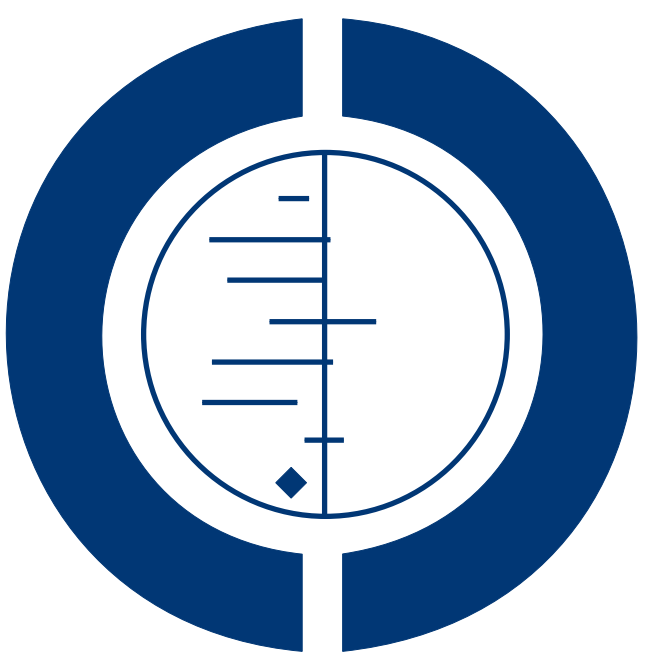

\section{THE COCHRANE COLLABORATION ${ }^{\circledR}$}

This is a reprint of a Cochrane review, prepared and maintained by The Cochrane Collaboration and published in The Cochrane Library 2012, Issue 5

http://www.thecochranelibrary.com

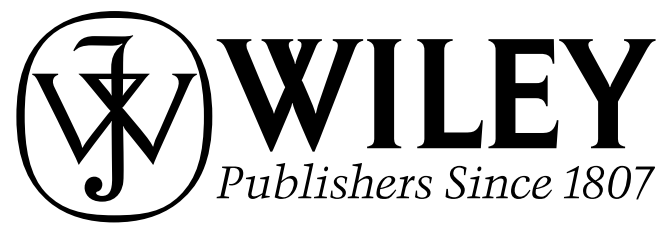

Maintenance treatment with antipsychotic drugs for schizophrenia (Review)

Copyright $\odot 2012$ The Cochrane Collaboration. Published by John Wiley \& Sons, Ltd. 
TABLE OF CONTENTS

HEADER . . . . . . . . . . . . . . . . . . . . . . . . . . . . . . . . . . . . . . . . . . . . .

ABSTRACT . . . . . . . . . . . . . . . . . . . . . . . . . . . . . . . . . . . . . . . . . . . . . . 1

PLAIN LANGUAGE SUMMARY . . . . . . . . . . . . . . . . . . . . . . . . . . . . . . . . . . . . . . . . . . . . .

SUMMARY OF FINDINGS FOR THE MAIN COMPARISON ．．．．．．．． . . . . . . . . . . . . . . . 2

BACKGROUND . . . . . . . . . . . . . . . . . . . . . . . . . . . . . . . . . . . . . . . . . . . 5

OBJECTIVES . . . . . . . . . . . . . . . . . . . . . . . . . . . . . . . . . . . . . . . . . . .

METHODS . . . . . . . . . . . . . . . . . . . . . . . . . . . . . . . . . . . . . . .

RESULTS . . . . . . . . . . . . . . . . . . . . . . . . . . . . . . . . . . . . . . . . . . . .

Figure 1. . . . . . . . . . . . . . . . . . . . . . . . . . . . . . . . . . . . . . . 12

Figure 2. . . . . . . . . . . . . . . . . . . . . . . . . . . . . . . . . . . . . . . .

Figure 3. . . . . . . . . . . . . . . . . . . . . . . . . . . . . . . . . . . . . . 16

Figure 4. . . . . . . . . . . . . . . . . . . . . . . . . . . . . . . . . . . . . . . .

Figure 5. . . . . . . . . . . . . . . . . . . . . . . . . . . . . . . . . . . . . 23

Figure 6. . . . . . . . . . . . . . . . . . . . . . . . . . . . . . . . . . . . . . . .

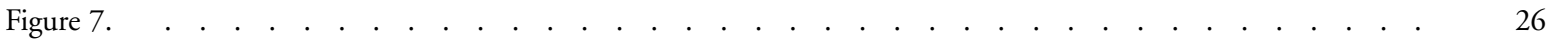

DISCUSSION . . . . . . . . . . . . . . . . . . . . . . . . . . . . . . . . . . . . . . . . . . . .

AUTHORS' CONCLUSIONS . . . . . . . . . . . . . . . . . . . . . . . . . . . . . . . . . . .

ACKNOWLEDGEMENTS . . . . . . . . . . . . . . . . . . . . . . . . . . . . . . . . . . . . . . .

REFERENCES . . . . . . . . . . . . . . . . . . . . . . . . . . . . . . . . . . . . . . . . 33

CHARACTERISTICS OF STUDIES . . . . . . . . . . . . . . . . . . . . . . . . . . . . . . . . . 43

DATA AND ANALYSES . . . . . . . . . . . . . . . . . . . . . . . . . . . . . . . . . . . . . . . . . . . . . . .

Analysis 1.1. Comparison 1 Maintenance treatment with antipsychotic drugs versus placebo/no treatment, Outcome 1

Relapse: up to 3 months.

Analysis 1.2. Comparison 1 Maintenance treatment with antipsychotic drugs versus placebo/no treatment, Outcome 2 Relapse: 4 to 6 months.

Analysis 1.3. Comparison 1 Maintenance treatment with antipsychotic drugs versus placebo/no treatment, Outcome 3 Relapse: 7 to 12 months. . . . . . . . . . . . . . . . . . . . . . . . . . . . . . . . . . . . . . . .

Analysis 1.4. Comparison 1 Maintenance treatment with antipsychotic drugs versus placebo/no treatment, Outcome 4 Relapse: $>12$ months. . . . . . . . . . . . . . . . . . . . . . . . . . . . . . . .

Analysis 1.5. Comparison 1 Maintenance treatment with antipsychotic drugs versus placebo/no treatment, Outcome 5 Relapse: independent of duration.

Analysis 1.6. Comparison 1 Maintenance treatment with antipsychotic drugs versus placebo/no treatment, Outcome 6 Leaving the study early: due to any reason.

Analysis 1.7. Comparison 1 Maintenance treatment with antipsychotic drugs versus placebo/no treatment, Outcome 7 Leaving the study early: due to adverse events. .

Analysis 1.8. Comparison 1 Maintenance treatment with antipsychotic drugs versus placebo/no treatment, Outcome 8 Leaving the study early: due to inefficacy.

Analysis 1.9. Comparison 1 Maintenance treatment with antipsychotic drugs versus placebo/no treatment, Outcome 9 Global state: number of participants improved.

Analysis 1.10. Comparison 1 Maintenance treatment with antipsychotic drugs versus placebo/no treatment, Outcome 10 Service use: number of participants hospitalised. . . . . . . . . . . . . . . . . . . . . . . . . . . . . . . .

Analysis 1.11. Comparison 1 Maintenance treatment with antipsychotic drugs versus placebo/no treatment, Outcome 11 Service use: number of participants discharged.

Analysis 1.12. Comparison 1 Maintenance treatment with antipsychotic drugs versus placebo/no treatment, Outcome 12 Death: any.

Analysis 1.13. Comparison 1 Maintenance treatment with antipsychotic drugs versus placebo/no treatment, Outcome 13 Death: due to natural causes.

Analysis 1.14. Comparison 1 Maintenance treatment with antipsychotic drugs versus placebo/no treatment, Outcome 14 Suicide.

Analysis 1.15. Comparison 1 Maintenance treatment with antipsychotic drugs versus placebo/no treatment, Outcome 15

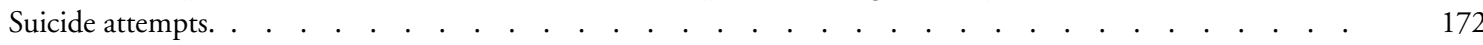

Maintenance treatment with antipsychotic drugs for schizophrenia (Review)

Copyright $\odot 2012$ The Cochrane Collaboration. Published by John Wiley \& Sons, Ltd. 
Analysis 1.16. Comparison 1 Maintenance treatment with antipsychotic drugs versus placebo/no treatment, Outcome 16 Suicide ideation. . . . . . . . . . . . . . . . . . . . . . . . . . . . . . . . . .

Analysis 1.17. Comparison 1 Maintenance treatment with antipsychotic drugs versus placebo/no treatment, Outcome 17 Violent/aggressive behaviour.

Analysis 1.18. Comparison 1 Maintenance treatment with antipsychotic drugs versus placebo/no treatment, Outcome 18 Adverse effects: at least one adverse event.

Analysis 1.19. Comparison 1 Maintenance treatment with antipsychotic drugs versus placebo/no treatment, Outcome 19 Adverse effects: movement disorders: at least one movement disorder. . . . . . . . . . . . . . . . . . . .

Analysis 1.20. Comparison 1 Maintenance treatment with antipsychotic drugs versus placebo/no treatment, Outcome 20 Adverse effects: movement disorders: akathisia.

Analysis 1.21. Comparison 1 Maintenance treatment with antipsychotic drugs versus placebo/no treatment, Outcome 21 Adverse effects: movement disorders: akinesia. . . . . . . . . . . . . . . . . . . . . . . . . .

Analysis 1.22. Comparison 1 Maintenance treatment with antipsychotic drugs versus placebo/no treatment, Outcome 22 Adverse effects: movement disorders: dyskinesia. . . . . . . . . . . . . . . . . . . . . . . . . . . . . .

Analysis 1.23. Comparison 1 Maintenance treatment with antipsychotic drugs versus placebo/no treatment, Outcome 23 Adverse effects: movement disorders: dystonia. . . . . . . . . . . . . . . . . . . . . . . . . . . .

Analysis 1.24. Comparison 1 Maintenance treatment with antipsychotic drugs versus placebo/no treatment, Outcome 24 Adverse effects: movement disorders: rigor. . . . . . . . . . . . . . . . . . . . . . . . . . . . . . . . . .

Analysis 1.25. Comparison 1 Maintenance treatment with antipsychotic drugs versus placebo/no treatment, Outcome 25 Adverse effects: movement disorders: tremor.

Analysis 1.26. Comparison 1 Maintenance treatment with antipsychotic drugs versus placebo/no treatment, Outcome 26 Adverse effects: movement disorders: use of antiparkinson medication. . . . . . . . . . . . . . . . . . .

Analysis 1.27. Comparison 1 Maintenance treatment with antipsychotic drugs versus placebo/no treatment, Outcome 27 Adverse effects: sedation.

Analysis 1.28. Comparison 1 Maintenance treatment with antipsychotic drugs versus placebo/no treatment, Outcome 28 Adverse effects: weight gain. . . . . . . . . . . . . . . . . . . . . . . . . . . . . . . . . . . . .

Analysis 1.29. Comparison 1 Maintenance treatment with antipsychotic drugs versus placebo/no treatment, Outcome 29 Quality of life.

Analysis 1.30. Comparison 1 Maintenance treatment with antipsychotic drugs versus placebo/no treatment, Outcome 30 Number of participants employed: 7 to 12 months. . . . . . . . . . . . . . . . . . . . . . . . . . . . . .

Analysis 2.1. Comparison 2 Subgroup analysis (relapse at 12 months), Outcome 1 Subgroup analysis: participants with a first episode.

Analysis 2.2. Comparison 2 Subgroup analysis (relapse at 12 months), Outcome 2 Subgroup analysis: participants in remission.

Analysis 2.3. Comparison 2 Subgroup analysis (relapse at 12 months), Outcome 3 Subgroup analysis: various durations of stability before entering the study. . . . . . . . . . . . . . . . . . . . . . . . . . . . . . . . . . . . . . . . .

Analysis 2.4. Comparison 2 Subgroup analysis (relapse at 12 months), Outcome 4 Subgroup analysis: abrupt withdrawal versus tapering. . . . . . . . . . . . . . . . . . . . . . . . . . . . . . . . . . . . . . . . . . . .

Analysis 2.5. Comparison 2 Subgroup analysis (relapse at 12 months), Outcome 5 Subgroup analysis: single antipsychotic drugs.

Analysis 2.6. Comparison 2 Subgroup analysis (relapse at 12 months), Outcome 6 Subgroup analysis: depot versus oral drugs.

Analysis 2.7. Comparison 2 Subgroup analysis (relapse at 12 months), Outcome 7 Subgroup analysis: first- versus secondgeneration antipsychotic drugs. . . . . . . . . . . . . . . . . . . . . . . . . . . . . . . . . . . . . . . . . .

Analysis 2.8. Comparison 2 Subgroup analysis (relapse at 12 months), Outcome 8 Subgroup analysis: appropriate versus unclear allocation concealment. . . . . . . . . . . . . . . . . . . . . . . . . . . . . . . . . . . . . . . . . .

Analysis 2.9. Comparison 2 Subgroup analysis (relapse at 12 months), Outcome 9 Subgroup analysis: blinded versus open

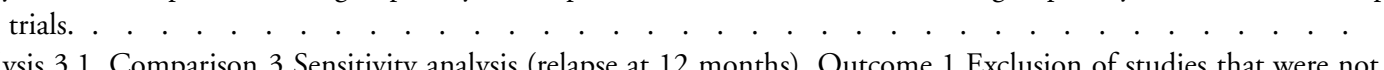

Analysis 3.1. Comparison 3 Sensitivity analysis (relapse at 12 months), Outcome 1 Exclusion of studies that were not explicitly described as randomised.

Analysis 3.2. Comparison 3 Sensitivity analysis (relapse at 12 months), Outcome 2 Exclusion of non-double-blind studies. . . . . . . . . . . . . . . . . . . . . . . . . . . . . . . . . . . . . . . . . . . . . . . . . . .

A

Maintenance treatment with antipsychotic drugs for schizophrenia (Review)

Copyright $\odot 2012$ The Cochrane Collaboration. Published by John Wiley \& Sons, Ltd. 
Analysis 3.4. Comparison 3 Sensitivity analysis (relapse at 12 months), Outcome 4 Original authors' assumptions on dropouts.

Analysis 3.5. Comparison 3 Sensitivity analysis (relapse at 12 months), Outcome 5 Inclusion of only large studies (> 200 participants).

Analysis 3.6. Comparison 3 Sensitivity analysis (relapse at 12 months), Outcome 6 Exclusion of studies with clinical diagnosis. . . . . . . . . . . . . . . . . . . . . . . . . . . . . . . . . . . . 213

Analysis 3.7. Comparison 3 Sensitivity analysis (relapse at 12 months), Outcome 7 Three months stable. . . . . 214

Analysis 3.8. Comparison 3 Sensitivity analysis (relapse at 12 months), Outcome 8 Six months stable. . . . . . 215

Analysis 3.9. Comparison 3 Sensitivity analysis (relapse at 12 months), Outcome 9 Nine months stable. . . . . . 216

Analysis 3.10. Comparison 3 Sensitivity analysis (relapse at 12 months), Outcome 10 Exclusion of studies with unclear randomisation method. . . . . . . . . . . . . . . . . . . . . . . . . . . . . . .

Analysis 3.11. Comparison 3 Sensitivity analysis (relapse at 12 months), Outcome 11 Exclusion of studies with unclear allocation concealment method. . . . . . . . . . . . . . . . . . . . . . . . . . . . 218

ADDITIONAL TABLES . . . . . . . . . . . . . . . . . . . . . . . . . . . . . . . . . . . . . . . . .

APPENDICES . . . . . . . . . . . . . . . . . . . . . . . . . . . . . . . . . . . . . . . . . . . .

HISTORY . . . . . . . . . . . . . . . . . . . . . . . . . . . . . . . . . . . . . . . . . . 229

CONTRIBUTIONS OF AUTHORS . . . . . . . . . . . . . . . . . . . . . . . . . . . . . . . . . . . . . . . . . . .

DECLARATIONS OF INTEREST . . . . . . . . . . . . . . . . . . . . . . . . . . . . . . . . . . . . . . . . . . . .

SOURCES OF SUPPORT . . . . . . . . . . . . . . . . . . . . . . . . . . . . . . . . . . . . . . . . . . . . .

DIFFERENCES BETWEEN PROTOCOL AND REVIEW . . . . . . . . . . . . . . . . . . . . . . . . . 230

INDEX TERMS . . . . . . . . . . . . . . . . . . . . . . . . . . . . . . . . . . . . . 230 


\title{
[Intervention Review]
}

\section{Maintenance treatment with antipsychotic drugs for schizophrenia}

\author{
Stefan Leucht ${ }^{1}$, Magdolna Tardy ${ }^{1}$, Katja Komossa ${ }^{2}$, Stephan Heres ${ }^{1}$, Werner Kissling ${ }^{1}$, John M Davis ${ }^{3}$ \\ ${ }^{1}$ Klinik und Poliklinik für Psychiatrie und Psychotherapie, Technische Universität München Klinikum rechts der Isar, München, \\ Germany. ${ }^{2}$ Klinik und Poliklinik für Psychosomatische und Medizin und Psychotherapie, Technische Universität München, Klinikum \\ rechts der Isar, München, Germany. ${ }^{3}$ University of Illinois at Chicago, Chicago, USA \\ Contact address: Stefan Leucht, Klinik und Poliklinik für Psychiatrie und Psychotherapie, Technische Universität München Klinikum \\ rechts der Isar, Möhlstr. 26, München, 81675, Germany. Stefan.Leucht@lrz.tu-muenchen.de.
}

Editorial group: Cochrane Schizophrenia Group.

Publication status and date: New, published in Issue 5, 2012.

Review content assessed as up-to-date: 21 February 2012.

Citation: Leucht S, Tardy M, Komossa K, Heres S, Kissling W, Davis JM. Maintenance treatment with antipsychotic drugs for schizophrenia. Cochrane Database of Systematic Reviews 2012, Issue 5. Art. No.: CD008016. DOI: 10.1002/14651858.CD008016.pub2.

Copyright (C) 2012 The Cochrane Collaboration. Published by John Wiley \& Sons, Ltd.

\begin{abstract}
A B S T R A C T
Background

The symptoms and signs of schizophrenia have been firmly linked to high levels of dopamine in specific areas of the brain (limbic system). Antipsychotic drugs block the transmission of dopamine in the brain and reduce the acute symptoms of the disorder. This review examined whether antipsychotic drugs are also effective for relapse prevention.
\end{abstract}

\section{Objectives}

To review the effects of maintaining antipsychotic drugs for people with schizophrenia compared to withdrawing these agents.

\section{Search methods}

We searched the Cochrane Schizophrenia Group's Specialised Register (November 2008), with additional searches of MEDLINE, EMBASE and clinicaltrials.gov (June 2011).

\section{Selection criteria}

We included all randomised trials comparing maintenance treatment with antipsychotic drugs and placebo for people with schizophrenia or schizophrenia-like psychoses.

\section{Data collection and analysis}

We extracted data independently. For dichotomous data we calculated relative risks (RR) and their 95\% confidence intervals (CI) on an intention-to-treat basis based on a random-effects model. For continuous data, we calculated mean differences (MD) or standardised mean differences (SMD) again based on a random-effects model.

\section{Main results}

The review currently includes 65 randomised controlled trials (RCTs) and 6493 participants comparing antipsychotic medication with placebo. The trials were published from 1959 to 2011 and their size ranged between 14 and 420 participants. In many studies the methods of randomisation, allocation and blinding were poorly reported. Although this and other potential sources of bias limited 
the overall quality, the efficacy of antipsychotic drugs for maintenance treatment in schizophrenia was clear. Antipsychotic drugs were significantly more effective than placebo in preventing relapse at seven to 12 months (primary outcome; drug 27\%, placebo 64\%, 24 RCTs, n=2669, RR 0.40 CI 0.33 to 0.49 , number needed to treat for an additional beneficial outcome (NNTB 3 CI 2 to 3 ). Hospitalisation was also reduced, however, the baseline risk was lower (drug 10\%, placebo 26\%, 16 RCTs, n=2090, RR 0.38 CI 0.27 to 0.55 , NNT 5 CI 4 to 9). More participants in the placebo group than in the antipsychotic drug group left the studies early due to any reason (at 7-12 months: drug 38\%, placebo 66\%, 18 RCTs, $n=2420$, RR 0.55 CI 0.46 to 0.66 , NNTB 4 CI 3 to 5 ) and due to inefficacy of treatment (at 7-12 months: drug 20\%, placebo 50\%, 18 RCTs, $n=2420$, RR 0.36 CI 0.28 to 0.45 , NNTB 3 CI 2 to 4). Quality of life was better in drug-treated participants (3 RCTs, $n=527$, SMD -0.62 CI -1.15 to -0.09). Conversely, antipsychotic drugs as a group and irrespective of duration, were associated with more participants experiencing movement disorders (e.g. at least one movement disorder: drug 16\%, placebo 9\%, 22 RCTs, n=3411, RR 1.55 CI 1.25 to 1.93, NNTH 25 CI 13 to 100), sedation (drug $13 \%$, placebo $9 \%, 10$ RCTs, n=146, RR 1.50 CI 1.22 to 1.84 , number needed to treat for an additional harmful outcome (NNTH) not significant) and weight gain (drug 10\%, placebo 6\%, 10 RCTs, n=321, RR 2.07 CI 1.31 to 3.25, NNTH 20 CI 14 to 33). The results of the primary outcome were robust in a number of subgroup, meta-regression and sensitivity analyses, the main exception being that the drug-placebo difference in longer trials was smaller than in shorter trials.

\section{Authors' conclusions}

The results clearly demonstrate the superiority of antipsychotic drugs compared to placebo in preventing relapse. This effect must be weighed against the side effects of antipsychotic drugs. Future studies should focus on outcomes of social participation and clarify the long-term morbidity and mortality associated with these drugs.

\section{PLAIN LANGUAGE SUMMARY}

\section{Maintenance treatment with antipsychotic drugs for schizophrenia}

Antipsychotic drugs are the mainstay of treatment of schizophrenia. The current report presents the first systematic review comparing the effects of all antipsychotic drugs compared to placebo for maintenance treatment, that is relapse prevention after the acute phase. Randomised controlled trials (RCTs) since the 1950s have consistently shown that antipsychotic drugs effectively reduce relapses and need for hospitalisation. Conversely, they are, as a group, associated with a number of side effects such as movement disorders, weight gain and sedation. 


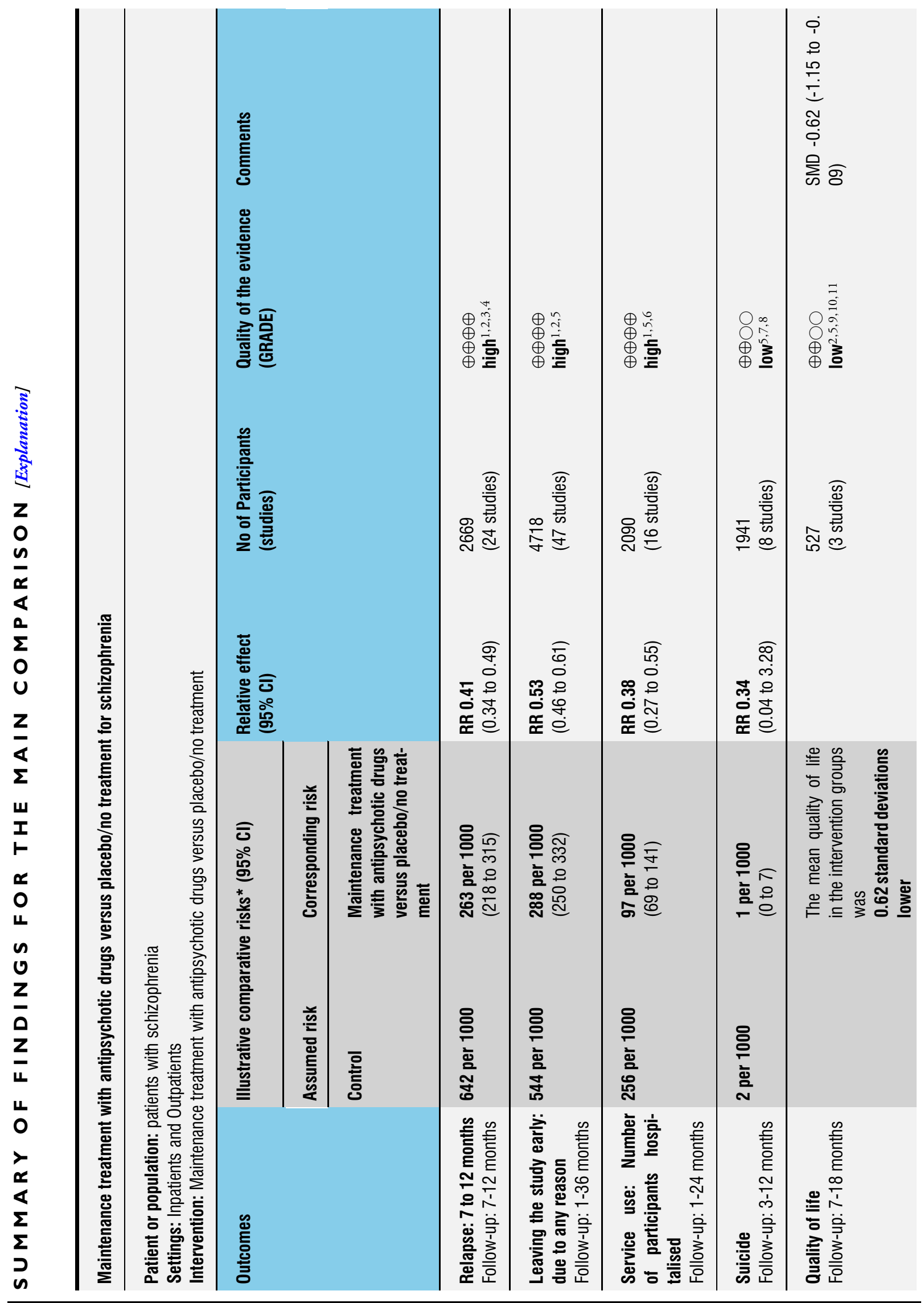

Maintenance treatment with antipsychotic drugs for schizophrenia (Review)

Copyright @ 2012 The Cochrane Collaboration. Published by John Wiley \& Sons, Ltd. 

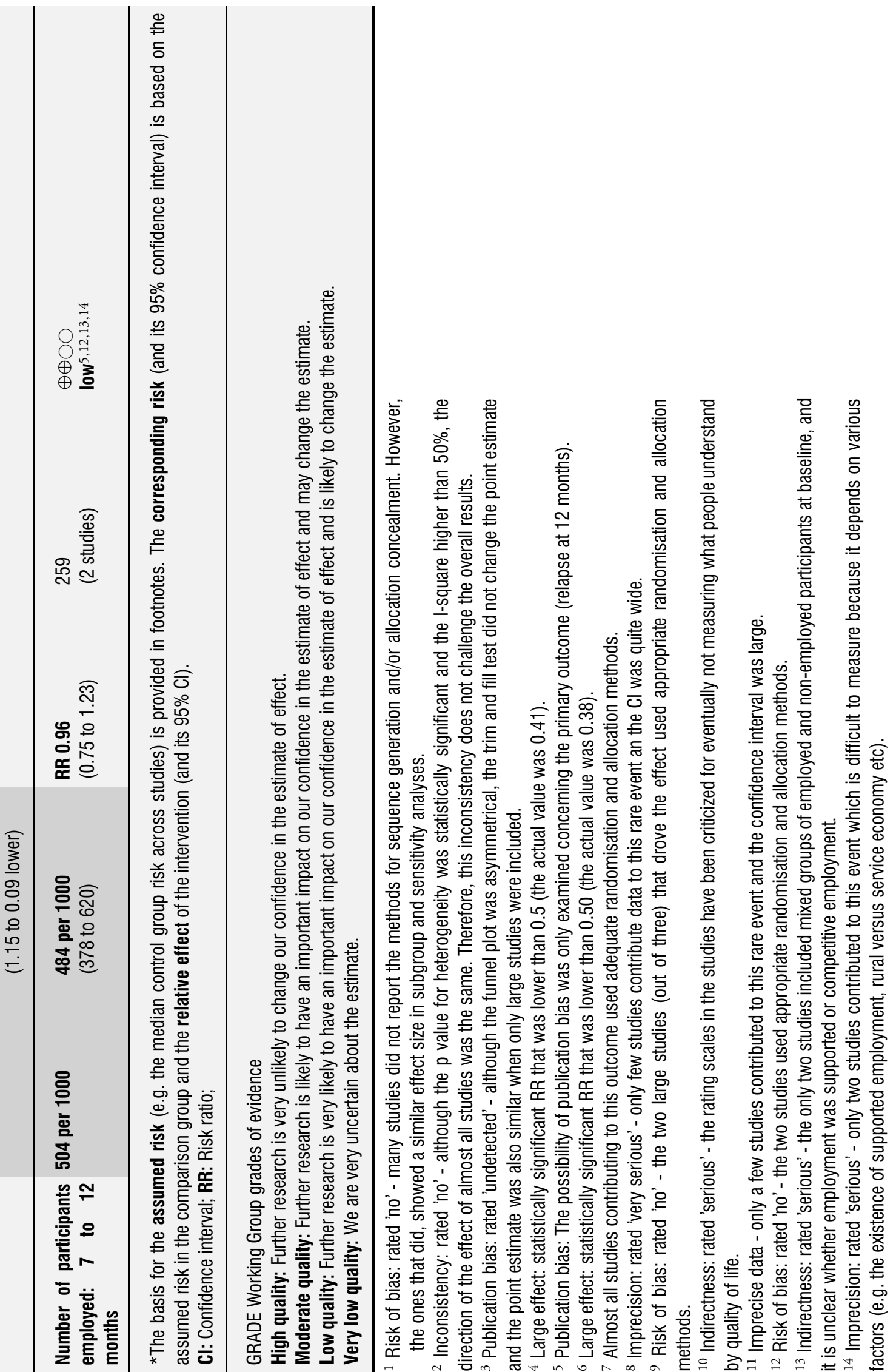

Maintenance treatment with antipsychotic drugs for schizophrenia (Review)

Copyright @ 2012 The Cochrane Collaboration. Published by John Wiley \& Sons, Ltd. 


\section{B A C K G R O U N D}

\section{Description of the condition}

Schizophrenia is often a chronic and disabling psychiatric disorder. It afflicts approximately $1 \%$ of the population worldwide with few gender differences. Its typical manifestations are 'positive' symptoms such as fixed, false beliefs (delusions) and perceptions without cause (hallucinations); 'negative' symptoms such as apathy and lack of drive, disorganisation of behaviour and thought; and catatonic symptoms such as mannerisms and bizarre posturing (Carpenter 1994). The degree of suffering and disability is considerable with $80 \%$ to $90 \%$ of people not employed (Marvaha 2004) and up to $10 \%$ dying (Tsuang 1978).

\section{Description of the intervention}

Antipsychotic drugs are the mainstay of treatment for schizophrenia. They can be classified according to their biochemical structure (e.g. butyrophenones, phenothiazines, thioxanthenes, etc.), the doses necessary for an antipsychotic effect (high-potency versus low-potency antipsychotic drugs) and their risk of producing movement disorders ('atypical' versus 'typical' antipsychotic drugs). What they all have in common is that they block, to a greater or lesser extent, the transmission of dopamine in the brain. Currently there is not a single antipsychotic drug available that is not a dopamine receptor antagonist and the hypothesis that dopamine plays a role in the causation of schizophrenia has been partly derived from the mechanism of action of antipsychotic drugs (Berger 2003). Furthermore, there is no firm evidence that - except for clozapine and possibly some other second-generation antipsychotic drugs (Kane 1988; Leucht 2009; Leucht 2009a; Wahlbeck 1999) - any of these agents is more effective than another (Klein 1969). Early (non-systematic) reviews (Baldessarini 1985; Davis 1975) showed that keeping people with schizophrenia on antipsychotic drugs after successful treatment of the acute episode substantially lowers relapse risk, for example from $53.2 \%$ to $15.6 \%$ within a period of approximately 9.7 months (Gilbert 1995). Conversely, the side-effect burden can be considerable, as antipsychotic drugs produce movement disorders, sedation, weight gain and are even related with sudden death. Therefore, clinicians and those with schizophrenia often face a trade-off between protection against further psychotic episodes and adverse effects.

\section{How the intervention might work}

The theory is that schizophrenia is a chronic disorder caused by hyperdopaminergic states in the limbic system (Berger 2003). All antipsychotic drugs block dopamine receptors. Continuous treatment with antipsychotic drugs may be necessary to keep the dopaminergic tone low and to avoid psychotic relapses.

\section{Why it is important to do this review}

Although it is clear that maintenance treatment with antipsychotic drugs reduces relapse rates, previous reviews (Baldessarini 1985; Davis 1975; Gilbert 1995) did not meet modern systematic review criteria and addressed only one outcome (relapse). Important subgroups such as those with a first psychotic break have also not been addressed. In terms of Cochrane reviews there is currently only a single publication that reviewed the effects of withdrawing chlorpromazine (Almerie 2007).

\section{O B JE C T IVES}

To review the effects of maintaining antipsychotic drug treatment for people with schizophrenia compared to withdrawing these agents.

\section{METHODS}

\section{Criteria for considering studies for this review}

\section{Types of studies}

All relevant randomised controlled trials (RCTs). We excluded quasi-randomised trials, such as those where allocation is undertaken on surname. If a trial was described as double-blind, but it was implied it had been randomised, we included it, but excluded such trials in a sensitivity analysis. Randomised cross-over studies were eligible but only data up to the point of first cross-over were used because of the instability of the problem behaviours and the likely carry-over effects of the treatments (Elbourne 2002).

\section{Types of participants}

We included people with schizophrenia and schizophrenia-like psychoses (schizophreniform and schizoaffective disorders) who had stabilised on antipsychotic medications. There is no clear evidence that the schizophrenia-like psychoses are caused by fundamentally different disease processes or require different treatment approaches (Carpenter 1994).

\section{Types of interventions}

1. Antipsychotic drugs: any dose or mode of administration (oral or by injection). There is no evidence for large differences in the efficacy of the available antipsychotic drugs (e.g. Davis 1989; Duggan 2005; Leucht 2009; Srisurapanont 2004). All currently available antipsychotic drugs have in common that they act via the blockade of dopamine and their classification according to their 
chemical properties (e.g. butyrophenones, thioxanthenes or phenothiazines) does not have an important clinical impact. Other classifications into 'low versus high-potency' or 'typical versus atypical' are continuums, at best (Leucht 2009). We therefore decided to include all antipsychotic drugs that are currently on the market in at least one country.

2. Active or inactive placebo, or no treatment.

\section{Types of outcome measures}

The outcomes were analysed for different lengths of follow-up: up to three months, up to six months, up to one year and more than one year.

\section{Primary outcomes}

Relapse at one year as defined by the original studies or by a deterioration in mental state requiring further treatment.

\section{Secondary outcomes}

\section{Leaving the study early}

1.1 Leaving the study early due to any reason (acceptability of treatment)

1.2 Leaving the study early due to inefficacy

1.3 Leaving the study early due to adverse effects (overall tolerability)

\section{Global state}

2.1 Number of participants improved

\section{Service use}

3.1 Hospitalisation

3.2 Readiness for discharge

\section{Death \\ 4.1 Death due to natural causes \\ 4.2 Suicide}

\section{Suicide attempts}

\section{Violent/aggressive behaviour}

\section{Adverse effects}

7.1 Number of participants with at least one adverse effect

7.2 Number of participants with movement disorders (any, akathisia, dystonia, rigor tremor, use of antiparkinson medication) 7.3 Number of participants with tardive dyskinesia
7.4 Number of participants with sedation

7.5 Number of participants with weight gain

\section{Quality of life/satisfaction with care}

8.1 Participant's satisfaction with care

8.2 Carer's satisfaction with care

8.3 Quality of life

\section{Number of participants in employment}

\section{0. 'Summary of findings' table}

We used the GRADE approach to interpret findings ( Schünemann 2008) and used GRADEPRO to import data from Review Manager to create 'Summary of findings' tables. These tables provide outcome-specific information concerning the overall quality of evidence from each included study in the comparison, the magnitude of effect of the interventions examined and the sum of available data on all outcomes that we rated as important to patient care and decision making. We anticipated including the following long-term main outcomes in a 'Summary of findings' table:

- relapse,

- acceptability of treatment - leaving the study early due to any reason,

- service use - number of participants rehospitalised,

- adverse events - death due to suicide,

- participant's satisfaction with care,

- quality of life,

- number of participants in employment.

\section{Search methods for identification of studies}

No language restriction was applied within the limitations of the search tools.

\section{Electronic searches}

We searched the Cochrane Schizophrenia Group's Specialised Register (November 2008) with the term: \{[cessation* or withdr?w* or discontinu* or halt* or stop* or drop?out* or dropout* or rehospitalis* or relaps* or maintain* or maintenance* or recur* in title, abstract, index terms of REFERENCE] or [withdrawal* in interventions of STUDY]\}

This register is compiled by regular systematic searches of major databases including EMBASE, MEDLINE and PsycINFO; handsearches; and conference proceedings (see Group Module). The Cochrane Schizophrenia Group's Specialised Register is maintained on MeerKat 1.5. This version of MeerKat stores references as studies. When an individual reference is selected through a 
search, all references that have been identified as the same study are also selected.

Additional search: we searched MEDLINE (2008 to 6th June 2011) and EMBASE (2008 to 6th June 2011) with the term: (cessation* OR withdraw* OR discontinu* OR halt* OR stop* OR drop-out* OR dropout* OR drop out OR rehospitalis* OR relaps* OR maintain* OR maintenance* OR recur*) AND schizophr* OR schizoaff* Limits: Randomized Controlled Trial. We searched clinicaltrials.gov with the names of 13 second-generation antipsychotic drugs (amisulpride, aripiprazole, clozapine, iloperidone, lurasidone, olanzapine, quetiapine, risperidone, paliperidone, sertindole, ziprasidone, zotepine) (see also Appendix 1, Appendix 2, Appendix 3).

\section{Searching other resources}

\section{Reference searching}

We inspected the references of all included studies and of previous reviews (Davis 1975; Gilbert 1995) for more trials.

\section{Personal contact}

We contacted the first author of each included study for missing information and for the existence of further studies.

\section{Drug companies}

We contacted the manufacturers of antipsychotic drugs and asked them about further relevant studies and for missing information on identified studies.

\section{Data collection and analysis}

\section{Selection of studies}

Two review authors (SL, KK) independently inspected citations identified from the search. We identified potentially relevant reports and ordered full papers for reassessment. Where disagreements arose we asked a third member of the team for help and if it was impossible to decide, the full papers were ordered for assessment. This process was repeated for the full papers. If it was impossible to resolve disagreements these studies were added to those awaiting classification and we contacted the authors of the papers for clarification.

\section{Data extraction and management}

\section{Extraction}

Three review authors (SL, MT, KK) independently extracted data from included studies. Again, any disagreement was discussed with a third member of the review team, decisions documented and, if necessary, we contacted authors of studies for clarification.

\section{Management}

We extracted data onto standard simple forms.

\section{Scale-derived data}

\subsection{Valid measures}

We included continuous data from rating scales only if: (a) the psychometric properties of the measuring instrument had been described in a peer-reviewed journal (Marshall 2000); (b) the measuring instrument was not written or modified by one of the trialists.

\subsection{Endpoint versus change data}

Since there is no principal statistical reason why endpoint and change data should measure different effects (Higgins 2011, we decided to primarily use scale endpoint data. If endpoint data were not available we used change data.

\section{Common measure}

To facilitate comparison between trials, we intended to convert variables that can be reported in different metrics, such as days in hospital (mean days per year, per week or per month) to a common metric (e.g. mean days per month).

\section{Direction of graphs}

Where possible, we entered data in such a way that the area to the left of the line of no effect indicates a favourable outcome for maintenance treatment.

\section{Assessment of risk of bias in included studies}

Three authors (SL, MT, KK) worked independently by using criteria described in the Cochrane Handbook for Systematic Reviews of Interventions (Higgins 2011) to assess trial quality. This new set of criteria is based on evidence of associations between overestimate of effect and high risk of bias of the article, such as sequence generation, allocation concealment, blinding, incomplete outcome data and selective reporting. 
Where inadequate details of randomisation and other characteristics of trials were provided, we contacted authors of the studies in order to obtain additional information.

We have noted the level of risk of bias in both the text of the review and in the Summary of findings table 1.

\section{Measures of treatment effect}

\section{Dichotomous data}

The review focused on binary data, which are easier to interpret and can be more intuitively understood. For binary outcomes we calculated a standard estimation of the random-effects (Der-Simonian 1986) risk ratio (RR) and its $95 \%$ confidence interval (CI). It has been shown that RR is more intuitive (Boissel 1999) than odds ratios (ORs) and that ORs tend to be interpreted as RR by clinicians (Deeks 2000). This misinterpretation then leads to an overestimate of the impression of the effect. For statistically significant results we calculated the number needed to treat benefit/harm statistic (NNTB/NNTH), and its 95\% CI as the inverse of the risk difference (RD).

Where possible, efforts were made to convert outcome measures to dichotomous data. This could be done by identifying cut-off points on rating scales and dividing participants accordingly into 'clinically improved' or 'not clinically improved'. It was generally assumed that if there had been a $50 \%$ reduction in a scale-derived score such as the Brief Psychiatric Rating Scale (BPRS, Overall 1962) or the Positive and Negative Syndrome Scale (PANSS; Kay 1986), this could be considered as a clinically significant response (Leucht 2005a; Leucht 2005b). If data based on these thresholds were not available, we used the primary cut-off presented by the original authors.

\section{Continuous data}

\subsection{Summary statistic}

For continuous outcomes we estimated a mean difference (MD) between groups. MDs were based on the random-effects model as this takes into account any differences between studies even if there is no statistically significant heterogeneity. We did not calculate standardised mean differences (SMD) measures. However, there was one exception to this rule. In the case of where scales were of such similarity to allow pooling we calculated the SMD and, whenever possible, transformed the effect back to the units of one or more of the specific instruments.

\subsection{Skewed data}

Continuous data on clinical and social outcomes are often not normally distributed. To avoid the pitfall of applying parametric tests to non-parametric data, we applied the following standards to all data before inclusion:

(a) data from studies of at least 200 participants were entered in the analysis irrespective of the following rules, because skewed data pose less of a problem in large studies;

(b) endpoint data: when a scale starts from the finite number zero, we subtracted the lowest possible value from the mean, and divided this by the standard deviation. If this value was lower than 1 , it strongly suggested a skew and the study was excluded. If this ratio was higher than 1 but below 2, there is suggestion of skew. We entered the study and tested whether its inclusion or exclusion substantially changed the results. If the ratio was larger than 2 the study was included, because skew is less likely (Altman 1996; Higgins 2011);

(c) change data: when continuous data are presented on a scale that includes a possibility of negative values (such as change data), it is difficult to determine whether data are skewed or not. We entered the study, because change data tend to be less skewed and because excluding studies would also lead to bias, because not all the available information was used.

\section{Unit of analysis issues}

\section{Cluster trials}

Studies increasingly employ 'cluster randomisation' (such as randomisation by clinician or practice) but analysis and pooling of clustered data poses problems. First, authors often fail to account for intra-class correlation in clustered studies, leading to a 'unit of analysis' error (Divine 1992) whereby P values are spuriously low, CIs unduly narrow and statistical significance overestimated. This causes type I errors (Bland 1997; Gulliford 1999).

Where clustering is not accounted for in primary studies, we presented data in a table, with a $\left(^{*}\right)$ symbol to indicate the presence of a probable unit of analysis error. In subsequent versions of this review we will seek to contact first authors of studies to obtain intra-class correlation coefficients (ICCs) for their clustered data and to adjust for this by using accepted methods (Gulliford 1999). Where clustering had been incorporated into the analysis of primary studies, we present these data as if from a non-cluster randomised study, but adjusted for the clustering effect.

We have sought statistical advice and have been advised that the binary data as presented in a report should be divided by a 'design effect'. This is calculated using the mean number of participants per cluster $(\mathrm{m})$ and the ICCs [design effect $=1+(\mathrm{m}-1) * \mathrm{ICC}$ ] ( Donner 2002). If the ICC was not reported it was assumed to be 0.1 (Ukoumunne 1999).

If cluster studies have been appropriately analysed taking into account ICCs and relevant data documented in the report, synthesis with other studies would have been possible using the generic inverse variance technique. 


\section{Cross-over trials}

A major concern of cross-over trials is the carry-over effect. It occurs if an effect (e.g. pharmacological, physiological or psychological) of the treatment in the first phase is carried over to the second phase. As a consequence on entry to the second phase the participants can differ systematically from their initial state despite a wash-out phase. For the same reason cross-over trials are not appropriate if the condition of interest is unstable (Elbourne 2002). As both effects are very likely in schizophrenia, randomised crossover studies were eligible but only data up to the point of first cross-over.

\section{Studies with multiple treatment groups}

Where a study involved more than two treatment arms, especially two appropriate dose groups of an antipsychotic drug, the different dose arms were pooled and considered to be one. Where the additional treatment arms were not relevant, we did not reproduce these data.

\section{Dealing with missing data}

\section{Overall loss of credibility}

At some degree of loss to follow-up data must lose credibility (Xia 2009). The loss to follow-up in randomised schizophrenia trials is often considerable calling the validity of the results into question. Nevertheless, it is unclear which degree of attrition leads to a high degree of bias. We did not exclude trials from outcomes on the basis of the percentage of participants completing them. However, we used the 'Risk of bias' tool described above to indicate potential bias when more than $25 \%$ of the participants left the studies prematurely, when the reasons for attrition differed between the intervention and the control group and when no appropriate imputation strategies were applied.

\section{Dichotomous data}

We presented data on a 'once-randomised-always-analyse' basis, assuming an intention-to-treat (ITT) analysis. If the authors applied such a strategy, we used their results. If the original authors presented only the results of the per-protocol or completer population, we assumed that those participants lost to follow-up would have had the same percentage of events as those who remained in the study.

\section{Continuous data}

\subsection{General}

ITT was used when available. We anticipated that in some studies, in order to do an ITT analysis, the method of last observation carried forward (LOCF) would be employed within the study report. As with all methods of imputation to deal with missing data, LOCF introduces uncertainty about the reliability of the results (Leon 2006). Therefore, where LOCF data have been used in the analysis, it was indicated in the review.

\subsection{Missing standard deviations}

Where there are missing measures of variance for continuous data but an exact standard error and CI are available for group means, either ' $\mathrm{p}$ ' value or ' $\mathrm{t}$ ' value are available for differences in mean, we calculated the standard deviation value according to method described in Section 7.7.3 of the Cochrane Handbook for Systematic Reviews of Interventions (Higgins 2011). If standard deviations were not reported and could not be calculated from available data, we asked authors to supply the data. In the absence of data from authors, we used the mean standard deviation from other studies.

\section{Assessment of heterogeneity}

\section{Clinical heterogeneity}

We considered all included studies without any comparison to judge clinical heterogeneity.

We simply inspected all studies for clearly outlying situations or people that we had not predicted would arise. Should such situations or participant groups arise these will be fully discussed.

\section{Methodological heterogeneity}

We considered all included studies initially, without seeing comparison data, to judge methodological heterogeneity. We simply inspected all studies for clearly outlying methods that we had not predicted would arise. Should such methodological outliers arise these will be fully discussed.

\section{Statistical}

\subsection{Visual inspection}

We visually inspected graphs to investigate the possibility of statistical heterogeneity.

\subsection{Employing the $I^{2}$ statistic}

Heterogeneity between studies was investigated by considering the $\mathrm{I}^{2}$ statistic alongside the $\mathrm{Chi}^{2}$ ' $\mathrm{p}$ ' value. The $\mathrm{I}^{2}$ statistic provides an estimate of the percentage of inconsistency thought to be due to chance (Higgins 2003). The importance of the observed value of $\mathrm{I}^{2}$ depends on the magnitude and direction of effects and the strength of evidence for heterogeneity (e.g. 'p' value from $\mathrm{Chi}^{2}$ test, or a CI for $\mathrm{I}^{2}$ statistic). 
$\mathrm{I}^{2}$ estimateof $50 \%$ or greater accompanied by a statistically significant $\mathrm{Chi}^{2}$ statistic was interpreted as evidence of substantial levels of heterogeneity (Section 9.5.2 Cochrane Handbook for Systematic Reviews of Interventions - Higgins 2011) and reasons for heterogeneity were explored. If the inconsistency was high and the clear reasons were found, we presented these data separately.

\section{Assessment of reporting biases}

Reporting biases arise when the dissemination of research findings is influenced by the nature and direction of results (Egger 1997). These are described in Section 10.1 of the Cochrane Handbook for Systematic Reviews of Interventions (Higgins 2011). We are aware that funnel plots may be useful in investigating reporting biases but are of limited power to detect small-study effects. We did not use funnel plots for outcomes where there were 10 or fewer studies, or where all studies were of similar sizes. In other cases, where funnel plots were possible, we sought statistical advice in their interpretation.

\section{Data synthesis}

We employed a random-effects model for analyses (Der-Simonian 1986). We understand that there is no closed argument for preference for use of fixed- or random-effects models. The random-effects method incorporates an assumption that the different studies are estimating different, yet related, intervention effects. This does seem true to us and the random-effects model takes into account differences between studies even if there is no statistically significant heterogeneity. Therefore, the random-effects model is usually more conservative in terms of statistical significance, although as a disadvantage it puts added weight onto smaller studies, which can either inflate or deflate the effect size. We examined in a secondary analysis whether using a fixed-effect model markedly changed the results of the primary outcome.

\section{Subgroup analysis and investigation of heterogeneity}

Reasons for heterogeneity in the primary outcome were explored by the following subgroup analyses and unrestricted-maximumlikelihood-random-effect meta-regressions Comprehensive Metaanalysis Version 2 (Borenstein 2006). Post-hoc analyses are marked with an asterisk: people with only one episode of schizophrenia and people in remission, who may both have a better prognosis, single antipsychotic drugs*, depot versus oral medication* (depot drugs are thought to be superior due to better compliance), first- versus second-generation antipsychotic drugs* (to address the debate whether the more expensive second-generation drugs are more efficacious), unblinded versus blinded trials* and studies with appropriate and unclear allocation concealment methods*. We examined people who had been stable for different durations before study entry (at least 1, 3, 6, 12, 24 months and longer than
24 months) to find out whether after long-term stability antipsychotic drugs are no longer necessary. Abrupt versus gradual withdrawal of the prestudy antipsychotic drug, defined as a minimum taper period of three weeks or depot treatment before the study following Viguera $1997^{*}$, was examined because abrupt withdrawal may lead to rebound psychoses.

Duration of stability before study entry and duration of drug withdrawal in the placebo group were also examined by meta-regressions. Other meta-regressions addressed severity of illness at baseline, mean dose in chlorpromazine equivalents and study duration. Meta-regression was performed only if at least 10 studies per comparison were available (Higgins 2011).

\section{Sensitivity analysis}

\section{Implication of randomisation}

We excluded studies in a sensitivity analysis if they were described in some way as to imply randomisation. If there was no substantive difference when the implied randomised studies were excluded or added to those with better description of randomisation, then all data were employed from these studies.

\section{Implication of non double-blind trials}

We excluded trials in a sensitivity analysis if they were not doubleblind. If there was no substantive difference when the non doubleblind studies were excluded or added to the double-blind studies, then all data were employed from these studies.

\section{Assumptions for lost binary data}

Where assumptions had to be made regarding people lost to followup (see Dealing with missing data) we compared the findings when we used our assumption compared with completer data only. If there was a substantial difference, we reported results and discussed them but continued to employ our assumption.

All sensitivity analyses were made only for the primary outcome.

\section{RE S U L T}

\section{Description of studies}

See: Characteristics of included studies; Characteristics of excluded studies; Characteristics of ongoing studies.

For substantive description of studies please see Characteristics of included studies and Characteristics of excluded studies tables. 


\section{Results of the search}

The original search in the CSG register yielded 1163 reports and two previous reviews contained 66 (Gilbert 1995) and 24 studies (Davis 1975). One study was obtained from a pharmaceutical company (Pfizer 2000). The update search in 2011 identified another 669 reports. Overall, 185 studies were closely inspected. We included 116 publications on 65 studies and we excluded 69 publications on 49 studies (Figure 1). 
Figure I. Study flow diagram.

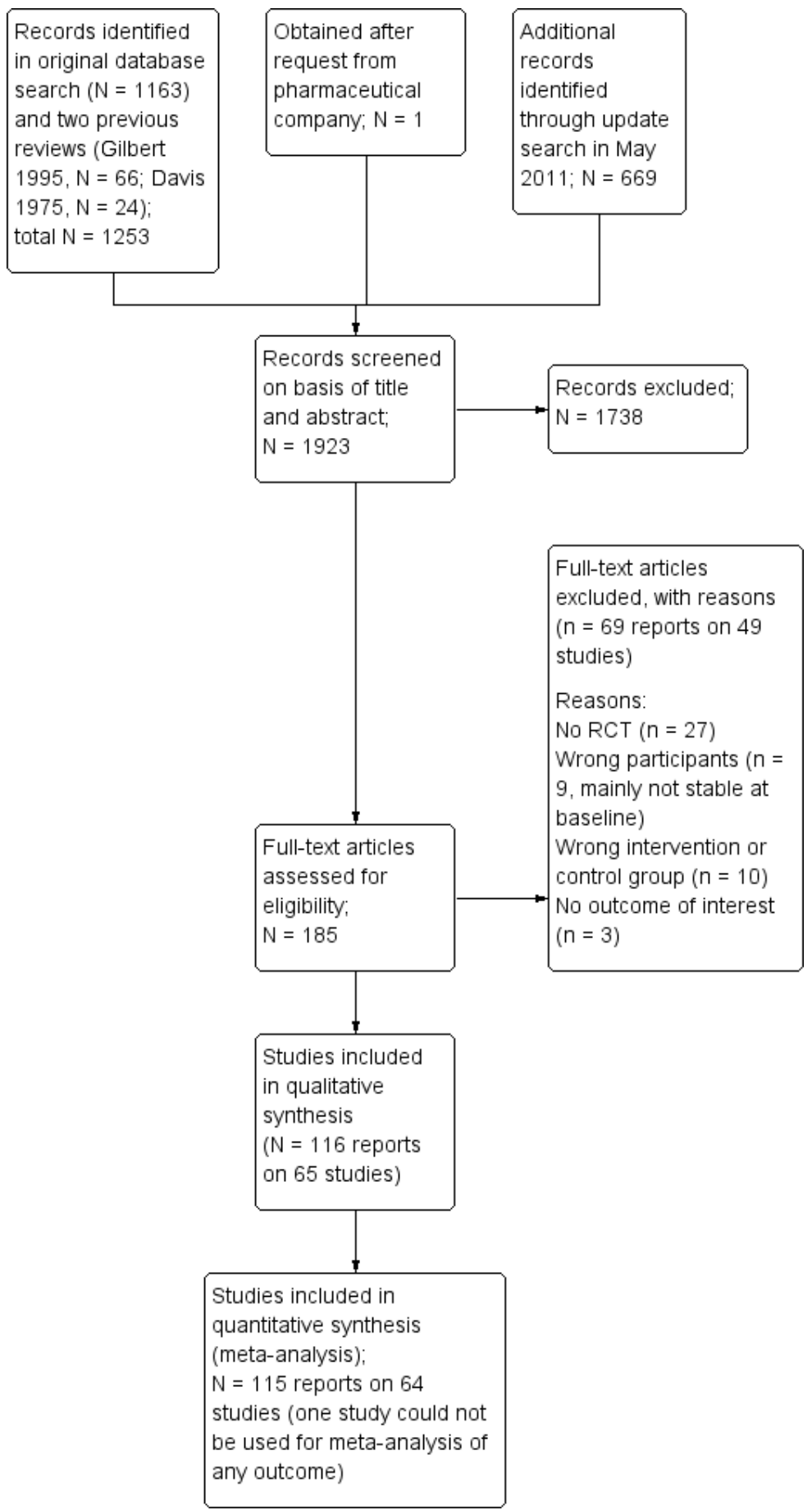




\section{Included studies}

Sixty-five studies (6493 participants) met the inclusion criteria.

\section{Length of trials}

Of the included studies, 14 had a duration up to three months. Twenty-five studies lasted up to six months and 19 up to 12 months. Six studies lasted more than 12 months. The longest study lasted three years.

\section{Participants}

In 32 studies, participants were diagnosed according to clinical diagnoses (i.e. specific diagnostic criteria were not mentioned). Four studies used the Diagnostic and Statistical Manual Version II (DSM-II), five studies DSM-III, four DSM-III-R, seven DSMIV and one DSM-IV-TR. Three studies used the Present State Examination (PSE), four Research Diagnostic Criteria (RDC) and one Feighner's criteria. In one study, participants were diagnosed according to International Statistical Classification of Diseases and Related Health Problems (ICD)-9 and RDC, one according to ICD-9 and PSE, one according to RDC and Schedule for Affective Disorder, and one according to PSE, RDC and Feighner's. The mean age was 40.8 years, the mean duration of illness was 13.6 years. In 11 studies, participants were in remission at baseline.

\section{Setting}

Thirty-one studies were conducted in hospitals and 27 studies in outpatients. Three studies included both inpatients and outpatients. Channabasavanna 1987, Hough 2010, Peuskens 2007 and Schering Plough 2010 did not report on setting.

\section{Study size}

Prien 1968 was the largest study with 420 participants, while Elie 1975 was the smallest study, randomising only 14 participants with schizophrenia. Thirty-three studies had fewer than 50 participants and 11 randomised more than 200 participants.

\section{Interventions}

Sixty-three studies compared maintenance treatment with antipsychotic drugs and placebo, two open RCTs compared antipsychotic drugs with no treatment. In most studies flexible doses of antipsychotic drugs could be applied. The dose ranges were: 50 to $1000 \mathrm{mg} /$ day for chlorpromazine (equivalent), 20 to 40 $\mathrm{mg}$ three-weekly for flupenthixol depot, 12.5 to $25 \mathrm{mg}$ threeweekly for fluphenazine depot or 1.25 to $-75 \mathrm{mg}$ twice-weekly for fluphenazine decanoate, 3 to $15 \mathrm{mg} /$ day for paliperidone, 10 to $160 \mathrm{mg} /$ week for penfluridol, 8 to $24 \mathrm{mg} /$ day for perphenazine, 2 to $12 \mathrm{mg} /$ day for pimozide, 15 to $150 \mathrm{mg} /$ day for prochlorpromazine, 200 to $400 \mathrm{mg} /$ day for promazine, 500 to $800 \mathrm{mg} /$ day for quetiapine, 189 to $1000 \mathrm{mg} /$ day for thioridazine, 5 to $50 \mathrm{mg} /$ day trifluoperazine and 40 to $160 \mathrm{mg} /$ day for ziprasidone. A few studies used fixed doses of aripiprazole $(15 \mathrm{mg} /$ day $)$, olanzapine $(10,15$ or $20 \mathrm{mg} /$ day), paliperidone depot 25,50 or $100 \mathrm{mg}$ fourweekly and zotepine $300 \mathrm{mg} /$ day. In a number of studies various antipsychotic drugs could be administered.

\section{Sponsor}

Most studies had either a neutral sponsor or sponsorship was not indicated. Fifteen studies were industry sponsored (Arato 2002; Baro 1970; Beasley 2003; Chen 2010; Cooper 2000; Hough 2010; Kramer 2007; Leff 1971; McCreadie 1989; Peuskens 2007; Pfizer 2000; Pigott 2003; Roelofs 1974; Sampath 1992; Schering Plough 2010). We note that frequently medication was provided by the manufacturers of the antipsychotic drugs, but we did not record such studies as primarily industry sponsored.

\section{Outcomes}

\subsection{Relapse}

The main relapse criteria in 26 was clinical judgement, in 17 studies need of medication, in 15 studies various rating-scale-based definitions were used, in three studies admission to hospital, in two dropout due to worsening of symptoms and in two studies the relapse criteria were not indicated.

\subsection{Leaving the study early}

The number of participants leaving the study early was recorded for the categories any reason, adverse events and lack of efficacy.

\subsection{Service use}

Service use was described as the number of patients rehospitalised and the number of patients discharged during the trial.

\subsection{Scales}

Scales that provided usable data are described below. It should be noted that we had a priori decided in the protocol to focus on dichotomous outcomes apart from quality of life (see Measures of treatment effect). However, a few authors used rating scales to examine extrapyramidal side effects and defined cut-offs to decide 
whether participants had a given side effect or not. We used these data and explain below which cut-offs were used.

\subsubsection{Adverse effects scales}

7.4.1.1 Abnormal Involuntary Movement Scale (AIMS) (Guy 1976)

This scale has been used to assess tardive dyskinesia, a long-term, drug-induced movement disorder and short-term movement disorders such as tremor. A low score indicates low levels of abnormal involuntary movements. In Odejide 1982 all participants with any positive AIMS score were considered to have tardive dyskinesia. In Beasley 2003 the cut-off was 3 or more on any item, or 2 or more on any two of the items. In Levine 1980 the cut-off was any item rated 2. In Chen 2010 the cut-off was 2 or more on the global severity item.

7.4.1.2 Barnes Akathisia Scale (BAS) (Barnes 1989)

The scale comprises items rating the observable, restless movements that characterise akathisia, a subjective awareness of restlessness, and any distress associated with the condition. These items are rated from 0 (normal) to 3 (severe). In addition, there is an item for rating global severity (from 0 (absent) to 5 (severe)). A low score indicates low levels of akathisia. In Beasley 2003 all participants with a BAS score of 2 or more were considered to have akathisia. In Chen 2010 the cut-off was 2 or more on the global severity item.

7.4.1.3 Simpson-Angus Scale (SAS) (Simpson 1970)

The 10 -item scale, with a scoring system of 0 to 4 for each item, measures drug-induced parkinsonism, a short-term drug-induced movement disorder. A low score indicates low levels of parkinsonism. In Beasley 2003 all participants with a SAS score of 4 or more were considered to have parkinsonism. In Chen 2010 the cut-off was 1 or more on the mean SAS score.

\subsubsection{Quality of life scales}

7.4.2.1 Heinrichs-Carpenter Quality of Life Scale (Carpenter 1994)

This semi-structured interview is administered and rated by trained clinicians. It contains 21 items rated on a 7-point scale based on the interviewer's judgement of patient functioning. A total quality-of-life score and four subscale scores are calculated, with higher scores indicating less impairment.

7.4.2.2 Symptom Questionnaire of Kellner and Sheffield (Kellner 1973)
The 30-item self-completion questionnaire measures subjective well-being. A total score and four subscale scores are obtainable from the questionnaire.

7.4.2.3 Schizophrenia Quality of Life Scale (Wilkinson 2000)

The scale is a self-administered rating scale that includes 33 items concerning the subject's symptoms and well-being over the preceding seven days, on a scale from 0 (never) to 4 (always). Total scores range from 0 to 100 , with low scores representing a better outcome.

\subsection{Other adverse effects}

Other adverse events such as death, suicide, violent/aggressive behaviour, at least one adverse event, at least one movement disorder, akathisia, akinesia, dystonia rigor, tremor, use of antiparkinson medication, tardive dyskinesia, sedation and weight gain were reported in a dichotomous manner in terms of the number of participants with a given side effect.

\subsection{Global state (number of participants improved)}

The number of participants improved at the end of the studies was assessed by the Clinical Global Impression (CGI) scale (Guy 1976) or similar rating systems. The CGI compares the conditions of the person standardised against other people with the same diagnosis. A 7-point scoring system is used with low scores showing decreased severity, overall improvement, or both.

\subsection{Number of participants employed}

This outcome was described as the number of participants being employed at the end of the trials.

\section{Excluded studies}

We excluded 49 studies. Twenty-seven studies were excluded because they were not (appropriately) randomised. Nine studies were excluded because they did not examine suitable participants (e.g. participants had not been stabilised on antipsychotic drugs before study start, Bourin 2008; Engelhardt 1967; Lauriello 2005; Lecrubier 1997). Ten studies were excluded because of wrong interventions, most of them did not have a placebo control group. Three studies were excluded because they did not report any usable or relevant outcomes.

\section{Risk of bias in included studies}

For graphical representations of our judgements of risk of bias please refer to Figure 2 and Figure 3. Full details of judgements are seen in the 'Risk of bias' tables. 
Figure 2.

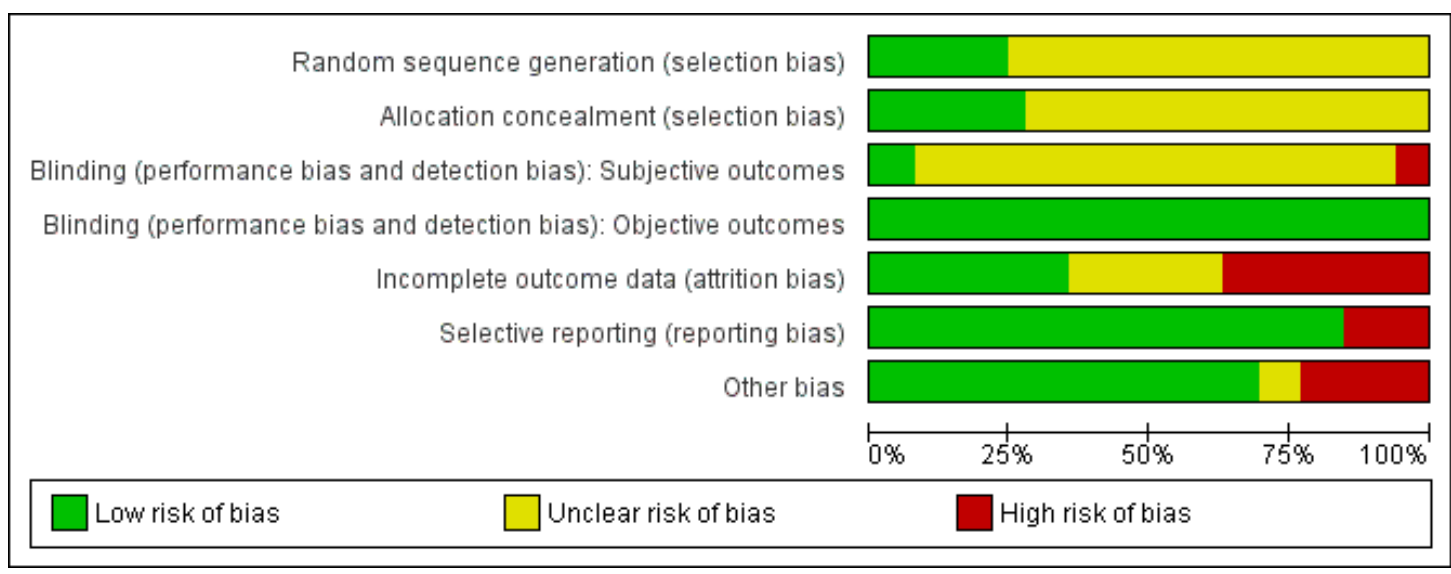


Figure 3.

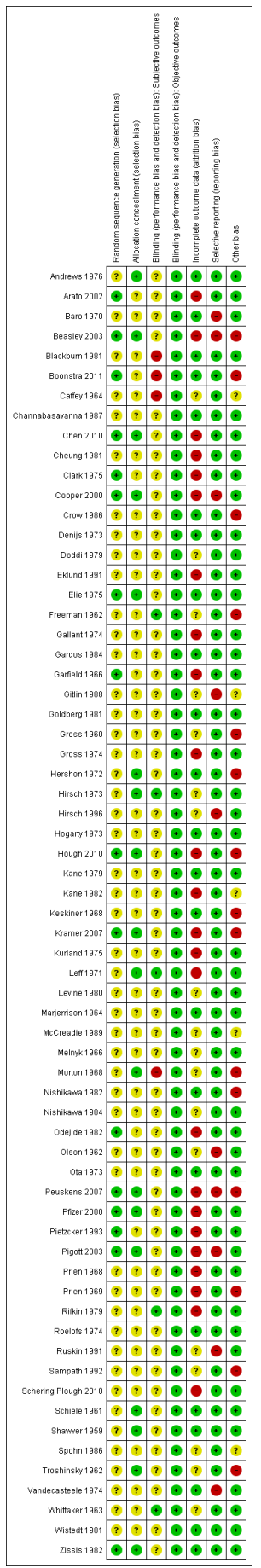

Maintenance treatment with antipsychotic drugs for schizophrenia (Review)

Copyright $\odot 2012$ The Cochrane Collaboration. Published by John Wiley \& Sons, Ltd. 


\section{Allocation}

In 16 studies, random sequence generation was adequate. In the remaining 49 studies this was unclear. Among these, 46 studies were described as randomised, but 35 of them did not provide further details about random sequence generation. Eleven studies gave further information about randomisation, but these were rather superficial and thus still rated as unclear. Three further studies (Channabasavanna 1987; McCreadie 1989; Ota 1973) did not provide any information about sequence generation, but they were double-blind, therefore we assumed randomisation.

In 18 studies, allocation concealment was rated as adequate. For example, some studies reported that the only people with access to the identity of patients were the hospital pharmacist (e.g. Andrews 1976; Hershon 1972), a research assistant (e.g. Hirsch 1973), a psychiatrist without contact to participants (Troshinsky 1962) or a unit secretary (Leff 1971). Beasley 2003, Hough 2010 and Kramer 2007 used an interactive voice-response system for allocation concealment. One study (Pfizer 2000) used treatment cards numbered for each subject and investigators and pharmacists allocated numbers to subjects. Chen 2010 reported that AstraZeneca prepared individually numbered study drugs and packed them according to the randomisation sequence. Two studies mentioned that codes were not broken until the time of the analysis and that the code was unknown to the investigators (Cooper 2000; Zissis 1982).

The remaining 47 studies did not provide any details on allocation concealment. Therefore, it was unclear for most of the studies whether adequate allocation concealment methods were used.

\section{Blinding}

All studies were rated as 'low risk of bias' concerning objective outcomes, because we considered blinding to be less important for these.

Concerning subjective outcomes we rated five studies to have a low risk of bias. In them it was either tested that blinding had worked (Freeman 1962; Hirsch 1973; Leff 1971; Whittaker 1963) or the authors had applied specific measures to improve blinding (prophylactic antiparkinson medication to avoid unmasking by side effects, Rifkin 1979).

Four studies were rated with a high risk of bias for subjective outcomes. Boonstra 2011 was an open study, without providing any further information. In Caffey 1964, the placebo group received medication only every other day and blinding was not fully maintained. Blackburn 1981 and Morton 1968 reported that nurses had made correct guesses as to who was on drug and who was on placebo.

In the other 56 studies, we rated the risk of bias for subjective outcomes as unclear. Except for Pietzcker 1993, which was an open trial with rating scales being additionally rated by a second blind assessor, all these studies were described as double-blind. But as antipsychotic drugs have side effects we considered that we should make a conservative judgment about the success of blinding. Many of these reports did not provide any details about how doubleblind conditions were maintained. It was usually just stated that the studies were "double-blind" or it was simply indicated that "identical capsules" were used. Some studies using depot antipsychotic drugs reported that sesame oil injections were used in the placebo groups (e.g. Gardos 1984 and Keskiner 1968).

\section{Incomplete outcome data}

The number of participants leaving the studies early was frequently high leading to a judgement of high risk of bias in 24 included studies. The most frequent reason for leaving the studies early was 'relapse', because many studies had predefined in their protocols that once participants had relapsed they had to discontinue the trial. This had two consequences: the primary outcome relapse was frequently not affected by attrition, because most participants reached this end point. However, there was a risk of bias for other outcomes (e.g. side effects), because the reasons for leaving the studies early differed between participants on placebo (mainly relapse/inefficacy) and participants on antipsychotic drugs (other reasons).

Only 10 studies (Arato 2002; Beasley 2003; Boonstra 2011; Cooper 2000; Crow 1986; Hough 2010; Kramer 2007; Peuskens 2007; Pietzcker 1993; Schering Plough 2010) used survival analyses to examine relapse rates, while most other studies simply counted the numbers of participants who relapsed. We, therefore, had to restrict this review to analysis of relapse rates rather than more sensitive parameters such as 'time to relapse'.

\section{Selective reporting}

We judged 55 studies to be free of selective reporting. The following studies did not (sufficiently) report on predefined outcomes: Baro 1970, Beasley 2003, Cooper 2000, Gitlin 1988, Hirsch 1996, Olson 1962, Peuskens 2007, Pigott 2003, Ruskin 1991 and Vandecasteele 1974.

\section{Other potential sources of bias}

We judged 45 studies to be free of other potential sources of bias and in five studies this was unclear (Caffey 1964, Gitlin 1988, Kane 1982, McCreadie 1989, Spohn 1986). Beasley 2003, Boonstra 2011, Hough 2010 and Kramer 2007 were terminated prematurely after interim analyses. The doses in Prien 1969 were very high (trifluoperazine $80 \mathrm{mg} /$ day) and in Nishikawa 1982 (chlorpromazine $75 \mathrm{mg} /$ day, haloperidol $3 \mathrm{mg} /$ day) they were very 
low. There were baseline imbalances in terms of the mean number of previous hospitalisations, mean age and duration of illness (Peuskens 2007, which was also terminated prematurely) or in terms of gender and baseline medication (Sampath 1992). In five studies participants who relapsed were discontinued and their code was broken, which can be a threat for blinding (Crow 1986; Freeman 1962; Gross 1960; Hershon 1972; Morton 1968). Another reason was the administration of additional antipsychotic drugs in case of deterioration (Keskiner 1968). In one study three out of 19 participants in the placebo group continued to receive active medication (Troshinsky 1962, which was also terminated prematurely).

\section{Effects of interventions}

See: Summary of findings for the main comparison Maintenance treatment with antipsychotic drugs versus placebo/ no treatment for schizophrenia

A summary of the pooled results is presented in Figure 4.

Figure 4. Summary of pooled results

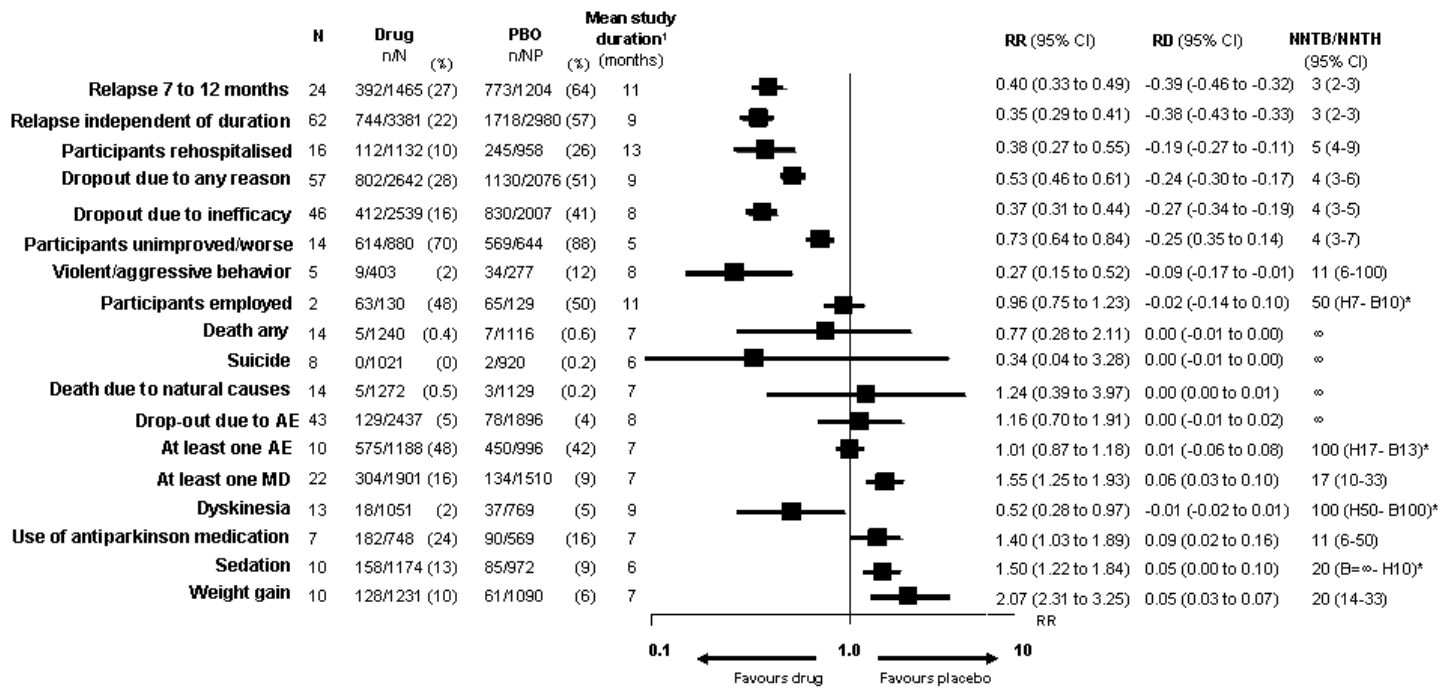

The random effects model by DerSimonian and Laird was used troughout with weights calculated by the Mantel-Haenszel method, the mean study duration was weighted by sample size of the individual trials, $\mathrm{AE}=$ adverse events, $\mathrm{MD}=$ movement disorders, $\mathrm{n}=$ number of participants with an event, $\mathrm{NP}=$ total number of participarts, $N=$ number of studies, $\mathrm{PBO}=$ placebo, $\mathrm{RR}=$ risk ratio, $\mathrm{RD}=$ risk difference, $\mathrm{Cl}=$ confidence interval, $\mathrm{NN} T \mathrm{TNN} \mathrm{NH}=$ number needed to treat to benefttharm

\section{Comparison I. Maintenance treatment with antipsychotic drugs versus placebo/no treatment}

\section{I.I Relapse}

Antipsychotic medication was significantly more effective than placebo in preventing relapse in studies lasting up to three months (percentage of participants relapsed drug 12\%, placebo 37\%, 34 RCTs, n=3942, RR 0.30 CI 0.24 to 0.38 , NNTB 3 CI 3 to 4 ), four to six months (drug 18\%, placebo 50\%, 40 RCTs, $n=5285$, RR 0.35 CI 0.30 to 0.42 , NNTB 3 CI 3 to 4 ), seven to twelve months (primary outcome: drug 27\%, placebo 64\%, 24 RCTs, $n=2669$, RR 0.40 CI 0.33 to 0.49 , NNTB 3 CI 2 to 3 ), more than twelve 
months (drug 44\%, placebo 79\%, 6 RCTs, n=811, RR 0.59 CI 0.42 to 0.82 , NNTB 3 CI 2 to 6 ), and all studies combined (drug $22 \%$, placebo $57 \%, 62$ RCTs, $n=6392$, RR 0.35 CI 0.29 to 0.41 , NNTB 3 CI 2 to 3). There was a significant heterogeneity of the study results up to three months ( $\left.\mathrm{p}<.0001, \mathrm{I}^{2}=54 \%\right)$, four to six months $\left(\mathrm{p}<.00001, \mathrm{I}^{2}=63 \%\right)$, seven to twelve months $(\mathrm{p}<.0001$, $\left.\mathrm{I}^{2}=63 \%\right)$, more than twelve months $\left(\mathrm{p}<.00001, \mathrm{I}^{2}=85 \%\right)$, and all studies combined $\left(\mathrm{p}<.00001, \mathrm{I}^{2}=74 \%\right)$. However, in all studies the relapse rates were lower in the antipsychotic drug group than in the placebo group. Therefore, the heterogeneity expressed a difference in the magnitude of the superiority rather than in the direction of the effect. Subgroup analyses and meta-regressions showed that the heterogeneity may be in part explained by study duration and differences between oral and depot medication (see 2.5 and 2.9 below).

\section{I.2 Leaving the study early}

\subsubsection{Due to any reason}

Studies lasting up to three months (drug 4\%, placebo $33 \%, 8$ RCTs, n=245, RR 0.23 CI 0.07 to 0.72 , NNTB not significant), between four to six months (drug 22\%, placebo 44\%, 17 RCTs, $\mathrm{n}=1646$, RR 0.48 CI 0.35 to 0.66 , NNTB 6 CI 4 to 11$)$ and between seven to twelve months (drug $38 \%$, placebo 66\%, 18 RCTs, $\mathrm{n}=2420$, RR 0.55 CI 0.46 to 0.66 , NNTB 4 CI 3 to 5) showed a significant difference in favour of antipsychotic medication. Overall, there was a significant difference in favour of antipsychotic medication (drug 30\%, placebo 54\%, 47 RCTs, n=4718, RR 0.53 CI 0.46 to 0.61 , NNTB 4 CI 3 to 6 ). There was no significant difference for studies lasting more than twelve months (drug 32\%, placebo $46 \%$, 4 RCTs, $n=407$, RR 0.68 CI 0.36 to 1.26 ), but these long-term data were only based on four studies. There was considerable heterogeneity within the group of studies lasting up to twelve months $\left(\mathrm{p}<.00001, \mathrm{I}^{2}=81 \%\right)$ and in all studies combined $\left(\mathrm{p}<.00001, \mathrm{I}^{2}=70 \%\right)$, but again this reflected heterogeneity in the degree of superiority rather than in the direction of the effect.

\subsubsection{Due to adverse events}

There was no significant difference in studies lasting up to three months (drug 1\%, placebo 0\%, 8 RCTs, n=245, RR 2.84 CI 0.12 to 65.34 ), four to six months (drug 4\%, placebo 4\%, 14 RCTs, $\mathrm{n}=1549$, RR 0.99 CI 0.57 to 1.74 ), seven to twelve months (drug $7 \%$, placebo 5\%, 17 RCTs, $\mathrm{n}=2339$, RR 1.24 CI 0.59 to 2.60 ) and in studies lasting more than twelve months (drug $0 \%$, placebo $0 \%$, 4 RCTs, $n=200$, RR not estimable). Overall, there was no significant difference between groups (drug 5\%, placebo 4\%, 43 RCTs, $n=4333$, RR 1.16 CI 0.70 to 1.91 ). There was significant heterogeneity in group of studies lasting seven to twelve months $\left(\mathrm{p}=0.008, \mathrm{I}^{2}=63 \%\right)$ and overall $\left(\mathrm{p}=0.005, \mathrm{I}^{2}=49 \%\right)$. A possible explanation is that in particular in recent trials not only tolerability related adverse events but also efficacy related adverse events (e.g. exacerbation of psychosis) were summarised as "dropouts due to adverse events". This may explain the clearest outlier (Beasley 2003) where all dropouts due to adverse events were efficacy related. Removing this study and Arato 2002 (where details about dropout due to adverse events were not presented), the data are no longer heterogeneous and significantly more patients in the antipsychotic group left early for adverse events at twelve months (RR 2.08, CI 1.21 to 3.60; heterogeneity test: $\mathrm{p}=0.35, \mathrm{I}^{2}=10 \%$ ), but not overall (RR 1.49, CI 0.98 to 2.29 ; heterogeneity test: $\mathrm{p}=$ $\left.0.22, \mathrm{I}^{2}=18 \%\right)$.

\subsubsection{Due to inefficacy}

Studies lasting up to three months (drug 6\%, placebo 33\%, 9 RCTs, n=295, RR 0.23 CI 0.07 to 0.79 , NNTB not significant), four to six months (drug 14\%, placebo 36\%, 16 RCTs, $n=1661$, RR 0.41 CI 0.31 to 0.54 , NNTB 5 CI 3 to 9), seven to twelve months (drug 20\%, placebo 50\%, 18 RCTs, $n=2420$, RR 0.36 CI 0.28 to 0.45 , NNTB 3 CI 2 to 4 ) and more than 12 months (drug 3\%, placebo $10 \%, 3$ RCTs, n=170, RR 0.27 CI 0.08 to 0.95 , NNTB not significant) showed a significant difference in favour of antipsychotic medication. Overall, there was a significant difference in favour of antipsychotic medication (drug 16\%, placebo $41 \%$, 46 RCTs, $\mathrm{n}=4564$, RR 0.37 CI 0.31 to 0.44 , NNTB $4 \mathrm{CI} 3$ to 5$)$. The results at three months ( $\left.\mathrm{p}=.04, \mathrm{I}^{2}=54 \%\right)$, at seven to twelve months $\left(\mathrm{p}<.0002, \mathrm{I}^{2}=64 \%\right)$ and pooling all studies $\left(\mathrm{p}<.0005, \mathrm{I}^{2}=48 \%\right)$ were heterogeneous, but, with the exception of Channabasavanna 1987 and Marjerrison 1964, all studies showed at least a trend in favour of antipsychotic drugs. Thus, the heterogeneity reflected differences in the degree of superiority rather than in the direction of the effect. Re-inspection of Channabasavanna 1987 and Marjerrison 1964 did not reveal reasons why these studies showed a slight trend in favour of placebo.

\section{I.3 Global state}

\subsubsection{Number of participants improved}

One study in the up to three month category (drug 58\%, placebo $13 \%, 1$ RCT, n=49, RR 4.61 CI 1.22 to 17.40 NNTB 2 CI 2 to 5) and studies in the four to six months category showed a significant difference in favour of antipsychotic medication (drug $30 \%$, placebo $11 \%$, 8 RCTs, $n=1037$, RR 2.33 CI 1.69 to 3.21 , NNTB 4 CI 2 to 8 ). The trend was the same in the seven to twelve months category, but the difference was not statistically significant (drug 26\%, placebo 13\%, 5 RCTs, n=438, RR 1.95 CI 0.91 to 4.18 ). When all studies were combined drugs were again significantly superior to placebo (drug $30 \%$, placebo $12 \%$, 14 RCTs, n=1524, RR 2.34 CI 1.68 to 3.26 , NNTB 4 CI 3 to 7$)$. The results at six months $\left(\mathrm{p}<0.00001, \mathrm{I}^{2}=84 \%\right)$, twelve 
months ( $\left.\mathrm{p}=0.0001, \mathrm{I}^{2}=82 \%\right)$ and overall $\left(\mathrm{p}<0.00001, \mathrm{I}^{2}=84 \%\right)$ were heterogeneous, but again except for one outlier (Morton 1968) all studies showed at least a trend in favour of antipsychotic drugs. Re-inspection of Morton 1968 did not reveal an obvious reason why this study showed a slight trend in favour of placebo.

\section{I.4. Service use}

\subsubsection{Number of participants hospitalised}

Three studies lasting four to six months (drug $0 \%$, placebo $34 \%$, 3 RCTs, n=109, RR 0.08 CI 0.01 to 0.42 , NNTB 3 CI 2 to 50), studies lasting seven to twelve months (drug 4\%, placebo 16\%, 8 RCTs, n=1295, RR 0.32 CI 0.18 to 0.57 , NNTB 6 CI 4 to 14 ) and three studies lasting more than twelve months (drug 25\%, placebo $44 \%$, 3 RCTs, n=631, RR 0.56 CI 0.44 to 0.70 , NNTB 5 CI 4 to 8 ) showed a significant difference in favour of antipsychotic medication. Overall, there was a significant difference in favour of antipsychotic medication (drug 10\%, placebo 26\%, 16 RCTs, $n=$ 2090, RR 0.38 CI 0.27 to 0.55 , NNTB 5 CI 4 to 9). There was no significant difference for studies lasting up to three months (drug $4 \%$, placebo $7 \%$, 2 RCTs, $n=55$, RR 0.42 CI 0.04 to 4.06) but these short-term data are only based on two small studies. There was some heterogeneity for studies lasting up to twelve months $\left(\mathrm{p}=.05, \mathrm{I}^{2}=50 \%\right)$ and all studies combined $\left(\mathrm{p}<.03, \mathrm{I}^{2}=45 \%\right)$, but all studies showed at least a trend in favour of antipsychotic drugs.

\subsubsection{Number of participants discharged}

Three studies in inpatients reported on the number of participants who could be discharged. There was no significant difference between groups (drug 5\%, placebo 1\%, 3 RCTs, n=404, RR 2.76 CI 0.69 to 11.06). All the three studies lasted four to six months.

\section{I.5 Death}

\subsubsection{Any}

In total there were five deaths in the drug group and seven deaths in the placebo group. There was no significant difference between groups in studies lasting up to three months (drug $0 \%$, placebo $0 \%, 1$ RCT, $\mathrm{n}=36$, RR not estimable), between four to six months (drug $1 \%$, placebo $0.25 \%, 5$ RCTs, $n=856$, RR 2.18 CI 0.48 to 9.81), seven to twelve month (drug $0.1 \%$, placebo $1 \%, 8$ RCTs, $\mathrm{n}=1464$, RR 0.33 CI 0.08 to 1.27 ) and all studies combined (drug $0.4 \%$, placebo $0.6 \%, 14$ RCTs, $n=2356$, RR 0.77 CI 0.28 to 2.11 ).

\subsubsection{Due to natural causes}

Studies lasting four to six months (drug $1 \%$, placebo $0.2 \%, 5$ RCTs, n=856, RR 2.18 CI 0.48 to 9.81), seven to twelve months (drug 0.1\%, placebo $0.3 \%$, 9 RCTs, n=1545, RR 0.54 CI 0.09 to 3.36 ) and all studies combined (drug $0.4 \%$, placebo $0.3 \%$, 14 RCTs, n=2401, RR 1.24 CI 0.39 to 3.97 ) did not reveal a significant difference between groups.

\section{I.6. Suicide}

Studies up to three months (drug 0\%, placebo $0 \%, 1$ RCT, $n=36$, RR not estimable), four to six months (drug $0 \%$, placebo $0 \%, 2$ RCTs, $n=730$, RR not estimable), seven to 12 months (drug $0 \%$, placebo $0.4 \%, 5$ RCTs, $n=1175$, RR 0.34 CI 0.04 to 3.28) and all studies combined irrespective of their duration (drug $0 \%$, placebo $0.2 \%, 8$ RCTs, $\mathrm{n}=1941$, RR 0.34 CI 0.04 to 3.28) did not reveal a significant difference.

\subsubsection{Suicide attempts}

There was no significant difference in terms of suicide attempts in two studies lasting four to six months (drug $0.4 \%$, placebo $0 \%$, 2 RCTs, n=466, RR 3.00 CI 0.13 to 71.51 ) and in three studies lasting seven to 12 months (drug $0 \%$, placebo $1 \%$, 3 RCTs, $n=$ 711, RR 0.25 CI 0.04 to 1.61). Altogether, there was no significant difference between groups (drug $0.2 \%$, placebo $1 \%, 5$ RCTs, $n=$ 1177, RR 0.47 CI 0.10 to 2.33 )

\subsubsection{Suicidal ideation}

There was no significant difference in the number of participants with suicidal ideation in one study in the up to three months category (drug $0 \%$, placebo $6 \%, 1$ RCT, n=49, RR 0.17 CI 0.01 to 3.88 ), in one study in the four to six months category (drug $0 \%$, placebo $0 \%, 1$ RCT, $\mathrm{n}=386$, RR not estimable), in one study in the seven to 12 months category (drug $2 \%$, placebo $0 \%, 1$ RCT, $\mathrm{n}=121$, RR 2.77 CI 0.11 to 66.57 ) and in all studies combined irrespective of duration (drug $0.4 \%$, placebo $0.3 \%, 3$ RCTs, $n=$ 556, RR 0.67 CI 0.04 to 10.56 ).

\section{I.7 Violent/aggressive behaviour}

In one small study in the up to three months category (drug $0 \%$, placebo $8 \%, 1$ RCT, $n=26$, RR 0.33 CI 0.01 to 7.50 ) and one study in the four to six months category (drug $0 \%$, placebo $10 \%$, 1 RCT, n=40, RR 0.20 CI 0.01 to 3.92) there was no difference in the number of participants with aggressive behaviour. However, in studies lasting seven to twelve months (drug 2\%, placebo $13 \%$, 3 RCTs, n=614, RR 0.28 CI 0.14 to 0.53 , NNTB not significant) and in all studies combined irrespective of their duration (drug $2 \%$, placebo $12 \%, 5$ RCTs, n=680, RR 0.27 CI 0.15 to 0.52 , NNTB 11 CI 6 to 100) fewer participants in the drug group than in the placebo group were violent/aggressive. 
I.8 Adverse effects

\subsubsection{At least one adverse effect}

One study in the up to three months category (drug $36 \%$, placebo 69\%, 1 RCT, n=49, RR 0.53 CI 0.30 to 0.93 , NNTB 3 CI 2 to 25 ) showed a significant difference between groups. Three studies in the four to six months category (drug 59\%, placebo 64\%, 3 RCTs, $n=776$, RR 0.96 CI 0.80 to 1.15 ), studies lasting seven to 12 months (drug 43\%, placebo 33\%, 6 RCTs, $n=1359$, RR 1.10 CI 0.88 to 1.38 ) and all studies combined irrespective of their duration (drug 48\%, placebo 45\%, 10 RCTs, n=2184, RR 1.01 CI 0.87 to 1.18 ) did not reveal a significant difference between groups. The results at six months $\left(\mathrm{p}=0.13, \mathrm{I}^{2}=52 \%\right), 12$ months $\left(\mathrm{p}=0.02, \mathrm{I}^{2}=64 \%\right)$ and overall $\left(\mathrm{p}=0.003, \mathrm{I}^{2}=64 \%\right)$ were heterogeneous. Similarly to the outcome 'leaving the study early due to adverse events' (see Section 1.2.2 above) it should be noted that in particular in recent trials efficacy related events can also be adverse events that may in part explain the heterogeneity. Ota 1973 even showed significantly more adverse events in the placebo group. The authors discussed this finding as withdrawal effects after abrupt stopping of medication. However, excluding this outlier did not change the results (all studies pooled: RR 1.05, CI 0.91 to 1.21 ; heterogeneity test: $\mathrm{p}=0.01, \mathrm{I}^{2}=60 \%$ ).

\subsubsection{Movement disorder}

\subsubsection{At least one movement disorder}

Studies lasting up to three months (drug 29\%, placebo 10\%, 4 RCTs, n=158, RR 2.42 CI 0.70 to 8.33) did not reveal any difference between groups. However, studies lasting four to six months (drug 18\%, placebo $11 \%, 8$ RCTs, n=1658, RR 1.45 CI 1.06 to 1.99, NNTH not significant), seven to 12 months (drug $13 \%$, placebo $7 \%, 10$ RCTs, n=1595, RR 1.52 CI 1.11 to 2.07 , NNTH $25 \mathrm{CI} 13$ to 100$)$ and all studies combined irrespective of their duration (drug 16\%, placebo 9\%, 22 RCTs, n=3411, RR 1.55 CI 1.25 to 1.93 , NNTH 17 CI 10 to 33 ) showed a significant difference in favour of placebo.

\subsubsection{Akathisia}

Studies in the up to three month category (drug 12\%, placebo 6\%, 1 RCT, n=49, RR 1.94 CI 0.24 to 15.97 ), the four to six months category (drug 12\%, placebo 3\%, 6 RCTs, $n=1009$, RR 1.67 CI 0.41 to 6.80 ), in the seven to 12 months category (drug $6 \%$, placebo $3 \%, 5$ RCTs, $n=968$, RR 1.74 CI 0.88 to 3.45 ) and all studies combined irrespective of their duration (drug $9 \%$, placebo 3\%, 12 RCTs, n=2026, RR 1.75 CI 0.87 to 3.51) did not show a significant difference. Results at six months $\left(\mathrm{p}=0.002, \mathrm{I}^{2}=\right.$
$73 \%)$ and overall $\left(\mathrm{p}=0.04, \mathrm{I}^{2}=48 \%\right)$ were heterogeneous due to one outlier (Clark 1975) in which significantly more participants in the placebo group than in the drug group had akathisia. Reinspection of this study did not reveal an obvious explanation. Removing this study reduced heterogeneity and significantly more participants in the drug group suffered from this side effect (RR 2.13, CI 1.18 to 3.86; heterogeneity test: $\mathrm{p}=0.20, \mathrm{I}^{2}=26 \%$ ).

\subsubsection{Akinesia}

There was no significant difference in one single small study in the up to three months category (drug 6\%, placebo 6\%, 1 RCT, $\mathrm{n}=49$, RR 0.97 CI 0.09 to 9.92).

\subsubsection{Dyskinesia}

Three studies in the four to six months category (drug $2 \%$, placebo $13 \%$, 3 RCTs, $\mathrm{n}=418$, RR $0.31 \mathrm{CI} 0.11$ to 0.84 , NNTB not significant) and all studies combined (drug 2\%, placebo 5\%, 13 RCTs, $n=1820$, RR 0.52 CI 0.28 to 0.97 , NNTB not significant) showed a significant difference in favour of antipsychotic medication. There was no significant difference in one study in the up to three months category (drug 3\%, placebo $0 \%, 1$ RCT, $n=49$, RR 1.50 CI 0.06 to 34.91) and in nine studies in the seven to 12 months category (drug $2 \%$, placebo $2 \%, 9$ RCTs, $n=1353, \mathrm{RR}$ 0.68 CI 0.30 to 1.58$)$.

\subsubsection{Dystonia}

One study in the up to three months category (drug 6\%, placebo $0 \%, 1$ RCT, $n=49$, RR 2.50 CI 0.13 to 49.22 ), two studies in the four to six months category (drug $16 \%$, placebo $9 \%, 2$ RCTs, $n=$ 382, RR 1.75 CI 0.94 to 3.29) and three studies in the seven to 12 months category (drug 2\%, placebo $0 \%$, 3 RCTs, n=393, RR 3.97 CI 0.44 to 35.54 ) did not show a significant difference in terms of dystonia. However, when all studies were pooled irrespective of their duration there was a significant superiority of placebo (drug 9\%, placebo 3\%, 6 RCTs, $n=824$, RR 1.89 CI 1.05 to 3.41, NNTH not significant).

\subsubsection{Rigidity}

One study in the up to three months category (drug 18\%, placebo $25 \%, 1$ RCT, n=49, RR 0.73 CI 0.24 to 2.22 ), three studies in the four to six months category (drug $17 \%$, placebo $8 \%, 3$ RCTs, $\mathrm{n}=160$, RR 1.98 CI 0.67 to 5.85 ), one study in the seven to 12 months category (drug $0 \%$, placebo $0 \%, 1$ RCT, $n=40$, RR not estimable) and all studies combined (drug 15\%, placebo $9 \%, 5$ 
RCTs, $\mathrm{n}=249$, RR 1.25 CI 0.54 to 2.88 ) did not reveal a significant difference in terms of rigor.

\subsubsection{Tremor}

One study in the up to three months category (drug 27\%, placebo $19 \%, 1$ RCT, n=49, RR 1.09 CI 0.40 to 3.01), three studies in the four to six months category (drug $8 \%$, placebo $10 \%, 3$ RCTs, $\mathrm{n}=160$, RR 0.92 CI 0.33 to 2.61), six studies in the seven to 12 months category (drug 5\%, placebo 3\%, 6 RCTs, $n=1259$, RR $1.41 \mathrm{CI} 0.82$ to 2.43 ) and all studies combined (drug 6\%, placebo $4 \%, 10$ RCTs, $\mathrm{n}=1468$, RR 1.25 CI 0.81 to 1.93 ) did not reveal a significant difference in terms of tremor.

\subsubsection{Use of antiparkinson medication}

In the four to six months category (drug 22\%, placebo $13 \%, 3$ RCTs, $n=841$, RR 1.53 CI 0.90 to 2.61 ) and in the seven to 12 months category (drug 29\%, placebo $20 \%, 4$ RCTs, $n=476$, RR 1.33 CI 0.86 to 2.05 ) no significant differences between groups were revealed. Overall, there was a significant difference in favour of placebo (drug 24\%, placebo 16\%, 7 RCTs, n=1317, RR 1.40 CI 1.03 to 1.89 , NNTH $11 \mathrm{CI} 6$ to 50 ).

\subsubsection{Sedation}

Studies lasting between four to six months showed no significant difference (drug 7\%, placebo 4\%, 6 RCTs, n=1577, RR $1.33 \mathrm{CI}$ 0.86 to 2.07 ) as well as studies lasting seven to 12 months (drug $32 \%$, placebo $21 \%$, 4 RCTs, $n=569$, RR 1.72 CI 0.90 to 3.31 ). All studies combined showed a significant difference in favour of placebo (drug 13\%, placebo 9\%, 10 RCTs, n=2146, RR $1.50 \mathrm{CI}$ 1.22 to 1.84 , NNTH not significant). There was some heterogeneity in the 12 months results ( $\mathrm{p}=0.09, \mathrm{I}^{2}=55 \%$ ). Removing the clearest outlier (Cooper 2000) which used zotepine, a drug that is known to be very sedating (Leucht 2009), reduced heterogeneity but overall antipsychotics still produced more sedation (all studies combined: RR 1.38 CI 1.11 to 1.71 , heterogeneity test: $\mathrm{p}=0.94$, $\left.\mathrm{I}^{2}=0 \%\right)$.

\subsubsection{Weight gain}

Three studies in the four to six months category showed no significant difference (drug 7\%, placebo 4\%, 3 RCTs, $n=736$, RR 1.76 CI 0.92 to 3.37). However, studies lasting seven to twelve months (drug 12\%, placebo 7\%, 7 RCTs, n=1585, RR $2.57 \mathrm{CI}$ 1.30 to 5.07 , NNTH 17 CI 13 to 25 ) and all studies combined (drug 10\%, placebo 6\%, 10 RCTs, n=2321, RR 2.07 CI 1.31 to 3.25, NNTH 20 CI 14 to 33) showed a significant difference in favour of placebo. There was some heterogeneity in the 12 months results $\left(\mathrm{p}=0.03, \mathrm{I}^{2}=58 \%\right)$, but all studies showed at least a trend in favour of placebo. Thus, the heterogeneity expressed differences in the degree of weight gain rather than in the direction of effect.

\section{I.9 Quality of life}

Two studies (Beasley 2003; Kramer 2007) in the seven to 12 months category showed an almost significant trend in favour of drug (2 RCTs, $\mathrm{n}=509$, SMD $-0.62 \mathrm{CI}-1.26$ to 0.01 ), while one study (Cheung 1981) lasting more than 12 months showed no significant difference ( 1 RCT, $\mathrm{n}=18$, SMD $-0.61 \mathrm{CI}-1.66$ to 0.45 ). When all three studies were combined, drugs were again superior (3 RCTs, $\mathrm{n}=527 \mathrm{SMD}-0.62 \mathrm{CI}-1.15$ to -0.09 ). Tentative back-calculation to the Schizophrenia Quality of Life Scale used in Kramer 2007 yielded an MD of 8.4 points. There was significant heterogeneity ( $\mathrm{p}=.003, \mathrm{I}^{2}=82 \%$ ) which may be in part due to the use of different scales (see discussion 2.9 below), but the direction of the effect was the same in all studies.

\section{I.I 0 Number of participants employed}

In two studies in the seven to 12 months category there was no significant difference in terms of number of participants employed (drug 48\%, placebo 50\%, 2 RCTs, n=259, RR 0.96 CI 0.75 to 1.23).

\section{I.I I Publication bias}

The funnel plot of the primary outcome 'relapse at 12 months' was asymmetrical (see Figure 5) and this was corroborated by Egger's regression test (intercept $-1.33, \mathrm{t}$ value 2.68 , degrees of freedom (df) 22, p=0.014, Egger 1997) and a contour-enhanced funnelplot (Peters 2008, the plot can be received from the authors upon request). However, when adjusted by Duval's trim and fill method (Duval 2000) the RR did not change substantially (RR 0.46, CI $0.38-0.55$ ), neither did it when only large studies (defined as $>200$ participants) were included (5 RCTs, $n=1506$, RR 0.39, CI 0.32 to 0.48$)$. 
Figure 5. Funnel plot of comparison: I Maintenance treatment with antipsychotic drugs versus placebo/no treatment, outcome: I.I Relapse.

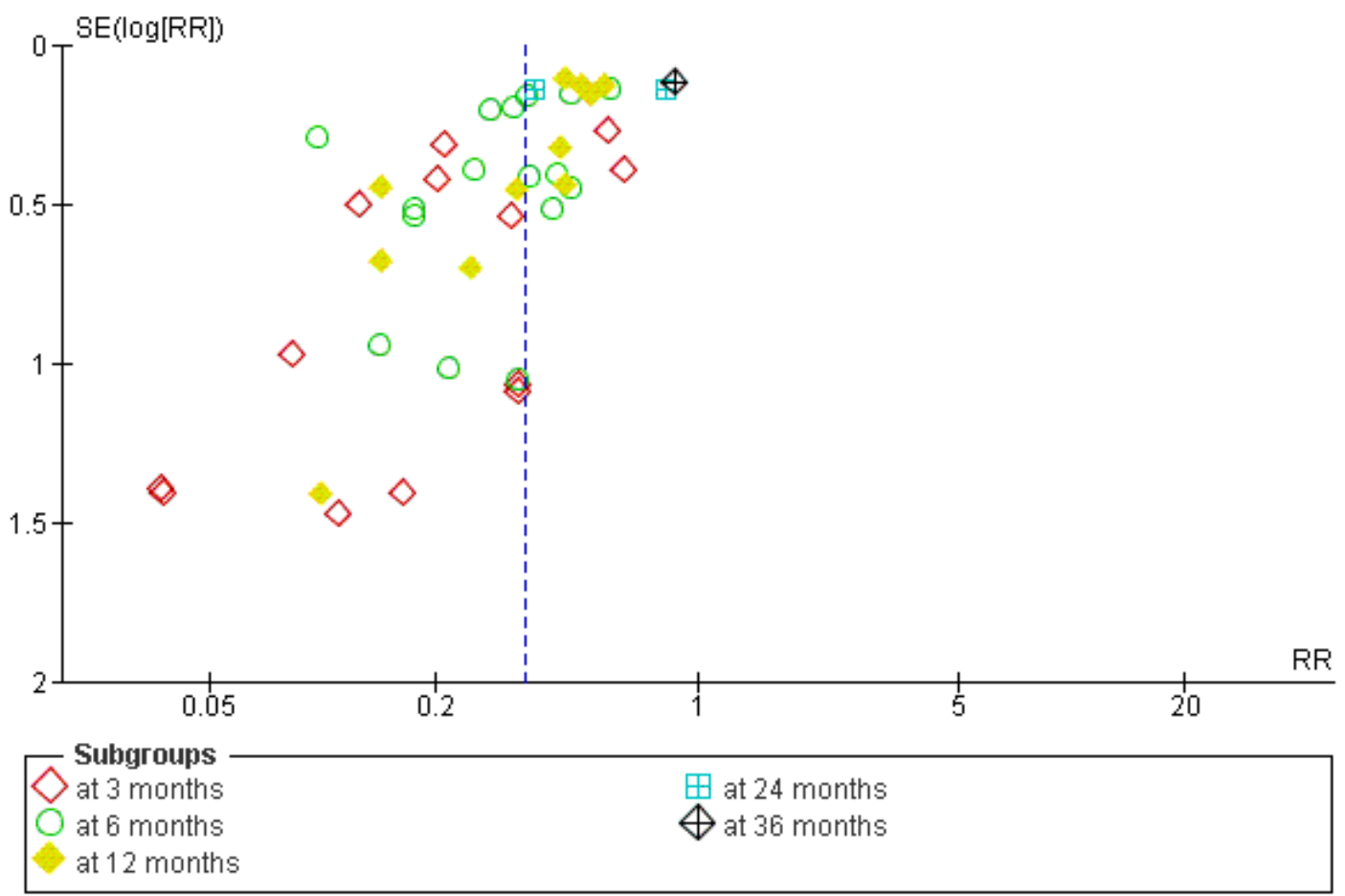

\section{Subgroup analyses (relapse at $\mathbf{I}$ months)}

All subgroup analyses were conducted only on the primary outcome 'relapse at 7 to 12 months'. A summary of the subgroup analyses is provided in Figure 6. 
Figure 6. Summary of subgroup analysis

$\begin{array}{llc}\text { Drug } & \text { PBo } & \text { Risk Ratio } \\ \mathbf{n} / \mathrm{N}(\%) & \mathrm{n} / \mathrm{N}(\%) & (95 \% \mathrm{Cl})\end{array}$

First versus multiple episode participants

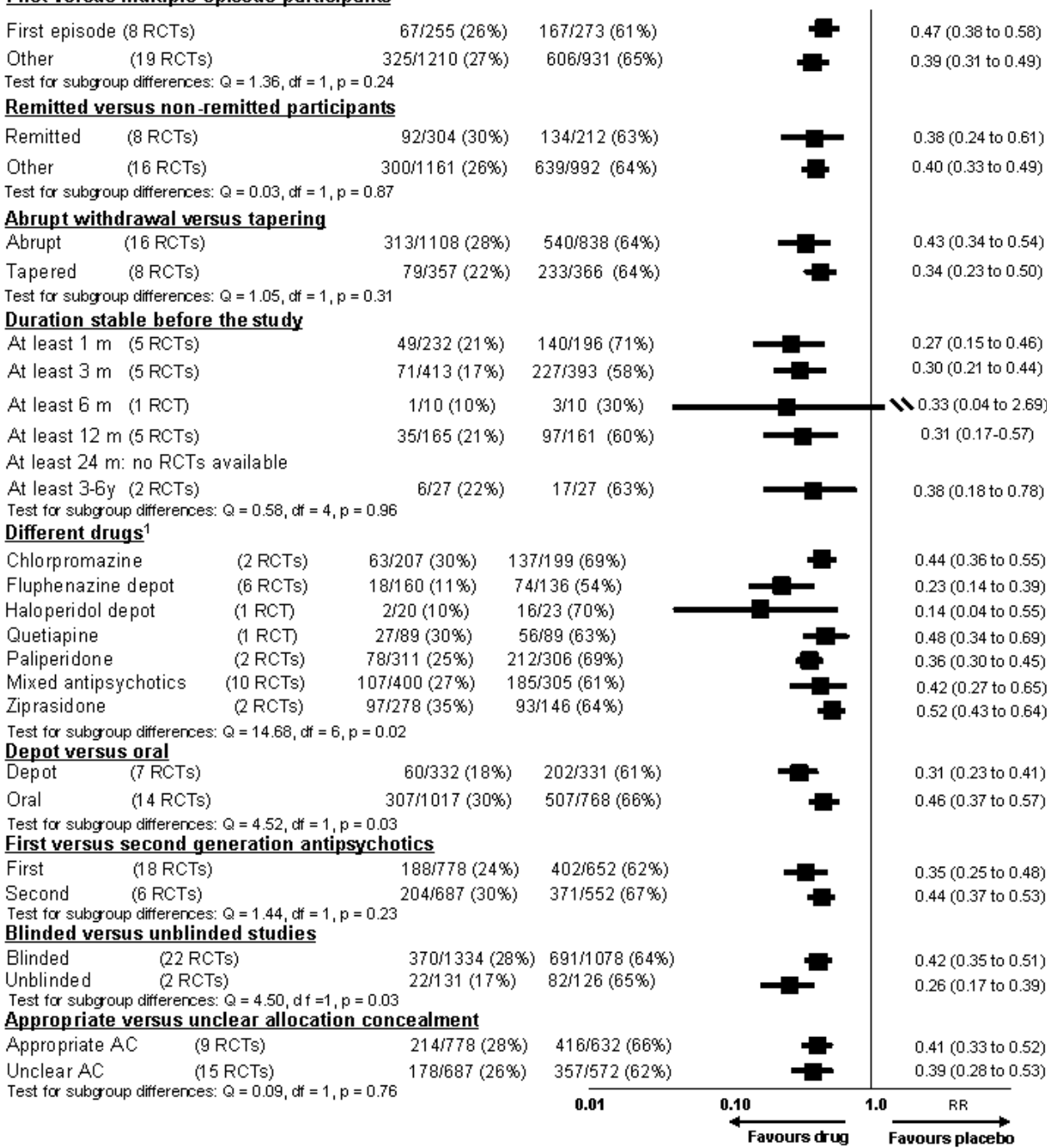

\footnotetext{
The DerSimonian and Laird random effects model was used throughout where the weights for the risk ratio were calculated using the Martel-Haenszel method, $\mathrm{PBO}=$ placebo, $\mathrm{n}=$ number of participants relapsed $\mathrm{N}=$ total number of patients, $\mathrm{RCTs}=$ number of included randornised controlled trials, $\mathrm{CI}=$ confidence interval, $\mathrm{m}=$ months, $\mathrm{y}=$ years, $\mathrm{AC}=$ allocation conce alment, $* * \mathrm{p}=0.001 ; \mathrm{l}_{\text {excluding the group }}$ "mixed antipsychotics" does not change the result
} 


\section{I Participants with a first episode of psychosis}

There was no significant difference between studies that included only people with a first episode (drug 26\%, placebo 61\%, 8 RCTs, $\mathrm{n}=528$, RR 0.47 , CI 0.38 to 0.58 ) and studies in people who had already experienced several episodes (drug 27\%, placebo 65\%, 19 RCTs, n=2141, RR 0.39, CI 0.31 to 0.49 ); (test for subgroup differences: $\left.\mathrm{Chi}^{2}=1.36, \mathrm{df}=1(\mathrm{P}=0.24), \mathrm{I}^{2}=26.5 \%\right)$.

\subsection{Participants in remission at baseline}

There was no significant difference between studies that included only participants who were in remission at baseline (drug 30\%, placebo $63 \%, 8$ RCTs, n=516, RR 0.38 , CI 0.24 to 0.61 ) and the rest of the studies (drug 26\%, placebo 64\%, 16 RCTs, RR 0.40, CI 0.33 to 0.49 ); (test for subgroup differences: $\mathrm{Chi}^{2}=0.03, \mathrm{df}=$ $\left.1(\mathrm{P}=0.87), \mathrm{I}^{2}=0 \%\right)$.

\subsection{Participants who had been stable for various periods before entering the trials}

Five studies included only participants who were stable for at least one month. Antipsychotic drugs significantly reduced relapse rates compared to placebo (drug 21\%, placebo $71 \%$, 5 RCTs, $n=428$, RR 0.27, CI 0.15 to 0.46 ). The same pattern was found for studies with participants stable at least three months (drug 17\%, placebo 58\%, 5 RCTS, n=806, RR 0.30, CI 0.21 to 0.44 ), stable at least 12 months (drug 21\%, placebo 60\%, 5 RCTs, $n=326$, RR 0.31, CI 0.17 to 0.57 ) and at least three to six years (drug $22 \%$, placebo $63 \%, 2$ RCTs, n=54, RR 0.38, CI 0.18 to 0.78 ). One small study included participants who were stable at least six months and the difference between drug and placebo was not statistically significant (drug 10\%, placebo 30\%, 1 RCT, n=20, RR 0.33, CI 0.04 to 2.69). Overall, there was no significant difference between the different durations of pre-trial stability (test for subgroup differences: $\left.\mathrm{Chi}^{2}=0.58, \mathrm{df}=4(\mathrm{P}=0.96), \mathrm{I}^{2}=0 \%\right)$.

\subsection{Abrupt withdrawal versus tapering}

There was no significant difference between studies in which antipsychotics were abruptly withdrawn (drug 28\%, placebo $64 \%$, 16 RCTs, n=1946, RR 0.43 , CI 0.34 to 0.54 ) or slowly tapered (drug 22\%, placebo 64\%, 8 RCTs, $n=723$, RR 0.34 , CI 0.23 to 0.50); (test for subgroup differences: $\mathrm{Chi}^{2}=1.05, \mathrm{df}=1(\mathrm{P}=$ $\left.0.31), \mathrm{I}^{2}=4.9 \%\right)$.

\subsection{Single antipsychotic drugs and depot versus oral medication}

The test for subgroup differences suggested that the depot versions of haloperidol and fluphenazine reduced relapse rates more than single other oral antipsychotics (test for subgroup differences: Chi $\left.2=14.68, \mathrm{df}=6(\mathrm{P}=0.02), \mathrm{I}^{2}=59.1 \%\right)$. This was confirmed when the subgroup of studies using depot antipsychotics (drug 18\%, placebo $61 \%, 7$ RCTs, $n=563$, RR 0.31 , CI 0.23 to 0.41 ) was compared with the subgroup of studies using oral antipsychotics (drug 30\%, placebo 66\%, 14 RCTs, $n=1785$, RR 0.46, CI 0.37 to 0.57$)$; (test for subgroup differences: $\mathrm{Chi}^{2}=4.52, \mathrm{df}=1(\mathrm{P}=$ $\left.0.03), \mathrm{I}^{2}=77.9 \%\right)$.

\subsection{First- versus second-generation antipsychotic drugs}

There was no significant difference in reduction of relapse risk between first generation antipsychotics (drug 24\%, placebo 62\%, 18 RCTs, $n=1430$, RR 0.35 , CI 0.25 to 0.48 ) and second generation antipsychotics (drug 30\%, placebo 67\%, 6 RCTs, $n=1239$, RR 0.44 , CI 0.37 to 0.53 ). This was shown by the test for subgroup differences $\left(\mathrm{Chi}^{2}=1.44, \mathrm{df}=1(\mathrm{P}=0.23), \mathrm{I}^{2}=30.4 \%\right)$.

\subsection{Appropriate versus unclear allocation concealment}

The degree of relapse reduction by antipsychotics was not different in studies that used appropriate allocation concealment (drug $28 \%$, placebo $66 \%, 9$ RCTs, $n=1410$, RR 0.41 , CI 0.33 to 0.52 ) and studies in which this was unclear (drug $26 \%$, placebo $62 \%$, 15 RCTs, $\mathrm{n}=1259$, RR 0.39, CI 0.28 to 0.53 ); (test for subgroup differences: $\left.\mathrm{Chi}^{2}=0.09, \mathrm{df}=1(\mathrm{P}=0.76), \mathrm{I}^{2}=0 \%\right)$.

\subsection{Blinded versus unblinded trials}

The single two open trials found a larger relapse risk reduction by antipsychotics (drug 17\%, placebo 65\%, 2 RCTs, n=257, RR 0.26 , CI 0.17 to 0.39 ) than the double-blind trials (drug $28 \%$, placebo $64 \%, 22$ RCTs, n=2412, RR 0.42, CI 0.35 to 0.51 ); (test for subgroup differences: $\left.\mathrm{Chi}^{2}=4.50, \mathrm{df}=1(\mathrm{P}=0.03), \mathrm{I}^{2}=77.8 \%\right)$.

\subsection{Meta-regression}

\subsubsection{Severity of illness at baseline}

The studies used many different scales (e.g. Clinical Global Impression scale (CGI), Brief Psychiatric Rating Scale (BPRS), Positive and Negative Syndrome Scale (PANNS)) to assess participants' severity at baseline. Therefore, a meta-regression based on a scale-defined severity of the illness was impossible. But it should be noted that the subgroup analysis comparing participants in remission at baseline with the rest of the studies did not yield a significant difference (see Section 2.2 above). 
2.9.2 Duration the participants were stable before the start of the study

There was no statistically significant effect on the difference in relapse risk at 7 to 12 months based on the duration the participants had been stable before they entered the studies (slope 0.001, CI 0.002 to $0.004, \mathrm{p}=0.44)$.

\subsubsection{Duration of taper in the placebo group}

There was no statistically significant effect on the difference in relapse risk at 7 to 12 months based on how rapidly the medication was withdrawn from the placebo group (slope -0.003 , CI -0.014 to $0.008, \mathrm{p}=0.55)$.

\subsubsection{Mean dose in chlorpromazine equivalents}

There was no statistically significant effect on the difference in relapse risk at 7 to 12 months based on the mean dose in chlorpromazine equivalents used in the antipsychotic drug groups (slope 0.0004 , CI -0.001 to $0.002, \mathrm{p}=0.43$ ).

\subsubsection{Study duration (relapse, all studies included)}

There was a statistically significant association in study duration with the difference relapse risk between antipsychotic drugs and placebo. The superiority of antipsychotic drugs was smaller in longer trials than in shorter trials (slope $=0.007$, 95\% CI 0.002 $0.010, \mathrm{p}<0.0001$, see Figure 7).

Figure 7. Meta-regression study duration

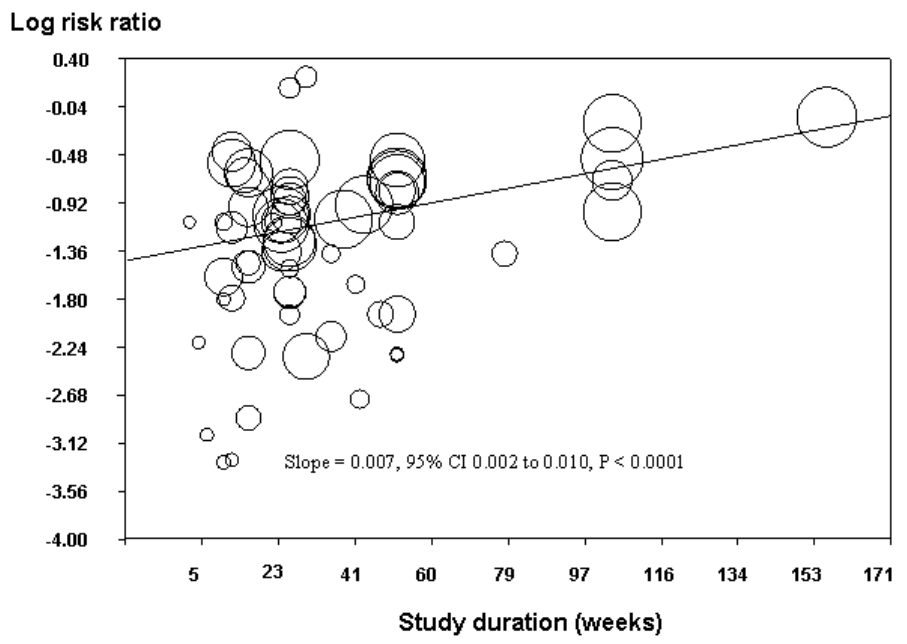

come 'relapse at 12 months'.

\section{Sensitivity analyses}

All sensitivity analyses were conducted only on the primary out- $\quad 3.1$ Exclusion of studies for which randomisation was implied 


\section{because they were double blind}

There was one study (McCreadie 1989) for the primary outcome relapse 7 to 12 months that was not explicitly described as randomised, although randomisation was likely because it was double blind. Excluding this study did not change the overall results (drug 27\%, placebo 64\%, 23 RCTs, n=2654, RR 0.40, CI 0.33 to 0.49 , NNTB 3 CI 2 to 3 ).

\subsection{Exclusion of randomised, open studies}

There were two randomised, open studies (Boonstra 2011; Pietzcker 1993). Excluding these studies did not change the overall results (drug 28\%, placebo $64 \%, 22$ RCTs, $n=2412$, RR 0.42 , CI 0.35 to 0.51 , NNTB 3 CI 2 to 3 ).

\subsection{Fixed-effects model}

When a fixed-effects model was applied, antipsychotic medication remained significantly more effective than placebo in preventing relapse (drug 27\%, placebo 64\%, 24 RCTs, n=2669, RR $0.40 \mathrm{CI}$ 0.36 to 0.44 , NNTB 2 CI 2 to 3 ).

\subsection{Original authors' assumptions on attrition}

There was no important difference if the original data of the authors' rather than our assumption on participants who had discontinued the studies was applied (drug 27\%, placebo 64\%, 24 RCTs, $n=2669$, RR 0.40 , CI 0.33 to 0.49 , NNTB 3 CI 2 to 3 ).

\subsection{Inclusion of large studies only (>200 participants)}

Including only large studies did not markedly change the effect size (see publication bias above).

\subsection{Exclusion of studies that used clinical criteria to diagnose the participants}

Excluding studies that did not use standardised diagnostic criteria did not change the overall results (drug 29\%, placebo 67\%, 16 RCTs, $n=2325$, RR 0.42 , CI 0.36 to 0.49 , NNTB 3 CI 2 to 3 ).

\section{7 to 3.9 Inclusion of only those participants who had been in the studies without a relapse for 3, 6 and 9 months}

Even when only participants who had not relapsed for three (drug $14 \%$, placebo $35 \%, 20$ RCTs, n=2942, RR 0.40 , CI 0.30 to 0.55 ), six (drug 15\%, placebo 38\%, 13 RCTs, $n=1382$, RR 0.40, CI 0.26 to 0.61 ) or nine months(drug $18 \%$, placebo $42 \%$; 10 RCTs, $n=$ 831, RR 0.46 , CI 0.29 to 0.73 ) after study start were included in the analysis, antipsychotic drugs were still clearly more efficacious than placebo.

\subsection{Exclusion of studies with unclear randomisation} methods

Excluding studies with unclear randomisation methods did not markedly change the overall results (drug $27 \%$, placebo $65 \%, 8$ RCTs, n=1564, RR 0.41, CI 0.34 to 0.50 ).

\section{I I Exclusion of studies with unclear allocation concealment methods}

Excluding studies with unclear allocation concealment methods did not markedly change the overall results (drug $28 \%$, placebo $66 \%, 9$ RCTs, $\mathrm{n}=1410$, RR 0.41 , CI 0.33 to 0.52 ).

\subsection{Summary of findings table}

The results of seven a priori chosen outcomes - relapse, leaving the study early due to any reason, rehospitalisation, suicide, satisfaction with care, quality of life and employment - were considered more closely in a 'Summary of findings' table (see Summary of findings table 1). Based on this tool we considered the results for the outcomes relapse, leaving the studies early due to any reason and rehospitalisation to be high, for suicide and quality of life to be poor and for employment to be very poor. Moreover, no data on the outcome satisfaction with care were available. The judgements derived from this instrument were used for the discussion section of the review (see discussion - Summary of main results).

\section{I S C U S S I O N}

\section{Summary of main results}

\section{General}

This review currently includes 65 studies with 6493 participants that compared antipsychotic maintenance treatment with placebo. The included studies were published over a long period (from 1959 to 2010) and in different settings (e.g. inpatients and outpatients) and countries. Despite this variety the results consistently demonstrated a superiority of antipsychotic drugs in the primary outcome relapse at seven to 12 months. This superiority remained robust in a number of sensitivity analyses. However, many included studies were relatively small, for example 46 randomised fewer than 100 people. Many trials were of short duration, only four studies lasted two years and only one study lasted three years. Thus, nothing is known about the effects of antipsychotic drugs compared to placebo after three years. Furthermore, while almost all studies reported on relapse and leaving the study early, all other outcomes were much more rarely recorded and side-effect reporting was especially poor. As it is unfortunately typical for RCTs 
in schizophrenia, the methods of randomisation, allocation concealment and blinding were frequently not reported. But as those studies that reported appropriate allocation methods yielded similar results, this potential source of bias should not challenge the overall findings.

\section{Treatment effects}

\section{I Relapse}

The results demonstrate that antipsychotic drugs reduce relapse rates more effectively than placebo. This effect was apparent as early as three months after discontinuation of antipsychotic drugs and remained significant in studies between 13 and 36 months. However, studies lasting longer than 12 months were scarce. Thus, further studies longer than 12 months and maybe even longer than 36 months would be desirable to understand the very long-term effects of antipsychotic drugs. This is even more important since the meta-regression showed decreasing effect sizes over time (Figure 7). There were frequent instances of significant heterogeneity, which may be due to differences in drugs, participants (e.g. degree of severity at baseline) or definitions of relapse. Nevertheless, almost all single studies favoured antipsychotic drugs and therefore the heterogeneity reflected differences in the degree of superiority rather than differences in the direction of the effect.

\subsection{Leaving the study early}

Clearly fewer participants in the drug group than in the placebo group left the studies early due to any reason or due to inefficacy of treatment. Leaving a study due to any reason is often considered to be a measure of acceptability of treatment. We would be hesitant to apply this interpretation here, because relapses were the most frequent reason for leaving the studies early and in many studies it was predefined by the protocol that participants had to discontinue once they had relapsed. Therefore, it was not really the participants' choice ('acceptability') to remain in a trial or not, and leaving the study early reflected efficacy rather than tolerability.

That more participants in the placebo group left the studies early due to inefficacy of treatment supports the relapse preventing effect of antipsychotics.

There was no difference in the number of participants leaving the studies early due to adverse events. It should be noted that events such as 'worsening of psychosis' are, by definition, also recorded as adverse events, especially in modern trials. This may in part explain the significant heterogeneity of the results. Moreover, this mix of tolerability- and efficacy-related adverse events shows that 'leaving the studies early due to adverse events' is not an ideal measure of overall tolerability.

\subsection{Service use - number of participants hospitalised}

Fewer participants in the drug group than in the placebo group had to be re-hospitalised. Again, there was moderate heterogeneity, but all the individual studies showed at least a trend to antipsychotic drugs. This finding is important, because in many industrialised countries hospitalisation contributes highly to the direct cost of schizophrenia. Only 16 studies provided data on this outcome. Although it should be noted that only 27 trials were conducted in outpatients (in inpatients rehospitalisation cannot be an outcome) and although it depends on the setting how easily patients are admitted, this relatively hard and easy-to-measure outcome should be recorded in all future trials.

\subsection{Service use - number of participants discharged}

Many older trials were conducted in inpatient settings. Under these circumstances it was of interest to analyse whether the participants could be stabilised to such an extent that they could be discharged at the end of the trial. There was no significant difference between drug and placebo; however, only three trials contributed to this outcome so that the results are inconclusive.

\subsection{Global state - number of participants improved}

The results showed that antipsychotic drugs improved participants' global state more than placebo. But these findings also show that many participants were 'stable', but not in remission at study start. If they had all been in remission, further improvements would not have been possible. This demonstrates the importance of our subgroup analysis on people in remission.

\subsection{Death}

There was no significant difference in the number of participants dying for any reason, natural causes or suicide. There was also no difference in the number of suicide attempts and suicidal ideation; however, in most studies the outcome death was not clearly reported. This is problematic, because there is some epidemiological evidence that long-term treatment with antipsychotic drugs may increase mortality (Ray 2009; Weinmann 2009). Conversely, it is hoped that maintenance treatment with antipsychotic drugs might reduce suicides and another epidemiological study showed that treatment with antipsychotic drugs was associated with reduced mortality (Tiihonen 2009). We feel that future long-term studies should consistently report this hard and important outcome.

\subsection{Violence, aggressive behaviour}

Fewer participants in the antipsychotic drug group had aggressive episodes. Although this finding is based on only five trials, it is an argument in favour of the use of antipsychotic drugs for maintenance treatment. Although the overall incidence is low, violence 
seems to be more frequent among people with schizophrenia compared to the general population contributing to the stigma of the disorder (Walsh 2002).

\subsection{Adverse effects}

Adverse effects were often poorly and incompletely reported. Nevertheless, antipsychotic drugs produced more movement disorders in terms of at least one movement disorder, akathisia (after removing an outlier), dystonia and use of antiparkinson medication. They also produced more sedation and weight gain. We highlight that we combined all antipsychotic drugs in the analysis, but antipsychotic drugs differ largely in their risk for these adverse events. For example, high-potency conventional antipsychotic drugs, such as haloperidol, produce many movement disorders while many newer, so-called second-generation antipsychotic drugs, such as olanzapine, are associated with significant weight gain (Leucht 2009). Therefore, our tolerability findings are not generalisable to all compounds. Dyskinesia was the only outcome that occurred more frequently in the placebo group. At first glance this finding is peculiar. We speculate that these dyskinesias frequently were withdrawal dyskinesia after abrupt stopping of antipsychotic drugs rather than tardive dyskinesia. However, it was usually not clearly reported when this adverse event occurred. This is another example for a need of better side-effect reporting in randomised schizophrenia trials (Papanikolaou 2004; Pope 2010).

\subsection{Quality of life}

Three studies showed better quality of life in the antipsychotic drug groups and when they were combined the superiority was statistically significant. Due to the small number of trials this finding is not robust and more evidence is needed. Moreover, the three trials applied different rating scales and our decision to pool them using the SMD as an effect size may be debatable. However, analysing the trials separately with WMDs would not have changed the conclusion, because two trials showed a significant superiority (Beasley 2003; Kramer 2007) and the third, smaller trial (Cheung 1981) showed a trend in favour of antipsychotic drugs. The relevance is, however, high, because we had assumed that due to their side effects antipsychotic drugs could worsen quality of life. If confirmed by further trials, improved quality of life would be another strong argument for maintenance treatment with antipsychotic drugs.

\subsection{Employment}

Only two studies addressed this outcome and did not find a significant difference. This finding is inconclusive. It highlights the limitations of the current evidence. It is clear that antipsychotic drugs suppress symptoms of schizophrenia, but whether this also leads to better functional outcomes is unclear. A review suggested that $80 \%$ to $90 \%$ of people with schizophrenia are not employed
(Marvaha 2004). In our opinion to find out whether maintenance treatment with antipsychotic drugs improves outcomes of social participation is an important research agenda for the future.

\section{Publication bias}

The funnel plot was clearly asymmetrical suggesting the possibility of a publication bias. However, other reasons than unpublished studies can make funnel plots asymmetrical. For example, small studies are often conducted in single centres with very motivated investigators who make sure that drugs are compliantly taken. This may be more difficult in large, multicentre studies. To examine the impact of potentially undetected small studies we made a sensitivity analysis in which we only included larger studies, which we defined by a sample size of at least 200. In this group of studies there was still a clear reduction of the relapse risk at 12 months by antipsychotic drugs. Therefore, even if only the larger studies were considered, the superiority of antipsychotic drugs is not questioned. Duval's and Tweedy's trim and fill method did also not suggest a substantial effect from missing small trials (Duval 2000).

\section{Subgroup analyses and investigation of heterogeneity}

The heterogeneity of many results was statistically significant, which was expected in a review that pooled different drugs and doses, that combined studies that used different relapse definitions and that were published over a period of 50 years. Nevertheless, in most studies the direction of the effects was the same. Therefore, the heterogeneity reflected only differences in the degree of superiority in relapse prevention. Moreover, most subgroup analyses and meta-regressions did not reveal any statistically significant differences (see Figure 6 for summary). This finding is important, because it may be interpreted that the relapse preventing effects of antipsychotic drugs can be generalised to many patients.

\section{I People with a first episode of schizophrenia and people in remission}

The effects of antipsychotic drugs were similar in first-episode compared to multiple-episode participants, and if participants were in remission at baseline or not. First-episode and remitted people with schizophrenia are thought to have a better prognosis, but our results suggest that they equally benefit from antipsychotic relapse prevention. Approximately $20 \%$ of people with a first episode of schizophrenia will not have a second one within five years (Robinson 1999), but the problem is that they can not be identified in advance. 


\subsection{People who had been stable for various periods before} entering the trials

The relapse preventing effects of antipsychotic drugs were independent from the duration that participants had been stable before entering the studies. Even in those participants who had been stable for up to 3 to 6 years (Cheung 1981; Sampath 1992) relapse rates were higher among placebo-treated than among drug-treated individuals. This is important for the recommended duration of antipsychotic maintenance treatment in guidelines, because it can be argued that even patients who have taken antipsychotic drugs for such a duration still benefit from them. But as only two small studies (Cheung 1981; Sampath 1992) with a total of only 54 participants contributed to this finding, more evidence is clearly needed for solid recommendations.

\subsection{Abrupt versus gradual withdrawal of antipsychotic drugs}

There is a theory that long-term treatment with antipsychotic drugs leads to a compensatory upregulation of dopamine receptors. If antipsychotic drugs are withdrawn abruptly, dopamine receptors are hypersensitive leading to rebound psychosis (Moncrieff 2006). This phenomenon has been called 'supersensitivity psychosis'. In contrast to the now outdated report by Viguera 1997 we did not find a difference in relapse reduction between studies in which drugs were abruptly or gradually withdrawn, neither in a dichotomised subgroup analysis applying the same cut-off as Viguera 1997 (who defined gradual withdrawal by a taper duration of at least 3 weeks or stopping depot antipsychotic drugs that have a long half-life) nor in a meta-regression with duration of taper as a continuous parameter. It should be noted that subgroup analysis and meta-regression are observational, crude methods and can, therefore, not rule out this theory which needs thorough investigation. It is also possible that supersensitivity psychosis explains a part of the decreasing effect sizes in longer trials (see Figure 7 and below). We would therefore strongly recommend slow tapering of antipsychotic drugs.

\subsection{Single antipsychotic drugs, depot versus oral medication and first-generation versus second-generation antipsychotic drugs}

There were no differences between the single antipsychotic drugs used apart from depot antipsychotic drugs (in particular depot formulations of haloperidol and fluphenazine) being more effective than oral antipsychotic drugs. Although this result fits to the theory that depot antipsychotic drugs improve the adherence that is crucial for relapse prevention, subgroup analyses are of observational nature. Only head-to-head comparisons of oral and depot antipsychotic drugs can decide whether the latter are more effective. A recent update of our systematic review on this question (Leucht 2011) did not find a difference between oral and depot medication (Kishimoto 2012). As a group so-called second- generation antipsychotic drugs did not differ in relapse reduction from first-generation antipsychotic drugs. This supports previous suggestions that this classification should be abandoned, because there is no single definition that fits to all drugs that are considered to be second-generation or atypical antipsychotic drugs (Leucht 2009).

\subsection{Appropriate versus unclear allocation concealment methods}

There was no difference between the RRs of studies that used appropriate and unclear allocation concealment methods. It should, however, be noted that the original analyses on this question found larger differences between studies with appropriate and inappropriate allocation concealment than between appropriate and unclear allocation concealment (e.g. Schulz 1995). Studies with inappropriate allocation concealment were excluded a priori from our review.

\subsection{Open versus double-blind studies}

Open trials were associated with a stronger difference between drugs and placebo than blinded trials, but as there were only two open RCTs (Boonstra 2011; Pietzcker 1993) the impact of this effect was small.

\subsection{Meta-regression on study duration}

There was a statistically significant association between longer study duration and smaller relapse reduction by antipsychotic drugs compared to placebo. This result could indicate that antipsychotic drugs lose their efficacy over time. We emphasise that there are many possible explanations for this counterintuitive finding. Participants' severity in shorter and longer trials could be different, and notably the decreasing relapse preventing effects could also be an effect of decreasing drug compliance over time. However, studies that last longer than two years and either use depot antipsychotic drugs or thoroughly monitor compliance are needed to investigate the long-term effects of antipsychotic drugs.

\section{Sensitivity analyses}

The results of the primary outcome were not much different when studies that were not clearly described as randomised were excluded, when open studies were excluded, when a fixed-effects model instead of a random-effects model was applied, when we used the original authors' assumptions on dropouts instead of our approach, and when studies with unclear randomisation or allocation concealment methods were excluded. These sensitivity analyses underline the robustness of the results.

A final sensitivity analysis in which we analysed only those participants who had not relapsed for various durations after study start again addressed supersensitivity psychosis: it revealed that even in 
those participants who had not relapsed for nine months subsequent relapse rates were clearly lower in the drug group than in the placebo group. This finding opposes the theory that many relapses were merely rebound effects after rapid withdrawal (Moncrieff 2006).

\section{Overall completeness and applicability of evidence}

The 65 included studies were conducted in various settings (e.g. inpatients and outpatients, different countries, stable superiority antipsychotic drugs in trials from different years), populations (e.g. participants in remission at baseline or not) and methods (e.g. different definitions of relapse). Therefore, we believe that the evidence is quite complete and applicable to routine care. There are several limitations, however: while almost all studies reported on relapse, there is much less evidence on other outcomes such as hospitalisation and adverse events, which were inadequately reported. There were very few studies that lasted longer than one year. Thus, the long-term effects of maintenance treatment are unclear. Finally, in most studies antipsychotic drugs were withdrawn abruptly. There is a theory that long-term treatment leads to changes in dopamine receptors ('hypersensitivity psychosis') and re-emergence of symptoms after abrupt withdrawal (Moncrieff 2006). Although our meta-regression and sensitivity analysis did not detect an effect, future studies should withdraw antipsychotic drugs gradually rather than abruptly and to rule out or confirm this, supersensitivity psychosis should be an important research agenda.

\section{Quality of the evidence}

Almost all studies were randomised and double-blind but for most of them details were not presented. Therefore it is unclear whether the studies were adequately randomised, whether treatment allocation was really concealed and whether blinding worked. Concerning blinding this may be less important in objective outcomes such as death or weight gain. Concerning allocation concealment we at least found that there was no difference in the primary outcome between studies that used appropriate and unclear methods. Dropout rates were often high, partly because it was specified in many studies' methods that participants had to discontinue once they relapsed. This poses mainly a problem for other outcomes than relapse. While relapse and leaving the studies early was quite consistently reported, the evidence about other outcomes was much more scarce. Without original study protocols being available we cannot judge with absolute certainty whether these were not measured or whether there were cases of selective reporting. The current approach to report only those outcomes that occurred in at least $5 \%$ to $10 \%$ of the participants should be abandoned, because rare but important side effects might be over- looked. In individual trials there were also other problems, such as too high or too low doses, early termination of studies, baseline imbalances etc. In summary, the overall quality of the studies according to these criteria is moderate. Nevertheless, due to the consistency of the results in subgroup and sensitivity analyses, the overall superiority of antipsychotic drugs in reducing relapse rates is not challenged.

\section{Potential biases in the review process}

We a priori decided to pool all antipsychotic drugs in this review. We feel that this is justified for efficacy-related outcomes, because most antipsychotic drugs do not differ in efficacy and if differences exist between some antipsychotic drugs these are not large (Leucht 2009). The decision to pool all studies irrespective of the antipsychotic drug used is more problematic for side effects, because antipsychotic drugs differ to a large extent in this regard. Thus, any differences in side effects compared to placebo cannot be generalised to all antipsychotic compounds. Similarly, we analysed only a selection of common and important side effects, but many others exist. The study search was mainly based on the Cochrane Schizophrenia Group's register of trials. This is largely made up of searches of published literature. It is possible that there are unpublished studies that we are not aware of and there is a possibility of publication bias, although the funnel plot may also be asymmetrical due to other factors. More sensitive time-to-relapse data derived from survival analyses that are considered more appropriate measures were not available for most studies, and, therefore, we had to restrict ourselves to the number of participants relapsed. We have chosen to use the random-effects model for our analyses, which does not assume that the populations from which the different trials are derived are the same. This technique does emphasise the results from smaller trials and it is these studies that are likely to be most prone to bias. Nevertheless, the results of a fixed-effect model in a sensitivity analysis of the primary outcome were similar. Finally, we highlight that many subgroup and metaregression analyses were conducted in this review, many of which were added post-hoc after requests from reviewers. This raises the problem of type I errors (i.e. chance findings due to multiple testing).

\section{Agreements and disagreements with other studies or reviews}

We are aware of three other reviews that compared maintenance treatment with any antipsychotic drug with placebo. Gilbert 1995, Baldessarini 1985 and Davis 1975 were consistent with our results because they found that participants with schizophrenia who were withdrawn from antipsychotic drugs relapsed significantly more frequently than participants who continued them. However, all three reports did not meet modern criteria of systematic reviews, 
did not analyse relapse at different points in time and did not address any other outcome. A review by some members of the current review team was restricted to second-generation antipsychotics (Leucht 2009b, an update of Leucht 2003). Second-generation antipsychotic drugs clearly reduced relapse rates compared to placebo and the relative risk was similar to that in the current review (RR $0.41,95 \% \mathrm{CI} 0.28$ to 0.59 ), but the absolute risk difference was smaller (RD $0.20,95 \%$ CI 0.11 to 0.30 ). The previous review included only seven trials and the inclusion criteria were different (e.g. studies that only followed up acute-phase responders (a design that corrupts randomisation) were also included and participants were not required to be stable on antipsychotic drugs or to be on antipsychotic drugs at all at study start). In terms of Cochrane reviews, Almerie 2007 examined withdrawal of chlorpromazine compared to placebo and also found a significant relapse risk reduction.

\section{AUTHORS' CONCLUSIONS}

\section{Implications for practice}

\section{For people with schizophrenia}

For people with schizophrenia it may be important to know that antipsychotic drugs are more efficacious than placebo in preventing relapse. Thus, if people stop their antipsychotic drug many will have a relapse. Conversely, they need to be aware that antipsychotic drugs have a number of side effects, such as movement disorders, weight gain and sedation, which, differ between compounds. They might tell their doctors that they want to be involved in the choice of the antipsychotic that is best for them.

\section{For clinicians}

Clinicians should know that most studies lasted no longer than one year and that the longest study lasted three years. Thus, nothing is known about the very long-term effects of antipsychotic drugs compared to placebo. The clear superiority of antipsychotic drugs was quite consistent for different types of settings (e.g. inpatient and outpatients) and participants (people with a first and multiple episodes, duration of stability before study start), and it was robust to statistical assumptions. Whether antipsychotic drugs save lives by preventing suicides or increase mortality due to their side effects could not be clarified by this review.

\section{For managers/policy makers}

The data suggest that people on antipsychotic drugs need to be hospitalised less frequently than those receiving placebo. This is important for managers, because in many countries hospitalisation accounts for a big proportion of the overall costs of this disease. But they should also note that less than one third of the relapsed participants had such severe relapses that rehospitalisation was necessary.

\section{Implications for research}

\section{General}

Outcome reporting remains insufficient in antipsychotic drug trials. Strict adherence to the CONSORT statement (CONsolidated Standards Of Reporting Trials; Moher 2001) would make such studies much more informative.

\section{Specific}

Although difficult to conduct due to ethical concerns it would be interesting to have more studies that last longer than two years. Such studies should not only examine relapse but also other outcomes such as rehospitalisation, outcomes reflecting social participation and death. Participants' compliance should be monitored. Table 1 presents an outline.

\section{ACKNOW LEDGEMENTS}

We thank the editorial team of the Cochrane Schizophrenia Group for its enormous support. We thank Richard Skodnek, MD, for his work on a preliminary version of this review. We also thank Astellas, Bristol MyersSquibb, EliLilly, Lundbeck, Pfizer, Johnson \& Johnson, SanofiAventis, Eric Chen, George Gardos, Julian Leff, and Erik Denys for sending additional information on their studies. We thank Michael Borenstein and Georgia Salanti for their statistical advice and for conducting statistical analyses.

The Cochrane Schizophrenia Group Editorial Base in Nottingham, UK, produces and maintains standard text for use in the Methods section of their reviews. We have used some of this text as the basis of what appears here and adapted it as required. 


\section{R E F E R E N C E S}

\section{References to studies included in this review}

Andrews 1976 \{published data only\}

* Andrews P, Hall JN, Snaith RP. A controlled trial of phenothiazine withdrawal in chronic schizophrenic patients. British Journal of Psychiatry 1976;128:451-5.

Arato 2002 \{published data only\}

* Arato M, O'Connor R, Meltzer HY. A 1-year, doubleblind, placebo-controlled trial of ziprasidone 40, 80 and $160 \mathrm{mg} /$ day in chronic schizophrenia: the Ziprasidone Extended Use in Schizophrenia (ZEUS) study. International Clinical Psychopharmacology 2002;17:207-15.

Baro 1970 \{published data only\}

* Baro F, Brugmans J, Dom R, Van Lommel R. Maintenance therapy of chronic psychotic patients with a weekly oral dose of R 16341. A controlled double-blind study. Journal of Clinical Pharmacology 1970;10:330-41.

Beasley 2003 \{published data only\}

* Beasley CM, Sutton VK, Hamilton SH, Walker DJ, Dossenbach M, Taylor CC, et al.A double-blind, randomised, placebo-controlled trial of olanzapine in the prevention of psychotic relapse. Journal of Clinical Psychopharmacology 2003;23:582-94.

Beasley CM, Sutton VK, Taylor CC, Sethuraman G, Dossenbach M, Naber D. Is quality of life among minimally symptomatic patients with schizophrenia better following withdrawal or continuation of antipsychotic treatment?. Journal of Clinical Psychopharmacology 2006;26:40-4. Beasley CM, Walker DJ, Sutton VK, Alaka K, Naber D, Namjoshi M. The effectiveness of olanzapine versus placebo in maintaining the quality of life in stabilized patients with schizophrenia. European Neuropsychopharmacology 2003;13: S342.

\section{Blackburn 1981 \{published data only\}}

* Blackburn HL, Allen JL. Behavioral effects of interrupting and resuming tranquilizing medication among schizophrenics. Journal of Nervous and Mental Disease 1981; 133:303-8.

Boonstra 2011 \{published data only\} Boonstra G. Schizophrenia termination of pharmacotherapySTOP-trial. Current Controlled Trials 2005. [ISRCTN: 6332944]

* Boonstra G, Burger H, Grobbe DE, Kahn RS.

Antipsychotic prophylaxis is needed after remission from a first psychotic episode in schizophrenia patients: results from an aborted randomised trial. International Journal of Psychiatry in Clinical Practice 2011;15(2):128-34.

Caffey 1964 \{published data only\}

Caffey EM, Diamond LS, Frank TV, Grasberger JC,

Herman L, Klett CJ, et al.Discontinuation or reduction of chemotherapy in chronic schizophrenics. Journal of Chronic Diseases 1964;17:347-58.

Caffey EM, Forrest IS, Frank TV, Klett CJ. Phenothiazine excretion in chronic schizophrenics. American Journal of Psychiatry 1963;120:578-82.

Channabasavanna 1987 \{published data only\} Channabasavanna SM, Michael A. Penfluridol maintenance therapy in schizophrenia: a controlled study. Indian Journal of Psychiatry 1987;29:333-6.

Chen 2010 \{published data only\} Chen EYH, Hui CLM, Lam M, Law CW, Chiu CPY, Chung DWS, et al.A double-blind randomised placebocontrolled study of relapse prevention in remitted firstepisode psychosis patients following one year of maintenance therapy. Schizophrenia Research 2008;98:11-2.

* Chen EYH, Hui CLM, Lam MML, Chiu CPY, Law CW, Chung DWS, et al.Maintenance treatment with quetiapine versus discontinuation after one year of treatment in patients with remitted first episode psychosis: randomised controlled trial. British Medical Journal 2010;341:c4024.

\section{Cheung 1981 \{published data only\}}

Cheung HK. Schizophrenics fully remitted on neuroleptics for 3-5 years - to stop or continue drugs?. British Journal of Psychiatry 1981;138:490-4.

\section{Clark 1975 \{published data only\}}

Clark ML, Huber WK, Hill D, Wood F, Costiloe JP. Pimozide in chronic schizophrenic outpatients. Diseases of the Nervous System 1975;36:137-41.

\section{Cooper 2000 \{published data only\}}

Cooper SJ, Butler A, Tweed J, Raniwalla J, Welch C. Zotepine in the prevention of relapse. Proceedings of the 6th World Congress of Biological Psychiatry; 1997 June 2227; Nice, France. 1997.

* Cooper SJ, Butler A, Tweed J, Welch C, Raniwalla J. Zotepine in the prevention of recurrence: a randomised, double-blind, placebo-controlled study for chronic schizophrenia. Psychopharmacology 2000;150:237-43. Cooper SJ, Butler A, Tweed JA, Welch CP, Wighton AJ, Appleby $\mathrm{P}$, et al.Zotepine is effective in preventing recurrence in patients with chronic schizophrenia. Proceedings of the 11th European College of Neuropsychopharmacology Congress; 1998 Oct 31 - Nov 4; Paris, France. 1998. Cooper SJ, Butler A, Tweed JA, Welch CP, Wighton AJ, Appleby $\mathrm{P}$, et al.Zotepine is effective in preventing recurrence in patients with chronic schizophrenia. Schizophrenia Research 2000;41:207-8.

\section{Crow 1986 \{published data only\}}

Crow TJ, MacMillan JF, Johnson AL, Johnstone EC. A randomised controlled trial of prophylactic neuroleptic treatment. British Journal of Psychiatry 1986;148:120-7.

\section{Denijs 1973 \{published data only\}}

Denijs EL, Vereeken JL. Pimozide (OrapR, R 6238) in residual schizophrenia. A clinical evaluation with long- 
term double-blind follow-up. Psychiatria, Neurologia,

Neurochirurgia 1973;76:47-59.

\section{Doddi 1979 \{published data only\}}

Dotti A, Bersani G, Rubino IA, Eliseo C. Double-blind trial of fluphenazine decanoate against placebo in ambulant maintenance treatment of chronic schizophrenics [Studio in doppio cieco della flufenazina decanoato versus placebo nella terapia ambulatoriale di mantenimento di pazienti schizofrenici cronici]. Rivista di Psichiatria 1979;14: 374-83.

Eklund 1991 \{published data only\} Eklund K. Low dose of haloperidol decanoate is effective against relapses in schizophrenia patients. A doubleblind placebo controlled study. Proceedings of the 17th Collegium Internationale Neuro-Psychopharmacologicum Congress; 1990 Sep 10-14; Kyoto, Japan. 1990:287.

* Eklund K, Forsman A. Minimal effective dose and relapse - double-blind trial: haloperidol decanoate vs. placebo. Clinical Neuropharmacology 1991;14:S7-S15.

Elie 1975 \{published data only\}

Elie R, Gagnon MA, Gauthier R, Jequier JC. Effects of neuroleptic withdrawal on the drug-induced extrapyramidal syndrome of chronic schizophrenia [Effets d'un sevrage neuroleptique sur le syndrome extrapyramidal medicamenteux de la schizophrenie chronique]. Union Medicale du Canada 1975;104:909-14.

Freeman 1962 \{published data only\}

Freeman LS, Alson E. Prolonged withdrawal of chlorpromazine in chronic patients. Diseases of the Nervous System 1962;23:522-5.

Gallant 1974 \{published data only\}

Gallant DM, Mielke DH, Spirtes MA, Swanson WC, Bost R. Penfluridol: an efficacious long-acting oral antipsychotic compound. American Journal of Psychiatry 1974;131: 699-702.

Gardos 1984 \{published data only\} Gardos G, Cole JO, Rapkin RM, LaBrie RA, Baquelod E, Moore $\mathrm{P}$, et al.Anticholinergic challenge and neuroleptic withdrawal. Changes in dyskinesia and symptom measures. Archives of General Psychiatry 1984;41:1030-5.

Garfield 1966 \{published data only\} Garfield SL, Gershon S, Sletten I, Neubauer H, Ferrel E. Withdrawal of ataractic medication in schizophrenic patients. Diseases of the Nervous System 1966;27:321-5.

Gitlin 1988 \{published data only\}

Gitlin MJ, Midha KK, Fogelson D, Nuechterlein KH. Persistence of fluphenazine in plasma after decanoate withdrawal. Journal of Clinical Psychopharmacology 1988;8: 53-6.

Goldberg 1981 \{published data only\} Goldberg SC, Shenoy RS, Sadler A, Hamer R, Ross B. The effects of a drug holiday on relapse and tardive dyskinesia in chronic schizophrenics. Psychopharmacology Bulletin 1981; 17:116-7.

Shenoy RS, Sadler AG, Goldberg SC, Hamer RM, Ross B. Effects of a six-week drug holiday on symptom status, relapse, and tardive dyskinesia in chronic schizophrenics. Journal of Clinical Psychopharmacology 1981;1:141-5.

\section{Gross 1960 \{published data only\}}

Gross M, Hitchman IL, Reeves WP, Lawrence J, Newell PC. Discontinuation of treatment with ataractic drugs. A preliminary report. American Journal of Psychiatry 1960; 116:931-2.

Gross 1974 \{published data only\}

Gross HS. A double-blind comparison of once-a-day pimozide, trifluoperazine, and placebo in the maintenance care of chronic schizophrenic outpatients. Current Therapeutic Research 1974;16:696-705.

Hershon 1972 \{published data only\}

* Hershon HI, Kennedy PF, McGuire RJ. Persistence of extra-pyramidal disorders and psychiatric relapse after withdrawal of long-term phenothiazine therapy. British Journal of Psychiatry 1972;120(554):41-50.

Stevens BC. Role of fluphenazine decanoate in lessening the burden of chronic schizophrenics on the community. Psychological Medicine 1973;3:141-58.

Hirsch 1973 \{published data only\} Hankoff LD, Engelhardt DM, Freedman N, Mann D, Maroolis R. Denial of illness in schizophrenic outpatients: effects of psychopharmacological treatment. Archives of General Psychiatry 1960;3:657-66.

* Hirsch SR, Gaind R, Rohde PD, Stevens BC, Wing JK. Outpatient maintenance of chronic schizophrenic patients with long-acting fluphenazine: double-blind placebo trial. Report to the Medical Research Council Committee on Clinical Trials in Psychiatry. British Medical Journal 1973;1: 633-7.

Hirsch 1996 \{published data only\} Hirsch SR, Bowen JT, Emami J. The effect of life events and medication in the aetiology of schizophrenic relapse. Schizophrenia Research 1993;9:266.

* Hirsch SR, Bowen JT, Emami J, Cramer P, Jolley A, Haw $\mathrm{C}$, et al.A one year prospective study of the effect of life events and medication in the aetiology of schizophrenic relapse. British Journal of Psychiatry 1996;168:49-56.

Hogarty 1973 \{published data only\} Goldberg SC, Schooler NR, Hogarty GE, Roper M. Prediction of relapse in schizophrenic outpatients treated by drug and sociotherapy. Archives of General Psychiatry 1977; 34:171-84.

* Hogarty GE, Goldberg SC. Drug and sociotherapy in the aftercare of schizophrenic patients. One-year relapse rates. Archives of General Psychiatry 1973;28:54-64.

Hogarty GE, Goldberg SC, Schooler NR. Drug and sociotherapy in the aftercare of schizophrenic patients. III. Adjustment of nonrelapsed patients. Archives of General Psychiatry 1974;31:609-18.

Hogarty GE, Goldberg SC, Schooler NR, Ulrich RF. Drug and sociotherapy in the aftercare of schizophrenic patients. 
II. Two-year relapse rates. Archives of General Psychiatry 1974;31:603-8.

Hogarty GE, Munetz MR. Pharmacogenic depression among outpatient schizophrenic patients: a failure to substantiate. Journal of Clinical Psychopharmacology 1984;4: $17-24$.

Hogarty GE, Schooler NR, Ulrich R, Mussare F, Ferro P, Herron E. Fluphenazine and social therapy in the aftercare of schizophrenic patients. Relapse analyses of a two-year controlled study of fluphenazine decanoate and fluphenazine hydrochloride. Archives of General Psychiatry 1979;36:1283-94.

Hogarty GE, Ulrich RF. Temporal effects of drug and placebo in delaying relapse in schizophrenic outpatients. Archives of General Psychiatry 1977;34:297-301.

\section{Hough 2010 \{published data only\}}

Hough D, Gopal S, Vijapukar U, Lim P, Morozova M, Eerdekens M. Paliperidone palmitate in prevention of symptom recurrence in patients with schizophrenia: a randomised, double-blind, placebo-controlled study. Proceedings of the 161st Annual Meeting of the American Psychiatric Association; 2008 May 3-8, Washington DC, USA. 2008.

* Hough D, Gopal S, Vjapukar U, Lim P, Morozowa M, Eerdekens M. Paliperidone palmitate maintenance treatment in delaying the time to relapse in patients with schizophrenia: a randomised, double-blind, placebocontrolled study. Schizophrenia Research 2010;116:107-17.

Kane 1979 \{published data only\}

Kane JM, Rifkin A, Quitkin F, Nayak D, Saraf K, Ramos Lorenzi JR, et al.Low dose fluphenazine decanoate in maintenance treatment of schizophrenia. Psychiatry Research 1979;1:341-8.

Kane 1982 \{published data only\}

* Kane JM, Rifkin A, Quitkin F, Nayak D, Ramos-Lorenzi J. Fluphenazine vs. placebo in patients with remitted, acute first-episode schizophrenia. Archives of General Psychiatry 1982;39:70-3.

Kane JM, Rifkin A, Woerner M, Reardon G. Lowdose neuroleptics in outpatient schizophrenics. Psychopharmacology Bulletin 1982;18:20-1.

Keskiner 1968 \{published data only\}

* Keskiner A, Holden JMC, Itil TM. Maintenance treatment of schizophrenic outpatients with a depot phenothiazine. Psychosomatics 1968;9:166-71.

Keskiner A, Simeon J, Fink M, Itil TM. Long-acting phenothiazine (fluphenazine decanoate) treatment of psychosis. Archives of General Psychiatry 1968;18:477-81. King DJ, Devaney N, Cooper SJ, Blomqvist M, Mitchel MJ. Pharmacokinetics and antipsychotic effect of remoxipride in chronic schizophrenic patients. Journal of Psychopharmacology 1990;4:83-9.

Kinross-Wright J, Charalampous KD. A controlled study of a very long-acting phenothiazine preparation. International Journal of Neuropsychiatry 1965;1:66-70.
Kramer 2007 \{published data only\}

* Kramer M, Simpson G, Maciulis V, Kushner S, Vijapurkar $\mathrm{U}$, Lim P, et al.Paliperidone extended-release tablets for prevention of symptom recurrence in patients with schizophrenia: a randomised, double-blind, placebocontrolled study. Journal of Clinical Psychopharmacology 2007;27:6-14.

\section{Kurland 1975 \{published data only\}}

Kurland AA, Ota KY. Penfluridol: once-a-week oral maintenance neuroleptic in the management of chronic schizophrenics. Psychopharmacology Bulletin 1975;11:12-4. * Kurland AA, Ota KY, Slotnick VB. Penfluridol: a longacting oral neuroleptic. A controlled study. Journal of Clinical Pharmacology 1975;15:611-21.

\section{Leff 1971 \{published data only\}}

Leff JP, Hirsch SR, Gaind R, Rohde PD, Stevens BC. Life events and maintenance therapy in schizophrenic relapse. British Journal of Psychiatry 1973;123:659-60.

* Leff JP, Wing JK. Trial of maintenance therapy in schizophrenia. British Medical Journal 1971;3:599-604.

Levine 1980 \{published data only\}

Gelenberg AJ, Doller JC, Schooler NR, Mieske M, Severe J, Mandel MR. Acute extrapyramidal reactions with fluphenazine hydrochloride and fluphenazine decanoate. American Journal of Psychiatry 1979;136:217-9.

* Levine J, Schooler NR, Severe J, Escobar J, Gelenberg A, Mandel M, et al.Discontinuation of oral and depot fluphenazine in schizophrenic patients after one year of continuous medication: a controlled study. Advances in Biochemical Psychopharmacology 1980;24:483-93.

Mandel MR, Severe JB, Schooler NR, Gelenberg AJ, Mieske M. Development and prediction of postpsychotic depression in neuroleptic-treated schizophrenics. Archives of General Psychiatry 1982;39:197-203.

Schooler NR, Levine J. Dosage and side effect comparisons between oral and depot fluphenazine. Psychopharmacology Bulletin 1977;13:29-31.

Schooler NR, Levine J, NIMH-PRB Collaborative Fluphenazine Study Group. The initiation of longterm pharmacotherapy in schizophrenia: dosage and side effect comparison between oral and depot fluphenazine. Pharmacopsychiatry 9;1976:159-69.

Schooler NR, Levine J, NIMH-PRB Collaborative Fluphenazine Study Group. The initiation of longterm pharmacotherapy in schizophrenia: dosage and side effect comparisons between oral and depot fluphenazine. Pharmacopsychiatry 1976;9:159-69.

Schooler NR, Levine J, Severe JB. Depot fluphenazine in the prevention of relapse in schizophrenia: evaluation of a treatment regimen. Psychopharmacology Bulletin 1979;15: 44-7.

Schooler NR, Levine J, Severe JB, Brauzer B, DiMascio A, Klerman GL, et al.Prevention of relapse in schizophrenia. An evaluation of fluphenazine decanoate. Archives of General Psychiatry 1980;37:16-24. 
Marjerrison 1964 \{published data only\}

Marjerrison G, Irvine D, Stewart CN, Williams R, Matheu

$\mathrm{H}$, Demay M. Withdrawal of long-term phenothiazines

from chronically hospitalized psychiatric patients. Canadian Psychiatric Association Journal 1964;9(4):290-8.

McCreadie 1989 \{published data only\}

McCreadie RG, Wiles D, Grant S, Crockett GT, Mahmood

$Z$, Livingston MG, et al.The Scottish first episode schizophrenia study. Acta Psychiatrica Scandinavica 1989; 80:597-602.

Melnyk 1966 \{published data only\}

* Melnyk WT, Worthington AG, Laverty SG. Abrupt withdrawal of chlorpromazine and thioridazine from schizophrenic in-patients. Canadian Psychiatric Association Journal 1966;11:410-3.

Morton 1968 \{published data only\}

Morton MR. A study of the withdrawal of chlorpromazine or trifluoperazine in chronic schizophrenia. American Journal of Psychiatry 1968;124:1585-8.

Nishikawa 1982 \{published data only\}

Nishikawa T, Tsuda A, Tanaka M, Koga I, Uchida Y.

Prophylactic effect of neuroleptics in symptom-free schizophrenia. Psychopharmacology 1982;77:301-4.

Nishikawa 1984 \{published data only\}

Nishikawa T, Tsuda A, Tanaka M, Hoaki Y, Koga I, Uchida Y. Prophylactic effect of neuroleptics in symptomfree schizophrenics: a comparative dose response study of haloperidol and propericiazine. Psychopharmacology 1984; 82:153-6.

Odejide 1982 \{published data only\}

Odejide OA, Aderounmu AF. Double-blind placebo substitution: withdrawal of fluphenazine decanoate in schizophrenic patients. Journal of Clinical Psychiatry 1982; 43:195-6.

Olson 1962 \{published data only\}

* Olson GW, Peterson DB. Intermittent chemotherapy for chronic psychiatric inpatients. Journal of Nervous and Mental Disease 1962;134:1459.

Olson GW, Peterson DB. Sudden removal of tranquilizing drugs from chronic psychiatric patients. Journal of Mental and Nervous Disease 1960;131:252-5.

Ota 1973 \{published data only\}

Ota KY, Kurland AA. A double-blind comparison of haloperidol oral concentrate, haloperidol solutabs and placebo in the treatment of chronic schizophrenia. Journal of Clinical Pharmacology 1973;13:99-110.

Peuskens 2007 \{published data only\} Peuskens J, Trivedi J, Malyarov S, Brecher M, Svensson $\mathrm{O}$, Miller F, et al.Prevention of schizophrenia relapse with extended release quetiapine fumarate dosed once daily: a randomised, placebo-controlled trial in clinically stable patients. Psychiatry 2007;4(11):34-50.

Pfizer 2000 \{published data only\}

Pfizer 2000. Multicentre double-blind study of ziprasidone versus placebo in relapse prevention for hospitalised patients with chronic or subchronic schizophrenia. Study report. Unpublished.

Pietzcker 1993 \{published data only\}

Gaebel W, Frick U, Kopcke W, Linden M, Mueller P, Mueller Spahn F, et al.Early neuroleptic intervention in schizophrenia: are prodromal symptoms valid predictors of relapse?. British Journal of Psychiatry Supplementum 1993; 163:8-12.

Gaebel W, Janner M, Frommann N, Pietzcker A, Kopcke $\mathrm{W}$, Linden $\mathrm{M}$, et al.First vs multiple episode schizophrenia: two-year outcome of intermittent and maintenance medication strategies. Schizophrenia Research 2002;53(1-2): 145-59.

Gaebel W, Moeller HJ. Treatment strategies in first episode schizophrenia. Proceedings of the 12th World Congress of Psychiatry; 2002 Aug 24-29; Yokohama, Japan. 2002.

* Pietzcker A, Gaebel W, Koepcke W, Linden M, Mueller P, Mueller-Spahn F, et al.Intermittent versus maintenance neuroleptic long-term treatment in schizophrenia - 2-year results of a German multicenter study. Journal of Psychiatric Research 1993;27:321-39.

Pietzcker A, Gaebel W, Kopcke W, Linden M, Muller P, Muller-Spahn, et al.A German multicenter study on the neuroleptic long-term therapy of schizophrenic patients. Preliminary report. Pharmacopsychiatry 1986;19:161-6.

Pigott 2003 \{published data only\}

Pigott TA, Carson WH, Saha AR, Torbeyns AF, Stock EG, Ingenito GG. Aripiprazole for the prevention of relapse in stabilized patients with chronic schizophrenia: a placebocontrolled 26-week study. Journal of Clinical Psychiatry 2003;64:1048-56.

Prien 1968 \{published data only\}

Gardos G, Cole JO, LaBrie RA. A 12-year follow-up study of chronic schizophrenics. Psychopharmacology 1982;33: 983-4.

Prien RF, Cole JO. High dose chlorpromazine therapy in chronic schizophrenia. Report of National Institute of Mental Health - psychopharmacology research branch collaborative study group. Archives of General Psychiatry 1968;18:482-95.

* Prien RF, Cole JO, Belkin NF. Relapse in chronic schizophrenics following abrupt withdrawal of tranquillizing medication. British Journal of Psychiatry 1968;115:679-86. Prien RF, DeLong SL, Cole JO, Levine J. Ocular changes occurring with prolonged high dose chlorpromazine therapy. Results from a collaborative study. Archives of General Psychiatry 1970;23:464-8.

Prien RF, Levine J, Cole JO. Indications for high dose chlorpromazine therapy in chronic schizophrenia. Diseases of the Nervous System 1970;31:739-45.

Prien 1969 \{published data only\}

Prien RF, Levine J, Cole JO. High dose trifluoperazine therapy in chronic schizophrenia. American Journal of Psychiatry 1969;126:305-13. 
Rifkin 1979 \{published data only\}

Rifkin A, Quitkin F, Kane J, Klein DF. Fluphenazine decanoate, oral fluphenazine, and placebo in the treatment of remitted schizophrenics. II. Rating scale data. Psychopharmacology Bulletin 1977;13:40-50.

Rifkin A, Quitkin F, Kane J, Klein DF, Ross D. The effect of fluphenazine upon social and vocational functioning in remitted schizophrenics. Biological Psychiatry 1979;14: 499-508.

* Rifkin A, Quitkin F, Klein DF. Fluphenazine decanoate, oral fluphenazine, and placebo in treatment of remitted schizophrenics. II. Rating scale data. Archives of General Psychiatry 1977;34:15-9.

Rifkin A, Quitkin F, Rabiner CJ, Klein DF. Comparison of fluphenazine decanoate, oral fluphenazine, and placebo in remitted outpatient schizophrenics. Psychopharmacology Bulletin 1976;12:24-6.

Rifkin A, Quitkin F, Rabiner CJ, Klein DF. Fluphenazine decanoate, fluphenazine hydrochloride given orally, and placebo in remitted schizophrenics. I. Relapse rates after one year. Archives of General Psychiatry 1977;34:43-7.

Roelofs 1974 \{published data only\} Roelofs GA. Penfluridol (R 16341) as a maintenance therapy in chronic psychotic patients: a double-blind clinical evaluation. Acta Psychiatrica Scandinavica 1974;50: 219-24.

Ruskin 1991 \{published data only\}

Ruskin PE, Nyman G. Discontinuation of neuroleptic medication in older, outpatient schizophrenics. A placebocontrolled, double-blind trial. Journal of Nervous and Mental Disease 1991;179:212-4.

Sampath 1992 \{published data only\}

* Sampath G, Shah A, Krska J, Soni SD. Neuroleptic discontinuation in the very stable schizophrenic patient - relapse rates and serum neuroleptic levels. Human Psychopharmacology 1992;7:255-64.

Soni SD, Mallik A, Schiff AA. Sulpiride in negative schizophrenia: a placebo-controlled double-blind assessment. Human Psychopharmacology 1990;5:233-8.

Schering Plough 2010 \{published data only\}

* Kane JM, Mackle M, Snow-Adami L, Zhao J, Szegedi A, Panagides J. A randomised placebo-controlled trial of asenapine for the prevention of relapse of schizophrenia after long-term treatment. Journal of Clinical Psychiatry 2011;72(3):349-55.

Schiele 1961 \{published data only\}

Schiele BC, Vestre ND, Stein KE. A comparison of thioridazine, trifluoperazine, chlorpromazine, and placebo: a double-blind controlled study on the treatment of chronic, hospitalized, schizophrenic patients. Journal of Clinical and Experimental Psychopathology and Quarterly Review of Psychiatry and Neurology 1961;22:151-62.

Shawver 1959 \{published data only\}

Shawver JR, Gorham DR, Leskin LW, Good WW, Kabnick $\mathrm{DE}$. Comparison of chlorpromazine and reserpine in maintenance drug therapy. Diseases of the Nervous System 1959;20:452-7.

Spohn 1986 \{published data only\}

Spohn HE, Coyne L, Larson J, Mittleman F, Spray J, Hayes K. Episodic and residual thought pathology in chronic schizophrenics: effect of neuroleptics. Schizophrenia Bulletin 1986;12:394-407.

Troshinsky 1962 \{published data only\}

Troshinsky C, Aaronson HG, Stone RK. Maintenance phenothiazines in aftercare of schizophrenic patients. Pennsylvania Psychiatric Bulletin 1962;2:11-5.

Vandecasteele 1974 \{published data only\} Vandecasteele AJ, Vereecken JL. A double-blind clinical evaluation of penfluridol (R 16 341) as a maintenance therapy in schizophrenia. Acta Psychiatrica Scandinavica 1974;50:346-53.

Whittaker 1963 \{published data only\} Whittaker CB, Hoy RM. Withdrawal of perphenazine in chronic schizophrenia. British Journal of Psychiatry 1963; 109:422-7.

Wistedt 1981 \{published data only\}

* Wistedt B. A depot neuroleptic withdrawal study. A controlled study of the clinical effects of the withdrawal of depot fluphenazine decanoate and depot flupenthixol decanoate in chronic schizophrenic patients. Acta Psychiatrica Scandinavica 1981;64:65-84.

Wistedt B. Neuroleptics and depression. Archives of General Psychiatry 1982;39:745.

Wistedt B, Jorgensen A, Wiles D. A depot neuroleptic withdrawal study. Plasma concentration of fluphenazine and flupenthixol and relapse frequency. Psychopharmacology 1982;78:301-4.

Wistedt B, Palmstierna T. Depressive symptoms in chronic schizophrenic patients after withdrawal of long-acting neuroleptics. Journal of Clinical Psychiatry 1983;44:369-71. Wistedt B, Ranta J. Comparative double-blind study of flupenthixol decanoate and fluphenazine decanoate in the treatment of patients relapsing in a schizophrenic symptomatology. Acta Psychiatrica Scandinavica 1983;67: 378-88.

Wistedt B, Wiles D, Jorgensen A. A depot neuroleptic withdrawal study neurological effects. Psychopharmacology 1983;80:101-5.

Zissis 1982 \{published data only\}

Zissis NP, Psaras M, Lyketsos G. Haloperidol decanoate, a new long-acting antipsychotic, in chronic schizophrenics: double-blind comparison with placebo. Current Therapeutic Research 1982;31:650-5.

\section{References to studies excluded from this review}

\section{Allen 1997 \{published data only\}}

Allen DN, Gilbertson MW, Barry E, Kammen DP, Gurklis JA. Haloperidol improves memory in schizophrenia. Proceedings of the 150th Annual Meeting of the American Psychiatric Association; 1997 May 17-22; San Diego, California, USA. 1997. 
Bourin 2008 \{published data only\}

Bourin M, Debelle M, Heisterberg J, Josiassen MK, Ostergaard JB, Sands E. Efficacy of bifeprunox in patients in the post-acute, maintenance phase of schizophrenia: findings from a 6-month study. Schizophrenia Research 2008;98:158.

Branchey 1981 \{published data only\} Branchey MH, Branchey LB, Richardson MA. Effects of gradual decrease and discontinuation of neuroleptics on clinical condition and tardive dyskinesia. Psychopharmacology Bulletin 1981;17:118-20.

* Branchey MH, Branchey LB, Richardson MA. Effects of neuroleptic adjustment on clinical condition and tardive dyskinesia in schizophrenic patients. American Journal of Psychiatry 1981;138:608-12.

Breier 1987 \{published data only\}

Breier A, Wolkowitz OM, Doran AR, Roy A, Boronow J, Hommer DW, et al.Neuroleptic responsivity of negative and positive symptoms in schizophrenia. American Journal of Psychiatry 1987;144:1549-55.

Chouinard 1980 \{published data only\}

Chouinard G, Annable L, Jones BD, Collu R. Lack of tolerance to long-term neuroleptic treatment in dopamine tuberoinfundibular system. Acta Psychiatrica Scandinavica 1980; 64:353-62.

Claghorn 1974 \{published data only\}

Claghorn JL, Johnstone EE, Cook TH, Itschner L. Group therapy and maintenance treatment of schizophrenics.

Archives of General Psychiatry 1974;31:361-5.

Collins 1967 \{published data only\}

Collins AD, Dundas J. A double-blind trial of amitriptylineperphenazine, perphenazine and placebo in chronic withdrawn inert schizophrenics. British Journal of Psychiatry 1967;113:1425-9.

Condray 1995 \{published data only\} Condray R, Van Kammen DP, Steinhauer SR, Kasparek A, Yao JK. Language comprehension in schizophrenia: trait or state indicator?. Biological Psychiatry 1995;38:287-96.

Curson 1985 \{published data only\}

* Curson DA, Barnes TR, Bamber RW, Platt SD, Hirsch SR, Duffy JC. Long term depot maintenance of chronic schizophrenic out patients: the seven year follow up of the Medical Research Council fluphenazine/placebo trial. II. The incidence of compliance problems, side effects, neurotic symptoms and depression. British Journal of Psychiatry 1985;146:469-74.

Curson DA, Barnes TR, Bamber RW, Platt SD, Hirsch SR, Duffy JC. Long-term depot maintenance of chronic schizophrenic out-patients: the seven year follow-up of the Medical Research Council fluphenazine/placebo trial. III. Relapse postponement or relapse prevention? The implications for long-term outcome. British Journal of Psychiatry 1985;146:474-80.

Curson DA, Barnes TR, Bamber RW, Platt SD, Hirsch SR, Duffy JC. Long-term depot maintenance of chronic schizophrenic out-patients: the seven year follow-up of the
Medical Research Council fluphenazine- placebo trial I. Course of illness, stability of diagnosis, and the role of a special maintenance clinic. British Journal of Psychiatry 1985;146:464-9.

Degkwitz 1970 \{published data only\} Degkwitz R, Bauer MP, Gruber M, Hampel G, Luxenburger $\mathrm{O}$, Richartz $\mathrm{M}$, et al.Time relationship between the appearance of persisting extrapyramidal hyperkineses and psychotic recurrences following sudden interruption of prolonged neuroleptic therapy of chronic schizophrenic patients. Arzneimittelforschung 1970;20(7):890-3.

Diamond 1960 \{published data only\}

Diamond LS, Marks JB. Discontinuance of tranquilizers among chronic schizophrenic patients receiving maintenance dosage. Journal of Nervous and Mental Disease 1960;131:247-51.

Double 1993 \{published data only\}

* Double DB, Warren GC, Evans M, Rowlands RP. Efficacy of maintenance use of anticholinergic agents. Acta Psychiatrica Scandinavica 1993;88:381-4.

Elie R, Morin L, Tetreault L. Effects of ethopropazine and trihexyphenidyl on several parameters of the neuroleptic syndrome [Effets de l'ethopropazine et du trihexyphenidyle sur quelques parametres du syndrome neuroleptique]. Encephale 1972;61:32-52.

Engelhardt 1967 \{published data only\} Engelhardt DM, Rosen B, Freedman N, Margolis R. Phenothiazines in prevention of psychiatric hospitalisation. Archives of General Psychiatry 1967;16:98-101.

Gleeson 2004 \{published data only\} Gleeson J, Wade D, Mcgorry P, Albiston D, Castle D, Gilbert M, et al.Episode ii: prevention of relapse following early psychosis. Schizophrenia Research 2004;70:61-2.

Goldberg 1967 \{published data only\}

* Goldberg SC, Schooler NR, Mattsson N. Paranoid and withdrawal symptoms in schizophrenia: differential symptom reduction over time. Journal of Nervous and Mental Disease 1967;145:158-62.

Mefferd RBJr, Labrosse EH, Gawienowski AM, Williams RJ. Influence of chlorpromazine on certain biochemical variables of chronic male schizophrenics. Journal of Nervous and Mental Disease 1958;127:167-79.

Good 1958 \{published data only\} Good WW, Sterling M, Holtzman WH. Termination of chlorpromazine with schizophrenic patients. American Journal of Psychiatry 1958;115:443-8.

Greenberg 1966 \{published data only\} Greenberg LM, Roth S. Differential effects of abrupt versus gradual withdrawal of chlorpromazine in hospitalized chronic schizophrenic patients. American Journal of Psychiatry 1966;123:221-6.

Hine 1958 \{published data only\} Hine FR. Chlorpromazine in schizophrenic withdrawal and in the withdrawn schizophrenic. Journal of Nervous and Mental Disease 1958;127:220-7. 
Hunt 1967 \{published data only\}

Hunt PV. A comparison of the effects of oxypertine and trifluoperazine in withdrawn schizophrenics. British Journal of Psychiatry 1967;113:1419-24.

Ionescu 1983 \{published data only\} Ionescu R, Tiberiu C, Miklos R, Angelescu C, Persiceanu AM. Penfluridol in the maintenance therapy of schizophrenia. Neurologie et Psychiatrie 1983;21:33-41.

Janecek 1963 \{published data only\}

Janecek J, Schiele BC, Bellville T, Anderson R. The effects of withdrawal of trifluoperazine on patients maintained on the combination of tranylcypromine and trifluoperazine: a double-blind study. Current Therapeutic Research, Clinical and Experimental 1963;85:608-15.

Johnstone 1988 \{published data only\}

* Johnstone EC, Crow TJ, Frith CD, Owens DG. The Northwick Park "functional" psychosis study: diagnosis and treatment response. Lancet 1988;2:119-25.

Johnstone EC, Crow TJ, Owens DGC, Frith CD. The Northwick Park 'functional' psychosis study. Phase 2 maintenance treatment. Journal of Psychopharmacology 1991;5:388-95.

Johnstone EC, Owens DGC. Does early treatment have an effect on outcome?. Proceedings of the 10th European College of Neuropsychopharmacology Congress; 1997 Sep 13-17; Vienna, Austria. 1997.

Kellam 1971 \{published data only\}

Kellam AM, Jones KS. A double-blind controlled trial of thiothixene and perphenazine in chronic schizophrenics shown to require maintenance therapy. Acta Psychiatrica Scandinavica 1971;47:174-85.

Lauriello 2005 \{published data only\}

Lauriello J, McEvoy JP, Rodriguez S, Bossie CA, Lasser RA. Long-acting risperidone vs. placebo in the treatment of hospital inpatients with schizophrenia. Schizophrenia Research 2005;72:249-58.

Lecrubier 1997 \{published data only\}

Lecrubier Y. Amisulpride in deficit schizophrenia.

Proceedings of the 6th World Congress Biological

Psychiatry, 1997 Jun 22-27; Nice, France. 1997.

Loo 1997 \{published data only\}

Loo H, Poirier-Littre MF, Theron M, Rein W, Fleurot O. Amisulpride versus placebo in the medium-term treatment of the negative symptoms of schizophrenia. British Journal of Psychiatry 1997;170:18-22.

Mefferd 1958 \{published data only\}

Mefferd RB, Labrosse EH, Gawienowski AM, Williams $\mathrm{RJ}$. Influence of chlorpromazine on certain biochemical variables of chronic male schizophrenics. Journal of Nervous and Mental Disease 1958;127(2):167-79.

Mosher 1975 \{published data only\}

Bola JR, Mosher LR. Treatment of acute psychosis without neuroleptics: two-year outcomes from the Soteria project. Journal of Nervous and Mental Disease 2003;191:219-29. Matthews SM, Roper MT, Mosher LR, Menn AZ. A non neuroleptic treatment for schizophrenia: analysis of the two year postdischarge risk of relapse. Schizophrenia Bulletin 1979;5:322-33.

Mosher LR, Menn A, Matthew SM. Soteria: evaluation of a home-based treatment for schizophrenia. American Journal of Orthopsychiatry 1975;45:455-67.

* Mosher LR, Menn AZ. Community residential treatment for schizophrenia: two year follow up. Hospital and Community Psychiatry 1978;29:715-23.

Müller 1982 \{published data only\}

Müller P, Hartmann W, Jung F, Kind J, Lohrengel S, Steuber H. To prevent relapse of schizophrenic psychoses [Zur Rezidivprophylaxe schizophrener Psychosen]. Ferdinand Enke Verlag Stuttgart 1982;14:1-144.

Paul 1972 \{published data only\}

Paul GL, Tobias LL, Holly BL. Maintenance psychotropic drugs in the presence of active treatment programs. A "triple-blind" withdrawal study with long-term mental patients. Archives of General Psychiatry 1972;27:106-15.

Peet 1981 \{published data only\}

Peet M, Middlemiss DN, Yates RA. Propranolol in schizophrenia II. Clinical and biochemical aspects of combining propranolol with chlorpromazine. British Journal of Psychiatry 1981;138:112-7.

Pickar 1986 \{published data only\}

Pickar D, Labarca R, Doran AR, Wolkowitz OM, Roy A, Breier A, et al.Longitudinal measurement of plasma homovanillic acid levels in schizophrenic patients. Correlation with psychosis and response to neuroleptic treatment. Archives of General Psychiatry 1986;43:669-76.

Pickar 2003 \{published data only\}

Pickar D, Bartko JJ. Effect size of symptom status in withdrawal of typical antipsychotics and subsequent clozapine treatment in patients with treatment-resistant schizophrenia. American Journal of Psychiatry 2003;160: 1133-8.

Pigache 1993 \{published data only\}

* Pigache RM. Effects of placebo, orphenadrine, and rising doses of chlorpromazine, on PAT performance in chronic schizophrenia. A two year longitudinal study. Schizophrenia Research 1993;10:51-9.

Pigache RM. The clinical relevance of an auditory attention task (PAT) in a longitudinal study of chronic schizophrenia with placebo substitution for chlorpromazine. Schizophrenia Research 1993;10:39-50.

Pigache RM, Norris HN. Measurement of drug action in schizophrenia. Clinical Science 1973;44:28P.

Pigache RM, Norris HN. Selective attention as an index of the anti-psychotic action of chlorpromazine in schizophrenia. British Psychological Society Bulletin 1973;20: 160.

Rassidakis 1970 \{published data only\}

Rassidakis NC, Kondakis X, Papanastassiou A, Michalakeas A. Withdrawal of antipsychotic drugs from chronic psychiatric patients. Bulletin of the Menninger Clinic 1970; 34(4):216-22. 
Ravaris 1965 \{published data only\}

* Ravaris CL, Weaver LA, Brooks GW. A controlled study of fluphenazine enanthate in chronic schizophrenic patients. Diseases of the Nervous System 1965;25:33-9.

Ravaris CL, Weaver LA, Brooks GW. Further studies with fluphenazine enanthate: II. Relapse rate in patients deprived of medication. American Journal of Psychiatry 1967;124: 248-9.

Schlossberg 1978 \{published data only\} Schlossberg A, Shadmi M. A comparative controlled study of two long-acting phenothiazines: pipotiazine palmitate and fluphenazine decanoate. Current Therapeutic Research 1978;23(5):642-54.

Singh 1990 \{published data only\} Singh H, Hunt JI, Vitiello B, Simpson GM. Neuroleptic withdrawal in patients meeting criteria for supersensitivity psychosis. Journal of Clinical Psychiatry 1990;51:319-21.

Smelson 2006 \{published data only\}

Smelson DA, Tunis SL, Nyhuis AW, Faries DE, Kinon BJ, Ascher-Svanum H. Antipsychotic treatment discontinuation among individuals with schizophrenia and co-occurring substance use. Journal of Clinical Psychopharmacology 2006; 26:666-7.

Soni 1990 \{published data only\}

Soni SD, Mallik A, Schiff AA. Sulpiride in negative schizophrenia: a placebo-controlled double-blind assessment. Human Psychopharmacology 1990;5:233-8.

Tollefson 1999 \{published data only\}

Dellva MA, Tollefson GD, Mattler CA, Kinon BJ, Grundy SL. A controlled, double-blind investigation of the clozapine discontinuation syndrome with conversion to either olanzapine or placebo. Schizophrenia Research 1999;36: $277-8$.

* Tollefson GD, Dellva MA, Mattler CA, Kane JM, Wirshing DA, Kinon BJ, et al.Controlled, double-blind investigation of the clozapine discontinuation symptoms with conversion to either olanzapine or placebo. Journal of Clinical Psychopharmacology 1999;19:435-43.

Tollefson GD, Dellva MA, Mattler CA, Kinon BJ, Grundy SL. A controlled, double-blind investigation of the clozapine discontinuation syndrome with conversion to either olanzapine or placebo. Proceedings of the 11th European College of Neuropsychopharmacology Congress; 1998 Oct 31 - Nov 4; Paris, France. 1998.

Vaddadi 1986 \{published data only\}

Vaddadi KS, Gilleard CJ, Mindham RH, Butler R. A controlled trial of prostaglandin $\mathrm{E} 1$ precursor in chronic neuroleptic resistant schizophrenic patients. Psychopharmacology 1986;88:362-7.

Van Kammen 1982 \{published data only\} Van Kammen DP, Bunney WE, Docherty JP, Jimerson DC, Post RM, Siris P, et al.Amphetamine-induced catecholamine activation in schizophrenia and depression: behavioral and physiological effects. Advances in Biochemical Psychopharmacology 1977;16:655-9.

Van Kammen DP, Bunney WE Jr, Docherty JP, Marder SR, Ebert MH, Rosenblatt JE, et al.D-Amphetamineinduced heterogeneous changes in psychotic behavior in schizophrenia. American Journal of Psychiatry 1982;139: 991-7.

Van Kammen DP, Docherty JP, Marder SR, Schulz SC, Bunney WE Jr. Lack of behavioral supersensitivity to damphetamine after pimozide withdrawal. A trial with schizophrenic patients. Archives of General Psychiatry 1980; 37:287-90.

Van Kammen DP, Docherty JP, Marder SR, Siris SG, Bunney WE Jr. D amphetamine raises serum prolactin in man: evaluations after chronic placebo, lithium and pimozide treatment. Life Sciences 1978;23:1487-92.

Van Praag 1973 \{published data only\} Van Praak HM, Dols LCW. Fluphenazine enanthate and fluphenazine decanoate: a comparison of their duration of action and motor side effects. American Journal of Psychiatry 1973;130:801-4.

Wiedemann 2001 \{published data only\}

Wiedemann G, Hahlweg K, Muller U, Feinstein E, Hank G, Dose M. Effectiveness of targeted intervention and maintenance pharmacotherapy in conjunction with family intervention in schizophrenia. European Archives of Psychiatry and Clinical Neuroscience 2001;251:72-84.

Wright 1964 \{published data only\}

Wright RLD, Lynes PG. Value of continuous drug administration for chronic long-term mental hospital patients. Canadian Psychiatric Association Journal 1964;60: 352-7.

Wunderink 2006 \{published data only\} Wunderink A, Nienhuis, Sytema S, Wiersma D. Guided discontinuation versus maintenance treatment in remitted first episode psychosis: relapse rates and functional outcome. Schizophrenia Research 2006;86:S51.

Zeller 1956 \{published data only\} Zeller WW, Graffagnino PN, Cullen CF, Rietman HJ. Use of chlorpromazine and reserpine in the treatment of emotional disorders. Journal of the American Medical Association 1956;160:179-84.

Zwanikken 1973 \{published data only\} Zwanikken 1973. Penfluridol (R 16341). A long-acting oral neuroleptic, as maintenance therapy for schizophrenic and mentally retarded patients. Psychiatria, Neurologia, Neurochirurgia 1973;76:83-92.

\section{References to ongoing studies}

\section{Eerdekens 2010 \{published data only\}} Eerdekens. Evaluate the efficacy in the prevention of recurrence of the symptoms of schizophrenia. Sponsor: Johnson \& Johnson Pharmaceutical Research \& Development, LL.C 2010. [CTG: NCT00111189]

\section{Additional references}




\section{Almerie 2007}

Almerie MQ, Alkhateeb H, Essali A, Matar HE, Rezk E. Cessation of medication for people with schizophrenia already stable on chlorpromazine. Cochrane Database of Systematic Reviews 2007, Issue 1. [DOI: 10.1002/ 14651858.CD006329]

Altman 1996

Altman DG, Bland JM. Detecting skewness from summary information. British Medical Journal 1996;313:1200.

Baldessarini 1985

Baldessarini RJ. Chemotherapy in psychiatry: principles and practice. Cambridge, MA: Harvard University Press, 1985.

\section{Barnes 1989}

Barnes TR. A rating scale for drug-induced akathisia. British Journal of Psychiatry 1989;154:672-6.

\section{Berger 2003}

Berger M. Psychische Erkrankungen. Klinik und Therapie. 2nd Edition. München: Urban \& Fischer, 2003.

\section{Bland 1997}

Bland JM, Kerry SM. Statistics notes. Trials randomised in clusters. British Medical Journal 1997;315:600.

\section{Boissel 1999}

Boissel JP, Cucherat M, Li W, Chatellier G, Gueyffier F, Buyse $\mathrm{M}$, et al.The problem of therapeutic efficacy indices. 3. Comparison of the indices and their use. Therapie 1999; 54(4):405-11.

Borenstein 2006

Borenstein M, Hedges LV, Higgins JPT, Rothstein H. Comprehensive Meta-analysis Version 2. Biostat, 2006.

\section{Carpenter 1994}

Carpenter WT, Buchanan RW. Schizophrenia. New England Journal of Medicine 1994;330:681-90.

Davis 1975

Davis JM. Overview: maintenance therapy in psychiatry: I. Schizophrenia. American Journal of Psychiatry 1975;132 (12):1237-45.

Davis 1989

Davis JM, Barter JT, Kane JM. Antipsychotic drugs. In: Kaplan HI, Sadock BJ editor(s). Comprehensive Textbook of Psychiatry. 5th Edition. Baltimore: Williams \& Wilkins, 1989:1591-1626.

Deeks 2000

Deeks J. Issues in the selection for meta-analyses of binary data. Proceedings of the 8th International Cochrane Colloquium; 2000 Oct 25-28; Cape Town, South Africa. 2000.

\section{Der-Simonian 1986}

Der-Simonian R, Laird N. Meta-analysis in clinical trials. Controlled Clinical Trials 1986;7:177-88.

Divine 1992

Divine GW, Brown JT, Frazer LM. The unit of analysis error in studies about physicians' patient care behavior. Journal of General Internal Medicine 1992;7:623-9.

\section{Duggan 2005}

Duggan L, Fenton M, Rathbone J, Dardennes R, El-Dosoky A, Indran S. Olanzapine for schizophrenia. Cochrane Database of Systematic Reviews 2005, Issue 2. [DOI: 10.1002/14651858.CD001359.pub2]

\section{Duval 2000}

Duval S, Tweedie R. Trim and fill: a simple funnel-plotbased method of testing and adjusting for publication bias in meta-analysis. Biometrics 2000;56:455-63.

\section{Egger 1997}

Egger M, Davey-Smith G, Schneider M, Minder CSO. Bias in meta-analysis detected by a simple, graphical test. British Medical Journal 1997;13:629-34.

Elbourne 2002

Elbourne DR, Altman DG, Higgins JP, Curtin F, Worthington HV, Vail A. Meta-analyses involving crossover trials: methodological issues. International Journal of Epidemiology 2002;31:140-9.

\section{Endicott 1976}

Endicott J, Spitzer RL, Fleiss JL, Cohen J. The global assessment scale. A procedure for measuring overall severity of psychiatric disturbance. Archives of General Psychiatry 1976;33(6):766-71.

\section{Gilbert 1995}

Gilbert P, Harris MJ, McAdams LA, Bowers MB, Charney DS, Glazer WM. Neuroleptic withdrawal in schizophrenic patients. A review of the literature. Archives of General Psychiatry 1995;52:173-88.

\section{Gulliford 1999}

Gulliford MC, Ukoumunne OC, Chinn S. Components of variance and intraclass correlations for the design of community-based surveys and intervention studies: data from the Health Survey for England 1994. American Journal of Epidemiology 1999;149:876-83.

Guy 1976

Guy W. ECDEU assessment manual for psychopharmacologyrevised 1976. Washington, DC: DHEW. National Institute of Mental Health, 1976.

\section{Higgins 2011}

Higgins JPT, Green S (editors). Cochrane Handbook for Systematic Reviews of Interventions Version 5.0.2 [updated September 2011]. The Cochrane Collaboration, 2011 Available from www.cochrane-handbook.org.

\section{Kane 1988}

Kane JM, Honigfeld G, Singer J, Meltzer H, and the Clozaril Collaborative study group. Clozapine for the treatmentresistant schizophrenic. A double-blind comparison with chlorpromazine. Archives of General Psychiatry 1988;45: 789-96.

\section{Kay 1986}

Kay SR, Opler LA, Fiszbein A. Positive And Negative Syndrome Scale (PANSS) Manual. North Tonawanda, NY: Multi-Health Systems, 1986. 


\section{Kellner 1973}

Kellner R, Sheffield BF. A self-rating scale of distress. Psychological Medicine 1973;3:88-100.

\section{Kishimoto 2012}

Kishimoto T, Robenzadeh A, Leucht C, Leucht S, Watanabe

$\mathrm{K}$, Mimura M, et al.New results alter balance of evidence of long-acting injectable vs. oral antipsychotics regarding relapse prevention in schizophrenia: a systematic review and meta-analysis. in press.

Klein 1969

Klein DF, Davis JM. Diagnosis and Drug Treatment of Psychiatric Disorders. Baltimore: Williams \& Wilkins, 1969.

Leon 2006

Leon AC, Mallinckrodt CH, Chuang-Stein C, Archibald

DG, Archer GE, Chartier K. Attrition in randomised controlled clinical trials: methodological issues in psychopharmacology. Biological Psychiatry 2006;59: $1001-5$.

\section{Leucht 2003}

Leucht S, Barnes TR, Kissling W, Engel RR, Correll C, Kane JM. Relapse prevention in schizophrenia with new-generation antipsychotics: a systematic review and exploratory meta-analysis of randomised, controlled trials. American Journal of Psychiatry 2003;160:1209-22.

\section{Leucht 2005a}

Leucht S, Kane JM, Kissling W, Hamann J, Etschel E, Engel R. Clinical implications of Brief Psychiatric Rating Scale scores. British Journal of Psychiatry 2005;187:366-71.

\section{Leucht 2005b}

Leucht S, Kane JM, Kissling W, Hamann J, Etschel E, Engel RR. What does the PANSS mean?. Schizophrenia Research 2005;79(2-3):231-8. [PUBMED: 15982856]

\section{Leucht 2009}

Leucht S, Corves C, Arbter D, Engel R, Li C, Davis JM. A meta-analysis comparing second-generation and firstgeneration antipsychotics for schizophrenia. Lancet 2009; 373:31-41

\section{Leucht 2009a}

Leucht S, Komossa K, Rummel-Kluge C, Corves C, Hunger H, Schmid F, et al.A meta-analysis of head to head comparisons of second generation antipsychotics in the treatment of schizophrenia. American Journal of Psychiatry 2009;166:152-63

Leucht 2009b

Leucht S, Arbter D, Engel RR, Kissling W, Davis JM. How effective are second-generation antipsychotic drugs? A meta-analysis of placebo-controlled trials. Molecular Psychiatry 2009;14:429-47.

\section{Leucht 2011}

Leucht C, Heres S, Kane JM, Kissling W, Davis JM, Leucht S. Oral versus depot antipsychotic drugs for schizophrenia a critical systematic review and meta-analysis of randomised long-term trials. Schizophrenia Research 2011;127:83-92.

\section{Marshall 2000}

Marshall M, Lockwood A, Bradley C, Adams C, Joy C, Fenton M. Unpublished rating scales: a major source of bias in randomised controlled trials of treatments for schizophrenia. British Journal of Psychiatry 2000;176: 249-52.

\section{Marvaha 2004}

Marwaha S, Johnson S. Schizophrenia and employment? A review. Social Psychiatry and Psychiatric Epidemiology 2004; 39:337-49.

\section{Moher 2001}

Moher D, Schulz KF, Altman D. The CONSORT statement: revised recommendations for improving the quality of reports of parallel-group randomised trials. Journal of the American Medical Association 2001;285: 1987-1.

\section{Moncrieff 2006}

Moncrieff J. Does antipsychotic withdrawal provoke psychosis? Review of the literature on rapid onset psychosis (supersensitivity psychosis) and withdrawal-related relapse. Acta Psychiatrica Scandinavica 2006;114(1):3-13.

\section{Overall 1962}

Overall JE, Gorham DR. The Brief Psychiatric Rating Scale. Psychological Reports 1962;10:799-12.

\section{Papanikolaou 2004}

Papanikolaou PN, Churchill R, Wahlbeck K, Ioannidis JP. Safety reporting in randomised trials of mental health interventions. American Journal of Psychiatry 2004;161: $1692-7$.

Peters 2008

Peters JL, Sutton AJ, Jones DR, Abrams KR, Rushton L. Contour-enhanced meta-analysis funnel plots help distinguish publication bias from other causes of asymmetry. Journal of Clinical Epidemiology 2008;61:991-6.

Pope 2010

Pope A, Adams C, Paton C, Weaver T, Barnes TR. Assessment of adverse effects in clinical studies of antipsychotic medication: survey of methods used. British Journal of Psychiatry 2010;197:67-72.

Ray 2009

Ray WA, Chung CP, Murray KT, Hall K, Stein CM. Atypical antipsychotic drugs and the risk of sudden cardiac death. New England Journal of Medicine 2009;360:225-35.

\section{Robinson 1999}

Robinson D, Woerner MG, Alvir JM, Bilder R, Goldman $\mathrm{R}$, Geisler S, et al.Predictors of relapse following response from a first episode of schizophrenia or schizoaffective disorder. Archives of General Psychiatry 1999;56:241-7.

\section{Schulz 1995}

Schulz KF, Chalmers I, Hayes RJ, Altman DG. Empirical evidence of bias. Dimensions of methodological quality associated with estimates of treatment effects in controlled trials. Journal of the American Medical Association 1995;273: 408-12. 


\section{Simpson 1970}

Simpson EN, Angus JWF. A rating scale for extrapyramidal side-effects. Acta Psychiatrica Scandinavica Supplementum 1970;212:11-9.

\section{Srisurapanont 2004}

Srisurapanont M, Maneeton B, Maneeton N. Quetiapine for schizophrenia. Cochrane Database of Systematic Reviews 2004, Issue 2. [DOI: 10.1002/ 14651858.CD000967.pub2]

\section{Stata 2002}

Stata Corporation. Intercooled Stata 7.0 for Windows. Stata Corporation, 2002.

Tiihonen 2009

Tiihonen J, Lönnqvist J, Wahlbeck K, Klaukka T, Niskanen L, Tanskanen A, et al.11-year follow-up of mortality in patients with schizophrenia: a population-based cohort study (FIN11 study). Lancet 2009;374:620-7.

Tsuang 1978

Tsuang MT. Suicide in schizophrenics, manics, depressives, and surgical controls: a comparison with general population suicide mortality. Archives of General Psychiatry 1978;35: $153-55$.

\section{Viguera 1997}

Viguera AC, Baldessarini RJ, Hegarty JD, van Kammen DP, Tohen M. Clinical risk following abrupt and gradual withdrawal of maintenance neuroleptic treatment. Archives of General Psychiatry 1997;54:49-55.

\section{Wahlbeck 1999}

Wahlbeck K, Cheine M, Essali MA, Rezk E. Clozapine vs typical neuroleptic medication for schizophrenia. Cochrane Database of Systematic Reviews 1999, Issue 2. [DOI: 10.1002/14651858.CD000059]

\section{Walsh 2002}

Walsh E, Buchanan A, Fahy T. Violence and schizophrenia: examining the evidence. British Journal of Psychiatry 2002; 180:490-5.

\section{Weinmann 2009}

Weinmann S, Read J, Aderhold V. Influence of antipsychotics on mortality in schizophrenia: systematic review. Schizophrenia Research 2009;113(1):1-11.

Wilkinson 2000

Wilkinson G, Hesdon B, Wild D, Cookson R, Farina C, Sharma V, et al.Self-report quality of life measure for people with schizophrenia: the SQLS. British Journal of Psychiatry 2000;177:42-6.

Xia 2009

Xia J, Adams CE, Bhagat N, Bhagat V, Bhoopathi P, ElSayeh H, et al.Loss to outcomes stakeholder survey: the LOSS study. Psychiatric Bulletin 2009;33(7):254-7.

\section{References to other published versions of this review}

\section{Leucht 2012}

Leucht S, Tardy M, Komossa K, Heres S, Kissling W, Salanti $\mathrm{G}$, et al.Antipsychotic drugs versus placebo for relapse prevention in schizophrenia: systematic review and metaanalysis. Lancet in press.

* Indicates the major publication for the study 


\section{CHARACTERISTICS OF STUDIES}

\section{Characteristics of included studies [ordered by study ID]}

\section{Andrews 1976}

Methods

Randomisation: randomised, no further details.

Allocation: pharmacists held the key.

Blinding: double, identical capsules.

Duration: 42 weeks.

Design: parallel.

Location: single-centre.

Setting: hospital.

Participants

Diagnosis: schizophrenia (clinical diagnosis), continuously in hospital for at least 6 years (mean 28 years).

$\mathrm{N}=32$.

Gender: 32 men.

Age: mean 58 years.

History: duration stable- 8 weeks, duration ill NI- mean duration of hospitalisation 28 years, number of previous hospitalisations- n.i., age at onset- n.i., severity of illness- mean Wing Behaviour Scale Withdrawal Score 2.14, baseline antipsychotic dose-216mg/day $\mathrm{CPZ}$ equivalent

Interventions

1. Drug: Chlorpromazine - mean dose: $216 \mathrm{mg} /$ day. $\mathrm{N}=15$.

Allowed dose range: the participants were kept on their initial dose

2. Placebo: Duration of taper 0 days. $\mathrm{N}=17$.

Rescue medication: benzodiazepines, anticholinergics.

Outcomes

Examined:

Relapse (need of antipsychotic medication).

Leaving the study early.

Unable to use / Not included:

Behaviour: Ward Behaviour Rating Scale of Wing (no SD / no prespecified outcome of interest)

Notes

Risk of bias

\begin{tabular}{|c|c|c|}
\hline Bias & Authors' judgement & Support for judgement \\
\hline $\begin{array}{l}\text { Random sequence generation (selection } \\
\text { bias) }\end{array}$ & Unclear risk & Randomised, no further details. \\
\hline Allocation concealment (selection bias) & Low risk & Pharmacists held the key. \\
\hline $\begin{array}{l}\text { Blinding (performance bias and detection } \\
\text { bias) } \\
\text { Subjective outcomes }\end{array}$ & Unclear risk & Double, identical capsules. \\
\hline
\end{tabular}

Maintenance treatment with antipsychotic drugs for schizophrenia (Review)

Copyright () 2012 The Cochrane Collaboration. Published by John Wiley \& Sons, Ltd. 
Andrews 1976 (Continued)

\begin{tabular}{l|l|l|}
$\begin{array}{l}\text { Blinding (performance bias and detection } \\
\text { bias) } \\
\text { Objective outcomes }\end{array}$ & Double, identical capsules. \\
\hline
\end{tabular}

Incomplete outcome data (attrition bias) Low risk All participants completed the trial. All outcomes

\begin{tabular}{lll} 
Selective reporting (reporting bias) & Low risk & No evidence for selective reporting. \\
\hline Other bias & Low risk & No obvious other bias. \\
\hline
\end{tabular}

Arato 2002

Methods

Randomisation: random, computer-generated randomisation code.

Allocation: procedure not described.

Blinding: double.

Duration: 12 months.

Design: parallel.

Location: multi-centre.

Setting: inpatient.

Participants

Diagnosis: chronic, stable schizophrenia (DSM-III-R), less than markedly ill on Clinical Global Impression Scale

$\mathrm{N}=278$.

Gender: 203 men, 75 women.

Age: mean 49.7 years.

History: duration stable- n.i., duration ill- mean 21.8 years, number of previous hospitalisations- mean 10.1, age at onset- mean 27.9 years, severity of illness- mean PANSS 85.8, mean CGI severity 4.02, baseline antipsychotic dose n.i..

Interventions

1. Drug: ziprasidone - Fixed doses of 40,80 or $160 \mathrm{mg} /$ day. ${ }^{* *} \mathrm{~N}=207$

2. Placebo: Duration of taper $<3$ days. $\mathrm{N}=71$.

Rescue medication: anticholinergics, lorazepam, temazepam, no additional antipsychotic medication

Outcomes

Examined:

Relapse: (Clinical Global Impressionof much worse or more, PANSS items hostility or uncooperativeness $>6$, or in need for additional treatment for exacerbation of symptoms) Leaving the study early.

Adverse events: binary outcome for generel, specific (movement disorders) - interviews Unable to use / Not included:

Mental state: PANSS total score and subscores (no predefined outcome of interest) Global state: much worse or more - Clinical Global Impression Severity Scale (no prespecified outcome of interest)

Functioning: Global Assessment of Functioning Scale (no prespecified outcome of interest)

Adverse effects: extrapyramidal symptoms (Simpson Angus Scale, Barnes Akathisia Scale, Abnormal Involuntary Movements Scale - all no SD / continous side-effect results were 
not among the prespecified outcomes of interest)

Physiological measures: ECG, vital signs, weight, ophthalmological assessment, lab tests (all no SD, no data / not prespecified outcomes of interest)

Notes

** The results of the three dose groups were pooled. 16 participants from one centre were excluded due to protocol violations. Intention-to-treat were only those participants who had received at least one dose. How many did not receive one dose is unclear

\section{Risk of bias}

\begin{tabular}{|c|c|c|}
\hline Bias & Authors' judgement & Support for judgement \\
\hline $\begin{array}{l}\text { Random sequence generation (selection } \\
\text { bias) }\end{array}$ & Low risk & $\begin{array}{l}\text { Randomised, computer-generated ran- } \\
\text { domised code. }\end{array}$ \\
\hline Allocation concealment (selection bias) & Unclear risk & Procedure not described. \\
\hline $\begin{array}{l}\text { Blinding (performance bias and detection } \\
\text { bias) } \\
\text { Subjective outcomes }\end{array}$ & Unclear risk & Double, no further details. \\
\hline $\begin{array}{l}\text { Blinding (performance bias and detection } \\
\text { bias) } \\
\text { Objective outcomes }\end{array}$ & Low risk & Double, no further details. \\
\hline $\begin{array}{l}\text { Incomplete outcome data (attrition bias) } \\
\text { All outcomes }\end{array}$ & High risk & $\begin{array}{l}64 \% \text { of the participants left the study early, } \\
\text { most due to relapse. The rate was higher } \\
\text { in the placebo group }(86 \%) \text { than in the } \\
\text { medication group }(-57 \%) \text {. This was prob- } \\
\text { ably not a problem for the primary out- } \\
\text { come relapse, but for secondary outcomes } \\
\text { for which the last-observation-carried-for- } \\
\text { ward method was used. Appropriate sur- } \\
\text { vival curve analysis was used for the pri- } \\
\text { mary outcome relapse }\end{array}$ \\
\hline Selective reporting (reporting bias) & Low risk & No selective reporting. \\
\hline Other bias & Low risk & No obvious other bias. \\
\hline
\end{tabular}


Methods

Randomisation: matched pairs were formed and then randomised, no further details.

Allocation: procedure not described.

Blinding: double, indistinguishable placebo.

Duration: 10 weeks.

Design: parallel.

Location: single-centre.

Setting: hospital, sponsored.

Participants

Diagnosis: chronic psychotic hospitalised patients mainly with schizophrenic and paranoid behaviour patterns, suspected of relapsing after withdrawal of medication (clinical diagnosis).

$\mathrm{N}=26$.

Gender: 26 men.

Age: n.i.

History: duration stable- 8 months pre-treatment with penfluridol to find optimum dose, duration ill- n.i., number of previous hospitalisations- n.i., age at onset- n.i., severity of illness- n.i., but hospitalised, baseline antipsychotic dose- $23.4 \mathrm{mg} /$ day

Interventions

1. Drug: penfluridol once weekly - Fixed dose, mean dose: n.i., range 10-40mg/weekly. $\mathrm{N}=13$

2. Placebo: Duration of taper: 0 days. $\mathrm{N}=13$.

Rescue medication: sedative neuroleptics allowed for 2 weeks, dexbenzitide

Outcomes

Examined:

Relapse: need of medication as decided by two psychiatrists.

Unable to use / Not included:

Mental state: Psychiatric Evaluation Scale (no predefined outcome of interest)

Adverse effects: movement disorders (Factor Construct Outcome Scale, no data for randomised phase / continous side-effect results were not among the prespecified outcomes of interest), neurologic effects (graphometric and tapping test, no data for randomised phase / no prespecified outcomes of interest)

Notes

Risk of bias

\begin{tabular}{lll}
\hline Bias & Authors' judgement & Support for judgement \\
\hline $\begin{array}{l}\text { Random sequence generation (selection } \\
\text { bias) }\end{array}$ & Unclear risk & $\begin{array}{l}\text { Matched pairs were formed and then ran- } \\
\text { domised, no further details }\end{array}$ \\
\hline Allocation concealment (selection bias) & Unclear risk & Procedure not described.
\end{tabular}

Blinding (performance bias and detection Unclear risk bias)

Double, indistinguishable placebo.

Subjective outcomes 
Baro 1970 (Continued)

Blinding (performance bias and detection Low risk

Double, indistinguishable placebo.

bias)

Objective outcomes

Incomplete outcome data (attrition bias) Low risk

All outcomes

Apart from those participants who relapsed no participant left the study early and re-

lapse was the only outcome

Selective reporting (reporting bias) High risk

Adverse events were not reported for the double-blind phase.

Other bias

Low risk

No obvious other bias.

Beasley 2003

Methods

Participants

Interventions
Randomisation: randomised, 2:1 ratio, by an interactive voice response system.

Allocation: interactive voice response system.

Blinding: double, no further details.

Duration: one year, but the study was terminated early. Maximum length was 30 weeks.

Design: parallel.

Location: multi-centre.

Setting: outpatient.

Diagnosis: schizophrenia ( $\mathrm{n}=266)$ or schizoaffective disorder $(\mathrm{n}=60$, DSM-IV). BPRS total score $<36$, positive symptoms at most mild, Global Assessment of Functioning at least 40 , currently on maintenance antipsychotic medication

$\mathrm{N}=326$.

Gender: 173 men, 153 women.

Age: mean 35.9 years.

History: duration stable- 8 weeks, duration ill- mean 11.1 years, number of previous hospitalisations- n.i., age at onset- mean 24.7 years, severity of illness- mean PANSS total score at baseline 43, baseline antipsychotic dose- mean $13.4 \mathrm{mg}$ olanzapine/day

Participants were first converted to olanzapine and then stabilized for 8 weeks before randomisation

1. Drug: olanzapine - Fixed dose of either 10, 15 or $20 \mathrm{mg} /$ day. Mean dose $13.4 \mathrm{mg} /$ day. $\mathrm{N}=224$

2. Placebo: Duration of taper: 0 days. $\mathrm{N}=102$.

Rescue medication: a one time increase of the same medication (olanzapine or placebo) was allowed. Furthermore, antiparkinson medication and benzodiazepines were allowed

Outcomes

Examined:

Relapse: any BPRS positive item > 4, absolute increase of a positive item or of the positive subscore, hospitalisation due to positive symptoms, suicide or suicide attempt

Leaving the study early.

Adverse effects: binary outcomes for general, specific (movement disorders) - open interviews

Quality of life: Heinrich Carpenter Quality of Life Scale. 


\begin{tabular}{|c|c|c|}
\hline & \multicolumn{2}{|c|}{$\begin{array}{l}\text { Unable to use / Not included: } \\
\text { Mental state: PANSS (no prespecified outcome of interest). } \\
\text { Adverse effects: adverse effects with an incidence }<10 \% \text { (no data), laboratory, EPS-scales } \\
\text { (in part no data / no prespecified outcome of interest), EPS-scales (no SD / continous } \\
\text { side-effect results were not among the prespecified outcomes) } \\
\text { Physiological measures: vital signs (no prespecified outcome of interest) }\end{array}$} \\
\hline \multicolumn{3}{|l|}{ Notes } \\
\hline \multicolumn{3}{|l|}{ Risk of bias } \\
\hline Bias & Authors' judgement & Support for judgement \\
\hline $\begin{array}{l}\text { Random sequence generation (selection } \\
\text { bias) }\end{array}$ & Low risk & $\begin{array}{l}\text { Randomised, } 2: 1 \text { ratio, by an interactive } \\
\text { voice response system }\end{array}$ \\
\hline Allocation concealment (selection bias) & Low risk & Interactive voice response system. \\
\hline $\begin{array}{l}\text { Blinding (performance bias and detection } \\
\text { bias) } \\
\text { Subjective outcomes }\end{array}$ & Unclear risk & Double, no further details. \\
\hline $\begin{array}{l}\text { Blinding (performance bias and detection } \\
\text { bias) } \\
\text { Objective outcomes }\end{array}$ & Low risk & Double, no further details. \\
\hline $\begin{array}{l}\text { Incomplete outcome data (attrition bias) } \\
\text { All outcomes }\end{array}$ & High risk & $\begin{array}{l}\text { The overall attrition of } 26 \% \text { was accept- } \\
\text { able, but many more participants in the } \\
\text { placebo group than in the olanzapine group } \\
\text { left the study early. Kaplan-Meier survival } \\
\text { analysis was used for the analysis of relapse, } \\
\text { ANOVA based on last-observation-carried- } \\
\text { forward was used for continuous outcomes }\end{array}$ \\
\hline Selective reporting (reporting bias) & High risk & $\begin{array}{l}\text { Only those adverse events with a frequency } \\
\text { of at least } 10 \% \text { were reported. Use of an- } \\
\text { tiparkinson medication has not been re- } \\
\text { ported }\end{array}$ \\
\hline Other bias & High risk & $\begin{array}{l}\text { The study was terminated early when there } \\
\text { was a sufficient difference, but this was pre- } \\
\text { planned }\end{array}$ \\
\hline
\end{tabular}


Allocation: procedure not described.

Blinding: double, thiamine chloride used as placebo, participants and nurses were told that a new medication was given, but nurses soon new that this was a placebo.

Duration: 16 weeks.

Design: parallel.

Location: single-centre.

Setting: in hospital.

Participants

Diagnosis: schizophrenia (clinical diagnosis).

$\mathrm{N}=45$.

Gender: 45 men.

Age: $20-40$ years.

History: duration stable- n.i., but clinically tranquilised and making a satisfactory adjustment on phenothiazine medication, duration ill- n.i., but mean length of current hospitalisation 45 months (range 3-129), number of previous hospitalisations- all more than one, age at onset- n.i., severity of illness- n.i., but all in open hospital ward, baseline antipsychotic dose- prochlorpromazine $15-150 \mathrm{mg} /$ day, perphenazine $12-24 \mathrm{mg} / \mathrm{day}$, chlorpromazine $50-800 \mathrm{mg} /$ day, promazine $200-400 \mathrm{mg} /$ day, trifluoperazine $6 \mathrm{mg} /$ day

Interventions

1. Drug: prochlorpromazine, perphenazine, chlorpromazine, promazine or trifluoperazine. Fixed doses continued with the same drug and dose taken before the study. Mean dose: n.i. $\mathrm{N}=30$

2. Placebo: Duration of taper: 0 days. $\mathrm{N}=15^{*}$.

Rescue medication: not allowed.

Outcomes

Examined:

Relapse (need of medication or deterioriation of state or transfer to closed ward)

Unable to use / Not included:

Behaviour: Patient Adjustment Report (no prespecified outcome of interest)

Mental state: Taylor Manifest Anxiety Scale (no prespecified outcome of interest)

Notes

* Another 15 participants were treated only for 8 weeks with placebo and then switched back to their initial antipsychotic drug

Risk of bias

\begin{tabular}{l|l|l}
\hline Bias & Authors' judgement & Support for judgement \\
\hline $\begin{array}{l}\text { Random sequence generation (selection } \\
\text { bias) }\end{array}$ & Unclear risk & Randomised, no further details. \\
\hline Allocation concealment (selection bias) & Unclear risk & Procedure not described. \\
\hline $\begin{array}{l}\text { Blinding (performance bias and detection } \\
\text { bias) } \\
\text { Subjective outcomes }\end{array}$ & High & $\begin{array}{l}\text { Double, thiamine chloride used as placebo, } \\
\text { participants and nurses were told that a new } \\
\text { medication was given, but nurses soon new } \\
\text { that this was a placebo }\end{array}$
\end{tabular}


Blackburn 1981 (Continued)

\begin{tabular}{l|l|l|}
$\begin{array}{l}\text { Blinding (performance bias and detection } \\
\text { bias) }\end{array}$ & Low risk & $\begin{array}{l}\text { Double, thiamine chloride used as placebo, } \\
\text { Objective outcomes }\end{array}$ \\
\hline
\end{tabular}

Incomplete outcome data (attrition bias) Low risk $\quad$ Only completers were included in the staAll outcomes tistical analysis, but because the drop-out rate was only $13 \%$ we did not consider this a source of bias

\begin{tabular}{lll}
\hline Selective reporting (reporting bias) & Low risk & No evidence for selective reporting. \\
\hline Other bias & Low risk & No clear other risk of bias. \\
\hline
\end{tabular}

\section{Boonstra 2011}

\begin{tabular}{|c|c|}
\hline Methods & $\begin{array}{l}\text { Randomisation: An independent rater created randomisation lists stratified for gender } \\
\text { with randomly permuted blocks of } 4 \text { allocation groups } \\
\text { Allocation: procedure not described. } \\
\text { Blinding: open. } \\
\text { Duration: } 24 \text { months. } \\
\text { Design: parallel. } \\
\text { Location: multi-center. } \\
\text { Setting: outpatient. }\end{array}$ \\
\hline Participants & $\begin{array}{l}\text { Diagnosis: first episode schizophrenia (DSM-IV). } \\
\text { N=20. } \\
\text { Gender: } 17 \text { men, } 3 \text { women. } \\
\text { Age: mean } 29.8 \text { years. } \\
\text { History: duration stable- } 1 \text { year, duration ill- } 2.6 \text { years, number of previous hospitalisa- } \\
\text { tions- } 0 \text {, age at onset- } 27.3 \text { years, severity of illness- PANSS total score } 49 \text {, baseline an- } \\
\text { tipsychotic dose- } 3 \mathrm{mg} / \text { day haloperidol equivalents (olanzapine, risperidone, quetiapine, } \\
\text { zuclopenthixol) }\end{array}$ \\
\hline Interventions & $\begin{array}{l}\text { 1. Drug: olanzapine, risperidone, quetiapine, zuclopenthixol. Flexible doses. Mean dose: } \\
\text { n.i. } N=9 \\
\text { 2. No treatment: Duration of taper: } 6-12 \text { weeks. } N=11 \text {. } \\
\text { Rescue medication: not indicated. }\end{array}$ \\
\hline Outcomes & $\begin{array}{l}\text { Examined: } \\
\text { Relapse: clinicial judgement. } \\
\text { Leaving the study early. } \\
\text { Rehospitalisation. }\end{array}$ \\
\hline Notes & $\begin{array}{l}\text { Sponsor: The Netherlands Organisation for Health Research and Development and } \\
\text { EliLilly }\end{array}$ \\
\hline
\end{tabular}

\section{Risk of bias}

Maintenance treatment with antipsychotic drugs for schizophrenia (Review) 
Boonstra 2011 (Continued)

\begin{tabular}{|c|c|c|}
\hline Bias & Authors' judgement & Support for judgement \\
\hline $\begin{array}{l}\text { Random sequence generation (selection } \\
\text { bias) }\end{array}$ & Low risk & $\begin{array}{l}\text { An independent rater created randomisa- } \\
\text { tion lists stratified for gender with ran- } \\
\text { domly permuted blocks of } 4 \text { allocation } \\
\text { groups }\end{array}$ \\
\hline Allocation concealment (selection bias) & Unclear risk & Procedure not described. \\
\hline $\begin{array}{l}\text { Blinding (performance bias and detection } \\
\text { bias) } \\
\text { Subjective outcomes }\end{array}$ & High risk & Open study. \\
\hline $\begin{array}{l}\text { Blinding (performance bias and detection } \\
\text { bias) } \\
\text { Objective outcomes }\end{array}$ & Low risk & Open study. \\
\hline $\begin{array}{l}\text { Incomplete outcome data (attrition bias) } \\
\text { All outcomes }\end{array}$ & Low risk & $\begin{array}{l}5 \text { out of } 20 \text { participants left the study } \\
\text { early }(25 \%) \text {. Probably an acceptable rate, } \\
\text { there was no big difference between drug } \\
\text { and placebo group. Kaplan-Meier survival } \\
\text { curves were used for the primary outcome } \\
\text { relapse }\end{array}$ \\
\hline Selective reporting (reporting bias) & Low risk & No evidence for selective reporting. \\
\hline Other bias & High risk & $\begin{array}{l}\text { Premature termination after interim analy- } \\
\text { sis. }\end{array}$ \\
\hline
\end{tabular}

Caffey 1964

Methods

Randomisation: randomised, no further details.

Allocation: procedure not described.

Blinding: double, identical tablets. However, placebo dose reduction group received medication only every other day. Therefore, blinding was not fully maintained.

Duration: 16 weeks.

Design: parallel.

Location: multi-centre.

Setting: in hospital.

Participants

Diagnosis: schizophrenia (clinical diagnosis), one third paranoid subtype, without central nervous system disease, without lobotomy

$\mathrm{N}=259$.

Gender: all men.

Age: mean 40 years.

History: duration stable- stable doses for at least 3 months before the study, duration ill- $\mathrm{n}$. i., but currently hospitalized for a mean of 10 years, number of previous hospitalisations- 
n.i., age at onset- n.i., severity of illness- n.i., baseline antipsychotic dose- chlorpromazine mean $400 \mathrm{mg} /$ day, thioridazine mean $350 \mathrm{mg} /$ day

Interventions

1. Drug: chlorpromazine or thioridazine.* Fixed dose, continuation of the dose given in the stabilization phase. Mean dose: chlorpromazine mean $400 \mathrm{mg} /$ day, thioridazine mean $350 \mathrm{mg} /$ day. $\mathrm{N}=88$

2. Placebo: Duration of taper: $1-8$ days. $\mathrm{N}=171$.

Rescue medication: not indicated.

Examined:

Relapse: definitive worsening of the condition and medication again necessary, usually joint decision of treatment team

Unable to use / Not included:

Mental state: Inpatient Multidimensional Psychiatric Scale (no prespecified outcome of interest)

Behaviour: Psychotic Reaction Profile Scale (no prespecified outcome of interest)

Notes

* There was another group which received half the original dose. It was not considered in this review

\section{Risk of bias}

Bias

Random sequence generation (selection Unclear risk bias)

\section{Support for judgement}

Randomised, no further details.

\begin{tabular}{|c|c|c|}
\hline Allocation concealment (selection bias) & Unclear risk & Procedure not described. \\
\hline $\begin{array}{l}\text { Blinding (performance bias and detection } \\
\text { bias) } \\
\text { Subjective outcomes }\end{array}$ & High risk & $\begin{array}{l}\text { Double, iden- } \\
\text { tical tablets. However, placebo dose reduc- } \\
\text { tion group received medication only every } \\
\text { other day. Therefore, blinding was not fully } \\
\text { maintained }\end{array}$ \\
\hline $\begin{array}{l}\text { Blinding (performance bias and detection } \\
\text { bias) } \\
\text { Objective outcomes }\end{array}$ & Low risk & $\begin{array}{l}\text { Double, iden- } \\
\text { tical tablets. However, placebo dose reduc- } \\
\text { tion group received medication only every } \\
\text { other day. Therefore, blinding was not fully } \\
\text { maintained }\end{array}$ \\
\hline
\end{tabular}

Incomplete outcome data (attrition bias) Unclear risk All outcomes

Selective reporting (reporting bias)

Low risk
It is unclear whether there were dropouts or whether the authors analysed only study completers

No evidence for selective reporting. 
Caffey 1964 (Continued)

Other bias $\quad$ Unclear risk

22 participants who had relapsed in the first 8 weeks were entered in the study again. As the number is small, it is unclear whether they affected the results

Channabasavanna 1987

Methods

Randomisation: n.i., but double-blind study.

Allocation: procedure not described.

Blinding: double, identical capsules.

Duration: 12 weeks.

Design: parallel.

Location: single-centre.

Setting: unclear.

Participants

Diagnosis: chronic schizophrenia (DSM-III), all on maintenance medication for control of continuous symptoms, all stable for at least 6 months

$\mathrm{N}=30$.

Gender: 16 men, 12 women.

Age: mean 36.0 years.

History: duration stable- at least 6 months, duration ill- mean 11.1 years, number of previous hospitalisations- n.i., age at onset- 24.9 years, severity of illness- n.i., baseline antipsychotic dose- mean $297.5 \mathrm{mg} /$ day chlorpromazine equivalent

Interventions

1. Drug: penfluridol. Fixed dose of $55 \mathrm{mg} /$ week. $\mathrm{N}=15$.

2. Placebo: Duration of taper: 0 days. $\mathrm{N}=15$.

Rescue medication: antiparkinson medication and haloperidol, but this was considered to be a relapse

Outcomes

Examined:

Relapse (need of additional haloperidol medication).

Unable to use / Not included:

Mental state (Scale for the Assessment of Positive Symptoms and Negative Symptoms no data /no predefined outcome of interest)

Adverse effects: extrapyramidal side-effects (Simpson Angus Scale - no data / continuous side-effect results were not among the prespecified outcomes)

Physiological measures: mean body weight, pulse rate, blood pressure, laboratory (all no data / no prespecified outcomes of interest)

Notes

Risk of bias

Bias

Random sequence generation (selection Unclear risk bias)

Authors' judgement

\section{Support for judgement}

N.i., but double-blind study. 


\section{Channabasavanna 1987 (Continued)}

\begin{tabular}{|c|c|c|}
\hline Allocation concealment (selection bias) & Unclear risk & Procedure not described. \\
\hline $\begin{array}{l}\text { Blinding (performance bias and detection } \\
\text { bias) } \\
\text { Subjective outcomes }\end{array}$ & Unclear risk & Double, identical capsules. \\
\hline $\begin{array}{l}\text { Blinding (performance bias and detection } \\
\text { bias) } \\
\text { Objective outcomes }\end{array}$ & Low risk & Double, identical capsules. \\
\hline $\begin{array}{l}\text { Incomplete outcome data (attrition bias) } \\
\text { All outcomes }\end{array}$ & Low risk & $\begin{array}{l}\text { Only study completers were used in the } \\
\text { final analysis, but as there were only two } \\
\text { dropouts (one in each group) this was not } \\
\text { necessarily a problem }\end{array}$ \\
\hline Selective reporting (reporting bias) & Low risk & $\begin{array}{l}\text { Rating scale results were not reported, but } \\
\text { these were not of interest for the review }\end{array}$ \\
\hline Other bias & Low risk & No clear evidence for other bias. \\
\hline
\end{tabular}

Chen 2010

Methods

Randomisation: sequence by computer, fixed block size of four without stratification. Allocation: AstraZeneca prepared individually numbered sets of study drugs, packed them according to the randomisation sequence and then shipped them to the study team in numbered but apparently identical sets.

Blinding: identical capsules, "investigators, patients and all research staff were blind to the study drugs and the block size".

Duration: 1 year.

Design: parallel.

Location: single-center (all in Early Assessment Service for Young People with Psychosis (EASY) in Hong Kong).

Setting: outpatient.

Participants

Diagnosis: schizophrenia and related psychoses (DSM-IV), all first episode, all well remitted, all had remained well on maintenance medication for 1 year

$\mathrm{N}=178$.

Gender: 24.2

Age: 80 men, 98 women.

History: duration stable- 1 year, duration ill- 2.3 years, number of previous hospitalisations- 0 (first episode), age at onset- 21.9 years, severity of illness- mean PANSS 36,

baseline antipsychotic dose- $153 \mathrm{mg} /$ day chlorpromazine equivalents

Interventions

1. Drug: quetiapine. Fixed dose of $400 \mathrm{mg} /$ day. $\mathrm{N}=89$.

2. Placebo: Duration of taper (days): $35 . \mathrm{N}=89$.

Rescue medication: antipsychotics not allowed. 
Chen 2010 (Continued)

\begin{tabular}{ll}
\hline Outcomes & Examined: \\
& Relapse: (i) an increase in at least one of the following Positive and Negative Syndrome \\
& Scale psychotic symptom items to a threshold score (delusion, hallucinatory behaviour, \\
conceptual disorganisation, unusual thought content, suspiciousness; (ii) Clinical Global & Impression Severity of Illness 3 or above and (iii) CGI change 5 or above) \\
& Leaving the study early. \\
& Rehospitalisation. \\
& Suicide attempts. \\
& Adverse effects: akathisia, tardive dyskinesia, tremor, sedation, weight gain \\
& Open employment status. \\
\hline Notes & \\
\hline
\end{tabular}

\section{Risk of bias}

\begin{tabular}{|c|c|c|}
\hline Bias & Authors' judgement & Support for judgement \\
\hline $\begin{array}{l}\text { Random sequence generation (selection } \\
\text { bias) }\end{array}$ & Low risk & $\begin{array}{l}\text { Sequence by computer, fixed block size of } \\
\text { four without stratification }\end{array}$ \\
\hline Allocation concealment (selection bias) & Low risk & $\begin{array}{l}\text { AstraZeneca prepared individually num- } \\
\text { bered sets of study drugs, packed them ac- } \\
\text { cording to the randomisation sequence and } \\
\text { then shipped them to the study team in } \\
\text { numbered but apparently identical capsules }\end{array}$ \\
\hline $\begin{array}{l}\text { Blinding (performance bias and detection } \\
\text { bias) } \\
\text { Subjective outcomes }\end{array}$ & Unclear risk & $\begin{array}{l}\text { Identical capsules, "investigators, patients } \\
\text { and all research staff were blind to the study } \\
\text { drugs and the block size" }\end{array}$ \\
\hline $\begin{array}{l}\text { Blinding (performance bias and detection } \\
\text { bias) } \\
\text { Objective outcomes }\end{array}$ & Low risk & $\begin{array}{l}\text { Identical capsules, "investigators, patients } \\
\text { and all research staff were blind to the study } \\
\text { drugs and the block size" }\end{array}$ \\
\hline $\begin{array}{l}\text { Incomplete outcome data (attrition bias) } \\
\text { All outcomes }\end{array}$ & High risk & $\begin{array}{l}72 \% \text { of the participants left the study early. } \\
\text { As most participants dropped out after re- } \\
\text { lapse this outcome was not affected, but it } \\
\text { is a source of bias for other outcomes. Sur- } \\
\text { vival analysis for the primary outcome re- } \\
\text { lapse }\end{array}$ \\
\hline Selective reporting (reporting bias) & Low risk & No evidence for selective reporting. \\
\hline Other bias & Low risk & No clear other bias. \\
\hline
\end{tabular}


Duration: 18 months.

Design: parallel.

Location: single-centre.

Setting: outpatient.

Diagnosis: schizophrenia (mainly Schneiderian first-rank symptoms), last relapse 30-60 months ago, fully remitted since and maintained on antipsychotic drugs

$\mathrm{N}=30$.

Gender: 12 men, 18 women.

Age: 39.9 years.

History: duration stable- mean 44 months, duration ill- mean 10.2 years, number of previous hospitalisations- mean 1.6, age at onset- mean 29.7 years, severity of illness- $n$.

i., baseline antipsychotic dose- $151 \mathrm{mg} /$ day chlorpromazine equivalents

Interventions

Outcomes
1. Drug: switched to various antipsychotic drugs with similar profile as the previous one. Fixed/flexible dose: probably flexible. Allowed dose range: n.i.. Mean dose: n.i.. N=15

2. Placebo: benzodiazepine ('active placebo'). Duration of taper 0 days. $\mathrm{N}=15$

Rescue medication: n.i..

Examined:

Relapse: recurrence of symptoms definitely of schizophrenic type, or symptoms not diagnostic of schizophrenia (e.g. sleep problems) which could not be controlled with other measures than antipsychotic drugs or ECT

Leaving the study early.

Quality of life: subjective distress (Symptom Questionnaire of Kellner and Sheffield)

Notes

\section{Risk of bias}

\begin{tabular}{l|ll} 
Bias & Authors' judgement & Support for judgement \\
\hline $\begin{array}{l}\text { Random sequence generation (selection } \\
\text { bias) }\end{array}$ & Unclear risk & $\begin{array}{l}\text { Randomly in group of 15 each, no further } \\
\text { details. }\end{array}$ \\
\hline $\begin{array}{l}\text { Allocation concealment (selection bias) } \\
\begin{array}{l}\text { Blinding (performance bias and detection } \\
\text { bias) } \\
\text { Subjective outcomes }\end{array}\end{array}$ & Unclear risk & Procedure not described. \\
\hline
\end{tabular}

Blinding (performance bias and detection Low risk

Double, no further details.

bias)

Objective outcomes 


\section{Cheung 1981 (Continued)}

\begin{tabular}{l|l}
$\begin{array}{l}\text { Incomplete outcome data (attrition bias) } \\
\text { All outcomes }\end{array}$ & High risk
\end{tabular} \begin{tabular}{l}
$\begin{array}{l}12 \text { participants left the study early (40\%) } \\
\text {, among those } 10 \text { from the placebo group } \\
\text { and } 8 \text { for relapse. Outcomes other than re- } \\
\text { lapse and leaving early are clearly prone to } \\
\text { bias due to this difference in leaving the } \\
\text { study early }\end{array}$ \\
\hline
\end{tabular}

Selective reporting (reporting bias) Low risk

Use of benzodiazepines was not indicated, but this was not an outcome of interest in our review

\begin{tabular}{l|l} 
Other bias $\quad$ Low risk $\quad$ No evidence for other bias.
\end{tabular}

\section{Clark 1975}

Methods

Participants
Randomisation: random, in blocks of eight, stratified for age, duration ill and time since last admission.

Allocation: procedure not described.

Blinding: double, identical capsules, each participant had an individual stock bottle.

Duration: 24 weeks.

Design: parallel.

Location: single-centre.

Setting: outpatient.

\begin{tabular}{|c|c|}
\hline Participants & $\begin{array}{l}\text { Diagnosis: chronic schizophrenia (clinical diagnosis), } 22 \text { undifferentiated, } 7 \text { paranoid, } 1 \\
\text { schizoaffective, no severe other psychiatric or somatic illnesses, no severely ill participants } \\
\mathrm{N}=40 \text {. } \\
\text { Gender: } 40 \text { women. } \\
\text { Age: mean } 42.8 \text { years (range } 24-60 \text { ). } \\
\text { History: duration stable- maintained on medication in an outpatient status for at least } \\
3 \text { months, "relatively stable state of health", duration ill- mean } 11.6 \text { years, number of } \\
\text { previous hospitalisations- mean } 6.1 \text {, age at onset - NI, severity of illness- mean CGI } \\
\text { severity score } 2.94 \text {, baseline antipsychotic dose- n.i. }\end{array}$ \\
\hline Interventions & $\begin{array}{l}\text { 1. Drug: pimozide. }{ }^{*} \text { Flexible dose. Allowed dose range: } 2-20 \mathrm{mg} / \text { day. Mean dose: } 5.3 \\
\mathrm{mg} / \text { day. } \mathrm{N}=15 \\
\text { 2. Drug: thioridazine.* Flexible dose. Allowed dose range: } 75-750 \mathrm{mg} / \text { day. Mean dose: } \\
\text { 189mg/day. } \mathrm{N}=15 \\
\text { 3. Placebo: Duration of taper: } 0 \text { days. } \mathrm{N}=10 \text {. } \\
\text { Rescue medication: antiparkinson medication, bedside sedation }\end{array}$ \\
\hline Outcomes & $\begin{array}{l}\text { Examined: } \\
\text { Relapse (worsening of global state). } \\
\text { Leaving early. } \\
\text { Global state: number of participants improved according to Clinical Global Impressions } \\
\text { Scale } \\
\text { Adverse effects: binary outcomes - open interview. } \\
\text { Unable to use / Not included: }\end{array}$ \\
\hline
\end{tabular}




\begin{tabular}{|c|c|c|}
\hline & \multicolumn{2}{|c|}{$\begin{array}{l}\text { Mental state: BPRS (no SD / no prespecified outcome of interest) } \\
\text { Functioning: Katz Lyerly Scale of Social Adjustment, Patient Rating Form, Family Rating } \\
\text { Form (all no SD / no prespecified outcomes of interest) } \\
\text { Physiological measures: biological parameters (temperature, mean weight, pulse, blood } \\
\text { pressure, all no data / all no prespecified outcomes of interest), laboratory (blood count, } \\
\text { urine analysis, liver enzymes, blood sugar, protein bound iodine, all no prespecified } \\
\text { outcomes of interest) }\end{array}$} \\
\hline Notes & \multicolumn{2}{|c|}{${ }^{*}$ The results of pimozide and thioridazine were combined in the analysis } \\
\hline \multicolumn{3}{|l|}{ Risk of bias } \\
\hline Bias & Authors' judgement & Support for judgement \\
\hline $\begin{array}{l}\text { Random sequence generation (selection } \\
\text { bias) }\end{array}$ & Low risk & $\begin{array}{l}\text { Random, in blocks of eight, stratified for } \\
\text { age, duration ill and time since last admis- } \\
\text { sion }\end{array}$ \\
\hline Allocation concealment (selection bias) & Unclear risk & Procedure not described. \\
\hline $\begin{array}{l}\text { Blinding (performance bias and detection } \\
\text { bias) } \\
\text { Subjective outcomes }\end{array}$ & Unclear risk & $\begin{array}{l}\text { Double, identical capsules, each partici- } \\
\text { pant had an individual stock bottle }\end{array}$ \\
\hline $\begin{array}{l}\text { Blinding (performance bias and detection } \\
\text { bias) } \\
\text { Objective outcomes }\end{array}$ & Low risk & $\begin{array}{l}\text { Double, identical capsules, each partici- } \\
\text { pant had an individual stock bottle }\end{array}$ \\
\hline $\begin{array}{l}\text { Incomplete outcome data (attrition bias) } \\
\text { All outcomes }\end{array}$ & High risk & $\begin{array}{l}\text { Overall } 36 \% \text { left the study early. The spe- } \\
\text { cific reasons why the participants dropped } \\
\text { out were not indicated by group }\end{array}$ \\
\hline Selective reporting (reporting bias) & Low risk & No clear source for selective reporting. \\
\hline Other bias & Low risk & No clear other sources of bias. \\
\hline
\end{tabular}


Methods
Randomisation: computer-generated randomisation list.

Allocation: allocation to treatment was on a double-blind basis, codes were not broken until the time of analysis.

Blinding: double-blind, no further details.

Duration: 26 weeks.

Design: parallel.

Location: multi-centre, multi-national.

Setting: inpatient $(n=33)$ and outpatient $(n=86)$, sponsored.

Diagnosis: chronic schizophrenia (DSM-III-R), at least mildly ill according to CGI, had a history of recurrence in last 18 months, currently maintained on antipsychotic medication

$\mathrm{N}=121$.

Gender: 82 men, 37 women (intent-to-treat dataset).

Age: 42.3 years.

History: duration stable- n.i., duration ill- mean 13.6 years, number of previous hospitalisations- n.i., age at onset- mean 28.7 years, severity of illness- mean BPRS 49.1, mean CGI 4.2, baseline antipsychotic dose- n.i.

Interventions

1. Drug: zotepine. Fixed dose of $300 \mathrm{mg} /$ day which could be reduced once to $150 \mathrm{mg} /$ day. Mean dose: n.i.. $\mathrm{N}=63$

2. Placebo: Duration of taper: 0 days. $\mathrm{N}=58$.

Rescue medication: antipsychotic drugs not allowed, but benzodiazepines

Outcomes

Examined:

Relapse: (i) a moderate clinical deterioration from baseline (an increase in CGI severity score of at least 2 points plus an increase of 2 points in at least two positive symptom items on the BPRS persisting for two assessments over 3 days, but not requiring hospitalisation; (ii) deterioration requiring hospitalisation accompanied, on one assessment, by an increase in CGI severity score of at least 2 points plus an increase of 2 points in at least two positive symptom items on the BPRS; and (iii) severe clinical deterioration (an increase in CGI severity score to 'severely ill' for 24 hours, or, if in hospital, requiring special observation for suicidal or aggressive behaviour)

Global state: number of participants improved according to CGI

Adverse effects: binary outcomes - open interview.

Unable to use / Not included:

Mental state: BPRS, SANS (no prespecified outcomes of interest)

Adverse effects: extrapyramidal side-effects (SAS, AIMS, no SD / continous side-effect results were not among the prespecified outcomes)

Physiological measures: laboratory, vital signs, ECG (all no data / no prespecified outcomes of interest)

Notes

\section{Risk of bias}

Bias

\section{Support for judgement}




\section{Cooper 2000 (Continued)}

Random sequence generation (selection Low risk

Computer-generated randomisation list. bias)

Allocation concealment (selection bias) Low risk

Allocation to treatment was on a doubleblind basis, codes were not broken until the time of analysis

Blinding (performance bias and detection Unclear risk

Double-blind, no further details.

bias)

Subjective outcomes

Blinding (performance bias and detection Low risk

Double-blind, no further details.

bias)

Objective outcomes

Incomplete outcome data (attrition bias) High risk

All outcomes

The overall rate of participants leaving the study early was very high (76\%) and many more participants in the placebo group than in the drug group dropped out due to relapse. Kaplan-Meier survival analysis was used for primary outcome relapse. No full ITT analysis, only those participants with at least one post-baseline assessment were included, but only two participants were excluded on this basis

Selective reporting (reporting bias) High risk

Only those adverse events that were reported on at least four occasions and serious adverse events were reported

\begin{tabular}{lll} 
Other bias $\quad$ Low risk No clear other bias. \\
\hline
\end{tabular}

\section{Crow 1986}

Methods

Randomisation: random, no further details.

Allocation: allocation lists prepared by pharmacy for five antipsychotic drugs mentioned below, concealment is unclear.

Blinding: double, no further details.

Duration: 104 weeks.

Design: parallel.

Location: multi-centre.

Setting: outpatient.

Participants

Diagnosis: first episode of schizophrenia (Present State Examination)

$\mathrm{N}=120$.

Gender: 74 men, 46 women.

Age: mean 26.3 years (range 16-59 years).

History: duration stable- 30 days after discharge all on active medication, duration 
ill- 2.8 months (between illness onset and admission to hospital), number of previous hospitalisations- n.i., age at onset- n.i., severity of illness- most participants were 'well' at the beginning of the study ( 91 well, 13 psychotic features, 10 defect state, 6 unspecific symptoms), baseline antipsychotic dose- n.i.

Interventions

1. Drug: flupenthixol i.m., chlorpromazine, haloperidol, pimozide, trifluoperazine Flexible dose. Allowed dose range: no upper limit, but lower limit was flupenthixol i.m. $40 \mathrm{mg} / \mathrm{month}$, chlorpromazine $200 \mathrm{mg} /$ day, haloperidol $3 \mathrm{mg} /$ day, pimozide $4 \mathrm{mg} /$ day, trifluoperazine $5 \mathrm{mg} /$ day. Mean dose: flupenthixol $84 \mathrm{mg} / \mathrm{month}(\mathrm{n}=31)$, chlorpromazine $366 \mathrm{mg} /$ day $(\mathrm{n}=3)$, haloperidol $11.8 \mathrm{mg} /$ day $(\mathrm{n}=3)$, pimozide $7.8 \mathrm{mg} /$ day $(\mathrm{n}=5)$, trifluoperazine $11.5 \mathrm{mg} /$ day $(\mathrm{n}=12) . \mathrm{N}=54$

2. Placebo: Duration of taper (days): 30 days on drug, then received half dose for 30 days before they were put on placebo. $\mathrm{N}=66$

Rescue medication: antiparkinson medication, antidepressants, anxiolyties

\begin{tabular}{ll} 
Outcomes & Examined: \\
& $\begin{array}{l}\text { Relapse: rehospitalisation or rehospitalisation thought necessary although not possible } \\
\text { or need of medication } \\
\text { Unable to use / Not included: } \\
\text { Hallucinations, delusions (no data / no predefined outcomes of interest) }\end{array}$ \\
\hline Notes & \\
\hline
\end{tabular}

Risk of bias

\begin{tabular}{l|l|l}
\hline Bias & Authors' judgement & Support for judgement \\
\hline $\begin{array}{l}\text { Random sequence generation (selection } \\
\text { bias) }\end{array}$ & Unclear risk & Random, no further details. \\
\hline Allocation concealment (selection bias) & Unclear risk & $\begin{array}{l}\text { Allocation lists prepared by pharmacy for } \\
\text { five antipsychotic drugs mentioned below, } \\
\text { concealment is unclear }\end{array}$ \\
\hline
\end{tabular}

Blinding (performance bias and detection Unclear risk

Double, no further details.

bias)

Subjective outcomes

Blinding (performance bias and detection Low risk

bias)

Objective outcomes

Incomplete outcome data (attrition bias) Low risk All outcomes

No clear bias. overall rate of leaving early of $11 \%$ is acceptable. Survival curve analysis was used for the primary outcome relapse

Selective reporting (reporting bias)

Low risk

No evidence for selective reporting. 


\section{Denijs 1973}

Rethods
Randomisation: random, no further details.
Allocation: procedure not described.
Blinding: double, identical capsules.
Duration: 26 weeks.
Design: parallel.
Location: single-centre.
Setting: in hospital.

Participants

Diagnosis: residual schizophrenia (DSM-II), chronic, currently treated with antipsychotic drugs

$\mathrm{N}=40$.

Gender: 40 women.

Age: mean 58.5 years.

History: duration stable- all participants were switched to two months treatment with pimozide and only those who were treated effectively (=markedly improved) were randomised, duration ill- mean 30.5 years, duration of current hospitalisation mean 24 . 5 years (range 1-43), number of previous hospitalisations- n.i., age at onset- mean 28 years, severity of illness- n.i., baseline antipsychotic dose- pimozide mean $7.72 \mathrm{mg} / \mathrm{day}$

Interventions

1. Drug: pimozide. Flexible dose. Allowed dose range: n.i.. Mean dose: n.i.. $N=20$

2. Placebo: Duration of taper: 0 days. $\mathrm{N}=20$.

Rescue medication: not allowed, only dose increase of pimozide or placebo-pimozide was possible. Additional use of haloperidol meant relapse

Outcomes

Examined:

Relapse: need of additional haloperido)

Adverse effects: number of participants with at least one movement disorder, rigor and tremor

Unable to use / Not included:

Mental state: Overall Factor Construct Scale (no mean, no SD / no prespecified outcome of interest)

Behaviour: 'Psychiatric Evaluation Scale' (no mean, no SD / no prespecified outcome of interest)

Notes

Risk of bias

Bias

Random sequence generation (selection Unclear risk bias)

\section{Support for judgement}

Random, no further details. 


\section{Denijs 1973 (Continued)}

\begin{tabular}{|c|c|c|}
\hline Allocation concealment (selection bias) & Unclear risk & Procedure not described. \\
\hline $\begin{array}{l}\text { Blinding (performance bias and detection } \\
\text { bias) } \\
\text { Subjective outcomes }\end{array}$ & Unclear risk & Double, identical capsules. \\
\hline $\begin{array}{l}\text { Blinding (performance bias and detection } \\
\text { bias) } \\
\text { Objective outcomes }\end{array}$ & Low risk & Double, identical capsules. \\
\hline $\begin{array}{l}\text { Incomplete outcome data (attrition bias) } \\
\text { All outcomes }\end{array}$ & Low risk & $\begin{array}{l}2(5 \%) \text { of the participants left the study } \\
\text { early which is an acceptable rate. Both par- } \\
\text { ticipants were included in the endpoint } \\
\text { analysis }\end{array}$ \\
\hline Selective reporting (reporting bias) & Low risk & No evidence for selective reporting. \\
\hline Other bias & Low risk & No clear evidence for other bias. \\
\hline
\end{tabular}

\section{Doddi 1979}

Methods
Randomisation: no details (just reported as a "randomised study").

Allocation: procedure not described.

Blinding: "double-blind" ("patients and authors were not aware of the allocated treatment").

Duration: 9 months.

Design: randomised, parallel (enriched design: patients, who responded to fluphenazine long-acting treatment ( 25 or $50 \mathrm{mg} /$ month) for at least six to 12 months before study entry, were randomised to continue that treatment or to placebo). Ten out of 20 patients had been previously recruited in a study comparing fluphenazine with trifluorazine.

Location: no clear details.

Setting: outpatients.

Participants

Diagnosis: chronic schizophrenia with an acute episode within 6 to 12 months before study entry (no details about diagnostic criteria)

$\mathrm{N}=20$.

Gender: all men.

Age: 19 to 32 years.

History: duration stable at least six months, duration ill- some were first episode patients, some were patients with recurrence, number of previous hospitalisations- no data, age at onset- no data, severity of illness- fluphenazine group had a mean BPRS baseline score of 24.56 (SD 3.56); placebo group had a mean BPRS baseline score of 21.71, baseline antipsychotic dose ( 25 or $50 \mathrm{mg} / \mathrm{month})$

Interventions
1. Drug: fluphenazine depot. Fixed dose: 25 or $50 \mathrm{mg} / \mathrm{month}$ (long-acting formulation). Mean dose: $n$.i.. $\mathrm{N}=10$ randomised (but data available only for 9 patients who completed the study)

2. Placebo: Duration of taper (days): n.i.. $\mathrm{N}=10$ randomised (but data available only for 
Doddi 1979 (Continued)

7 patients who completed the study)

Rescue medication: antiparkinson medication at study entry (and then progressively tapered off, without a prespecified schedule)

Outcomes $\quad$ Examined:

Relapse: defined as worsening of clinical status needing an adjunctive new antipsychotic treatment

Unable to use / Not included:

Mental state: BPRS (no prespecified outcome of interest).

Notes

Risk of bias

\begin{tabular}{|c|c|c|}
\hline Bias & Authors' judgement & Support for judgement \\
\hline $\begin{array}{l}\text { Random sequence generation (selection } \\
\text { bias) }\end{array}$ & Unclear risk & $\begin{array}{l}\text { No details (just reported as a "randomised } \\
\text { study"). }\end{array}$ \\
\hline Allocation concealment (selection bias) & Unclear risk & Procedure not described. \\
\hline $\begin{array}{l}\text { Blinding (performance bias and detection } \\
\text { bias) } \\
\text { Subjective outcomes }\end{array}$ & Unclear risk & $\begin{array}{l}\text { Double-blind ("patients and authors were } \\
\text { not aware of the allocated treatment") }\end{array}$ \\
\hline $\begin{array}{l}\text { Blinding (performance bias and detection } \\
\text { bias) } \\
\text { Objective outcomes }\end{array}$ & Low risk & $\begin{array}{l}\text { Double-blind ("patients and authors were } \\
\text { not aware of the allocated treatment") }\end{array}$ \\
\hline $\begin{array}{l}\text { Incomplete outcome data (attrition bias) } \\
\text { All outcomes }\end{array}$ & Unclear risk & $\begin{array}{l}25 \% \text { of the participants dropped out, all } \\
\text { due to relapse. This may still be acceptable }\end{array}$ \\
\hline Selective reporting (reporting bias) & Low risk & No evidence for selective reporting. \\
\hline Other bias & Low risk & No clear other bias. \\
\hline
\end{tabular}

Eklund 1991

Methods

Randomisation: random, no further details.

Allocation: procedure not described.

Blinding: double, placebo injections, no further details.

Duration: 48 weeks.

Design: parallel.

Location: single-centre.

Setting: in- and outpatients. 
Eklund 1991 (Continued)

\begin{tabular}{|c|c|}
\hline Participants & $\begin{array}{l}\text { Diagnosis: schizophrenia (Research Diagnostic Criteria), requiring neuroleptic mainte- } \\
\text { nance treatment to prevent relapse } \\
\mathrm{N}=43 \text {. } \\
\text { Gender: n.i.. } \\
\text { Age: mean } 51.7 \text { (range } 25-65) \text { years. } \\
\text { History: duration stable- remained in the study after } 15 \text { weeks of haloperidol decanoate, } \\
\text { duration ill- n.i., number of previous hospitalisations- n.i., age at onset- n.i., severity of } \\
\text { illness- n.i., baseline antipsychotic dose- } 60 \mathrm{mg} \text { haloperidol decanoate per month }(-3 \text {. } \\
5 \mathrm{mg} / \text { day haloperidol) }\end{array}$ \\
\hline Interventions & $\begin{array}{l}\text { 1. Drug: haloperidol decanoate } 60 \mathrm{mg} / 4 \text { weeks. Fixed dose. } \mathrm{N}=20 \\
\text { 2. Placebo: Duration of taper: } 0 \text { days, but all on depot medication before study. } \mathrm{N}=23 \\
\text { Rescue medication: anticholinergics and sedation. }\end{array}$ \\
\hline Outcomes & $\begin{array}{l}\text { Examined: } \\
\text { Relapse: clinical judgement. } \\
\text { Leaving the study early. } \\
\text { Unable to use / Not included: } \\
\text { Mental state: Comprehensive Psychopathological Rating Scale (no mean, no SD / no } \\
\text { prespecified outcome of interest) } \\
\text { Adverse effects: extrapyramidal side-effects, tardive dyskinesia (no mean, no SD / con- } \\
\text { tinuous side-effect results were not among the prespecified outcomes) } \\
\text { Physiological measures: laboratory (prolactin and haloperidol levels, no mean/SD / no } \\
\text { prespecified outcomes of interest) }\end{array}$ \\
\hline Notes & \\
\hline
\end{tabular}

\section{Risk of bias}

\begin{tabular}{l|ll} 
Bias & Authors' judgement & Support for judgement \\
\hline $\begin{array}{l}\text { Random sequence generation (selection } \\
\text { bias) }\end{array}$ & Unclear risk & Random, no further details. \\
\hline $\begin{array}{l}\text { Allocation concealment (selection bias) } \\
\begin{array}{l}\text { Blinding (performance bias and detection } \\
\text { bias) } \\
\text { Subjective outcomes }\end{array}\end{array}$ & Unclear risk & Procedure not described. \\
\hline
\end{tabular}

Blinding (performance bias and detection Low risk bias)

Objective outcomes

Incomplete outcome data (attrition bias) High risk All outcomes
Double, placebo injections, no further details.

A considerable number of participants (42\%) left the study early. The number was clearly higher in the placebo group and the reasons differed. Data were analysed on an 
Eklund 1991 (Continued)

intent-to-treat basis

\begin{tabular}{lll}
\hline Selective reporting (reporting bias) & Low risk & No selective reporting. \\
\hline Other bias & Low risk & No clear other bias. \\
\hline
\end{tabular}

Elie 1975

\begin{tabular}{|c|c|}
\hline Methods & $\begin{array}{l}\text { Randomisation: random number table. } \\
\text { Allocation: all personnel except for the treating psychiatrist remained unaware of the } \\
\text { code until the end of the study. } \\
\text { Blinding: double (patients, scientists, nurses, only the treating psychiatrist knew the } \\
\text { treatment). } \\
\text { Duration: } 12 \text { days. } \\
\text { Design: parallel. } \\
\text { Location: single-centre. } \\
\text { Setting: inpatient. }\end{array}$ \\
\hline Participants & $\begin{array}{l}\text { Diagnosis: chronic schizophrenia (clinical diagnosis). } \\
\text { N=14. } \\
\text { Gender: } 14 \text { women. } \\
\text { Age: n.i.. } \\
\text { History: duration stable- n.i., duration ill- n.i., number of previous hospitalisations- n. } \\
\text { i., age at onset- n.i., severity of illness- n.i., baseline antipsychotic dose- n.i. }\end{array}$ \\
\hline Interventions & $\begin{array}{l}\text { 1. Drug: chlorpromazine - Fixed dose. Allowed dose range n.i.. Mean dose n.i.. } N=7 \\
\text { 2. Placebo: Duration of taper: } 0 \text { days. } N=7 \text {. } \\
\text { Rescue medication: benztropine. }\end{array}$ \\
\hline Outcomes & $\begin{array}{l}\text { Examined: } \\
\text { Relapse: worsening of psychotic symptoms. } \\
\text { Leaving the study early. } \\
\text { Unable to use / Not included: } \\
\text { Behaviour: NOSIE (no data / no prespecified outcome of interest) } \\
\text { Neurophysiological tests (no SDs / no prespecified outcome of interest) }\end{array}$ \\
\hline
\end{tabular}

Notes

Risk of bias

Bias

Random sequence generation (selection Low risk bias)

\section{Support for judgement}

Random number table.

All personnel except for the treating psychiatrist remained unaware of the code until the end of the study 
Elie 1975 (Continued)

\begin{tabular}{|c|c|c|}
\hline $\begin{array}{l}\text { Blinding (performance bias and detection } \\
\text { bias) } \\
\text { Subjective outcomes }\end{array}$ & Unclear risk & $\begin{array}{l}\text { Double (patients, scientists, nurses, only } \\
\text { the treating psychiatrist knew the treat- } \\
\text { ment) }\end{array}$ \\
\hline
\end{tabular}

Blinding (performance bias and detection Low risk

bias)

Objective outcomes

Double (patients, scientists, nurses, only the treating psychiatrist knew the treatment)

Incomplete outcome data (attrition bias) Low risk All outcomes

One participant in the placebo group left the study prematurely which is an acceptable rate

\begin{tabular}{lll}
\hline Selective reporting (reporting bias) & Low risk & No evidence for selective reporting. \\
\hline Other bias & Low risk & No clear other bias. \\
\hline
\end{tabular}

\section{Freeman 1962}

Methods

Randomisation: participants were ranked for morbidity, then matched, then randomised.

Allocation: procedure not described.

Blinding: double, identical capsules, each participant was provided medication in individual container. Staff guessed on which medication the participants were but could not guess adequately.

Duration: 26 weeks.

Design: parallel.

Location: single-centre.

Setting: in hospital.

Participants

Diagnosis: chronic, long term hospitalised male psychotics (clinical diagnosis), 86 schizophrenia, 6 chronic brain syndrome, 2 personality disorders, 2 n.i.

$\mathrm{N}=96$.

Gender: 96 men.

Age: 43.6 years.

History: duration stable- treated with chlorpromazine for at least 2 months, not ready for discharge, not assaultive, duration ill- n.i. but duration of current hospitalisation 12 . 3 years, number of previous hospitalisations NI- , age at onset- n.i., severity of illnessn.i., baseline antipsychotic dose- $224 \mathrm{mg}$ chlorpromazine per day

Interventions

1. Drug: chlorpromazine - Flexible dose. Allowed dose range: n.i.. Mean dose: n.i.. $\mathrm{N}=$ 48

2. Placebo: Duration of taper: 0 days. $\mathrm{N}=48$.

Rescue medication: occasional use of sedatives, antipsychotics were not allowed

Outcomes

Examined:

Relapse: condition worsened to such a point that ordinarily a complete change in treatment would be considered

Leaving early due to inefficacy. 
Freeman 1962 (Continued)

Unable to use / Not included:

Behaviour: Lyon's Behaviour Scale (no SD / no prespecified outcome of interest)

Notes

Risk of bias

\begin{tabular}{|c|c|c|}
\hline Bias & Authors' judgement & Support for judgement \\
\hline $\begin{array}{l}\text { Random sequence generation (selection } \\
\text { bias) }\end{array}$ & Unclear risk & $\begin{array}{l}\text { Participants were ranked for morbidity, } \\
\text { then matched, then randomised }\end{array}$ \\
\hline Allocation concealment (selection bias) & Unclear risk & Procedure not described. \\
\hline $\begin{array}{l}\text { Blinding (performance bias and detection } \\
\text { bias) } \\
\text { Subjective outcomes }\end{array}$ & Low risk & $\begin{array}{l}\text { Double, identical capsules, each partici- } \\
\text { pant was provided medication in individ- } \\
\text { ual container. Staff guessed on which med- } \\
\text { ication the participants were but could not } \\
\text { guess adequately }\end{array}$ \\
\hline
\end{tabular}

Blinding (performance bias and detection Low risk bias)

Double, identical capsules, each participant was provided medication in individual container. Staff guessed on which medication the participants were but could not guess adequately

Incomplete outcome data (attrition bias) Unclear risk All outcomes

It can be that there were participants leaving the study early but this was not clearly reported

\begin{tabular}{lll}
\hline Selective reporting (reporting bias) & Low risk & No evidence for selective reporting. \\
\hline Other bias & High risk & $\begin{array}{l}\text { Blind was broken once a participant re- } \\
\text { lapsed. }\end{array}$ \\
\hline
\end{tabular}

\section{Gallant 1974}

Methods

Randomisation: random, no further details.

Allocation: procedure not described.

Blinding: double, no further details.

Duration: 12 weeks.

Design: parallel.

Location: single-centre.

Setting: inpatient.

Participants

Diagnosis: severely ill, chronically hospitalized people with schizophrenia (clinical diagnosis)

$\mathrm{N}=50$. 


\begin{tabular}{|c|c|}
\hline & $\begin{array}{l}\text { Gender: } 25 \text { men, } 25 \text { women. } \\
\text { Age: medium } 41.5 \text { years. } \\
\text { History: duration stable- } 12 \text { weeks stabilisation phase., but how long the participants } \\
\text { were stable is unclear, duration ill- n.i., number of previous hospitalisations- n.i., but } \\
\text { median duration of current hospitalisation } 15.5 \text { years, age at onset- n.i., severity of illness- } \\
\text { all severely ill (Clinical Global Impression Score=6), baseline antipsychotic dose- } 100 \text { - } \\
160 \text { mg/week penfluridol }\end{array}$ \\
\hline Interventions & $\begin{array}{l}\text { 1. Drug: penfluridol once weekly. Fixed dose. Allowed dose range: } 40-160 \mathrm{mg} / \text { week. } \\
\text { Mean dose: n.i.. } \mathrm{N}=25 \\
\text { 2. Placebo: Duration of taper: } 0 \text { days. } \mathrm{N}=25 \text {. } \\
\text { Rescue medication: antiparkinson medication. }\end{array}$ \\
\hline Outcomes & $\begin{array}{l}\text { Examined: } \\
\text { Relapse: worsening of global state. } \\
\text { Leaving the study early. } \\
\text { Global state: number of participants according to the Clinical Global Impression Scale } \\
\text { Adverse effects: extrapyramidal side-effects. } \\
\text { Unable to use / Not included: } \\
\text { Mental state: Brief Psychiatric Rating Scale (no mean, no SD / no prespecified outcome } \\
\text { of interest) } \\
\text { Behaviour: Nurses' Observation Scale for Inpatient Evaluation (no mean, no SD / no } \\
\text { prespecified outcome of interest) } \\
\text { Physiological measures: laboratory, ECG, photosensitivity tests, ophthalmologic exam- } \\
\text { inations, vital signs (no clear data / no prespecified outcomes of interest) }\end{array}$ \\
\hline Notes & \\
\hline
\end{tabular}

\section{Risk of bias}

\begin{tabular}{l|l|l}
\hline Bias & Authors' judgement & Support for judgement \\
\hline $\begin{array}{l}\text { Random sequence generation (selection } \\
\text { bias) }\end{array}$ & Unclear risk & Random, no further details. \\
\hline $\begin{array}{l}\text { Allocation concealment (selection bias) } \\
\begin{array}{l}\text { Blinding (performance bias and detection } \\
\text { bias) } \\
\text { Subjective outcomes }\end{array}\end{array}$ & Unclear risk & Procedure not described. \\
\hline
\end{tabular}

Blinding (performance bias and detection Low risk

Double, no further details. bias)

Objective outcomes

Incomplete outcome data (attrition bias) High risk All outcomes
It is not entirely clear, whether there were dropouts in addition to 18 participants (7 drug, 11 placebo, 36\%) who left the study early due to relapse. However, the $36 \%$ 
Gallant 1974 (Continued)

drop out rate can be a problem for other outcomes

\begin{tabular}{lll}
\hline Selective reporting (reporting bias) & Low risk & No evidence for selective reporting. \\
\hline Other bias & Low risk & No evidence for other bias. \\
\hline
\end{tabular}

\section{Gardos 1984}

\begin{tabular}{|c|c|}
\hline Methods & $\begin{array}{l}\text { Randomisation: randomised, } 3: 1 \text { ratio. } \\
\text { Allocation: procedure not described. } \\
\text { Blinding: double, 'matching placebos' and sesame oil for fluphenazine decanoate treated } \\
\text { participants. } \\
\text { Duration: } 10 \text { weeks. } \\
\text { Design: parallel. } \\
\text { Location: two centres. } \\
\text { Setting: outpatient. }\end{array}$ \\
\hline Participants & $\begin{array}{l}\text { Diagnosis: chronic psychotic outpatients (DSM-III), schizophrenia }(\mathrm{n}=26) \text {, mental re- } \\
\text { tardation with psychosis }(\mathrm{n}=9) \text {, organic brain syndrome }(\mathrm{n}=1) \\
\mathrm{N}=36 \text {. } \\
\text { Gender: } 17 \text { men, } 19 \text { women. } \\
\text { Age: mean } 45.8 \text { years. } \\
\text { History: duration stable- n.i., but all receiving maintenance neuroleptic therapy, all for } \\
\text { at least } 5 \text { years, duration ill- n.i., but mean duration of neuroleptic treatment } 13.4 \\
\text { years, number of previous hospitalisations- } \mathrm{n} \text {.i., age at onset- n.i., severity of illness- n.i. } \\
\text {, baseline antipsychotic dose- mean } 365 \mathrm{mg} \text { day chlorpromazine equivalents }\end{array}$ \\
\hline
\end{tabular}

Interventions

1. Drug: various antipsychotic drugs. Fixed dose: keeping the dose of the antipsychotic the participant was on at the beginning of the study. Mean dose: $365 \mathrm{mg} /$ day chlorpromazine equivalents. $\mathrm{N}=9$

2. Placebo: Duration of taper: 28 days. $\mathrm{N}=27$.

Rescue medication: n.i..

Outcomes

Examined:

Relapse: major clinical deterioration.

Leaving the study early.

Unable to use / Not included:

Global state: Clinical Global Impression (no data for each group separately/no prespecified outcome of interest)

Mental state: Brief Psychiatric Rating Scale, Profile of Mood Symptoms (no data for each group separately/no prespecified outcome of interest)

Adverse effects: extrapyramidal side-effects (Abnormal Involuntary Movement Scale, Dyskinesia Rating Scale, no data for each group separately / continuous side-effect results were not among the prespecified outcomes), other adverse effects (Treatment Emergent Symptoms Scale, no data for each group separately / continuous side-effect results were not among the prespecified outcomes)

Notes

Maintenance treatment with antipsychotic drugs for schizophrenia (Review)

Copyright @ 2012 The Cochrane Collaboration. Published by John Wiley \& Sons, Ltd. 
Gardos 1984 (Continued)

\section{Risk of bias}

\begin{tabular}{|c|c|c|}
\hline Bias & Authors' judgement & Support for judgement \\
\hline $\begin{array}{l}\text { Random sequence generation (selection } \\
\text { bias) }\end{array}$ & Unclear risk & $\begin{array}{l}\text { Randomised, } 3: 1 \text { ratio (information ob- } \\
\text { tained from author). }\end{array}$ \\
\hline Allocation concealment (selection bias) & Unclear risk & Procedure not described. \\
\hline $\begin{array}{l}\text { Blinding (performance bias and detection } \\
\text { bias) } \\
\text { Subjective outcomes }\end{array}$ & Unclear risk & $\begin{array}{l}\text { Double, 'matching placebos' and sesame oil } \\
\text { for fluphenazine decanoate treated partici- } \\
\text { pants }\end{array}$ \\
\hline $\begin{array}{l}\text { Blinding (performance bias and detection } \\
\text { bias) } \\
\text { Objective outcomes }\end{array}$ & Low risk & $\begin{array}{l}\text { Double, 'matching placebos' and sesame oil } \\
\text { for fluphenazine decanoate treated partici- } \\
\text { pants }\end{array}$ \\
\hline $\begin{array}{l}\text { Incomplete outcome data (attrition bias) } \\
\text { All outcomes }\end{array}$ & Low risk & $\begin{array}{l}\text { The differential dropout rate (placebo } \\
\text { group } 8 / 27,0 / 9 \text { maintenance group, all due } \\
\text { to relapse) can have biased other outcomes } \\
\text { than relapse and leaving the study early. But } \\
\text { data on such other outcomes were not avail- } \\
\text { able anyways }\end{array}$ \\
\hline Selective reporting (reporting bias) & Low risk & No evidence for selective reporting. \\
\hline Other bias & Low risk & No evidence for other bias. \\
\hline
\end{tabular}

\section{Garfield 1966}

Methods
Randomisation: matched in three groups according to age and hospitalisation, then randomised using a table of random numbers.

Allocation: procedure not described.

Blinding: double, no further details.

Duration: 22 weeks (experimental phase).

Design: parallel.

Location: single-centre.

Setting: inpatient.
Participants
Diagnosis: schizophrenia (clinical diagnosis), undifferentiated type $(\mathrm{n}=10)$, hebephrenic $(\mathrm{n}=6)$, catatonic (5), paranoid (5), acute undifferentiated $(\mathrm{n}=1)$

$\mathrm{N}=27$.

Gender: 27 women.

Age: mean 42.4 years.

History: duration stable- on continuous phenothiazine medication at sufficient dose for at least 6 months, then stabilised another 2 months on the ward, total 8 months, duration ill NI- duration of current hospitalisation mean 11.42 years, number of previous hospitalisations- n.i., age at onset- n.i., severity of illness- n.i., baseline antipsychotic 
Garfield 1966 (Continued)

dose- chlorpromazine mean $610 \mathrm{mg} /$ day $(\mathrm{n}=17)$, thioridazine mean $480 \mathrm{mg} /$ day $(\mathrm{n}=5)$, trifluoperazine mean $25 \mathrm{mg} /$ day $(\mathrm{n}=3)$, perphenazine $24 \mathrm{mg} /$ day $(\mathrm{n}=1)$, prochlorperazine $60 \mathrm{mg} /$ day $(\mathrm{n}=1)$

Interventions

Outcomes
1. Drug: remained on previous antipsychotic medication (chlorpromazine, thioridazine, trifluoperazine, perphenazine, prochlorperazine). Fixed/flexible dose: not clear, but probably fixed. Allowed dose range: n.i.. Mean dose: n.i., because it is unclear which patients were allocated to which group. $\mathrm{N}=9$

2. Placebo: Duration of taper: 7 days. $\mathrm{N}=9^{* *}$.

Rescue medication: tranquilizer (=benzodiazepine).

Examined:

Relapse: worsening by three points on the factor scores of the IMPS or withdrawn due to being worse

Leaving the study early.

Global state: improvement by three points on the factor scores of the IMPS or withdrawn due to being ready for discharge

Unable to use / Not included:

Mental state: Inpatient Multidimensional Psychiatric Scale (no data / no prespecified outcome of interest)

Behaviour: Psychotic Reaction Profile (no data / no prespecified outcome of interest)

Notes

** a second placebo group that was referred to a specialised ward was not used in our calculations $(n=9)$

\section{Risk of bias}

\begin{tabular}{l|l|l}
\hline Bias & Authors' judgement & Support for judgement \\
\hline $\begin{array}{l}\text { Random sequence generation (selection } \\
\text { bias) }\end{array}$ & Low risk & $\begin{array}{l}\text { Matched in three groups according to age } \\
\text { and hospitalisation, then randomised using } \\
\text { a table of random numbers }\end{array}$ \\
\hline $\begin{array}{l}\text { Allocation concealment (selection bias) } \\
\text { Blinding (performance bias and detection } \\
\text { bias) } \\
\text { Subjective outcomes }\end{array}$ & Unclear risk & Procedure not described. \\
\hline $\begin{array}{l}\text { Blinding (performance bias and detection } \\
\text { bias) } \\
\text { Objective outcomes }\end{array}$ & Low risk & Double, no further details. \\
\hline $\begin{array}{l}\text { Incomplete outcome data (attrition bias) } \\
\text { All outcomes }\end{array}$ & High risk & Double, no further details. \\
\hline
\end{tabular}




\section{Garfield 1966 (Continued)}

\begin{tabular}{l|l|l}
\hline Selective reporting (reporting bias) & Low risk & $\begin{array}{l}\text { Only two factors of the IMPS were pre- } \\
\text { sented, but this was no outcome of interest }\end{array}$ \\
\hline Other bias & Low risk & No clear other bias. \\
\hline
\end{tabular}

\section{Gitlin 1988}

\begin{tabular}{|c|c|}
\hline Methods & $\begin{array}{l}\text { Randomisation: random, no further details. } \\
\text { Allocation: procedure not described. } \\
\text { Blinding: double, no further details. } \\
\text { Duration: } 24 \text { weeks (but we used only the first } 12 \text { weeks of this cross-over study). } \\
\text { Design: cross-over. } \\
\text { Location: single-centre. } \\
\text { Setting: inpatient. }\end{array}$ \\
\hline Participants & $\begin{array}{l}\text { Diagnosis: schizophrenia }(\mathrm{n}=10) \text {, schizoaffective disorder }(\mathrm{n}=2) \text { according to Research } \\
\text { Diagnostic Criteria, first episode no more than } 2 \text { years ago } \\
\mathrm{N}=12 \text {. } \\
\text { Gender: } 8 \text { men, } 4 \text { women. } \\
\text { Age: mean } 25 \text { years. } \\
\text { History: duration stable- all stabilised on } 12.5 \mathrm{mg} / \mathrm{two} \text { weeks fluphenazine depot for one } \\
\text { year, duration ill- }<3 \text { years, number of previous hospitalisations- n.i., age at onset- } \mathrm{n} . \mathrm{i} \text {, } \\
\text { severity of illness- n.i., baseline antipsychotic dose- } 12.5 \mathrm{mg} / \mathrm{two} \text { weeks fluphenazine i. } \\
\mathrm{m} \text {. }\end{array}$ \\
\hline Interventions & $\begin{array}{l}\text { 1. Drug: fluphenazine i.m. Fixed dose } 12.5 \mathrm{mg} / \text { two weeks fluphenazine i.m.. Mean dose: } \\
\text { 12.5mg/two weeks fluphenazine i.m.. } \mathrm{N}=\mathrm{n} . \mathrm{i} \text {. } \\
\text { 2. Placebo: Duration of taper } 0 \text { days, but depot study. } \mathrm{N}=\mathrm{n} . \mathrm{i} \text {. } \\
\text { Rescue medication: n.i.. }\end{array}$ \\
\hline Outcomes & $\begin{array}{l}\text { Unable to use / Not included: } \\
\text { Relapse: no data for first cross-over phase. } \\
\text { Prolactin levels (no data for first cross-over phase / no prespecified outcome of interest) }\end{array}$ \\
\hline Notes & $\begin{array}{l}\text { Depot study, at six weeks the full plasma level could still be measured, even at the end } \\
\text { of } 12 \text { weeks } 33 \% \text { still had substantial fluphenazine plasma levels. }\end{array}$ \\
\hline
\end{tabular}

\section{Risk of bias}

\begin{tabular}{l|ll}
\hline Bias & Authors' judgement & Support for judgement \\
\hline $\begin{array}{l}\text { Random sequence generation (selection } \\
\text { bias) }\end{array}$ & Unclear risk & Random, no further details. \\
\hline Allocation concealment (selection bias) & Unclear risk & Procedure not described.
\end{tabular}




\section{Gitlin 1988 (Continued)}

\begin{tabular}{|c|c|c|}
\hline $\begin{array}{l}\text { Blinding (performance bias and detection } \\
\text { bias) } \\
\text { Subjective outcomes }\end{array}$ & Unclear risk & Double, no further details. \\
\hline $\begin{array}{l}\text { Blinding (performance bias and detection } \\
\text { bias) } \\
\text { Objective outcomes }\end{array}$ & Low risk & Double, no further details. \\
\hline $\begin{array}{l}\text { Incomplete outcome data (attrition bias) } \\
\text { All outcomes }\end{array}$ & Unclear risk & Unclear, because not indicated. \\
\hline Selective reporting (reporting bias) & High risk & $\begin{array}{l}\text { Data not presented for both groups sepa- } \\
\text { rately. }\end{array}$ \\
\hline Other bias & Unclear risk & $\begin{array}{l}\text { Unclear - baseline imbalance can not be } \\
\text { addressed. }\end{array}$ \\
\hline
\end{tabular}

\section{Goldberg 1981}

Methods
Randomisation: randomly assigned.

Allocation: procedure not described.

Blinding: double, placebo injection.

Duration: 6 weeks.

Design: parallel.

Location: single-center.

Setting: outpatient.

\section{Participants}

Diagnosis: chronic schizophrenic outpatients (DSM-III).

\section{$\mathrm{N}=31$.}

Gender: n.i..

Age: 37 years.

History: duration stable- 2 years on fluphenazine decanoate 3 weekly, duration ill- n.i., number of previous hospitalisations- n.i., age at onset- 24 years, severity of illness- mean GAS (Global Assessment Scale Endicott 1976by Spitzer \& Endicott 1976), baseline antipsychotic dose- $39.3 \mathrm{mg} / 3$ weekly fluphenazine decanoate

Interventions

1. Drug: fluphenazine decanoate- Fixed doses. Allowed dose range: n.i. - same dose as before. Mean dose: n.i.. $\mathrm{N}=14$.

2. Placebo: Duration of taper: 0 days, but all on depot. $\mathrm{N}=17$.

Rescue medication: n.i..

\section{Outcomes}

\section{Examined:}

Relapse: clinical judgement.

Leaving the study early.

Adverse effects: tardive dyskinesia (AIMS).

Unable to use / Not included:

Social Adjustment Scale.

Depression: SADS (no mean, no SD / no prespecified outcome of interest) 
Goldberg 1981 (Continued)

Functioning: GAS (no mean, no SD / no prespecified outcome of interest)

Notes

Risk of bias

\begin{tabular}{|c|c|c|}
\hline Bias & Authors' judgement & Support for judgement \\
\hline $\begin{array}{l}\text { Random sequence generation (selection } \\
\text { bias) }\end{array}$ & Unclear risk & Random, no further deatils. \\
\hline Allocation concealment (selection bias) & Unclear risk & Procedure not described. \\
\hline $\begin{array}{l}\text { Blinding (performance bias and detection } \\
\text { bias) } \\
\text { Subjective outcomes }\end{array}$ & Unclear risk & Double, placebo injection. \\
\hline $\begin{array}{l}\text { Blinding (performance bias and detection } \\
\text { bias) } \\
\text { Objective outcomes }\end{array}$ & Low risk & Double, placebo injection. \\
\hline $\begin{array}{l}\text { Incomplete outcome data (attrition bias) } \\
\text { All outcomes }\end{array}$ & Low risk & $\begin{array}{l}3 \text { out of } 30 \text { participants }(10 \%) \text { left the study } \\
\text { early which is an acceptable rate, irrespec- } \\
\text { tive of the statistical analysis (completer } \\
\text { analysis) }\end{array}$ \\
\hline Selective reporting (reporting bias) & Low risk & No evidence for selective reporting. \\
\hline Other bias & Low risk & No evidence for other bias. \\
\hline
\end{tabular}

Gross 1960

$\begin{array}{ll}\text { Methods } & \text { Randomisation: random, no further details. } \\ \text { Allocation: procedure not described. } \\ \text { Blinding: double, unidentifiable capsules. } \\ \text { Duration: } 6 \text { months. } \\ \text { Design: parallel. } \\ \text { Location: single-centre. } \\ \text { Setting: outpatient. }\end{array}$




\section{Gross 1960 (Continued)}

\begin{tabular}{ll}
\hline Interventions & $\begin{array}{l}\text { 1. Drug: continuation of antipsychotic taken before the study - Fixed/flexible dose: } \\
\text { unclear. Allowed dose range: unclear. Mean dose: } n . i . . ~ N=46\end{array}$ \\
& $\begin{array}{l}\text { 2. Placebo: Duration of taper: "4 weeks to five months, usually } 2 \text { months". N=98 } \\
\text { Rescue medication: n.i.. }\end{array}$ \\
\hline Outcomes & $\begin{array}{l}\text { Examined: } \\
\text { Relapse: clinical diagnosis. } \\
\text { Unable to use / Not included: } \\
\text { Social adjustment: (not reported for the randomised participants / no predefined outcome } \\
\text { of interest) } \\
\text { Rehospitalisation (unclear numbers). }\end{array}$ \\
\hline Notes & \\
\hline
\end{tabular}

\section{Risk of bias}

\begin{tabular}{|c|c|c|}
\hline Bias & Authors' judgement & Support for judgement \\
\hline $\begin{array}{l}\text { Random sequence generation (selection } \\
\text { bias) }\end{array}$ & Unclear risk & Random, no further details. \\
\hline Allocation concealment (selection bias) & Unclear risk & Procedure not described. \\
\hline $\begin{array}{l}\text { Blinding (performance bias and detection } \\
\text { bias) } \\
\text { Subjective outcomes }\end{array}$ & Unclear risk & Double, unidentifiable capsules. \\
\hline $\begin{array}{l}\text { Blinding (performance bias and detection } \\
\text { bias) } \\
\text { Objective outcomes }\end{array}$ & Low risk & Double, unidentifiable capsules. \\
\hline $\begin{array}{l}\text { Incomplete outcome data (attrition bias) } \\
\text { All outcomes }\end{array}$ & Unclear risk & $\begin{array}{l}\text { Whether participants left the study early is } \\
\text { unclear. }\end{array}$ \\
\hline Selective reporting (reporting bias) & Low risk & No evidence for selective reporting. \\
\hline Other bias & High risk & In case of relapse the blind was broken. \\
\hline
\end{tabular}


Methods

Randomisation: randomised, no further details.

Allocation: procedure not described.

Blinding: double, identical capsules.

Duration: 16 weeks.

Design: parallel.

Location: single-centre.

Setting: inpatient.

Participants

Diagnosis: chronic schizophrenia (clinical diagnosis) with positive or negative symptoms, responsive to treatment with antipsychotic drugs, all so ill that they required continuous treatment with antipsychotic medication for at least 3 months

$\mathrm{N}=61$.

Gender: 37 men, 24 women.

Age: mean 45.7 years.

History: duration stable- all participants had received a neuroleptic for at least 4 weeks, then stabilized on a fixed dose for 2 weeks, the last 2 weeks of which they were stabilized on a fixed dose, duration ill- at least 2 years, number of previous hospitalisations- n.i. , age at onset- n.i. , severity of illness- n.i., baseline antipsychotic dose- chlorpromazine maximum dose $500 \mathrm{mg} /$ day, thioridazine $500 \mathrm{mg} /$ day, fluphenazine $30 \mathrm{mg} /$ day, trifluoperazine $30 \mathrm{mg} /$ day, other equipotent antipsychotics or combinations not exceeding the maximum doses

Interventions

1. Drug: pimozide - Flexible dose. Allowed dose range: $2-12 \mathrm{mg} /$ day. Mean dose: 6.3 $\mathrm{mg} /$ day. $\mathrm{N}=21$

2. Drug: trifluoperazine. Flexible dose. Allowed dose range: 5-30 mg/day. Mean dose: $17.5 \mathrm{mg} /$ day. $\mathrm{N}=20$

3. Placebo: Duration of taper: 21 days. $\mathrm{N}=20$.

Rescue medication: chloralhydrate, antiparkinson medication.

Outcomes

Examined:

Relapse: at least minimally worse on CGI.

Leaving the study early.

Unable to use / Not included:

Mental state: BPRS (no predefined outcome of interest).

Global state: CGI (no predefined outcome of interest).

Social activity: Family Rating Form (no SD / no predefined outcome of interest)

Social adjustment: Harbor View House Residents Rating Report (no SD / no predefined outcome of interest)

Adverse effects: open interview (no data).

Physiological measures: vital signs, laboratory (both no data / no predefined outcome of interest)

Notes

Risk of bias

Bias

Authors' judgement

Support for judgement 


\section{Gross 1974 (Continued)}

\begin{tabular}{l|l|l}
\hline $\begin{array}{l}\text { Random sequence generation (selection } \\
\text { bias) }\end{array}$ & Unclear risk & Randomised, no further details. \\
\hline Allocation concealment (selection bias) & Unclear risk & Procedure not described. \\
\hline $\begin{array}{l}\text { Blinding (performance bias and detection } \\
\text { bias) } \\
\begin{array}{l}\text { Subjective outcomes } \\
\hline\end{array}\end{array}$ & Unclear risk & Double, identical capsules. \\
\hline
\end{tabular}

Blinding (performance bias and detection Low risk

Double, identical capsules.

bias)

Objective outcomes

\begin{tabular}{l|l|l}
$\begin{array}{l}\text { Incomplete outcome data (attrition bias) } \\
\text { All outcomes }\end{array}$ & High risk & $\begin{array}{l}\text { The overall number of participants leav- } \\
\text { ing the study early (41\%) was considerable, } \\
\text { with a higher drop-out rate in the placebo } \\
\text { group }\end{array}$ \\
\hline $\begin{array}{l}\text { Selective reporting (reporting bias) } \\
\text { Other bias }\end{array}$ & Low risk & No evidence for selective reporting. \\
\hline
\end{tabular}

Hershon 1972

Methods

Randomisation: randomised, no further details.

Allocation: capsules dispensed by the hospital pharmacist who was the only person who knew what the capsules were and to whom they were given.

Blinding: double, placebo capsules, no further details.

Duration: range 13-22 weeks, mean 16 weeks.

Design: parallel.

Location: 2 centres.

Setting: inpatient.

Participants

Diagnosis: chronic schizophrenia (clinical diagnosis), $>70 \%$ of them with extrapyramidal side effects after long treatment with phenothiazines

$\mathrm{N}=63$.

Gender: 32 men, 31 women.

Age: mean 57 years.

History: duration stable- n.i., duration ill- n.i., but currently hospitalised for at least 4 years and treated with phenothiazines for a mean duration of 9.4 years, number of previous hospitalisations- n.i., age at onset- n.i., severity of illness- n.i., baseline antipsychotic dose- mean $17 \mathrm{mg} /$ day trifluoperazine ( $86 \%$ of the participants)

Interventions

1. Drug: trifluoperazine - Fixed dose (maintaining the initial dose, necessity of dose increase was considered to be a relapse). Mean dose: $17 \mathrm{mg} /$ day. $\mathrm{N}=31$

2. Placebo: Duration of taper: 0 days. $\mathrm{N}=32$.

Rescue medication: n.i.. 
Hershon 1972 (Continued)

\begin{tabular}{ll}
\hline Outcomes & Examined: \\
& Relapse: deterioriation of participant's condition to such a degree that additional an- \\
& tipsychotic medication was necessary \\
& Unable to use / Not included: \\
& Adverse effects: movement disorders (no randomised data). \\
\hline Notes & \\
\hline
\end{tabular}

Risk of bias

\begin{tabular}{|c|c|c|}
\hline Bias & Authors' judgement & Support for judgement \\
\hline $\begin{array}{l}\text { Random sequence generation (selection } \\
\text { bias) }\end{array}$ & Unclear risk & Randomised, no further details. \\
\hline Allocation concealment (selection bias) & Low risk & $\begin{array}{l}\text { Capsules dispensed by the hospital phar- } \\
\text { macist who was the only person who knew } \\
\text { what the capsules were and to whom they } \\
\text { were given }\end{array}$ \\
\hline $\begin{array}{l}\text { Blinding (performance bias and detection } \\
\text { bias) } \\
\text { Subjective outcomes }\end{array}$ & Unclear risk & $\begin{array}{l}\text { Double, placebo capsules, no further de- } \\
\text { tails. }\end{array}$ \\
\hline $\begin{array}{l}\text { Blinding (performance bias and detection } \\
\text { bias) } \\
\text { Objective outcomes }\end{array}$ & Low risk & $\begin{array}{l}\text { Double, placebo capsules, no further de- } \\
\text { tails. }\end{array}$ \\
\hline $\begin{array}{l}\text { Incomplete outcome data (attrition bias) } \\
\text { All outcomes }\end{array}$ & Low risk & $\begin{array}{l}16 \% \text { left the study early, all but one due } \\
\text { to relapse. This appears acceptable. relapse } \\
\text { and death were the only outcomes }\end{array}$ \\
\hline Selective reporting (reporting bias) & Low risk & No evidence for selective reporting. \\
\hline Other bias & High risk & $\begin{array}{l}\text { Participants with a relapse were probably } \\
\text { removed from the study and the blind bro- } \\
\text { ken. Study was probably terminated early }\end{array}$ \\
\hline
\end{tabular}


Methods

Participants
Randomisation: randomly allocated by research assistant.

Allocation: a part from the research assistant no one knew who was on drug or placebo until the data were analysed.

Blinding: double, sesame oil injections, unmarked ampoules. Blinding was tested at the end of the trial and it worked.

Duration: 9 months.

Design: parallel.

Location: two centres.

Setting: outpatient.

Diagnosis: chronic schizophrenia (Present State Examination), chronicity defined by at least 2 admissions or 1 admission lasting longer than 6 months, 71 schizophrenic psychosis with delusions or auditory hallucinations, six non affective delusional psychoses, three catatonic schizophrenia

$\mathrm{N}=81$.

Gender: 52 men, 29 women.

Age: mean 43.4 years.

History: duration stable- at least 8 weeks, duration ill- n.i., number of previous hospitalisations- 24 had $\leq 3$ and 57 had $\geq 4$ ), age at onset- n.i., severity of illness- n.i., baseline antipsychotic dose- $86 \%$ fluphenazine depot $25 \mathrm{mg} / \mathrm{month}$, no additional antipsychotic medication

Interventions

1. Drug - Fixed/flexible dose: Allowed dose range: $25 \mathrm{mg} / \mathrm{month}$ - no upper limit. Mean dose: $26.4 \mathrm{mg} / \mathrm{month} . \mathrm{N}=41$

2. Placebo: Duration of taper: n.i.. $\mathrm{N}=40$.

Rescue medication: antidepressants, antiparkinson medication

Outcomes

Examined:

Relapse: deterioration of condition to a degree that participant had to be taken out of the trial to ensure that active medication was prescribed, prescription of oral phenothiazines Adverse effects: use of antiparkinson medication.

Unable to use / Not included:

Mental state: Present State Examination (no data / no predefined outcome of interest)

Social functioning: Social Performance Schedule, Events Schedule of Bron and Birley

(both no predefined outcome of interest)

Notes

Risk of bias

Bias

Random sequence generation (selection Unclear risk bias)

Allocation concealment (selection bias)

Low risk
Support for judgement

Randomly allocated by research assistant.

Apart from the research assistant no one knew who was on drug or placebo until the data were analysed 
Hirsch 1973 (Continued)

\begin{tabular}{|c|c|c|}
\hline $\begin{array}{l}\text { Blinding (performance bias and detection } \\
\text { bias) } \\
\text { Subjective outcomes }\end{array}$ & Low risk & $\begin{array}{l}\text { Double, sesame oil injections, unmarked } \\
\text { ampoules. Blinding was tested at the end } \\
\text { of the trial and it worked }\end{array}$ \\
\hline
\end{tabular}

Blinding (performance bias and detection Low risk

bias)

Objective outcomes

Double, sesame oil injections, unmarked ampoules. Blinding was tested at the end of the trial and it worked

Incomplete outcome data (attrition bias) Unclear risk All outcomes

Overall, $43 \%$ of the participants left the study early (no complete ITT for some outcomes)

\begin{tabular}{lll}
\hline Selective reporting (reporting bias) & Low risk & No evidence for selected reporting. \\
\hline Other bias & Low risk & No evidence of other bias \\
\hline
\end{tabular}

\section{Hirsch 1996}

Methods

Randomisation: random, no further details.

Allocation: procedure not described.

Blinding: double, no further details.

Duration: one year.

Design: parallel.

Location: single-centre.

Setting: outpatient.

Participants

Diagnosis: schizophrenia (DSM-III-R).

$\mathrm{N}=21$.

Gender: data on randomised subsample are not available.

Age: data on randomised subsample are not available.

History: duration stable- for at least 6 months and all on maintenance treatment, duration ill- n.i., number of previous hospitalisations- n.i., age at onset- n.i., severity of illness- $n$.

i., baseline antipsychotic dose- n.i.

Interventions

1. Drug: fluphenazine depot. Fixed dose of $25 \mathrm{mg} / 2$ weeks. $\mathrm{N}=11$

2. Placebo: Duration of taper: 0 days. $\mathrm{N}=10$.

Rescue medication:

Haloperidol was given to participants who developed prodromal symptoms and was continued for 2 weeks unless relapse occurred

Outcomes

Unable to use / Not included:

No data could be used because they have not been presented for the randomised subset

Notes

Risk of bias 
Hirsch 1996 (Continued)

\begin{tabular}{|c|c|c|}
\hline Bias & Authors' judgement & Support for judgement \\
\hline $\begin{array}{l}\text { Random sequence generation (selection } \\
\text { bias) }\end{array}$ & Unclear risk & Random, no further details. \\
\hline Allocation concealment (selection bias) & Unclear risk & Procedure not described. \\
\hline $\begin{array}{l}\text { Blinding (performance bias and detection } \\
\text { bias) } \\
\text { Subjective outcomes }\end{array}$ & Unclear risk & Double, no further details. \\
\hline $\begin{array}{l}\text { Blinding (performance bias and detection } \\
\text { bias) } \\
\text { Objective outcomes }\end{array}$ & Low risk & Double, no further details. \\
\hline $\begin{array}{l}\text { Incomplete outcome data (attrition bias) } \\
\text { All outcomes }\end{array}$ & Unclear risk & Uncear, whether there were any drop-outs. \\
\hline Selective reporting (reporting bias) & High risk & $\begin{array}{l}\text { No useable data because data of the ran- } \\
\text { domised subsample have not been pre- } \\
\text { sented }\end{array}$ \\
\hline Other bias & Low risk & No clear evidence for other bias. \\
\hline
\end{tabular}

\section{Hogarty 1973}

Methods

Randomisation: randomly assigned, no further details.

Allocation: procedure not described.

Blinding: double, identical capsules, no further details.

Duration: 2-3 years (data available up to 2 years).

Design: parallel.

Location: three centres.

Setting: outpatient.

Participants

Diagnosis: schizophrenia (DSM-II, undifferentiated type $46.3 \%$, paranoid 39\%, acute differentiated $8 \%$, schizoid affective $2.7 \%$, other $3.8 \%$ ), currently hospitalised for less than 2 years

$\mathrm{N}=374$.

Gender: 159 men, 215 women.

Age: mean 34.4 years.

History: duration stable- 2 months transition phase, those who relapsed during this time were replaced, duration ill- n.i., number of previous hospitalisations- mean 2.6, age at onset- n.i., severity of illness- n.i., baseline antipsychotic dose- mean $265 \mathrm{mg}$ chlorpromazine per day

Interventions

Previous medication was gradually shifted to chlorpromazine for two months.

1. Drug: chlorpromazine - Flexible dose. Allowed dose range: $100 \mathrm{mg} / \mathrm{day}$. Mean dose:

- 260mg/day. $\mathrm{N}=192$ 
2. Placebo: Duration of taper: 0 days. $\mathrm{N}=182$.

Rescue medication: not indicated, but probably not allowed.

$\begin{array}{ll}\text { Outcomes } & \text { Examined: } \\ & \text { Relapse: clinical deterioration of such magnitude that hospitalisation appeared imminent } \\ & \text { Unable to use / Not included: } \\ \text { Leaving the study early (numbers not specified for each group separately) } & \text { Mental state: Brief Psychiatric Rating Scale, Inpatient Multidimensional Psychiatric } \\ \text { Scale, Springfield Symptom Index, Hopkin's Symptom Distress Check List (all no SDs } \\ \text { and data only given for subgroups / no predefined outcome of interest) } \\ \text { Social behaviour and adjustment: Katz Adjustment Scale, Major Role Adjustment In- } \\ \text { ventory (both no SDs and data presented only for subgroups / no predefined outcome } \\ \text { of interest) }\end{array}$

Notes

Half of the participants randomly received major role therapy in addition to chlorpromazine or placebo. For the purpose of this review the four resulting groups were pooled as described above

\section{Risk of bias}

\begin{tabular}{|c|c|c|}
\hline Bias & Authors' judgement & Support for judgement \\
\hline $\begin{array}{l}\text { Random sequence generation (selection } \\
\text { bias) }\end{array}$ & Unclear risk & Randomly assigned, no further details. \\
\hline Allocation concealment (selection bias) & Unclear risk & Procedure not described. \\
\hline $\begin{array}{l}\text { Blinding (performance bias and detection } \\
\text { bias) } \\
\text { Subjective outcomes }\end{array}$ & Unclear risk & $\begin{array}{l}\text { Double, identical capsules, no further de- } \\
\text { tails. }\end{array}$ \\
\hline $\begin{array}{l}\text { Blinding (performance bias and detection } \\
\text { bias) } \\
\text { Objective outcomes }\end{array}$ & Low risk & $\begin{array}{l}\text { Double, identical capsules, no further de- } \\
\text { tails. }\end{array}$ \\
\hline $\begin{array}{l}\text { Incomplete outcome data (attrition bias) } \\
\text { All outcomes }\end{array}$ & Low risk & $\begin{array}{l}\text { Relatively few participants left the study } \\
\text { early due to reasons other than relapse } \\
\text { which was the only outcome }(n=31) \text {. Al- } \\
\text { though it is unclear in which group they } \\
\text { occurred the small percentage does not rep- } \\
\text { resent an important risk of bias }\end{array}$ \\
\hline Selective reporting (reporting bias) & Low risk & No clear evidence for selective reporting. \\
\hline Other bias & Low risk & No clear other bias. \\
\hline
\end{tabular}




Rethods
Randomisation: patients were randomised in a 1 to 1 ratio (via a sponsor prepared,
Allocation: interactive voice system.
Blinding: double, no further details.
Duration: variable (the trial was terminated early after an interim analysis).
Design: parallel.
Location: multi-centre.
Setting: n.i..

\begin{tabular}{|c|c|}
\hline Participants & $\begin{array}{l}\text { Diagnosis: schizophrenia (DSM-IV-TR). } \\
\text { N=410. } \\
\text { Gender: } 220 \text { men, } 88 \text { women. } \\
\text { Age: mean } 39 \text { years. } \\
\text { History: duration stable- } 12 \text { weeks prospectively stable on fixed dose paliperidone, du- } \\
\text { ration ill- mean } 12 \text { years, number of previous hospitalisations- median } 2.6 \text {, age at onset- } \\
\text { mean } 27.3 \text { years, severity of illness- PANSS total mean } 53 \text { points, baseline antipsychotic } \\
\text { dose- n.i. }\end{array}$ \\
\hline
\end{tabular}

Interventions

1. Drug: paliperidone palmitate depot - Fixed dose: originally 25, 50 or $100 \mathrm{mg} / 4$ weeks; this dose was maintained. Mean dose: n.i.. N=206

2. Placebo: Duration of taper: 0 days. $\mathrm{N}=204$.

Rescue medication: n.i..

\begin{tabular}{|c|c|}
\hline Outcomes & $\begin{array}{l}\text { Examined: } \\
\text { Relapse: psychiatric rehospitalisation, deliberate self-injury or violent behaviour, suicidal } \\
\text { or homicidal ideation, certain predefined PANSS score } \\
\text { Leaving the study early. } \\
\text { Rehospitalisation. } \\
\text { Death natural causes and suicide. } \\
\text { Unable to use / Not included: } \\
\text { Mental state: Positive and Negative Syndrome Scale (no predefined outcome of interest) } \\
\text { Adverse effects: open interviews (only a few adverse events were indicated and these were } \\
\text { not of interest for the review) } \\
\text { Prolactin levels (no predefined outcome of interest). }\end{array}$ \\
\hline Notes & The study was stopped early after a significant interim analysis \\
\hline
\end{tabular}

Risk of bias

\begin{tabular}{lll}
\hline Bias & Authors' judgement & Support for judgement \\
\hline $\begin{array}{l}\text { Random sequence generation (selection } \\
\text { bias) }\end{array}$ & Low risk & $\begin{array}{l}\text { Patients were randomised in a } 1 \text { to } 1 \text { ratio } \\
\text { (via a sponsor prepared, computer gener- } \\
\text { ated randomisation scheme, assigned by an } \\
\text { interactive voice system) }\end{array}$
\end{tabular}




\section{Hough 2010 (Continued)}

\begin{tabular}{l|l|l|l|l}
\hline $\begin{array}{l}\text { Blinding (performance bias and detection } \\
\text { bias) } \\
\text { Subjective outcomes }\end{array}$ & Unclear risk & Double, no further details. \\
\hline
\end{tabular}

Blinding (performance bias and detection Low risk

Double, no further details.

bias)

Objective outcomes

Incomplete outcome data (attrition bias) High risk

All outcomes

Overall high drop-out rate (45\%). Clearly more participants in the placebo group (95) than in the drug group (31) left the study early due to relapse. This imbalance may have biased the results of other outcomes such as adverse events. Kaplan-Meier survival curve analysis was used for the primary outcome relapse

Selective reporting (reporting bias) Low risk

Those adverse events that occurred in at least $2 \%$ of the participants and severe adverse events were presented. We feel that's acceptable

Other bias High risk

Study was stopped early after an interim analysis.

Kane 1979

Methods

Randomisation: matched then each pair randomised, no further details.

Allocation: procedure not described.

Blinding: double, no further details.

Duration: 6 months.

Design: parallel.

Location: single-centre.

Setting: outpatient.

Participants

Diagnosis: probable or definite schizophrenia, any subtype (Research Diagnostic Criteria), in remission for at least 4 weeks or at stable clinical plateau despite vigorous chemotherapy

$\mathrm{N}=16$.

Gender: 14 men, 2 women.

Age: 26.7 years.

History: duration stable- mean 22.9 months in remission (minimum 6 months), duration ill- mean 6.1 years, number of previous hospitalisations- n.i., but a mean of 2.4 previous episodes, age at onset- mean 20.6 years, severity of illness- n.i., baseline antipsychotic dose- $3.8 \mathrm{mg}$ fluphenazine biweekly 
Kane 1979 (Continued)

\begin{tabular}{l|l}
\hline Interventions & 1. Drug: fluphenazine decanoate - Flexible dose. Allowed dose range: $1.25-5.0 \mathrm{mg}$ bi- \\
& weekly. Mean dose: $\mathrm{n} . \mathrm{i} . . \mathrm{N}=8$ \\
& 2. Placebo: Duration of taper: 0 days, but previously treated with depot medication. N= \\
& 8 \\
& Rescue medication: minor tranquilisers, additional antipsychotic drugs were not allowed \\
\hline Outcomes & Examined: \\
& $\begin{array}{l}\text { Relapse: increase in or re-emergence of significant symptoms suggesting imminent psy- } \\
\text { chotic relapse } \\
\text { Unable to use / Not included: } \\
\text { Leaving study early (no data). } \\
\text { Adverse effects (no data). }\end{array}$ \\
\hline Notes & \\
\hline
\end{tabular}

Risk of bias

\begin{tabular}{|c|c|c|}
\hline Bias & Authors' judgement & Support for judgement \\
\hline $\begin{array}{l}\text { Random sequence generation (selection } \\
\text { bias) }\end{array}$ & Unclear risk & $\begin{array}{l}\text { Matched, then each pair randomised, no } \\
\text { further details. }\end{array}$ \\
\hline Allocation concealment (selection bias) & Unclear risk & Procedure not described. \\
\hline $\begin{array}{l}\text { Blinding (performance bias and detection } \\
\text { bias) } \\
\text { Subjective outcomes }\end{array}$ & Unclear risk & Double, no further details. \\
\hline $\begin{array}{l}\text { Blinding (performance bias and detection } \\
\text { bias) } \\
\text { Objective outcomes }\end{array}$ & Low risk & Double, no further details. \\
\hline $\begin{array}{l}\text { Incomplete outcome data (attrition bias) } \\
\text { All outcomes }\end{array}$ & Low risk & $\begin{array}{l}\text { Two participant in the drug group ( } 1 \text { re- } \\
\text { lapse, } 1 \text { unclear) left the study early, and } 7 / 8 \\
\text { participants in the placebo group dropped } \\
\text { out due to relapse. As relapse and dropout } \\
\text { were the only outcomes, this did not lead } \\
\text { to bias }\end{array}$ \\
\hline Selective reporting (reporting bias) & Low risk & No evidence for selective reporting. \\
\hline Other bias & Low risk & No clear evidence for other bias. \\
\hline
\end{tabular}


Methods

Randomisation: random, no further details.

Allocation: procedure not described.

Blinding: double, all participants received both pills and injections (active or placebo)

to maintain double-blind conditions.

Duration: 1 year.

Design: parallel.

Location: single-centre.

Setting: outpatient.

Participants

Diagnosis: first episode schizophrenia (clinical diagnosis), no evidence of drug abuse or important medical illnesses. When diagnoses were reassessed by Research Diagnostic Criteria, 19 had schizophrenia, 3 had unspecific schizophrenic psychoses, 4 had other psychiatric disorders, one mania with schizotypal features and one depression with schizotypal features

$\mathrm{N}=28$.

Gender: 14 men, 14 women.

Age: mean 21.9 years.

History: duration stable- stable remission of at least 4 weeks, mean 16.9 weeks, duration ill- mean 17.6 weeks, number of previous hospitalisations- 0 , age at onset- mean 21.5 years, severity of illness- n.i., baseline antipsychotic dose- n.i.

Interventions

1. Drug: oral fluphenazine - Flexible dose. Allowed dose range: $5-20 \mathrm{mg} /$ day. Mean dose: n.i.. $\mathrm{N}=$ n.i.

2. Drug: depot fluphenazine - Flexible dose. Allowed dose range: $12.5-50 / \mathrm{mg}$ biweekly. Mean dose: n.i.. $\mathrm{N}=$ n.i.

2. Placebo: Duration of taper: 0 days. $\mathrm{N}=17$.

Rescue medication: not indicated.

Outcomes

Examined:

Relapse: a substantial clinical deterioration with a potential for marked social impairment. Patients were considered dropouts only if they showed no signs of clinical deterioration at the time they left the study

Leaving the study early.

Unable to use / Not included:

Social aspects of premorbid personality: Premorbid Asocial Adjustment Scale (data on placebo group only / no predefined outcome of interest)

Notes

The design was changed during the study in that only non-compliant patients were randomised to depot fluphenazine or depot placebo, and the randomisation was changed to 2-1-1 (placebo, oral fluphenazine, depot fluphenazine)

\section{Risk of bias}

\begin{tabular}{l|ll}
\hline Bias & Authors' judgement & Support for judgement \\
\hline $\begin{array}{l}\text { Random sequence generation (selection } \\
\text { bias) }\end{array}$ & Unclear risk & Random, no further details. \\
\hline Allocation concealment (selection bias) & Unclear risk & Procedure not described.
\end{tabular}

Maintenance treatment with antipsychotic drugs for schizophrenia (Review) 
Kane 1982 (Continued)

\begin{tabular}{l|l|l}
$\begin{array}{l}\text { Blinding (performance bias and detection } \\
\text { bias) }\end{array}$ & Unclear risk & $\begin{array}{l}\text { Double, all participants received both pills } \\
\text { and injections (active or placebo) to main- } \\
\text { Subjective outcomes }\end{array}$ \\
\hline
\end{tabular}

Blinding (performance bias and detection Low risk

bias)

Objective outcomes

Double, all participants received both pills and injections (active or placebo) to maintain double-blind conditions

Incomplete outcome data (attrition bias) High risk All outcomes

20 out of 28 participants left the study early, 10 for other reasons than relapse, which was the only outcome apart from leaving the study early. This may present a bias

\begin{tabular}{|c|c|c|}
\hline Selective reporting (reporting bias) & Low risk & No evidence for selective reporting. \\
\hline Other bias & Unclear risk & $\begin{array}{l}\text { The design was changed during the } \\
\text { study in that only non-compliant patients } \\
\text { were randomised to depot fluphenazine } \\
\text { or depot placebo, and the randomisa- } \\
\text { tion was changed to 2-1-1 (placebo, oral } \\
\text { fluphenazine, depot fluphenazine). It is un- } \\
\text { clear whether this biased the results }\end{array}$ \\
\hline
\end{tabular}

Keskiner 1968

Rethods
Allocation: procedure not described.
Blinding: double, placebo treated participants received injections of sesame oil in a similar
amount.
Duration: 12 weeks.
Design: parallel.
Location: single-centre.
Setting: outpatient.

Participants

Diagnosis: chronic schizophrenia (clinical diagnosis), 12 paranoid, 3 hebephrenic, 2 catatonic, 1 simple, 6 chronic undifferentiated, on antipsychotic medication for a mean duration of 2 years

$\mathrm{N}=24$.

Gender: 4 men, 20 women.

Age: mean 36 years.

History: duration stable- minimum six weeks stable on oral fluphenazine, duration illmean 12.4 years, number of previous hospitalisations- n.i., age at onset- mean 23.6 years, severity of illness- n.i., baseline antipsychotic dose- mean $28.5 \mathrm{mg}$ fluphenazine decanoate biweekly 


\section{Keskiner 1968 (Continued)}

\begin{tabular}{l|l}
\hline Interventions & $\begin{array}{l}\text { 1. Drug: fluphenazine decanoate - Flexible doses. Allowed dose range: } 12.5-75 / \mathrm{mg} \text { bi- } \\
\text { weekly. Mean dose: } \mathrm{n} . \mathrm{i} . \mathrm{N}=13\end{array}$ \\
& $\begin{array}{l}\text { 2. Placebo: sesame oil injections. Duration of taper: } 0 \text { days. } \mathrm{N}=11 \\
\text { Rescue medication: antiparkinson medication, additional fluphenazine decanoate - but } \\
\text { this was considered to be a relapse }\end{array}$ \\
\hline Outcomes & $\begin{array}{l}\text { Examined: } \\
\text { Relapse: clinical deterioration requiring additional antipsychotic drug treatment } \\
\text { Leaving study early. } \\
\text { Unable to use / Not included: } \\
\text { Global state: } 7 \text { point scale of severity (no data / no predefined outcome of interest) } \\
\text { Mental state: scale published by the authors (no SD / no predefined outcome of interest) } \\
\text { Adverse effects: scale published by the authors (no numbers) } \\
\text { Physiological measures: ECG, EEG, laboratory (all no data / no predefined outcomes of } \\
\text { interest) }\end{array}$ \\
\hline Notes & \\
\hline
\end{tabular}

\section{Risk of bias}

\begin{tabular}{|c|c|c|}
\hline Bias & Authors' judgement & Support for judgement \\
\hline $\begin{array}{l}\text { Random sequence generation (selection } \\
\text { bias) }\end{array}$ & Unclear risk & Randomly assigned, no further details. \\
\hline Allocation concealment (selection bias) & Unclear risk & Procedure not described. \\
\hline $\begin{array}{l}\text { Blinding (performance bias and detection } \\
\text { bias) } \\
\text { Subjective outcomes }\end{array}$ & Unclear risk & $\begin{array}{l}\text { Double, placebo treated participants re- } \\
\text { ceived injections of sesame oil in a similar } \\
\text { amount }\end{array}$ \\
\hline $\begin{array}{l}\text { Blinding (performance bias and detection } \\
\text { bias) } \\
\text { Objective outcomes }\end{array}$ & Low risk & $\begin{array}{l}\text { Double, placebo treated participants re- } \\
\text { ceived injections of sesame oil in a similar } \\
\text { amount }\end{array}$ \\
\hline $\begin{array}{l}\text { Incomplete outcome data (attrition bias) } \\
\text { All outcomes }\end{array}$ & Low risk & No participant left the study early. \\
\hline Selective reporting (reporting bias) & Low risk & No evidence for selective reporting. \\
\hline Other bias & High risk & $\begin{array}{l}\text { In case of deterioration the participants re- } \\
\text { ceived additional antipsychotic drugs. This } \\
\text { is a problem for the analysis of side-effects }\end{array}$ \\
\hline
\end{tabular}


Location: multi-centre.

Setting: outpatient, sponsored.

Participants

Interventions
Diagnosis: schizophrenia (DSM-IV), 80\% paranoid subtype, $14 \%$ undifferentiated subtype, initially with acute exacerbation, then 8 weeks run in and 6 weeks stabilisation phase

$\mathrm{N}=207$.

Gender: 121 men, 86 women.

Age: 38.3 years.

History: duration stable- at least 8 weeks, duration ill- mean 12.1 years, number of previous hospitalisations- median 3, age at onset- 26.2 years, severity of illness- mean PANSS total score 52.2, mean CGI severity 2.6, baseline antipsychotic dose- $10.8 \mathrm{mg} /$ day paliperidone

1. Drug: paliperidone- Flexible doses. Allowed dose range: 3 - 15mg/day Mean dose: 10. $8 \mathrm{mg} /$ day. $\mathrm{N}=105$

2. Placebo: Duration of taper: 0 days. $\mathrm{N}=102$.

Rescue medication: benzodiazepines, antiparkinson medication, propanolol, antidepressants when the dose was stable for at least 3 months before the study

\section{Outcomes}

Maintenance treatment with antipsychotic drugs for schizophrenia (Review)

Examined:

Relapse: (a) psychiatric hospitalisation (involuntary or voluntary admission); b) increase in Positive and Negative Syndrome Scale (PANSS) total score by $25 \%$ for 2 consecutive days for patients who scored more than 40 at randomisation or a 10-point increase for patients who scored 40 or below at randomisation; c) increase in the Clinical Global Impression-Severity (CGI-S) score to at least 4, for patients who scored 3 or below at randomisation, or to at least 5 , for patients whose CGI-S scores were 4 at randomisation, for 2 consecutive days; d) deliberate self-injury or aggressive behavior, or suicidal or homicidal ideation and aggressive behavior that was clinically significant; e) increase in prespecified individual PANSS item scores to at least 5, for patients whose scores were 3 or below at randomisation, or to at least 6 , for patients whose scores were 4 at randomisation, for 2 consecutive days)

Quality of life: Schizophrenia Quality-of-Life Scale.

Unable to use / Not included:

Mental state: PANSS (no predefined outcome of interest).

Behaviour: suicide, aggression (only mean scores which were no predefined outcomes of interest)

Functioning: Personal and Social Performance Scale (no predefined outcome of interest) Global state: CGI-severity (only mean score which was no predefined outcome of interest) Adverse effects: World Health Organization Adverse Reaction Terminology dictionary (no data / no predefined outcome of interest), movement disorders (Simpson Angus Scale, Barnes Akathisia Rating Scale, and Abnormal Involuntary Movement Scale (all no data / continuous side-effect results were not among the predefined outcomes of interest) Physiological measures: laboratory (except for metabolic problems no data), vital signs, 
Kramer 2007 (Continued)

ECG, prolactin (all no data / no predefined outcomes of interest)

Notes

Risk of bias

\begin{tabular}{|c|c|c|}
\hline Bias & Authors' judgement & Support for judgement \\
\hline $\begin{array}{l}\text { Random sequence generation (selection } \\
\text { bias) }\end{array}$ & Low risk & $\begin{array}{l}\text { Randomised, computerized randomisation } \\
\text { and stratification scheme }\end{array}$ \\
\hline Allocation concealment (selection bias) & Low risk & Interactive voice-response system. \\
\hline $\begin{array}{l}\text { Blinding (performance bias and detection } \\
\text { bias) } \\
\text { Subjective outcomes }\end{array}$ & Unclear risk & Double, no further details. \\
\hline $\begin{array}{l}\text { Blinding (performance bias and detection } \\
\text { bias) } \\
\text { Objective outcomes }\end{array}$ & Low risk & Double, no further details. \\
\hline $\begin{array}{l}\text { Incomplete outcome data (attrition bias) } \\
\text { All outcomes }\end{array}$ & High risk & $\begin{array}{l}\text { Only } 28 \text { out of } 207 \text { participants left the } \\
\text { study prematurely for another reason than } \\
\text { relapse. Therefore, missing outcomes may } \\
\text { not pose a problem for the primary out- } \\
\text { come which was assessed with the Kaplan- } \\
\text { Meier method. Nevertheless, high discon- } \\
\text { tinuations due to relapse ( } 75 / 207 \text { ) which } \\
\text { were much more frequent in the placebo } \\
\text { group than in the drug group pose a ma- } \\
\text { jor problem for secondary outcomes. No } \\
\text { full ITT (participants had to receive at least } \\
\text { one dose post-baseline) but only two par- } \\
\text { ticipants were excluded on this basis }\end{array}$ \\
\hline Selective reporting (reporting bias) & Low risk & No evidence for selective reporting. \\
\hline Other bias & High risk & $\begin{array}{l}\text { Study was terminated after an interim anal- } \\
\text { ysis showed a clear advantage of paliperi- } \\
\text { done }\end{array}$ \\
\hline
\end{tabular}


Methods

Allocation: procedure not described.
Blinding: double, identical capsules.
Duration: 12 weeks.
Design: parallel.
Location: single-centre.
Setting: inpatient.

Diagnosis: chronic schizophrenia (clinical diagnosis).

$\mathrm{N}=35$.

Gender: 19 men, 16 women.

Age: mean 43.9 years.

History: duration stable- maintained on neuroleptic for at least 3 months, prospective 12 week stabilization phase during which participants were switched to penfluridol, duration ill- n.i., number of previous hospitalisations- mean 1.34, age at onset- n.i., severity of illness- n.i., baseline antipsychotic dose- mean $64.1 \mathrm{mg} /$ week penfluridol

Interventions

1. Drug: penfluridol - Flexible dose. Allowed dose range: 20-120mg/week. Mean dose: n.i.. $\mathrm{N}=18$

2. Placebo: Duration of taper: 0 days. $\mathrm{N}=17$.

Rescue medication: antiparkinson medication, it seems that haloperidol was not allowed in the double-blind phase

Outcomes

Examined:

Relapse: psychiatric decompensation that could not be controlled by dose increase Leaving the study early.

Unable to use / Not included:

Global state: Clinical Global Impression Scale (no numbers / no predefined outcomes of interest)

Mental state: Brief Psychiatric Rating Scale (no numbers / no predefined outcomes of interest)

Behaviour: Nurses Observation Scale for Inpatient Behaviour (no numbers / no predefined outcomes of interest)

Physiological measures: vital signs (weight, pulse, blood pressure, respiratory frequency, temperature - no numbers / no predefined outcomes of interest)

Notes

Risk of bias

Bias Authors' judgement

Random sequence generation (selection Unclear risk bias)

Allocation concealment (selection bias)
Unclear risk

Procedure not described. 
Kurland 1975 (Continued)

\begin{tabular}{l|l|l}
$\begin{array}{l}\text { Blinding (performance bias and detection } \\
\text { bias) } \\
\text { Subjective outcomes }\end{array}$ & Dnclear risk & Double, identical capsules. \\
\hline
\end{tabular}

Blinding (performance bias and detection Low risk

Double, identical capsules.

bias)

Objective outcomes

Incomplete outcome data (attrition bias) High risk All outcomes
12 of 35 participants left the study early (34\%), 11 of them were in the placebo group. As all participants in the placebo group discontinued due to relapse, the primary outcome is not affected. But the results of all other outcomes are biased by this effect

Selective reporting (reporting bias) Low risk

Results on rating scales have not been reported, but these were not outcomes of interest in our review

No clear other bias

Other bias

Low risk

Leff 1971

Methods

Randomisation: random, no further details.

Allocation: trial medication was held by the unit secretary and dispensed to Julian Leff who gave it to the treating consultant. Only the unit secretary knew which pills were active drug and which were placebo.

Blinding: double, no further details. But side-effects were not troublesome in any patient and therefore doctors concerned probably received no clues about whether a patient was on active drug or not.

Duration: one year.

Design: parallel.

Location: single-centre.

Setting: outpatient.

Participants

Diagnosis: schizophrenia (Present State Examination), recently recovered from an acute episode, 32 florid schizophrenia, 3 delusional psychosis

$\mathrm{N}=35$.

Gender: n.i..

Age: 16-55 years.

History: duration stable- n.i., but stabilised at the pre-admission level during a 6-12 weeks outpatient period and recently recovered from an acute episode, duration ill- $\mathrm{n}$. i., number of previous hospitalisations- n.i., age at onset- n.i., severity of illness- n.i., baseline antipsychotic dose- n.i. 


\section{Leff 1971 (Continued)}

\begin{tabular}{l|l} 
Interventions & $\begin{array}{l}\text { 1. Drug: trifluoperazine or chlorpromazine (depending on the previous medication so } \\
\text { that so far as the patient was concerned there was no apparent change in medication) } \\
\text { Flexible dose. Allowed dose range: trifluoperazine } 5-25 \mathrm{mg} / \text { day, chlorpromazine } 100- \\
500 \mathrm{mg} / \text { day. Mean dose: chlorpromazine } 157.1 \mathrm{mg} / \mathrm{day} \text {, trifluoperazine } 12.3 \mathrm{mg} / \mathrm{day} . \mathrm{N}= \\
20\end{array}$ \\
$\begin{array}{ll}\text { 2. Placebo: Duration of taper: not indicated, probably } 0 \text { days. } \mathrm{N}=15 \\
\text { Rescue medication: antiparkinson medication, antidepressants, no antipsychotics (doc- } \\
\text { tors received a letter asking them not to prescribe other medication) }\end{array}$ \\
\hline Outcomes & $\begin{array}{l}\text { Examined: } \\
\text { Relapse: physician was sufficiently concerned about the patient's status to want to be } \\
\text { certain that he was on active drug } \\
\text { Leaving the study early. }\end{array}$ \\
\hline Notes &
\end{tabular}

Risk of bias

\begin{tabular}{l|l|l}
\hline Bias & Authors' judgement & Support for judgement \\
\hline $\begin{array}{l}\text { Random sequence generation (selection } \\
\text { bias) }\end{array}$ & Unclear risk & Random, no further details. \\
\hline Allocation concealment (selection bias) & Low risk & $\begin{array}{l}\text { Trial medication was held by the unit secre- } \\
\text { tary and dispensed to Julian Leff who gave } \\
\text { it to the treating consultant. Only the unit } \\
\text { secretary knew which pills were active drug } \\
\text { and which were placebo }\end{array}$ \\
\hline
\end{tabular}

Blinding (performance bias and detection Low risk bias)

Subjective outcomes

Blinding (performance bias and detection Low risk bias)

Objective outcomes

$$
\text { All outcomes }
$$$$
\text { Incomplete outcome data (attrition bias) }
$$

High risk

Selective reporting (reporting bias)

Low risk
Double, no further details. But side-effects were not troublesome in any patient and therefore doctors concerned probably received no clues about whether a patient was on active drug or not

Double, no further details. But side-effects were not troublesome in any patient and therefore doctors concerned probably received no clues about whether a patient was on active drug or not

Overall drop-out rate was $60 \%$, almost all due to relapse which occured much more frequently in the placebo group. This poses a problem for other outcomes than relapse

No evidence for selective reporting. 
Leff 1971 (Continued)

\begin{tabular}{|c|c|}
\hline Other bias & Low risk \\
\hline
\end{tabular}

Levine 1980

Methods

Randomisation: random 2:1, no further details.

Allocation: procedure not described.

Blinding: double, no further details.

Duration: 15 weeks.

Design: parallel.

Location: four hospitals.

Setting: outpatient.

\begin{tabular}{|c|c|}
\hline Participants & $\begin{array}{l}\text { Diagnosis: schizophrenia (DSM-II). } \\
\text { N=67. } \\
\text { Gender: } 34 \text { men, } 33 \text { women. } \\
\text { Age: mean } 31.7 \text { years. } \\
\text { History: duration stable- continuously and successfully treated for one year, duration ill- } \\
\text { n.i., number of previous hospitalisations- n.i., age at onset- n.i., severity of illness- n.i. } \\
\text {, baseline antipsychotic dose- oral fluphenazine mean } 24.4 \mathrm{mg} / \text { day, depot fluphenazine } \\
30.9 \mathrm{mg} / 3 \text { weeks }\end{array}$ \\
\hline
\end{tabular}

Interventions

1. Drug: oral fluphenazine $(n=6)$ or depot fluphenazine $(n=11)$. Fixed/flexible dose: unclear. Allowed dose range: unclear. Mean dose: unclear. $\mathrm{N}=17$

2. Placebo: Duration of taper: 0 days. $\mathrm{N}=50$.

Rescue medication: n.i., but antipsychotics were probably not allowed

Outcomes

Examined:

Relapse: rehospitalisation or deterioration in clinical condition which could not be managed within protocol limits (e.g., increased psychological support or adjustment of dosage)

Adverse effects: tardive dyskinesia (AIMS).

Notes

Risk of bias

\begin{tabular}{lll}
\hline Bias & Authors' judgement & Support for judgement
\end{tabular}

Random sequence generation (selection Unclear risk bias)

\section{Allocation concealment (selection bias) Unclear risk}

Blinding (performance bias and detection Unclear risk bias)

Subjective outcomes
Random 2:1, no further details.

Procedure not described.

Double, no further details. 
Levine 1980 (Continued)

\begin{tabular}{|c|c|c|}
\hline $\begin{array}{l}\text { Blinding (performance bias and detection } \\
\text { bias) } \\
\text { Objective outcomes }\end{array}$ & Low risk & Double, no further details. \\
\hline $\begin{array}{l}\text { Incomplete outcome data (attrition bias) } \\
\text { All outcomes }\end{array}$ & Unclear risk & $\begin{array}{l}\text { It is unclear whether there were participants } \\
\text { who left the study early }\end{array}$ \\
\hline Selective reporting (reporting bias) & Low risk & No evidence for selective reporting. \\
\hline Other bias & Low risk & No clear evidence for other bias. \\
\hline
\end{tabular}

\section{Marjerrison 1964}

Methods
Randomisation: randomly assigned.

Allocation: procedure not described.

Blinding: double - (apart from previous antipsychotic group) - three different colours which were again changed. Double-blind condition maintained for patients, ward nurses and psychiatrists.

Duration: 7 months.

Design: parallel.

Location: single-centre.

Setting: inpatient.

Participants

Diagnosis: chronic psychotic patients, treatment resistive in closed wards. No seizures, no antidepressants, no candidates for discharge

$\mathrm{N}=88$.

Gender: 38 men, 40 women.

Age: 47 years.

History: duration stable- 1 year on medication, duration ill- n.i., number of previous hospitalisations- n.i., age at onset- mean 28.1 years, severity of illness- mean 11.6 on modified Psychotic Reaction Profile (PRP), baseline antipsychotic dose- 39.3mg/ 3 weekly fluphenazine decanoate

Interventions

1. Drug: trifluoperazine (10-90 mg/day), chlorprothixene (50-450 mg/day), same medication (various drugs). Flexible doses. Allowed dose range: n.i.. Mean dose: n.i.. N=54.

2. Placebo: Duration of taper: 0 days. $\mathrm{N}=34$.

Rescue medication: antiparkinson, barbiturate sedation.

Outcomes

Examined:

Relapse: clinical judgement.

Unable to use / Not included:

Ward behaviour: unpublished rating scale (no predefined outcome of interest)

Urinary excretion (no predefined outcome of interest).

\section{Notes}

\section{Risk of bias}




\section{Marjerrison 1964 (Continued)}

\begin{tabular}{|c|c|c|}
\hline Bias & Authors' judgement & Support for judgement \\
\hline $\begin{array}{l}\text { Random sequence generation (selection } \\
\text { bias) }\end{array}$ & Unclear risk & Random, no further details. \\
\hline Allocation concealment (selection bias) & Unclear risk & Procedure not described. \\
\hline $\begin{array}{l}\text { Blinding (performance bias and detection } \\
\text { bias) } \\
\text { Subjective outcomes }\end{array}$ & Unclear risk & Double, different colours. \\
\hline $\begin{array}{l}\text { Blinding (performance bias and detection } \\
\text { bias) } \\
\text { Objective outcomes }\end{array}$ & Low risk & Double, different colours. \\
\hline $\begin{array}{l}\text { Incomplete outcome data (attrition bias) } \\
\text { All outcomes }\end{array}$ & Low risk & $\begin{array}{l}\text { Drop-outs } 10 \text { out of } 88 \text { is acceptable }(11 \%) \\
\text {, although only completers were analysed }\end{array}$ \\
\hline Selective reporting (reporting bias) & Low risk & No evidence for selective reporting. \\
\hline Other bias & Low risk & No evidence for other bias. \\
\hline
\end{tabular}

\section{McCreadie 1989}

\begin{tabular}{|c|c|}
\hline Methods & $\begin{array}{l}\text { Randomisation: assumed, because study was double-blind and because the first study } \\
\text { phase was randomised (no further details). } \\
\text { Allocation: procedure not described. } \\
\text { Blinding: double, no further details. } \\
\text { Duration: } 12 \text { months. } \\
\text { Design: parallel. } \\
\text { Location: single-center. } \\
\text { Setting: outpatient. }\end{array}$ \\
\hline Participants & $\begin{array}{l}\text { Diagnosis: first episode schizophrenia (Present State Examination, Feighner criteria and } \\
\text { Research Diagnostic Criteria) } \\
\text { N=15. } \\
\text { Gender: n.i. } \\
\text { Age: n.i. } \\
\text { History: duration stable- } 1 \text { year, duration ill- n.i., number of previous hospitalisations- } \\
\text { n.i., age at onset- n.i., severity of illness- n.i., baseline antipsychotic dose- n.i. }\end{array}$ \\
\hline Interventions & $\begin{array}{l}\text { 1. Drug: pimozide once weekly or i.m. flupenthixol. Flexible doses. Allowed dose range } \\
\text { n.i.. Mean dose: n.i.. } \mathrm{N}=8 \text {. } \\
\text { 2. Placebo: Duration of taper: } 0 \text { days } \mathrm{N}=7 \text {. } \\
\text { Rescue medication: antiparkinson medication. }\end{array}$ \\
\hline
\end{tabular}


McCreadie 1989 (Continued)

\begin{tabular}{|c|c|c|}
\hline Outcomes & \multicolumn{2}{|c|}{$\begin{array}{l}\text { Examined: } \\
\text { Relapse: re-admission. } \\
\text { Unable to use / Not included: } \\
\text { Leaving early (no data). } \\
\text { Cognition (no data for withdrawal study / no predefined outcome of interest) } \\
\text { Adverse effects: parkinsonism, tardive dyskinesia (no data for withdrawal study) }\end{array}$} \\
\hline \multicolumn{3}{|l|}{ Notes } \\
\hline \multicolumn{3}{|l|}{ Risk of bias } \\
\hline Bias & Authors' judgement & Support for judgement \\
\hline $\begin{array}{l}\text { Random sequence generation (selection } \\
\text { bias) }\end{array}$ & Unclear risk & Randomisation assumed. \\
\hline Allocation concealment (selection bias) & Unclear risk & Procedure not described. \\
\hline $\begin{array}{l}\text { Blinding (performance bias and detection } \\
\text { bias) } \\
\text { Subjective outcomes }\end{array}$ & Unclear risk & Double, no further details. \\
\hline $\begin{array}{l}\text { Blinding (performance bias and detection } \\
\text { bias) } \\
\text { Objective outcomes }\end{array}$ & Low risk & Double, no further details. \\
\hline $\begin{array}{l}\text { Incomplete outcome data (attrition bias) } \\
\text { All outcomes }\end{array}$ & Unclear risk & $\begin{array}{l}\text { It is unclear whether there were missing } \\
\text { data. }\end{array}$ \\
\hline Selective reporting (reporting bias) & Low risk & No evidence for selective reporting. \\
\hline Other bias & Unclear risk & Not entirely clear. \\
\hline
\end{tabular}

\section{Melnyk 1966}

Methods
Randomisation: random, no further details.

Allocation: procedure not described.

Blinding: double, "the staff, patients and investigators were not aware of which patients were to receive placebo instead of their medication".

Duration: 6 weeks.

Design: parallel.

Location: single-centre.

Setting: inpatient.
Diagnosis: schizophrenia (clinical diagnosis), paranoid schizophrenia $(\mathrm{n}=19)$, undifferentiated schizophrenia $(n=8)$, catatonic schizophrenia $(n=8)$, hebephrenic schizophrenia $(n=4)$, acute schizophrenic reaction $(n=1)$ 


\begin{tabular}{|c|c|}
\hline & $\begin{array}{l}\mathrm{N}=40 \text {. } \\
\text { Gender: } 20 \text { men, } 20 \text { women. } \\
\text { Age: n.i.. } \\
\text { History: duration stable- not indicated, but mean } 4.6 \text { months on current medication, } \\
\text { duration ill- mean } 12.18 \text { years, number of previous hospitalisations- n.i. but mean du- } \\
\text { ration of current hospitalisation } 18 \text { months, age at onset- n.i., severity of illness- n.i., } \\
\text { baseline antipsychotic dose- n.i. }\end{array}$ \\
\hline Interventions & $\begin{array}{l}\text { 1. Drug: chlorpromazine }(n=6) \text { or thioridazine }(n=14) \text {. Flexible dose. Allowed dose range: } \\
\text { 100-600mg/day. Mean dose: } n . i . . . N=20 \\
\text { 2. Placebo: Duration of taper (days): } 0 \text { days. } N=20 \text {. } \\
\text { Rescue medication: } n \text {.i.. }\end{array}$ \\
\hline Outcomes & $\begin{array}{l}\text { Examined: } \\
\text { Relapse: symptoms similar to those which had characterized the patient's illness prior to } \\
\text { successful treatment by phenothiazines } \\
\text { Unable to use / Not included: } \\
\text { Withdrawal symptoms (no numbers for each group separately / no predefined outcome } \\
\text { of interest) }\end{array}$ \\
\hline Notes & \\
\hline
\end{tabular}

\section{Risk of bias}

\begin{tabular}{|c|c|c|}
\hline Bias & Authors' judgement & Support for judgement \\
\hline $\begin{array}{l}\text { Random sequence generation (selection } \\
\text { bias) }\end{array}$ & Unclear risk & Random, no further details. \\
\hline Allocation concealment (selection bias) & Unclear risk & Procedure not described. \\
\hline $\begin{array}{l}\text { Blinding (performance bias and detection } \\
\text { bias) } \\
\text { Subjective outcomes }\end{array}$ & Unclear risk & $\begin{array}{l}\text { Double, "the staff, patients and investiga- } \\
\text { tors were not aware of which patients were } \\
\text { to receive placebo instead of their medica- } \\
\text { tion" }\end{array}$ \\
\hline
\end{tabular}

Blinding (performance bias and detection Low risk bias)

Double, "the staff, patients and investigaObjective outcomes tors were not aware of which patients were to receive placebo instead of their medication”

Incomplete outcome data (attrition bias) Unclear risk All outcomes
It was not reported whether participants left the study early, but it is well possible that there weren't any, because it was a relatively short inpatient study

\begin{tabular}{l|ll}
\hline Selective reporting (reporting bias) & Low risk & No evidence for selective reporting. \\
\hline Other bias & Low risk & No clear evidence for other bias. \\
\hline
\end{tabular}


Methods

Participants
Randomisation: random, no further details.

Allocation: the hospital pharmacist was responsible for supplying placebo and active drugs to the ward, no one concerned with the care of patients knew which patients were started on placebo.

Blinding: double, identical tablets, but in most cases nurses made correct forecasts on who was on drug and who was on placebo. Blind was broken when a participant relapsed.

Duration: 6 months.

Design: parallel.

Location: single-centre.

Setting: inpatient.

Diagnosis: chronic schizophrenia (clinical diagnosis by two psychiatrists)

$\mathrm{N}=40$.

Gender: 40 men.

Age: $25-55$ years.

History: duration stable- maintenance doses of tranquilisers had been administered for at least 18 months, in six participants who had to change treatment no change in symptoms was noted during 6 weeks, duration ill- n.i., number of previous hospitalisations- n.i. , but duration of current hospitalisation $>2$ years, age at onset- n.i., severity of illnessn.i., baseline antipsychotic dose- all but six participants were on chlorpromazine or trifluoperazine, dose n.i.

Interventions

1. Drug: chlorpromazine or trifluoperazine. Fixed/flexible dose: n.i.. Allowed dose range: n.i.. Mean dose: n.i.. $\mathrm{N}=20$

2. Placebo: Duration of taper: 0 days. $\mathrm{N}=20$.

Rescue medication: n.i.

Outcomes

Examined:

Relapse: worsening of global state.

Unable to use / Not included:

Mental state: Wing Scale (no SD / no predefined outcome of interest)

Global state: clinical impression of severity (no predefined outcome of interest)

Behaviour: Wing Scale (no SD / no predefined outcome of interest)

Leaving the study early (no data).

Notes

Risk of bias

\begin{tabular}{l|l|l} 
Bias & Authors' judgement & Support for judgement \\
\hline $\begin{array}{l}\text { Random sequence generation (selection } \\
\text { bias) }\end{array}$ & Unclear risk & Random, no further details. \\
\hline Allocation concealment (selection bias) & Low risk & $\begin{array}{l}\text { The hospital pharmacist was responsible } \\
\text { for supplying placebo and active drugs to } \\
\text { the ward, no one concerned with the care of } \\
\text { patients knew which patients were started } \\
\text { on placebo }\end{array}$
\end{tabular}


Morton 1968 (Continued)

\begin{tabular}{|c|c|c|}
\hline $\begin{array}{l}\text { Blinding (performance bias and detection } \\
\text { bias) } \\
\text { Subjective outcomes }\end{array}$ & High risk & $\begin{array}{l}\text { Double, identical tablets, but in most cases } \\
\text { nurses made correct forecasts on who was } \\
\text { on drug and who was on placebo }\end{array}$ \\
\hline $\begin{array}{l}\text { Blinding (performance bias and detection } \\
\text { bias) } \\
\text { Objective outcomes }\end{array}$ & Low risk & $\begin{array}{l}\text { Double, identical tablets, but in most cases } \\
\text { nurses made correct forecasts on who was } \\
\text { on drug and who was on placebo }\end{array}$ \\
\hline $\begin{array}{l}\text { Incomplete outcome data (attrition bias) } \\
\text { All outcomes }\end{array}$ & Unclear risk & It is unclear whether there were dropouts. \\
\hline Selective reporting (reporting bias) & Low risk & No evidence for selective reporting. \\
\hline Other bias & High risk & $\begin{array}{l}\text { Blind was broken when a participant re- } \\
\text { lapsed. }\end{array}$ \\
\hline
\end{tabular}

Nishikawa 1982

Methods

Randomisation: random, no further details.

Allocation: procedure not described.

Blinding: double, drug appearance was made identical with respect to taste, colour and volume by adding a kind of "stomatics".

Duration: three years.

Design: cross-over

Location: single-centre.

Setting: outpatient.

Participants

Diagnosis: schizophrenia (clinical diagnosis) in remission.

$\mathrm{N}=30$.

Gender: 21 men, 9 women.

Age: mean 33.2 years.

History: duration stable- "in remission", but details were not reported, duration illmean 7.3 years, number of previous hospitalisations- mean 2.4 , age at onset- 25.9 years, severity of illness- "in remission", baseline antipsychotic dose- n.i.

Interventions

1. Drug: chlorpromazine. Fixed dose of $75 \mathrm{mg} /$ day. $\mathrm{N}=10$.

2. Drug: haloperidol. Fixed dose of $3 \mathrm{mg} /$ day. $\mathrm{N}=10$.

3. Placebo: Duration of taper (days): 0 days. $\mathrm{N}=10$.

Rescue medication: only nitrazepam for sleep and biperiden for extrapyramidal sideeffects, no additional antipsychotic drugs

$\begin{array}{ll}\text { Outcomes } & \text { Examined: } \\ & \text { Relapse: clinical judgement. } \\ & \text { Unable to use / Not included: } \\ & \text { Number of symptom free days (no SD's / no predefined outcome of interest) }\end{array}$

Notes

There were also a diazepam and an imipramine group which were not of interest for the current review 
Nishikawa 1982 (Continued)

\section{Risk of bias}

\begin{tabular}{|c|c|c|}
\hline Bias & Authors' judgement & Support for judgement \\
\hline $\begin{array}{l}\text { Random sequence generation (selection } \\
\text { bias) }\end{array}$ & Unclear risk & Random, no further details. \\
\hline Allocation concealment (selection bias) & Unclear risk & Procedure not described. \\
\hline $\begin{array}{l}\text { Blinding (performance bias and detection } \\
\text { bias) } \\
\text { Subjective outcomes }\end{array}$ & Unclear risk & $\begin{array}{l}\text { Double, drug appearance was made identi- } \\
\text { cal with respect to taste, colour and volume } \\
\text { by adding a kind of "stomatics" }\end{array}$ \\
\hline $\begin{array}{l}\text { Blinding (performance bias and detection } \\
\text { bias) } \\
\text { Objective outcomes }\end{array}$ & Low risk & $\begin{array}{l}\text { Double, drug appearance was made identi- } \\
\text { cal with respect to taste, colour and volume } \\
\text { by adding a kind of "stomatics" }\end{array}$ \\
\hline $\begin{array}{l}\text { Incomplete outcome data (attrition bias) } \\
\text { All outcomes }\end{array}$ & Low risk & $\begin{array}{l}\text { No participant left the study early due to } \\
\text { other reasons than relapse in the first phase } \\
\text { of the study, the only outcome apart from } \\
\text { leaving the study early }\end{array}$ \\
\hline Selective reporting (reporting bias) & Low risk & No evidence for selective reporting. \\
\hline Other bias & High risk & $\begin{array}{l}\text { The doses used were very low for Western } \\
\text { standards. The study was initially planned } \\
\text { as a cross-over trial, but due to high dropout } \\
\text { rates after the first phase only the first treat- } \\
\text { ment phase was analysed. Nevertheless, this } \\
\text { did not interfere with the aims of our re- } \\
\text { view }\end{array}$ \\
\hline
\end{tabular}

Nishikawa 1984

Methods
Randomisation: random, no further details.

Allocation: procedure not described.

Blinding: double, drug appearance was made identical with respect to powder, color, tast and volume by adding a gastric acid.

Duration: one year.

Design: parallel.

Location: single-centre.

Setting: outpatient.
Diagnosis: schizophrenia (DSM-III), in remission or residual state

$\mathrm{N}=87$.

Gender: 53 men, 34 women.

Age: mean 41 years.

History: duration stable- n.i., but in remission, duration ill- mean 8.2 years, number of 
previous hospitalisations- mean 3.4, age at onset- mean 32.8 years, severity of illness- in remission or residual symptoms, baseline antipsychotic dose- n.i.

Interventions
1. Drug: haloperidol combined with biperidine and nitrazepam. Fixed dose: 1, 3 or 6 $\mathrm{mg} /$ day.* $\mathrm{N}=37$

2. Drug: propericiazine combined with biperidine and nitrazepam. Fixed dose: 10, 30 or $60 \mathrm{mg} /$ day. $^{*} \mathrm{~N}=37$

3. Placebo combined with biperidine and nitrazepam. Duration of taper: 0 days. $N=13$ Rescue medication: not indicated, probably no additional antipsychotic medication allowed

Outcomes

Examined:

Relapse: clinical judgement.

Leaving the study early.

Unable to use / Not included:

Prolactin levels (no predefined outcome of interest).

Notes

* only the highest doses were analysed for the purpose of this review

\section{Risk of bias}

\section{Bias}

Random sequence generation (selection Unclear risk bias)

\section{Allocation concealment (selection bias) Unclear risk}

Blinding (performance bias and detection Unclear risk bias)

Subjective outcomes

Blinding (performance bias and detection Low risk

bias)

Objective outcomes

Incomplete outcome data (attrition bias) Unclear risk All outcomes

\section{Support for judgement}

Random, no further details.

Procedure not described.

Double, drug appearance was made identical with respect to powder, color, tast and volume by adding a gastric acid

Double, drug appearance was made identical with respect to powder, color, tast and volume by adding a gastric acid

While in the placebo group and in the haloperidol group the rates of participants leaving early due to other reasons were low, 9 out of 12 participants in the propericiazine group discontinued due to overdose. It is questionable whether relapse rates could be accurately measured, because most participants did not reach the endpoint 
Nishikawa 1984 (Continued)

\begin{tabular}{l|l} 
Other bias $\quad$ Low risk $\quad$ No evidence for other bias.
\end{tabular}

\section{Odejide 1982}

Methods

Interventions

Outcomes
Randomisation: participants were matched for age, sex, duration of illness, and severity of symptoms in the preceding episode and then assigned based on a randomised schedule. Allocation: procedure not described.

Blinding: double, evaluating psychiatrist and participants were unaware of the contents of their injections. It seems that the treating psychiatrist was aware of the treatment.

Duration: 12 months.

Design: parallel.

Location: single-centre.

Setting: outpatient.

Diagnosis: schizophrenia (ICD-9 and Present State Examination), with two or more episodes and several first rank symptoms in previous episode, free of psychopathology for at least 12 months, on fluphenazine decanoate for at least 2 years

$\mathrm{N}=70$.

Gender: n.i..

Age: n.i..

History: duration stable- at least 12 months free of psychopathology, duration ill- n.i., number of previous hospitalisations- n.i., but at least two previous episodes, age at onsetn.i., severity of illness- BPRS $<10$ in all participants, baseline antipsychotic dose- n.i.

1. Drug: fluphenazine decanoate. Fixed dose of $50 \mathrm{mg}$ i.m. four/eight weekly. $\mathrm{N}=35$

2. Placebo: vitamin B complex i.m.. Duration of taper: 0 days. $\mathrm{N}=35$

Rescue medication: nitrazepam for sleep and benzhexol for extrapyramidal side-effects; additional antipsychotic drugs were not allowed

Examined:

Relapse (re-emergence of definite schizophrenic psychopathology necessitating hospital admission or other major treatment change)

Adverse effects: tardive dyskinesia (Aquired Involuntary Movements Scale)

Unable to use / Not included:

Mental state: Brief Psychiatric Rating Scale (no mean, no SD / no predefined outcome of interest)

Adverse effects: extrapyramidal symptoms - use of antiparkinson medication (combined with nitrazepam), use of additional nitrazepam for sleep (combined with use of antiparkinson medication)

\section{Notes}

Risk of bias

Bias
Authors' judgement
Support for judgement 
Odejide 1982 (Continued)

\begin{tabular}{|c|c|c|}
\hline $\begin{array}{l}\text { Random sequence generation (selection } \\
\text { bias) }\end{array}$ & Low risk & $\begin{array}{l}\text { Participants were matched for age, sex, du- } \\
\text { ration of illness, and severity of symptoms } \\
\text { in the preceding episode and then assigned } \\
\text { based on a randomised schedule }\end{array}$ \\
\hline Allocation concealment (selection bias) & Unclear risk & Procedure not described. \\
\hline $\begin{array}{l}\text { Blinding (performance bias and detection } \\
\text { bias) } \\
\text { Subjective outcomes }\end{array}$ & Unclear risk & $\begin{array}{l}\text { Double, evaluating psychiatrist and partic- } \\
\text { ipants were unaware of the contents of their } \\
\text { injections. It seems that treating psychia- } \\
\text { trist was aware of the treatment }\end{array}$ \\
\hline $\begin{array}{l}\text { Blinding (performance bias and detection } \\
\text { bias) } \\
\text { Objective outcomes }\end{array}$ & Low risk & $\begin{array}{l}\text { Double, evaluating psychiatrist and partic- } \\
\text { ipants were unaware of the contents of their } \\
\text { injections. It seems that treating psychia- } \\
\text { trist was aware of the treatment }\end{array}$ \\
\hline $\begin{array}{l}\text { Incomplete outcome data (attrition bias) } \\
\text { All outcomes }\end{array}$ & High risk & $\begin{array}{l}\text { Overall drop-out rate drug } 40 \% \text {, placebo } \\
66 \% \text {, most due to relapse. This poses a } \\
\text { risk for bias for other outcomes. Completer } \\
\text { analysis }\end{array}$ \\
\hline Selective reporting (reporting bias) & Low risk & No evidence for selective reporting. \\
\hline Other bias & Low risk & No clear evidence for other sources of bias. \\
\hline
\end{tabular}

\section{Olson 1962}

Methods

Randomisation: randomly selected and then assigned.

Allocation: procedure not described.

Blinding: identical pink capsules. Nurses, raters and patients were blind to the procedure. Treating physician was led to believe that half of the patients were on placebo, the other half on drug.

Duration: 30 days.

Design: parallel.

Location: single-center.

Setting: inpatients.

Participants

Diagnosis: chronically mentally ill, 67\%-83\% schizophrenia (clinical diagnosis), in hospital and apparently treated with antipsychotic drugs for the last 18 months $\mathrm{N}=60$.

Gender: n.i..

Age: mean 51 years.

History: duration stable- at least 60 days plus 30 days prospectively, duration ill- n.i. , number of previous hospitalisations- n.i., age at onset- n.i., severity of illness- n.i., baseline antipsychotic dose- n.i 
Olson 1962 (Continued)

\begin{tabular}{|c|c|c|}
\hline Interventions & \multicolumn{2}{|c|}{$\begin{array}{l}\text { 1. Drug: chlorpromazine or thioridazine. Fixed/flexible dose: n.i.. Allowed dose range: } \\
\text { n.i.. Mean dose: } n \text {.i.. } \mathrm{N}=30 \\
\text { 2. Placebo: Duration of taper: } 0 \text { days. } \mathrm{N}=30 \text {. } \\
\text { Rescue medication: not indicated. }\end{array}$} \\
\hline Outcomes & \multicolumn{2}{|c|}{$\begin{array}{l}\text { Examined: } \\
\text { Relapse: attrition because of behavioural upset. } \\
\text { Unable to use / Not included: } \\
\text { Behaviour: various scales (no data reported / no predefined outcome of interest) }\end{array}$} \\
\hline Notes & \multicolumn{2}{|c|}{$\begin{array}{l}\text { There were several study phases (alternation between drug and placebo). Only the first } \\
\text { month was of interest for the review }\end{array}$} \\
\hline \multicolumn{3}{|l|}{ Risk of bias } \\
\hline Bias & Authors' judgement & Support for judgement \\
\hline $\begin{array}{l}\text { Random sequence generation (selection } \\
\text { bias) }\end{array}$ & Unclear risk & Randomly selected and then assigned. \\
\hline Allocation concealment (selection bias) & Unclear risk & Procedure not described. \\
\hline $\begin{array}{l}\text { Blinding (performance bias and detection } \\
\text { bias) } \\
\text { Subjective outcomes }\end{array}$ & Unclear risk & $\begin{array}{l}\text { Identical pink capsules. Nurses, raters and } \\
\text { patients were blind to the procedure. Treat- } \\
\text { ing physician was led to believe that half of } \\
\text { the patients were on placebo, the other half } \\
\text { on drug }\end{array}$ \\
\hline $\begin{array}{l}\text { Blinding (performance bias and detection } \\
\text { bias) } \\
\text { Objective outcomes }\end{array}$ & Low risk & $\begin{array}{l}\text { Identical pink capsules. Nurses, raters and } \\
\text { patients were blind to the procedure. Treat- } \\
\text { ing physician was led to believe that half of } \\
\text { the patients were on placebo, the other half } \\
\text { on drug }\end{array}$ \\
\hline $\begin{array}{l}\text { Incomplete outcome data (attrition bias) } \\
\text { All outcomes }\end{array}$ & Unclear risk & $\begin{array}{l}\text { It is unclear how many participants left the } \\
\text { study during the first month }\end{array}$ \\
\hline Selective reporting (reporting bias) & High risk & $\begin{array}{l}\text { Data on behaviour scales were not reported, } \\
\text { including aggressive behaviour which was } \\
\text { an outcome in our review }\end{array}$ \\
\hline Other bias & Low risk & No evidence for other bias. \\
\hline
\end{tabular}


Design: parallel.

Location: single-centre.

Setting: inpatient.

Participants

Diagnosis: chronic schizophrenia (clinical diagnosis), all had previously responded to haloperidol and were adequately maintained on it

$\mathrm{N}=49$.

Gender: 24 men, 20 women.

Age: mean 42.5 years.

History: duration stable- all stabilised for 30 days on haloperidol concentrate, duration illn.i., but mean duration of hospitalisation 13.7 years, number of previous hospitalisationsn.i., age at onset- n.i., severity of illness- mean BPRS 46.6 (16 items scale, rating system unclear), mean Clinical Global Impression of severity 4.9, baseline antipsychotic dosemean $9.3 \mathrm{mg}$ haloperidol/day

Interventions

1. Drug: haloperidol tablets. ${ }^{*}$ Flexible dose. Allowed dose range: n.i.. Mean dose: mean $8.8 \mathrm{mg} /$ day. $\mathrm{N}=17$

2. Drug: haloperidol liquid.* Flexible dose. Allowed dose range: n.i.. Mean dose: 10.4 $\mathrm{mg} /$ day. $\mathrm{N}=16$

3. Placebo: Duration of taper: 0 days. $N=16$.

Rescue medication: antiparkinson medication was allowed.

Outcomes

Examined:

Relapse: deterioration of global state.

Unable to use / Not included:

Mental state: Brief Psychiatric Rating Scale (no SD / no predefined outcome of interest) Global state: Clinical Global Impression of Severity (no SD / no predefined outcome of interest)

Behaviour: Nurses Observation Scale for Inpatient Evalutation (no SD / no predefined outcome of interest)

Adverse effects: laboratory (insufficient data / no predefined outcome of interest), vital signs (insufficient data / no predefined outcome of interest)

Notes $\quad$ *Groups 1 and 2 were pooled for the purpose of this review.

\section{Risk of bias}

$\begin{array}{lll}\text { Bias Authors' judgement } & \text { Support for judgement }\end{array}$

\begin{tabular}{l|l}
\hline $\begin{array}{l}\text { Random sequence generation (selection } \\
\text { bias) }\end{array}$ & Unclear risk \\
\hline
\end{tabular}




\section{Ota 1973 (Continued)}

\begin{tabular}{l|l|l}
$\begin{array}{l}\text { Blinding (performance bias and detection } \\
\text { bias) }\end{array}$ & Unclear risk & $\begin{array}{l}\text { Double, all participants received both } \\
\text { (placebo) tablets and (placebo) liquid, no }\end{array}$ \\
\hline Subjective outcomes & further details
\end{tabular}

Blinding (performance bias and detection Low risk

bias)

Objective outcomes

Incomplete outcome data (attrition bias) Low risk All outcomes

Selective reporting (reporting bias) Low risk

Double, all participants received both (placebo) tablets and (placebo) liquid, no further details

\begin{tabular}{l|l} 
Other bias $\quad$ Low risk No clear other bias.
\end{tabular}

Peuskens 2007

Methods

Randomisation: random, no further details.

Allocation: procedure not described.

Blinding: double, identical capsules.

Duration: 52 weeks, however terminated early after a mean duration of 120 days.

Design: parallel.

Location: multi-centre.

Setting: probably mainly outpatients.

Participants

Diagnosis: schizophrenia (DSM-IV), duration ill at least 2 years, Positive and Negative Syndrome Scale total score $<60$ before randomised phase, Clinical Global Impression Severity Scale not more than moderately ill

$\mathrm{N}=197$.

Gender: 103 men, 69 women.

Age: mean 35 years.

History: duration stable- at least 20 weeks, retrospectively at least one month (no change of overall severity and medication), prospectively 16 weeks stabilisation phase during which all participants were switched to quetiapine, duration ill- mean 8.7 years, number of previous hospitalisations- n.i., but mean number of episodes 4.3 , age at onset- mean 26.5 years, severity of illness- mean Clinical Global Impression of severity 2.7, mean Positive and Negative Syndrome Scale total score 48.2, baseline antipsychotic dosequetiapine $649 \mathrm{mg} /$ day

Interventions

1. Drug: quetiapine XR. Flexible dose 400-800mg/day. Mean dose: $669 \mathrm{mg} /$ day. N=94 2. Placebo: Duration of taper: 4 days. $\mathrm{N}=103$.

Rescue medication: anticholinergic medication, sleep medication, lorazepam, no additional antipsychotic drugs

Outcomes

Examined:

Relapse: increase of Positive and Negative Syndrome Scale by at least 30 percent from baseline, Clinical Global Impression Scale much or very much worse, need for additional 
Peuskens 2007 (Continued)

antipsychotic medication

Leaving the study early.

Adverse events: open interviews.

Global state: number of participants improved according to Clinical Global Impression Scale

Extrapyramidal side-effects: use of antiparkinson medication, Barnes Akathisia Scale, Simpson Angus Scale, Aquired Involuntary Movements Scale

Unable to use / Not included:

Mental state: Positive and Negative Syndrome Scale / no predefined outcome of interest Laboratory: haematology, chemistry, glucose, Hba1c, insulin, lipids, urine analysis, thyroid function), ECG, vital signs, mean weight gain (all no predefined outcomes of interest)

Compliance (pill count / no predefined outcome of interest).

Notes

No participant terminated the preplanned study duration of one year. The authors reported that data after 6 months are not reliable because only a few patients were left. Therefore, relapse data after 6 months were not extracted

\section{Risk of bias}

\begin{tabular}{lll}
\hline Bias & Authors' judgement & Support for judgement
\end{tabular}

Random sequence generation (selection Low risk bias)

Allocation concealment (selection bias) Low risk

Blinding (performance bias and detection Unclear risk bias)

Subjective outcomes

Blinding (performance bias and detection Low risk bias)

Objective outcomes

Incomplete outcome data (attrition bias) High risk All outcomes
Correct randomisation assumed, because recent study from industry

Correct allocation concealment assumed, because recent study from industry

Double, identical capsules.
Double, identical capsules.
High risk

High risk

Overall drop-out rate was $41 \%$, most of them due to relapse $(76 \%)$, which occured much more frequently in the placebo group. This difference in attrition may have biased the results of other outcomes than relapse. Kaplan-Meier survival curve analysis was used for the primary outcome relapse

Only adverse events with a frequency of at least $5 \%$ were reported 
Peuskens 2007 (Continued)

Other bias

High risk
The study was terminated early after an interim analysis showed a clear superiority of quetiapine; there were certain baseline discrepancies in terms of mean age, duration ill and number of previous episodes

Pfizer 2000

Methods

Randomisation: randomised, computer-generated randomised code.

Allocation: Treatment cards numbered for each subject entering double-blind phase, investigator and pharmacist was to allocate numbers to subjects in strict sequence of entry to study.

Blinding: double, identical capsules in blisters.

Duration: 52 weeks.

Design: parallel.

Location: multi-centre.

Setting: inpatient.

Participants

Diagnosis: chronic or subchronic schizophrenia DSM-III-R.

$\mathrm{N}=146$.

Gender: 39 women, 107 men.

Age: mean 50 years.

History: duration stable- n.i., duration ill- mean 21.5 years, number of previous hospitalisations- mean 10.7, age at onset- mean 27.7 years, severity of illness- PANSS 87.1, baseline antipsychotic dose- n.i.

Interventions

1. Drug: ziprasidone. Fixed dose. Allowed dose range: $160 \mathrm{mg} /$ day. Mean dose: 160mg/ day. $\mathrm{N}=71$

2. Placebo: Duration of taper: 0 days. $\mathrm{N}=75$.

Rescue medication: other antipsychotics not allowed, concomitant medication for movement disorders, hypnotics, sedatives, anxiolytics

Outcomes

Examined:

Relapse: as defined by CGI-Improvement scale of 6 or more and/or score of 6 or more on PANSS items P7,G8 on two successive days

Adverse effects: number of participants with at least one adverse event, akathisia, dyskinesia, dystonia, tremor, use of antiparkinson medication, weight gain

Unable to use / Not included:

Global state: mean Clinical Global Impression Severity Scale (no means, no SDs / no predefined outcome of interest)

Mental state: Brief Psychiatric Rating Scale, AMDP system, Paranoid Depression Scale (all no means, no SDs / no predefined outcomes of interest)

Functioning: Global Assessment Scale (no mean, no SD / no predefined outcome of interest)

Subjective well-being (own scale - no mean, no SD).

Adverse effects: extrapyramidal side-effects (Aquired Involuntary Movement Scale - no SD, Simpson Angus Scale, Dosage Record and Treatment Emergent Symptoms Scale all no means, no SDs / continuous side-effect results were not among the prespecified 
outcome)

Concept of illness (concept of illness scale - no mean, no SD / no predefined outcome of interest)

Physiological measures: routine laboratory, ECG, EEG physical exams and vital signs (all no data / no predefined outcome of interest)

Pharmacokinetics (no predefined outcome of interest).

Compliance: doctors' assessment (no predefined outcome of interest)

Notes

\section{Risk of bias}

\begin{tabular}{|c|c|c|}
\hline Bias & Authors' judgement & Support for judgement \\
\hline $\begin{array}{l}\text { Random sequence generation (selection } \\
\text { bias) }\end{array}$ & Low risk & Computer-generated randomised code. \\
\hline Allocation concealment (selection bias) & Low risk & $\begin{array}{l}\text { Treatment cards numbered for each subject } \\
\text { entering double-blind phase, investigator } \\
\text { and pharmacist was to allocate numbers to } \\
\text { subjects in strict sequence of entry to study }\end{array}$ \\
\hline $\begin{array}{l}\text { Blinding (performance bias and detection } \\
\text { bias) } \\
\text { Subjective outcomes }\end{array}$ & Unclear risk & Double, identical capsules. \\
\hline
\end{tabular}

Blinding (performance bias and detection Low risk

Double, identical capsules.

bias)

Objective outcomes

Incomplete outcome data (attrition bias) High risk

All outcomes

$68 \%$ overall dropout, most due to relapse, which occured much more frequently in the placebo group, thus not a problem for this outcome and for drop-out but for other outcomes

\begin{tabular}{lll} 
Selective reporting (reporting bias) & Low risk & No evidence for selective reporting. \\
\hline Other bias & Low risk & No evidence for other bias. \\
\hline
\end{tabular}


Methods
Randomisation: centrally randomised by a specialised unit using an "adaptive randomisation method".

Allocation: procedure not described.

Blinding: open, only key rating scales were additionally rated by a second blind assessor.

Duration: 2 years.

Design: parallel.

Location: multi-centre.

Setting: outpatient.
Participants
Diagnosis: schizophrenia or schizoaffective disorder (ICD-9 and Research Diagnostic Criteria)

$\mathrm{N}=237$.

Gender: 124 women, 113 men.

Age: mean 34.6 years.

History: duration stable- at least 3 months in addition titrated to minimally effective dose which was maintained for at least 4 weeks, duration ill- mean 7.3 years, number of previous hospitalisations- n.i., age at onset- mean 27.3 years, severity of illness- mean CGI 3.8; mean BPRS total score 28.5, baseline antipsychotic dose- n.i.

Interventions

1. Drug: various antipsychotic drugs. Flexible dose, minimum $100 \mathrm{mg} /$ day chlorpromazine equivalent. Allowed dose range: 100 - unlimited chlorpromazine equivalents/ day. Mean dose: $201 \mathrm{mg} /$ day. $\mathrm{N}=122$

2. No treatment (=crisis management, medication was only given in case of a full relapse) . Duration of taper: $50 \%$ every two weeks, thus after 6 weeks only $12.5 \%$ of initial dose left, thus 42 days. Note that participants were not withdrawn after they had received crisis intervention. $\mathrm{N}=115$

Rescue medication: in the no treatment group additional antipsychotic medication could only be given in case of relapse

Outcomes

Examined:

Relapse: Brief Psychiatric Rating Scale total score - $>10$ increase, Global Assessement Scale $<20$ reduction, deterioration Clinical Global Impression Scale CGI $>7$

Unable to use / Not included:

Global state: Clinical Global Impression (no means, no SDs / no predefined outcome of interest)

Mental state: Brief Psychiatric Rating Scale, AMDP system, Paranoid Depression Scale (all no means, no SDs / no predefined outcome of interest)

Functioning: Global Assessment Scale (no mean, no SD / no predefined outcome of interest)

Subjective well-being (own scale - no mean, no SD / no predefined outcome of interest) Adverse effects: extrapyramidal side-effects (Aquired Involuntary Movement Scale - no SD, Simpson Angus Scale, Dosage Record and Treatment Emergent Symptoms Scale - all no means, no SDs / continuous side-effect results were not among the predefined outcomes of interest)

Concept of illness (concept of illness scale - no mean, no SD)

Compliance: doctors' assessment (no predefined outcome of interest)

Physiological measures: routine laboratory, ECG, EEG (no data / no predefined outcome of interest) 
Pietzcker 1993 (Continued)

Notes

There was a third group using intermittent treatment which was not of interest for this review

Risk of bias

\begin{tabular}{|c|c|c|}
\hline Bias & Authors' judgement & Support for judgement \\
\hline $\begin{array}{l}\text { Random sequence generation (selection } \\
\text { bias) }\end{array}$ & Low risk & $\begin{array}{l}\text { Centrally randomised by a specialised unit } \\
\text { using an "adaptive randomisation method" }\end{array}$ \\
\hline Allocation concealment (selection bias) & Unclear risk & Procedure not described. \\
\hline $\begin{array}{l}\text { Blinding (performance bias and detection } \\
\text { bias) } \\
\text { Subjective outcomes }\end{array}$ & Unclear risk & $\begin{array}{l}\text { Open, only key rating scales were addition- } \\
\text { ally rated by a second blind assessor }\end{array}$ \\
\hline $\begin{array}{l}\text { Blinding (performance bias and detection } \\
\text { bias) } \\
\text { Objective outcomes }\end{array}$ & Low risk & $\begin{array}{l}\text { Open, only key rating scales were addition- } \\
\text { ally rated by a second blind assessor }\end{array}$ \\
\hline $\begin{array}{l}\text { Incomplete outcome data (attrition bias) } \\
\text { All outcomes }\end{array}$ & High risk & $\begin{array}{l}\text { High two year discontinuation rate of } 43 \text {. } \\
7 \% \text {. Analysis was intention-to-treat based } \\
\text { on Kaplan-Meier survival curve analysis, } \\
\text { completer analyses were presented in addi- } \\
\text { tion if different. A risk of bias can not be ex- } \\
\text { cluded given the high discontinuation rate }\end{array}$ \\
\hline Selective reporting (reporting bias) & Low risk & No evidence for selective reporting. \\
\hline Other bias & Low risk & No clear evidence for other bias. \\
\hline
\end{tabular}

Pigott 2003

Methods

Randomisation: random, no further details.

Allocation: procedure not described.

Blinding: double, no further details.

Duration: 26 weeks.

Design: parallel.

Location: multi-centre.

Setting: in- and outpatient, sponsored.

Participants

Diagnosis: chronic schizophrenia (DSM-IV), at least two years of continuous antipsychotic medication

$\mathrm{N}=310$.

Gender: 174 men, 136 women.

Age: mean 42 years.

History: duration stable- no significant improvement or worsening of symptoms for at 
Pigott 2003 (Continued)

least 3 months, but all participants with significant symptoms (PANSS total score of at least 60 , but CGI-severity score no more than moderately ill), duration ill- at least 2 years, number of previous hospitalisations- n.i., age at onset- n.i., severity of illnessmean PANSS total score at baseline 81.1, mean CGI severity score at baseline 3.52, approximately $50 \%$ were in hospital, $20 \%$ were in partially supervised facilities, the rest were outpatients, baseline antipsychotic dose- n.i.

Interventions

1. Drug: aripiprazole. Fixed dose of $15 \mathrm{mg} /$ day. $\mathrm{N}=155$.

2. Placebo: Duration of taper (days): n.i. (pre-trial medication was tapered, when appropriate, before stopping treatment). $\mathrm{N}=155$

Rescue medication: additional antipsychotic drugs were not allowed

Outcomes

Examined:

Relapse: CGI at least minimally worse, a PANSS score of - 5 (moderately severe) on the subscore items of hostility or uncooperativeness on 2 successive days; or a - $20 \%$ increase in PANSS total score

Leaving the study early.

Body weight (mean change and number of participants with increase of body weight)

Unable to use / Not included:

Global state: CGI (no SD; no dichotomous data / no predefined outcome of interest)

Mental state: PANSS, BPRS (no SD / no predefined outcome of interest)

Adverse effects: extrapyramidal side-effects - Simpson-Angus Scale, Abnormal Involuntary Movement Scale, Barnes Akathisia Scale (all no SD / No predefined outcome of interest)

Physiological measures: vital signs (pulse rate, systolic and diastolic blood pressure, no data / no predefined outcome of interest), laboratory (haematology, no data; serum chemistries, no data a apart from creatinine phosphate / no predefined outcome of interest) urine tests, ECG (both no data / no predefined outcome of interest)

Notes

Risk of bias

\begin{tabular}{lll}
\hline Bias & Authors' judgement & Support for judgement \\
\hline $\begin{array}{l}\text { Random sequence generation (selection } \\
\text { bias) }\end{array}$ & Low risk & $\begin{array}{l}\text { Correct randomisation assumed, because } \\
\text { recent study from industry. }\end{array}$ \\
\hline Allocation concealment (selection bias) & Low risk & $\begin{array}{l}\text { Correct allocation concealment assumed, } \\
\text { because recent study from industry }\end{array}$ \\
\hline
\end{tabular}

Blinding (performance bias and detection Unclear risk

Double, no further details.

bias)

Subjective outcomes

Blinding (performance bias and detection Low risk

Double, no further details.

bias)

Objective outcomes 
Pigott 2003 (Continued)

\begin{tabular}{l|l|l}
\hline $\begin{array}{l}\text { Incomplete outcome data (attrition bias) } \\
\text { All outcomes }\end{array}$ & High risk & $\begin{array}{l}\text { A high number of participants }(62.2 \%) \\
\text { left the study early, mostly because of re- } \\
\text { lapse (61\%), which was more frequent in } \\
\text { the placebo group. For other outcomes this } \\
\text { could be a problem. For the primary out- } \\
\text { come survival analysis was used which was } \\
\text { not a full ITT (one post-baseline/dose) but } \\
\text { only few participants were excluded }\end{array}$ \\
\hline Selective reporting (reporting bias) & High risk & $\begin{array}{l}\text { Only those adverse events that occurred in } \\
\text { at least 5\% of the participants in either } \\
\text { group were reported }\end{array}$ \\
\hline Other bias & Low risk & No clear other bias. \\
\hline
\end{tabular}

\section{Prien 1968}

Methods

Randomisation: "randomly assigned", no further details.

Allocation: procedure not described.

Blinding: double, liquid form. no further details.

Duration: 24 weeks.

Design: parallel.

Location: multi-centre.

Setting: inpatient.

Participants

Diagnosis: schizophrenia (clinical diagnosis), continuously hospitalized for at least two years

$\mathrm{N}=420$.

Gender: n.i..

Age: mean 41.6 years.

History: duration stable- patients were observed on their normal hospital medicatin for eight weeks, duration ill- mean 17.4 years, mean age at first hospitalisation 24.2 years, mean duration of current hospitalisation- mean 13.1 years, number of previous hospitalisations- n.i., age at onset- mean 24.2 years, severity of illness- on the average markedly ill, participants were required to show positive or negative symptoms, baseline antipsychotic dose- n.i.

Interventions

1. Drug: chlorpromazine. Fixed dose of $300 \mathrm{mg} /$ day. $\mathrm{N}=208$.

*2. Drug: chlorpromazine. Fixed dose of $2000 \mathrm{mg} /$ day (titrated within 45 days, dose reduction to $1500 \mathrm{mg} /$ day was possible). $\mathrm{N}=208$

3. Placebo: Duration of taper: 0 days. $\mathrm{N}=212$.

*4. Routine treatment (any antipsychotic medication, any dose). $\mathrm{N}=210$

Rescue medication: n.i., but probably not allowed.

Outcomes

Examined:

Relapse: apatient was considered relapsed if he regressed and had to be returned to known medication before the end of the 24 week period

Adverse effects: based on clinical interview. 
Prien 1968 (Continued)

Unable to use / Not included:

Mental state: Inpatient Multidimensional Psychiatric Scale, Brief Psychiatric Rating Scale (both only p-values / no predefined outcome of interest)

Global state: CGI severity (no predefined outcome of interest)

Behaviour: Nurses' Observation Scale for Inpatient Evaluation (only p-values / no predefined outcome of interest)

Readiness for discharge: Discharge-Readiness Inventory (only p-values / no predefined outcome of interest)

Ophthalmologic examination (no predefined outcome of interest)

Notes

*We only analysed the low dose group, because the high dose was excessively high (2000mg chlorpromazine per day) and because the conventional treatment group was not double-blind

\section{Risk of bias}

\begin{tabular}{|c|c|c|}
\hline Bias & Authors' judgement & Support for judgement \\
\hline $\begin{array}{l}\text { Random sequence generation (selection } \\
\text { bias) }\end{array}$ & Unclear risk & Randomly assigned, no further details. \\
\hline Allocation concealment (selection bias) & Unclear risk & Procedure not described. \\
\hline $\begin{array}{l}\text { Blinding (performance bias and detection } \\
\text { bias) } \\
\text { Subjective outcomes }\end{array}$ & Unclear risk & Double, liquid formulation. \\
\hline
\end{tabular}

Blinding (performance bias and detection Low risk

Double, liquid formulation.

bias)

Objective outcomes

Incomplete outcome data (attrition bias) High risk

All outcomes

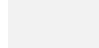

Overall 26\% dropped out (of which $87 \%$ due to relapse). $15 \%$ of the participants in the drug group compared to $38 \%$ of the participants in the placebo group left the study early. This difference in attrition is a problem for the analysis of other outcomes than relapse 
Blinding: double, identical capsules. Whether blinding was successful was not assessed, although in one group high doses associated with a lot of side-effects were administered.

Duration: 24 weeks.

Design: parallel.

Location: multi-centre.

Setting: inpatient.

Participants

Diagnosis: chronic schizophrenia (clinical diagnosis), hospitalised for at least 2 years.

$\mathrm{N}=341$.

Gender: n.i.

Age: mean 41.8 years.

History: duration stable- not clearly indicated, all were observed on their normal hospital medication for 4 weeks, quote "we may assume that the patients were well stabilised", duration ill- n.i., number of previous hospitalisations- n.i., but mean length of current hospitalisation 15 years, age at onset- n.i. , severity of illness- n.i., baseline antipsychotic dose- n.i.

Interventions

1. Drug: high dose trifluoperazine. Fixed dose of $80 \mathrm{mg} /$ day (reached within 35 days). $\mathrm{N}=117$

2. Drug: low dose trifluoperazine. Fixed dose of $15 \mathrm{mg} /$ day. $\mathrm{N}=113$

3. Placebo: Duration of taper: 0 days. $\mathrm{N}=111$.

Rescue medication: not indicated, but probably not allowed.

Outcomes

Examined:

Relapse: worsening of global state.

Adverse effects: clinical interview based on 40 items checklist

Unable to use / Not included:

Mental state: Inpatient Multidimensional Psychiatric Scale, Brief Psychiatric Rating Scale (both only p-values / no predefined outcome of interest)

Global state: CGI (no predefined outcome of interest).

Behaviour: Nurses' Observation Scale for Inpatient Evaluation (only p-values / no predefined outcome of interest)

Readiness for discharge: Discharge-Readiness Inventory (only p-values / no predefined outcome of interest)

Ophthalmologic examination (no predefined outcome of interest)

\section{Notes}

Risk of bias

\begin{tabular}{l|ll}
\hline Bias & Authors' judgement & Support for judgement \\
\hline $\begin{array}{l}\text { Random sequence generation (selection } \\
\text { bias) }\end{array}$ & Unclear risk & Randomised, no further details. \\
\hline Allocation concealment (selection bias) & Unclear risk & Procedure not described.
\end{tabular}


Prien 1969 (Continued)

\begin{tabular}{l|l}
$\begin{array}{l}\text { Blinding (performance bias and detection } \\
\text { bias) }\end{array}$ & Unclear risk \\
Subjective outcomes & $\begin{array}{l}\text { Double, identical capsules. Whether blind- } \\
\text { ing was successful was not assessed, al- } \\
\text { though in one group high doses associated } \\
\text { with a lot of side-effects were administered }\end{array}$ \\
\hline
\end{tabular}

Blinding (performance bias and detection Low risk

bias)

Objective outcomes

Double, identical capsules. Whether blinding was successful was not assessed, although in one group high doses associated with a lot of side-effects were administered

Incomplete outcome data (attrition bias) High risk All outcomes

The overall attrition was considerable (33\%) and clearly more participants discontinued the study early in the placebo group $(53 \%)$ than in the two drug groups (23\%), mainly due to inefficacy, which can be a problem for other outcomes than relapse. Not all participants were included in the final analysis

\begin{tabular}{|c|c|c|}
\hline Selective reporting (reporting bias) & Low risk & No evidence for selective reporting. \\
\hline Other bias & High risk & $\begin{array}{l}\text { The high-dose group used too high doses } \\
\text { ( } 80 \mathrm{mg} / \text { day) for current standards, even the } \\
\text { low-dose would nowadays be considered to } \\
\text { be quite high } / 15 \mathrm{mg} / \text { day) }\end{array}$ \\
\hline
\end{tabular}

Rifkin 1979

Methods

Randomisation: random, no further details.

Allocation: procedure not described.

Blinding: double-dummy technique, procyclidine was added to fluphenazine to avoid unmasking by extrapyramidal side-effects.

Duration: one year.

Design: parallel.

Location: single-centre.

Setting: outpatient.

Participants

Diagnosis: schizophrenia (hospital diagnosis, there was an additional evaluation based on research criteria (Kraepelinian), but the results of all participants are presented here) , in remission (no positive symptoms, but other symptoms could be present). Patients who were uncooperative in the stabilisation phase were not included in the study

$\mathrm{N}=73$.

Gender: 50 men, 23 women.

Age: mean 23.3 years.

History: duration stable- at least four weeks stable on fluphenazine before randomisation, duration ill- n.i., number of previous hospitalisations- mean 1.72 previous episodes, age at onset- n.i., severity of illness- n.i., baseline antipsychotic dose- n.i. 
Rifkin 1979 (Continued)

\begin{tabular}{|c|c|}
\hline Interventions & $\begin{array}{l}\text { 1. Drug: fluphenazine decanoate combined with procyclidine Flexible dose of } 0.5-2.0 \mathrm{ml} \\
\text { biweekly. Mean dose: } \mathrm{n} . \mathrm{i} . . \mathrm{N}=23 \\
\text { 2. Drug: oral fluphenazine combined with procyclidine. Flexible dose of } 5-20 \mathrm{mg} / \text { day. } \\
\text { Mean dose: n.i.. } \mathrm{N}=28 \\
\text { 3. Placebo: Duration of taper: } 0 \text { days. } \mathrm{N}=22 \text {. } \\
\text { Rescue medication: not clearly indicated, but probably not allowed }\end{array}$ \\
\hline Outcomes & $\begin{array}{l}\text { Examined: } \\
\text { Relapse: substantial deterioration with a potential of marked social impairment } \\
\text { Leaving the study early. } \\
\text { Adverse effects: dropout due to specific adverse events. } \\
\text { Unable to use / Not included: } \\
\text { Global state (CGI - no SD, data for relapsed subgroup only). } \\
\text { mental state (Brief Psychiatric Rating Scale - no SD, data for relapsed subgroup only) } \\
\text { Social adjustment: Katz Adjustment Scale - no SD, only data for relapsed subgroup and } \\
\text { a matched but not randomised subsample } \\
\text { Akinesia: Periodic Evaluation Record (no SD, data for relapsed subgroup only) } \\
\text { Death. }\end{array}$ \\
\hline Notes & \\
\hline
\end{tabular}

Risk of bias

\begin{tabular}{|c|c|c|}
\hline Bias & Authors' judgement & Support for judgement \\
\hline $\begin{array}{l}\text { Random sequence generation (selection } \\
\text { bias) }\end{array}$ & Unclear risk & Random, no further details. \\
\hline Allocation concealment (selection bias) & Unclear risk & Procedure not described. \\
\hline $\begin{array}{l}\text { Blinding (performance bias and detection } \\
\text { bias) } \\
\text { Subjective outcomes }\end{array}$ & Low risk & $\begin{array}{l}\text { Double-dummy technique, procyclidine } \\
\text { was added to fluphenazine to avoid un- } \\
\text { masking by extrapyramidal side-effects }\end{array}$ \\
\hline
\end{tabular}

Blinding (performance bias and detection Low risk bias)

Objective outcomes

Double-dummy technique, procyclidine was added to fluphenazine to avoid unmasking by extrapyramidal side-effects

Incomplete outcome data (attrition bias) High risk All outcomes
$67 \%$ of the participants discontinued the study due to relapse $(41 \%)$ or other reasons. More participants in the drug group discontinued due to adverse events, while more participants in the placebo group discontinued due to relapse. This differential attrition can cause bias

No evidence for selective reporting. 
Rifkin 1979 (Continued)

\begin{tabular}{|c|}
\hline Other bias \\
\hline
\end{tabular}

Roelofs 1974

Methods

Randomisation: divided into two comparable groups by an unbiased statistician.

Allocation: procedure not explained.

Blinding: double, identical capsules.

Duration: 6 months.

Design: parallel.

Location: single-centre.

Setting: inpatient, sponsored.

Participants

Diagnosis: chronic psychotic inpatients (clinical diagnosis), 13 schizophrenia, 1 dementia, 1 paranoia

$\mathrm{N}=15$.

Gender: 6 men, 9 women.

Age: median 54 years.

History: duration stable- n.i., duration ill- mean 17.7 years, number of previous hospitalisations- n.i., but mean duration of hospitalisation 11.3 years, age at onset- mean 36 . 3 years, severity of illness- n.i., baseline antipsychotic dose- n.i.

Interventions

1. Drug: penfluridol. Fixed/flexible dose: unclear, but different doses according to pretrial medication. Allowed dose range: unclear, but all participants received $40 \mathrm{mg} /$ week. Mean dose: 40mg/week. $\mathrm{N}=7$

2. Placebo: Duration of taper: 0 days. $\mathrm{N}=8$.

Rescue medication:

Dexetimide was given prophylactically to prevent extrapyramidal side-effects

Outcomes

Examined:

Relapse: need of additional antipsychotic medication.

Leaving the study early.

Unable to use / Not included:

Mental state: Zwanikken Scale (no mean, no SD / no predefined outcome of interest)

Behaviour: Zwanikken Scale (no mean, no SD / no predefined outcome of interest)

Adverse effects: interview (no data).

Notes

Risk of bias

\begin{tabular}{|c|c|c|}
\hline Bias & Authors' judgement & Support for judgement \\
\hline $\begin{array}{l}\text { Random sequence generation (selection } \\
\text { bias) }\end{array}$ & Unclear risk & $\begin{array}{l}\text { Divided into two comparable groups by an } \\
\text { unbiased statistician }\end{array}$ \\
\hline
\end{tabular}

Allocation concealment (selection bias)

Procedure not explained.

Maintenance treatment with antipsychotic drugs for schizophrenia (Review) 
Blinding (performance bias and detection Unclear risk

Double, identical capsules.

bias)

Subjective outcomes

Blinding (performance bias and detection Low risk

Double, identical capsules.

bias)

Objective outcomes

Incomplete outcome data (attrition bias) Low risk

All outcomes

\begin{tabular}{lll}
\hline Selective reporting (reporting bias) & Low risk & No evidence for selective reporting. \\
\hline Other bias & Low risk & No clear other bias. \\
\hline
\end{tabular}

\section{Ruskin 1991}

Methods

Randomisation: random, no further details.

Allocation: procedure not described.

Blinding: double, "participants and investigators were blind to treatment", no further details.

Duration: 6 months.

Design: parallel.

Location: single-centre.

Setting: outpatient.

Participants

Diagnosis: schizophrenia (DSM-III), not dangerous to themselves, no hospitalisation in the last year

$\mathrm{N}=23$.

Gender: 23 men.

Age: $>50$ years, mean 60.1 years.

History: duration stable- at least 1 month, last hospitalisation an average of 12.8 years ago, duration ill- n.i., number of previous hospitalisations- n.i., age at onset- n.i., severity of illness- mean BPRS psychosis subscale 6.2, baseline antipsychotic dose- 325 chlorpromazine equivalents (according to Davis's equivalents)

Interventions

Before randomisation all participants were put on haloperidol for one month or until they were considered stable

1. Drug: haloperidol. Fixed dose (dose before randomisation was maintained). Mean dose: n.i.. $\mathrm{N}=11$

2. Placebo: Duration of taper: 14 days. $\mathrm{N}=12$.

Rescue medication: n.i., but probably not allowed.

Outcomes

Examined:

Relapse: significant clinical design defined by either reoccurrence of symptoms or worsening of existing symptoms or prodromals signs such as sleep problems or anxiety Unable to use / Not included:

Mental state: BPRS (no data for each group / no predefined outcome of interest) 
Ruskin 1991 (Continued)

Quality of life: Heinrich Scale (no data for each group).

Notes

Risk of bias

\begin{tabular}{|c|c|c|}
\hline Bias & Authors' judgement & Support for judgement \\
\hline $\begin{array}{l}\text { Random sequence generation (selection } \\
\text { bias) }\end{array}$ & Unclear risk & Random, no further details. \\
\hline Allocation concealment (selection bias) & Unclear risk & Procedure not described. \\
\hline $\begin{array}{l}\text { Blinding (performance bias and detection } \\
\text { bias) } \\
\text { Subjective outcomes }\end{array}$ & Unclear risk & $\begin{array}{l}\text { Double, "participants and investigators } \\
\text { were blind to treatment", no further details }\end{array}$ \\
\hline $\begin{array}{l}\text { Blinding (performance bias and detection } \\
\text { bias) } \\
\text { Objective outcomes }\end{array}$ & Low risk & $\begin{array}{l}\text { Double, "participants and investigators } \\
\text { were blind to treatment", no further details }\end{array}$ \\
\hline $\begin{array}{l}\text { Incomplete outcome data (attrition bias) } \\
\text { All outcomes }\end{array}$ & Unclear risk & $\begin{array}{l}47 \% \text { of the participants left the study early, } \\
\text { most of them due to a relapse }(55 \%) \text {. This } \\
\text { attrition can be a source of bias for other } \\
\text { outcomes than relapse }\end{array}$ \\
\hline Selective reporting (reporting bias) & High risk & Data on quality of life were not reported. \\
\hline Other bias & Low risk & No clear evidence for other bias. \\
\hline
\end{tabular}

\section{Sampath 1992}

Methods
Randomisation: random, no further details.

Allocation: procedure not described.

Blinding: double, placebo was sesame oil of identical volume and identical in physical appearance.

Duration: 12 months.

Design: parallel.

Location: single-centre.

Setting: inpatient, sponsored.

Participants
Diagnosis: chronic schizophrenia (Research Diagnostic Criteria), stable for at least 5 years (absence of clinical deterioration and/or an increase of neuroleptic medication, retrospectively and in addition prospectively for at least 12 months), all on fluphenazine decanoate

$\mathrm{N}=24$.

Gender: n.i..

Age: mean 57.3 years. 
History: duration stable- retrospectively at least 5 years, prospectively for 12 months, mean 7 years, duration ill- mean 33.1 years, number of previous hospitalisations- n.i. , but mean duration of hospitalisation 24.9 years (unclear whether current or life-time total), age at onset- mean 24.3 years, severity of illness- mean BPRS total score 24.9, baseline antipsychotic dose- mean $41.9 \mathrm{mg}$ fluphenazine / 4 weeks

Interventions

1. Drug: fluphenazine decanoate.Fixed dose: mean $50.4 \mathrm{mg} / 4$ weeks. $\mathrm{N}=12$

2. Placebo: Duration of taper: 0 days, but all participants were on depot medication before the study. $\mathrm{N}=12$

Rescue medication: n.i., but probably not allowed.

Outcomes

Examined:

Relapse: at least 25\% increase of Brief Psychiatric Rating Scale total score and judgement of by nurse according to Psychotic Inpatient Profile

Unable to use / Not included:

Mental state: Brief Psychiatric Rating Scale total, Psychotic Inpatient Profile (for both scales means for subgroups only / no predefined outcome of interest)

Physiological measures: prolactin levels (no SD's / no predefined outcome of interest)

Notes

Risk of bias

\begin{tabular}{l|l|l}
\hline Bias & Authors' judgement & Support for judgement \\
\hline $\begin{array}{l}\text { Random sequence generation (selection } \\
\text { bias) }\end{array}$ & Unclear risk & Random, no further details. \\
\hline $\begin{array}{l}\text { Allocation concealment (selection bias) } \\
\text { Blinding (performance bias and detection } \\
\text { bias) } \\
\text { Subjective outcomes }\end{array}$ & Unclear risk & Procedure not described. \\
\hline $\begin{array}{l}\text { Blinding (performance bias and detection } \\
\text { bias) } \\
\text { Objective outcomes }\end{array}$ & Low risk & $\begin{array}{l}\text { Double, placebo was sesame oil of identical } \\
\text { volume and identical in physical appear- } \\
\text { ance }\end{array}$ \\
\hline $\begin{array}{l}\text { Incomplete outcome data (attrition bias) } \\
\text { All outcomes }\end{array}$ & Unclear risk & $\begin{array}{l}\text { Double, placebo was sesame oil of identical } \\
\text { volume and identical in physical appear- } \\
\text { ance }\end{array}$ \\
\hline \begin{tabular}{l} 
Selective reporting (reporting bias) \\
\hline $\begin{array}{l}\text { Other bias } \\
\text { L }\end{array}$
\end{tabular} & Low risk & $\begin{array}{l}\text { There is no statement on participants leav- } \\
\text { ing the study early }\end{array}$ \\
\hline
\end{tabular}




Rethods
Randomisation: random, no further details.
Allocation: procedure not described.
Blinding: double, identical capsules in taste.
Duration: 6 months.
Design: parallel.
Location: multi-centre.
Setting: unclear.

Participants

Diagnosis: schizophrenia (DSM-IV).

$\mathrm{N}=386$.

Gender: 221 men, 165 women.

Age: mean 38.9 years.

History: duration stable- 30 weeks, duration ill- mean 12.7 years, number of previous hospitalisations- n.i., age at onset- mean 26.7 years, severity of illness- n.i., baseline antipsychotic dose- all on asenapine 10 or $20 \mathrm{mg} /$ day

Interventions

1. Drug: asenapine. Fixed dose (same dose as at end of stabilisation phase): mean 17.6 $\mathrm{mg} /$ day. $\mathrm{N}=194$

2. Placebo: Duration of taper: 0 days. $\mathrm{N}=192$.

Rescue medication: benzodiazepines, anticholinergics, antidepressants

Outcomes

Examined:

Relapse: CGI-severity $>=4$, moderately ill for one week was accompanied by: PANSS total score increase $>=20 \%$ (a 10 point increase if PANSS was lower than 50), a PANSS item score $>=5$ on hostility of uncooperativeness or a PANSS item score $>=5$ and two items of unusual thought content, conceptual disorganisation or hallucinatory behaviour. Relapse was also judged to appear if in the investigator's opinion schizophrenia, risk of violence to self or others, or suicide risk increased so $>=1$ of the following was required: an additional $>=2 \mathrm{mg} /$ day lorazepam, compared with the highest open label dose for 1 week, addition of antipsychotic, addition or dosage increase of an antidepressant or moodstabiliser, increased psychiatric care, arrest or imprisonment, electroconvulsive therapy, or other relevant measures

Death: suicidal ideation, suicide attempts.

Adverse effects: at least one adverse event, at least one movement disorder, akathisia, sedation, weight gain

Unable to use / Not included:

Mental state: PANSS (no predefined outcome of interest).

Global state: CGI (no predefined outcome of interest).

Leaving the study early (data are unclear).

Hospitalisation (no data).

Electrocardiogram (no predefined outcome of interest).

Notes

Risk of bias

Bias

Authors' judgement

Support for judgement

Maintenance treatment with antipsychotic drugs for schizophrenia (Review) 
Schering Plough 2010 (Continued)

\begin{tabular}{|c|c|c|}
\hline $\begin{array}{l}\text { Random sequence generation (selection } \\
\text { bias) }\end{array}$ & Unclear risk & Random, no further details. \\
\hline Allocation concealment (selection bias) & Unclear risk & Procedure not described. \\
\hline $\begin{array}{l}\text { Blinding (performance bias and detection } \\
\text { bias) } \\
\text { Subjective outcomes }\end{array}$ & Unclear risk & Double, identical capsules in taste. \\
\hline $\begin{array}{l}\text { Blinding (performance bias and detection } \\
\text { bias) } \\
\text { Objective outcomes }\end{array}$ & Low risk & Double, identical capsules in taste. \\
\hline $\begin{array}{l}\text { Incomplete outcome data (attrition bias) } \\
\text { All outcomes }\end{array}$ & High risk & $\begin{array}{l}\text { High dropout rate, but exact number of } \\
\text { drop-outs could not be calculated. Drop- } \\
\text { outs were not clearly enough reported. Sur- } \\
\text { vival curve analysis was used for the pri- } \\
\text { mary outcome relapse }\end{array}$ \\
\hline Selective reporting (reporting bias) & Low risk & No evidence for selective reporting. \\
\hline Other bias & Low risk & No evidence for selective reporting. \\
\hline
\end{tabular}

\section{Schiele 1961}

\begin{tabular}{|c|c|}
\hline Methods & $\begin{array}{l}\text { Randomisation: random, no further details. } \\
\text { Allocation: only the hospital pharmacist had the code on what medication the patient } \\
\text { was on. } \\
\text { Blinding: double, identical capsules, each participant had his own container. } \\
\text { Duration: } 16 \text { weeks. } \\
\text { Design: parallel. } \\
\text { Location: single-centre. } \\
\text { Setting: inpatient. }\end{array}$ \\
\hline Participants & $\begin{array}{l}\text { Diagnosis: schizophrenia (clinical diagnosis), all withdrawn of subject to periodic dis- } \\
\text { turbances, all needed supervision or management } \\
\mathrm{N}=80 \text {. } \\
\text { Gender: } 80 \text { men. } \\
\text { Age: younger than } 55 \text { years, mean } 40.6 \text { years. } \\
\text { History: duration stable- } n \text {.i. ("participants had attained and maintained some degree of } \\
\text { improvement"), duration ill- n.i., but mean duration of current hospitalisation } 10 \text { years, } \\
\text { number of previous hospitalisations- mean } 1.6 \text {, age at onset- } \mathrm{n} . \mathrm{i} \text {, severity of illness- } \mathrm{n} \text {. } \\
\text { i., but "most required closed ward care", median baseline antipsychotic dose- chlorpro- } \\
\text { mazine } 475 \mathrm{mg} / \text { day ( } \mathrm{n}=30) \text {, mepazine } 200 \mathrm{mg} / \text { day ( } \mathrm{n}=35) \text {, trifluoperazine } 30 \mathrm{mg} / \text { day } \\
\text { ( } \mathrm{n}=6 \text { ), prochlorpromazine ( } \mathrm{n}=2 \text {, dose not indicated), combinations of drugs }(\mathrm{n}=7 \text {, doses } \\
\text { not indicated) }\end{array}$ \\
\hline
\end{tabular}


Schiele 1961 (Continued)

\begin{tabular}{|c|c|c|}
\hline Interventions & \multicolumn{2}{|c|}{$\begin{array}{l}\text { 1. Drug: chlorpromazine; flexible dose; allowed dose range } 200 \text { to } 1000 \mathrm{mg} / \text { day; mean } \\
\text { dose: } 894 \mathrm{mg} / \text { day (here mean maximum dose); } \mathrm{N}=20 \\
\text { 2. Drug: trifluoperazine; flexible dose; allowed dose range } 10 \text { to } 50 \mathrm{mg} / \text { day; mean dose: } \\
29 \mathrm{mg} / \text { day (here mean maximum dose); } \mathrm{N}=20 \\
\text { 3. Drug: thioridazine; flexible dose; allowed dose range } 200 \text { to } 1000 \mathrm{mg} / \text { day; mean dose: } \\
958 \mathrm{mg} / \text { day (here mean maximum dose); } \mathrm{N}=20 \\
\text { 4. Placebo: duration of taper: } 0 \text { days; } \mathrm{N}=20 \\
\text { Rescue medication: phenobarbital and bentropine methansulfonate, no additional an- } \\
\text { tipsychotic drugs }\end{array}$} \\
\hline Outcomes & \multicolumn{2}{|c|}{$\begin{array}{l}\text { Examined: } \\
\text { Relapse: worsening of global state } \\
\text { Adverse effects: clinical interview, number of participants receiving antiparkinson med- } \\
\text { ication } \\
\text { Unable to use / Not included: } \\
\text { Global state: CGI-Severity Scale (no predefined outcome of interest) } \\
\text { Behaviour: Manifest Behaviour Scale (no SD / no predefined outcome of interest) } \\
\text { Personality: Minnesota Multiphasic Personality Inventory (no SD / no predefined out- } \\
\text { come of interest) }\end{array}$} \\
\hline Notes & \multicolumn{2}{|c|}{ The results of all drug groups were pooled } \\
\hline \multicolumn{3}{|l|}{ Risk of bias } \\
\hline Bias & Authors' judgement & Support for judgement \\
\hline $\begin{array}{l}\text { Random sequence generation (selection } \\
\text { bias) }\end{array}$ & Unclear risk & Random, no further details \\
\hline Allocation concealment (selection bias) & Low risk & $\begin{array}{l}\text { Only the hospital pharmacist had the code } \\
\text { on what medication the patient was on }\end{array}$ \\
\hline $\begin{array}{l}\text { Blinding (performance bias and detection } \\
\text { bias) } \\
\text { Subjective outcomes }\end{array}$ & Unclear risk & $\begin{array}{l}\text { Double, identical capsules, each partici- } \\
\text { pant had his own container }\end{array}$ \\
\hline $\begin{array}{l}\text { Blinding (performance bias and detection } \\
\text { bias) } \\
\text { Objective outcomes }\end{array}$ & Low risk & $\begin{array}{l}\text { Double, identical capsules, each partici- } \\
\text { pant had his own container }\end{array}$ \\
\hline $\begin{array}{l}\text { Incomplete outcome data (attrition bias) } \\
\text { All outcomes }\end{array}$ & Low risk & $\begin{array}{l}\text { Only } 3 \text { out of } 80 \text { participants left the study } \\
\text { early and the reasons were well described }\end{array}$ \\
\hline Selective reporting (reporting bias) & Low risk & No selective reporting. \\
\hline Other bias & Low risk & No evidence for other bias. \\
\hline
\end{tabular}

Maintenance treatment with antipsychotic drugs for schizophrenia (Review) 
Methods

Participants

Randomisation: matched and then randomised by a research assistant.

Allocation: by a research assistant who carefully guarded the identity of patients and the assigned treatment regimen. Furthermore, medication was assigned by the director of professional services who kept the names for use in case a patient had to be withdrawn from the study.

Blinding: double, identical capsules.

Duration: 26 weeks.

Design: parallel.

Location: single-centre.

Setting: inpatient.

Diagnosis: chronic schizophrenia (clinical diagnosis), less than 50 years, on chlorpromazine for at least six months, had reached a stable improved state

$\mathrm{N}=80$.

Gender: n.i..

Age: all $<50$ years.

History: duration stable- n.i., duration ill- n.i., number of previous hospitalisations- $\mathrm{n}$. i., but median duration of current hospitalisation eight years, age at onset- n.i., severity of illness- n.i., baseline antipsychotic dose- n.i.

Interventions

1. Drug: chlorpromazine. Fixed dose of $200 \mathrm{mg} /$ day. $\mathrm{N}=40$.

2. Drug: reserpine*. Fixed dose of $2 \mathrm{mg} /$ day. $\mathrm{N}=40$.

3. Placebo: Duration of taper 0 days. $\mathrm{N}=40$.

Rescue medication: not indicated, probably not allowed.

Outcomes

Examined:

Leaving the study early.

Unable to use / Not included:

Mental state: Lorr Multidimensional Scale for Rating Psychiatric Patients (no SD / no predefined outcome of interest)

Behaviour: Psychiatric Behaviour Rating Scales (no SD / no predefined outcome of interest)

Notes $\quad$ *this group was not used in the analysis.

Risk of bias

Bias

Random sequence generation (selection Unclear risk bias)

Allocation concealment (selection bias) Low risk
Support for judgement

Matched and then randomised by a research assistant.

By a research assistant who carefully guarded the identity of patients and the assigned treatment regimen. Furthermore, medication was assigned by the director of professional services who kept the names for use in case a patient had to be withdrawn from the study 


\section{Shawver 1959 (Continued)}

\begin{tabular}{|c|c|c|}
\hline $\begin{array}{l}\text { Blinding (performance bias and detection } \\
\text { bias) } \\
\text { Subjective outcomes }\end{array}$ & Unclear risk & Double, identical capsules. \\
\hline $\begin{array}{l}\text { Blinding (performance bias and detection } \\
\text { bias) } \\
\text { Objective outcomes }\end{array}$ & Low risk & Double, identical capsules. \\
\hline $\begin{array}{l}\text { Incomplete outcome data (attrition bias) } \\
\text { All outcomes }\end{array}$ & Low risk & $\begin{array}{l}\text { Overall } 11 \% \text { dropped out, most of them } \\
\text { due to relapse }(88 \%) \text { in the placebo group. } \\
\text { As relapse, drop-out and suicide were the } \\
\text { only outcomes, this did not produce a risk } \\
\text { of bias }\end{array}$ \\
\hline Selective reporting (reporting bias) & Low risk & No evidence for selective reporting. \\
\hline Other bias & Low risk & No clear evidence of other bias. \\
\hline
\end{tabular}

\section{Spohn 1986}

Methods

Randomisation: random, no further details.

Allocation: procedure not explained.

Blinding: double, placebo matching in kind and dose the previous medication.

Duration: 10 weeks.

Design: parallel.

Location: three hospitals.

Setting: probably inpatients.

Participants

Diagnosis: schizophrenia (Schedule for Affective Disorder and Schizophrenia, and Research Diagnostic Criteria), all had previously responded to antipsychotic drugs

$\mathrm{N}=100$.

Gender: 73 men, 27 women.

Age: mean 32.6 years.

History: duration stable- prospectively participants had remained for 10 weeks on the same medication before the study, duration ill- mean 9.7 years, number of previous hospitalisations- n.i., average cumulative hospitalisation 6.5 years, age at onset- mean 22.9 years, severity of illness- n.i., baseline antipsychotic dose- n.i.

Interventions

1. Drug: various antipsychotic drugs. Fixed/flexible dose: probably flexible. Allowed dose range: n.i.. Mean dose: n.i.. $\mathrm{N}=36$

2. Placebo: Duration of taper 0 days. $\mathrm{N}=64$.

Rescue medication: n.i.

Outcomes

Examined:

Relapse: first signs of symptoms according to ward staff and project nurse, full deterioration was not waited for Unable to use / Not included:

Performance tests: Rohrschach test, Wechsler Adult Intelligence Scale (all no clear mean's, 
Spohn 1986 (Continued)

n's, no SD's / no predefined outcomes of interest)

Mental state: Brief Psychiatric Rating Scale (no clear mean, no number of participatns, no SD / no predefined outcome of interest)

Thought disorder: Thought Disorder Index, Psychological Rating Scale (all no clear mean's, no SD's / no predefined outcomes of interest)

Notes

Risk of bias

\begin{tabular}{l|ll} 
Bias & Authors' judgement & Support for judgement \\
\hline $\begin{array}{l}\text { Random sequence generation (selection } \\
\text { bias) }\end{array}$ & Unclear risk & Random, no further details. \\
\hline $\begin{array}{l}\text { Allocation concealment (selection bias) } \\
\begin{array}{l}\text { Blinding (performance bias and detection } \\
\text { bias) } \\
\text { Subjective outcomes }\end{array}\end{array}$ & Unclear risk & Procedure not explained. \\
\hline
\end{tabular}

Blinding (performance bias and detection Low risk bias)

Double, placebo matching in kind and dose

Objective outcomes

the previous medication

Incomplete outcome data (attrition bias) Unclear risk

All outcomes

Unclear, because these have not been indicated.

Selective reporting (reporting bias) Low risk

No evidence for selective reporting.

Other bias

Unclear risk

Unclear, baseline data have not been presented for both groups separately

Troshinsky 1962

\begin{tabular}{l} 
Rethods \\
Randomisation: randomised, no further details. \\
Allocation: psychiatrist without contact to the participants held the key \\
medication containers. \\
Blinding: double, exact placebo replicas. \\
Duration: -43 weeks. \\
Design: parallel. \\
Location: single-centre. \\
Setting: outpatient. \\
\hline Participants \\
Diagnosis: schizophrenia without positive symptoms (clinical diagnosis) \\
N=43. \\
Gender: 16 men, 27 women. \\
Age: typically $40-50$ years.
\end{tabular}


History: duration stable- out of hospital for at least a year (typically 2-4 years), duration ill- n.i., number of previous hospitalisations- typically 2-3, age at onset n.i., severity of illness n.i., but no positive symptoms at baseline, baseline antipsychotic dose- maximum $300 \mathrm{mg}$ chlorpromazine per day

Interventions
1. Drug: various phenothiazines, mainly chlorpromazine. Fixed/flexible dose: flexible. Allowed dose range: not limited, but complete discontinuation was not allowed. Mean dose: $150-200 \mathrm{mg} /$ day chlorpromazine. $\mathrm{N}=24$

2. Placebo: Duration of taper: 0 days. $\mathrm{N}=19$.

Rescue medication: not allowed.

Examined:

Relapse: clinical judgement.

Service use: number of participants rehospitalised.

Notes

\section{Risk of bias}

\begin{tabular}{|c|c|c|}
\hline Bias & Authors' judgement & Support for judgement \\
\hline $\begin{array}{l}\text { Random sequence generation (selection } \\
\text { bias) }\end{array}$ & Unclear risk & Randomised, no further details. \\
\hline Allocation concealment (selection bias) & Low risk & $\begin{array}{l}\text { Psychiatrist without contact to the partic- } \\
\text { ipants held the key and filled the medica- } \\
\text { tion containers }\end{array}$ \\
\hline $\begin{array}{l}\text { Blinding (performance bias and detection } \\
\text { bias) } \\
\text { Subjective outcomes }\end{array}$ & Unclear risk & Double, exact placebo replicas. \\
\hline $\begin{array}{l}\text { Blinding (performance bias and detection } \\
\text { bias) } \\
\text { Objective outcomes }\end{array}$ & Low risk & Double, exact placebo replicas. \\
\hline $\begin{array}{l}\text { Incomplete outcome data (attrition bias) } \\
\text { All outcomes }\end{array}$ & Unclear risk & $\begin{array}{l}\text { Unclear - whether participants discontin- } \\
\text { ued the study prematurely was not reported }\end{array}$ \\
\hline Selective reporting (reporting bias) & Low risk & No evidence for selective reporting. \\
\hline Other bias & High risk & $\begin{array}{l}\text { Some placebo participants continued to } \\
\text { take medication, study terminated early }\end{array}$ \\
\hline
\end{tabular}


Duration: 6 months

Design: parallel.

Location: single-centre.

Setting: inpatient.

Participants

Diagnosis: chronic schizophrenia (DSM-II), catatonic type $(n=2)$, residual type $(n=15)$, hebephrenic type $(\mathrm{n}=1)$, simple type $(\mathrm{n}=2)$, paranoid type $(\mathrm{n}=1)$

$\mathrm{N}=21$.

Gender: 21 women.

Age: mean 58 years.

History: duration stable- successfully maintained on penfluridol for at least 6 months, duration ill- mean 28.5 years, median duration of current hospitalisation 21 years, number of previous hospitalisations- n.i., age at onset- 29.5 years, severity of illness- n.i., baseline antipsychotic dose- mean $43 \mathrm{mg} /$ week penfluridol

Interventions

1. Drug: penfluridol. Fixed dose, mean $43 \mathrm{mg} /$ week. $\mathrm{N}=10$.

2. Placebo: Duration of taper: 0 days. $\mathrm{N}=11$.

Rescue medication: antiparkinson medication, haloperidol, but this was considered to be a sign of relapse

Outcomes

Examined:

Relapse: use of additional haloperidol.

Leaving the study early.

Unable to use / Not included:

Mental state: Zwanikken scale (no data / no predefined outcome of interest)

Adverse effects: Zwanikken scale (no data / continuous side-effect results were not among the predefined outcomes of interest)

Notes

Risk of bias

\begin{tabular}{|c|c|c|}
\hline Bias & Authors' judgement & Support for judgement \\
\hline $\begin{array}{l}\text { Random sequence generation (selection } \\
\text { bias) }\end{array}$ & Unclear risk & Randomised, no further details. \\
\hline Allocation concealment (selection bias) & Unclear risk & Procedure not described. \\
\hline $\begin{array}{l}\text { Blinding (performance bias and detection } \\
\text { bias) } \\
\text { Subjective outcomes }\end{array}$ & Unclear risk & Double, identical capsules. \\
\hline
\end{tabular}

Blinding (performance bias and detection Low risk

Double, identical capsules. bias)

Objective outcomes 
Vandecasteele 1974 (Continued)

\begin{tabular}{l|l|l}
\hline $\begin{array}{l}\text { Incomplete outcome data (attrition bias) } \\
\text { All outcomes }\end{array}$ & Low risk & No participant left the study prematurely. \\
\hline Selective reporting (reporting bias) & High risk & $\begin{array}{l}\text { Data on side-effects and the mental state } \\
\text { were not reported. }\end{array}$ \\
\hline Other bias & Low risk & No evidence for other bias. \\
\hline
\end{tabular}

\section{Whittaker 1963}

Methods

Randomisation: arbitrarily allocated.

Allocation: procedure not described.

Blinding: double (only the pharmacist knew which bottles were active. Participants were asked whether they were aware of the medication, but only one realised a change in taste. Nurses were also asked, but did not guess the right medication better than by chance alone.

Duration: 10 weeks.

Design: parallel.

Location: two centres.

Setting: inpatient.

Participants

Diagnosis: chronic schizophrenia (clinical diagnosis by at least two psychiatrists), all with paranoid condition, two additionally catatonic tendencies and one hebephrenic features, six were leucotomised

$\mathrm{N}=26$.

Gender: 26 men.

Age: mean 50.7 years.

History: duration stable- n.i., but all had been receiving maintenance doses of perphenazine for a mean of 16 months, duration ill- n.i., but mean duration of current hospitalisation 16.5 years, number of previous hospitalisations- n.i., age at onset- n.i. , severity of illness- n.i., baseline antipsychotic dose- two $12 \mathrm{mg}$ tid, one $20 \mathrm{mg}$ tid, all other $8 \mathrm{mg}$ tid and most less

Interventions

1. Drug: perphenazine liquid. Fixed dose (same dose as before the start of the study) two $12 \mathrm{mg}$ tid, one $20 \mathrm{mg}$ tid, all other $8 \mathrm{mg}$ tid and most less. Mean dose: see above. $\mathrm{N}=13$

2. Placebo. Duration of taper: 0 days. $\mathrm{N}=13$.

3. No medication*. Duration of taper: 0 days. $\mathrm{N}=13$.

Rescue medication: not allowed apart from antiparkinson medication

Outcomes

Examined:

Relapse: "major relapse" = replaced on active medication.

Unable to use / Not included:

Mental state: self-developed psychiatric rating scale - unpublished scale (no predefined outcome of interest)

Behaviour: Fergus Falls Behaviour Rating Scale (no mean, no SD / no predefined outcome of interest)

*This group was not used for the review. 
Whittaker 1963 (Continued)

\section{Risk of bias}

\begin{tabular}{|c|c|c|}
\hline Bias & Authors' judgement & Support for judgement \\
\hline $\begin{array}{l}\text { Random sequence generation (selection } \\
\text { bias) }\end{array}$ & Unclear risk & Arbitrarily allocated. \\
\hline Allocation concealment (selection bias) & Unclear risk & Procedure not described. \\
\hline $\begin{array}{l}\text { Blinding (performance bias and detection } \\
\text { bias) } \\
\text { Subjective outcomes }\end{array}$ & Low risk & $\begin{array}{l}\text { Double - only the pharmacist knew which } \\
\text { bottles were active. Participants were asked } \\
\text { whether they were aware of the medica- } \\
\text { tion, but only one realised a change in } \\
\text { taste. Nurses were also asked, but did not } \\
\text { guess the correct medication better than by } \\
\text { chance alone }\end{array}$ \\
\hline $\begin{array}{l}\text { Blinding (performance bias and detection } \\
\text { bias) } \\
\text { Objective outcomes }\end{array}$ & Low risk & $\begin{array}{l}\text { Double - only the pharmacist knew which } \\
\text { bottles were active. Participants were asked } \\
\text { whether they were aware of the medica- } \\
\text { tion, but only one realised a change in } \\
\text { taste. Nurses were also asked, but did not } \\
\text { guess the correct medication better than by } \\
\text { chance alone }\end{array}$ \\
\hline $\begin{array}{l}\text { Incomplete outcome data (attrition bias) } \\
\text { All outcomes }\end{array}$ & Unclear risk & $\begin{array}{l}\text { Dropouts were not reported. It is not clear, } \\
\text { whether there really no dropouts }\end{array}$ \\
\hline Selective reporting (reporting bias) & Low risk & No evidence for selective reporting. \\
\hline Other bias & Low risk & No clear evidence for other bias. \\
\hline
\end{tabular}

\section{Wistedt 1981}

\begin{tabular}{ll} 
Methods & Randomisation: random, no further details. \\
& Allocation: procedure not described. \\
& Blinding: double, placebo sesame oil. \\
& Duration: 26 weeks. \\
& Design: parallel. \\
& Location: single-centre. \\
& Setting: outpatient. \\
\hline Participants & Diagnosis: schizophrenia (according to Bleuler's concept, with three primary symptoms) \\
& , duration ill at least 2 years \\
& N=41. \\
& Gender: 15 men, 23 women. \\
& Age: mean 43.1 years. \\
& History: duration stable- outpatient and continuous antipsychotic treatment for at least
\end{tabular}


one year, on flupenthixol depot or fluphenazine depot for at least three months, prospective stabilisation phase of 6 months, duration ill- mean 13.3 years, number of previous hospitalisations- n.i., age at onset- mean 29.8 years, severity of illness- mean Comprehensive Psychopathological Rating Scale schizophrenia score 2.3, baseline antipsychotic dose- mean $21.42 \mathrm{mg}$ fluphenazine $/ 3$ weeks or $27.5 \mathrm{mg}$ flupenthixol/three weeks

Interventions

1. Drug: fluphenazine depot (most around 12.5 - $25 \mathrm{mg} / 3$ weeks, mean $21.42 \mathrm{mg} / 3$ weeks) or flupenthixol depot (most around $20-40 \mathrm{mg} / 3$ weeks, mean $27.5 / 3$ weeks) Fixed dose. $\mathrm{N}=24$

2. Placebo: Duration of taper: 0 days. $\mathrm{N}=17$.

Rescue medication: chloral hydrate, antiparkinson medication, additional antipsychotic drugs were not allowed

Outcomes

Examined:

Relapse: psychotic behaviour or increase in six subscales of the Comprehensive Psychopathological Rating Scale

Unable to use / Not included:

Mental state: Comprehensive Psychopathological Rating Scale (no SD / no predefined outcome of interest)

Behaviour: Nurses Observation Scale of Inpatient Evaluation (no SD / no predefined outcome of interest)

Adverse effects: extrapyramidal side-effects (Simpson Angus Scale, Acquired Involuntary Movements Scale, Akathisia Rating Scale (all no SD, akathisia scale was not published / continuous side-effect results were not among the predefined outcomes of interest) Physiological measures: various laboratory tests (no data / no predefined outcome of interest)

Life events (Life Event Scale / no predefined outcome of interest)

Notes

Risk of bias

\begin{tabular}{l|ll}
\hline Bias & Authors' judgement & Support for judgement \\
\hline $\begin{array}{l}\text { Random sequence generation (selection } \\
\text { bias) }\end{array}$ & Unclear risk & Random, no further details. \\
\hline $\begin{array}{l}\text { Allocation concealment (selection bias) } \\
\begin{array}{l}\text { Blinding (performance bias and detection } \\
\text { bias) } \\
\text { Subjective outcomes }\end{array}\end{array}$ & Unclear risk & Procedure not described. \\
\hline
\end{tabular}

Blinding (performance bias and detection Low risk

Double, placebo sesame oil.

bias)

Objective outcomes 
Wistedt 1981 (Continued)

\begin{tabular}{l|l|l}
\hline $\begin{array}{l}\text { Incomplete outcome data (attrition bias) } \\
\text { All outcomes }\end{array}$ & Low risk & $\begin{array}{l}\text { Overall 3 (7\%) out of 41 participants left } \\
\text { the study early. Although only completers } \\
\text { were analysed, due to the low rate this is } \\
\text { not a problem }\end{array}$ \\
\hline Selective reporting (reporting bias) & Low risk & No evidence for selective reporting. \\
\hline Other bias & Low risk & No obvious risk for other bias. \\
\hline
\end{tabular}

\section{Zissis 1982}

Methods

Participants
Randomisation: randomly assigned according to pre-established randomisation code. Allocation: randomisation code was unknown to the evaluating investigators.

Blinding: double, administered by a particular nurse.

Duration: 16 weeks.

Design: parallel.

Location: single-centre.

Setting: inpatient.
Diagnosis: chronic schizophrenia (Feighner's criteria), treated with antipsychotic drugs for at least 2 years and currently under control

$\mathrm{N}=32$.

Gender: 9 men, 23 women.

Age: mean 46.5 years.

History: duration stable- n.i., but treated with antipsychotic drugs for at least 2 years and currently under control, duration ill- mean 24.4 years, number of previous hospitalisations- n.i., but mean duration of current hospitalisation 9.6 years, age at onset- mean 22.1 years, severity of illness- n.i., baseline antipsychotic dose- n.i.

Interventions

1. Drug: haloperidol decanoate. Flexible dose. Allowed dose range: starting dose $1.5 \mathrm{ml}$ (=150mg) four-weekly, maximum $3 \mathrm{ml}(=300 \mathrm{mg})$ four-weekly. Median dose $1.5 \mathrm{ml}$ fourweekly. $\mathrm{N}=16$

2. Placebo: Duration of taper: 0 days. $\mathrm{N}=16$.

Rescue medication: antiparkinson medication, oral haloperidol, but this was considered to be a relapse

Outcomes

Examined:

Relapse: addition of oral haloperidol.

Leaving the study early.

Adverse effects: open interviews.

Unable to use / Not included:

Mental state: Brief Psychiatric Rating Scale (no SD / no predefined outcome of interest) Global state: Clinical Global Impression Severity Scale (no predefined outcome of interest)

Behaviour: Nurses Observation Scale for Inpatient Evaluation (no SD / no predefined outcome of interest)

Adverse effects: use of antiparkinson medication (only indicated for haloperidol group) , at least one movement disorder and sedation (patients received haloperidol) 
Zissis 1982 (Continued)

Notes

Risk of bias

\begin{tabular}{|c|c|c|}
\hline Bias & Authors' judgement & Support for judgement \\
\hline $\begin{array}{l}\text { Random sequence generation (selection } \\
\text { bias) }\end{array}$ & Low risk & $\begin{array}{l}\text { Randomly assigned according to pre-estab- } \\
\text { lished randomisation code }\end{array}$ \\
\hline Allocation concealment (selection bias) & Low risk & $\begin{array}{l}\text { Randomisation code was unknown to the } \\
\text { evaluating investigators }\end{array}$ \\
\hline $\begin{array}{l}\text { Blinding (performance bias and detection } \\
\text { bias) } \\
\text { Subjective outcomes }\end{array}$ & Unclear risk & Double, administered by a particular nurse. \\
\hline $\begin{array}{l}\text { Blinding (performance bias and detection } \\
\text { bias) } \\
\text { Objective outcomes }\end{array}$ & Low risk & Double, administered by a particular nurse. \\
\hline $\begin{array}{l}\text { Incomplete outcome data (attrition bias) } \\
\text { All outcomes }\end{array}$ & Low risk & $\begin{array}{l}12 \text { out of } 16 \text { participants in the placebo } \\
\text { group compared to } 0 \text { out of } 16 \text { in the } \\
\text { haloperidol group were withdrawn from } \\
\text { the trial due to inefficacy of treatment. As } \\
\text { the only outcomes were relapse, number } \\
\text { of participants improved and leaving the } \\
\text { study early this should not have been a } \\
\text { problem }\end{array}$ \\
\hline Selective reporting (reporting bias) & Low risk & No evidence for selective reporting. \\
\hline Other bias & Low risk & No other bias. \\
\hline
\end{tabular}

General abbreviations

CNS: central nervous system

CPZ: chlorpromazine

DSM: Diagnostic and Statistical Manual of Mental Disorders

ECG: electrocardiography

ECT: electroconvulsive therapy

EASY: Early Assessment Service for Young People with Psychosis

EEG: electroencephalography

EPS: extrapyramidal symptoms

HbA1c: glycated haemoglobin

ICD: International Statistical Classification of Diseases and Related Health Problems

IM: intramuscular injection

ITT: intention to treat

LOCF: last observation carried forward 
NI: not indicated

SD: standard deviation

tid: ter in die (3 times a day)

Rating scales

AIMS: Abnormal Involuntary Movement Scale

AMDP: Arbeitsgemeinschaft für Methodik und Dokumentation in der Psychiatrie

BAS: Barnes Akathisia Scale

CGI: Clinical Global Impression

BPRS: Brief Psychiatric Rating Scale

GAS: Global Assessment Scale

IMPS: Inpatient Multidimensional Psychiatric Rating Scale

MMPI: Minnesota Multiphasic Personality Inventory

NOSIE: Nurses Observation Scale for Inpatient Evaluation

PANSS: Positive And Negative Syndrome Scale

PRP: Psychotic Reaction Profile

PRS: Psychiatric Rating Scale

PSE: Present State Examination

RDC: Research Diagnostic Criteria

SADS: Schedule for Affective Disorders

SANS: Scale for the Assessment of Negative Symptoms

SAS: Simpson-Angus Scale

Characteristics of excluded studies [ordered by study ID]

\begin{tabular}{l|l}
\hline Study & Reason for exclusion \\
\hline Allen 1997 & Allocation: controlled clinical trial, not randomised. \\
\hline Bourin 2008 & $\begin{array}{l}\text { Allocation: randomised. } \\
\text { Participants: not stabilised on antipsychotic drugs. }\end{array}$ \\
\hline Branchey 1981 & Allocation: not randomised, matched groups. \\
\hline Breier 1987 & Allocation: not randomised. \\
\hline Chouinard 1980 & Allocation: not randomised. \\
\hline Claghorn 1974 & $\begin{array}{l}\text { Allocation: randomised. } \\
\text { Participants: schizophrenia. } \\
\text { Intervention: thiothixene alone versus thiothixene plus group therapy versus chlorpromazine alone versus } \\
\text { chlorpromazine plus group therapy }\end{array}$ \\
\hline Collins 1967 & \begin{tabular}{l} 
Allocation: not randomised. \\
\hline
\end{tabular}
\end{tabular}

Maintenance treatment with antipsychotic drugs for schizophrenia (Review) 
(Continued)

\begin{tabular}{|c|c|}
\hline Condray 1995 & Allocation: not randomised. \\
\hline Curson 1985 & Allocation: not randomised. \\
\hline Degkwitz 1970 & Allocation: not randomised. \\
\hline Diamond 1960 & Allocation: not randomised. \\
\hline Double 1993 & $\begin{array}{l}\text { Allocation: randomised. } \\
\text { Participants: schizophrenia. } \\
\text { Intervention: all participants were on neuroleptics and antiparkinson medication at baseline. They were then } \\
\text { randomised to neuroleptics plus continuation of antiparkinson medication versus neuroleptics alone }\end{array}$ \\
\hline Engelhardt 1967 & $\begin{array}{l}\text { Allocation: randomised. } \\
\text { Participants: chronic schizophrenic outpatients, not truly stabilised on antipsychotic drugs }\end{array}$ \\
\hline Gleeson 2004 & $\begin{array}{l}\text { Allocation: randomised. } \\
\text { Participants: first-episode psychosis. } \\
\text { Intervention: treatment as usual (including antipsychotics) versus multimodal relapse prevention therapy (in- } \\
\text { cluding antipsychotics and cognitive behavioral therapy/family intervention) }\end{array}$ \\
\hline Goldberg 1967 & Allocation: not randomised. \\
\hline Good 1958 & $\begin{array}{l}\text { Allocation: randomised. } \\
\text { Participants: schizophrenia. } \\
\text { Interventions: chlorpromazine versus placebo. } \\
\text { Outcomes: no usable outcome. }\end{array}$ \\
\hline
\end{tabular}

Greenberg 1966

Allocation: randomised.

Participants: chronic schizophrenic patients.

Intervention: abrupt versus gradual withdrawal of chlorpromazine, but chlorpromazine was withdrawn from both groups. Thus not appropriate control group

\begin{tabular}{ll}
\hline Hine 1958 & Allocation: not randomised. \\
\hline Hunt 1967 & Allocation: not randomised. \\
\hline
\end{tabular}

Ionescu 1983 Allocation: not randomised.

Janecek 1963 Allocation: randomised.

Participants: 50\% not diagnosed as with schizophrenia.

Johnstone 1988 Allocation: not randomised.

Kellam 1971 Allocation: not randomised.

Lauriello 2005 Allocation: randomised.

Participants: participants were acutely ill, not stable. 
(Continued)

\begin{tabular}{ll} 
Lecrubier 1997 & $\begin{array}{l}\text { Allocation: randomised. } \\
\text { Participants: not stable, not all on antipsychotics before the study }\end{array}$ \\
\hline Loo 1997 & $\begin{array}{l}\text { Allocation: randomised. } \\
\text { Participants: participants were not stable, most not on antipsychotics before the study }\end{array}$ \\
\hline Mefferd 1958 & $\begin{array}{l}\text { Allocation: randomised. } \\
\text { Participants: men with schizophrenia. } \\
\text { Intervention: chlorpromazine versus placebo. } \\
\text { Outcome: no usable outcome. }\end{array}$ \\
\hline Mosher 1975 & Allocation: not randomised. \\
\hline Müller 1982 & Allocation: part of the participants was matched, not randomised \\
\hline Paul 1972 & Allocation: not randomised. \\
\hline Peet 1981 & $\begin{array}{l}\text { Allocation: randomised. } \\
\text { Participants: schizophrenia. } \\
\text { Intervention: chlorpromazine versus chlorpromazine plus propranolol }\end{array}$ \\
\hline Pickar 1986 & Allocation: not randomised. \\
\hline
\end{tabular}

Pigache 1993 Allocation: randomised.

Participants: chronic schizophrenia.

Intervention: chlorpromazine, placebo, orphenadrine.

Outcome: no relevant outcome, only auditory attention task.

\begin{tabular}{ll}
\hline Rassidakis 1970 & Allocation: not randomised. \\
\hline Ravaris 1965 & $\begin{array}{l}\text { Allocation: randomised. } \\
\text { Participants: chronic schizophrenia. } \\
\text { Intervention: fluphenazine elixir plus placebo injection versus fluphenazine enanthate injection plus oral } \\
\text { placebo }\end{array}$ \\
\hline Schlossberg 1978 & $\begin{array}{l}\text { Allocation: randomised. } \\
\text { Participants: not stable. }\end{array}$ \\
\hline Singh 1990 & Allocation: not randomised. \\
\hline Smelson 2006 & Allocation: not randomised. \\
\hline Soni 1990 & $\begin{array}{l}\text { Allocation: randomised. } \\
\text { Participants: schizophrenia, not stabilised on antipsychotic drugs, because all had been withdrawn from an- } \\
\text { tipsychotic drugs for 8-20 months before study start }\end{array}$
\end{tabular}


(Continued)

Tollefson $1999 \quad$ Allocation: randomised, but switch study with very short duration (3-5 days)

Vaddadi 1986
Participants: schizophrenia.
Intervention: depot antipsychotics (fluphenazine depot, flupenthixol depot or clopenthixol depot) plus oral
dihomo gammalinolenic acid (DHLA) versus oral DHLA plus placebo injections versus DHLA placebo
capsules and placebo injections. What is lacking is a depot antipsychotic only group

Van Kammen 1982 Allocation: not randomised.

Van Praag 1973 Allocation: randomised.

Participants: psychotic participants.

Intervention: fluphenazine enanthate versus fluphenazine decanoate

Wiedemann $2001 \quad$ Allocation: randomised.

Participants: schizophrenia.

Intervention: continuation of current antipsychotic versus gradual withdrawal. However, antipsychotic was given again when early warning signs appeared, i.e. intermittent treatment, a design that was excluded a prior by our protocol

Wright $1964 \quad$ Allocation: not randomised.

Wunderink 2006 Allocation: randomised.

Participants: schizophrenia and related psychotic disorder.

Intervention: continuation of current antipsychotic versus gradual withdrawal. However, antipsychotic was given again when early warning signs appeared, i.e. intermittent treatment, a design that was excluded by the protocol. Approximately $50 \%$ of participants were never withdrawn

Zeller 1956 Allocation: all participants were in hospital. 95 were allocated to placebo (not randomly). Then 81 participants were "selected at random to match" the intervention group. We feel that this is no appropriate randomisation method

Zwanikken 1973 Allocation: randomised.

Participants: more than $50 \%$ had mental retardation, not schizophrenia

\section{Characteristics of ongoing studies [ordered by study ID]}

\section{Eerdekens 2010}

Trial name or title A randomised double-blind placebo-controlled parallel group study evaluating paliperidone palmitate in the prevention of recurrence in patients with schizophrenia

Methods Allocation: randomised, no further details.

Blinding: double-blind, no further details.

Location: multicentre study.

Duration: the study consists of 5 periods: an up to 7-day screening/washout/tolerability period, a 9-week open-label transition period, a 24-week open-label maintenance period, a randomised, variable-length double- 
Eerdekens 2010 (Continued)

blind, placebo-controlled recurrence prevention period, and an up to 52-week open-label extension period

\begin{tabular}{ll}
\hline Participants & Diagnosis: stable and symptomatic schizophrenia according to DSM-IV-TM \\
\hline Interventions & $\begin{array}{l}\text { 1. Paliperidone palmitate. } \\
\text { 2. Placebo. }\end{array}$ \\
\hline Outcomes & $\begin{array}{l}\text { The primary outcome is the time from randomisation to the first recurrence } \\
\text { Mental state: PANSS. } \\
\text { Global state: CGI-S. } \\
\text { Personal and Social Performance Scale, adverse events, labs and ECG-tests }\end{array}$ \\
\hline Starting date & March 2005. \\
\hline Contact information & ClinicalTrials.gov identifier: NCT00111189. \\
\hline Notes &
\end{tabular}

CGI: Clinical Global Impression

DSM: Diagnostic and Statistical Manual of Mental Disorders

ECG: electrocardiography

PANSS: Positive And Negative Syndrome Scale 
DATA ANDANALYSES

Comparison 1. Maintenance treatment with antipsychotic drugs versus placebo/no treatment

\begin{tabular}{|c|c|c|c|c|}
\hline Outcome or subgroup title & $\begin{array}{l}\text { No. of } \\
\text { studies }\end{array}$ & $\begin{array}{c}\text { No. of } \\
\text { participants }\end{array}$ & Statistical method & Effect size \\
\hline 1 Relapse: up to 3 months & 34 & 3942 & Risk Ratio (M-H, Random, 95\% CI) & $0.30[0.24,0.38]$ \\
\hline 2 Relapse: 4 to 6 months & 40 & 5285 & Risk Ratio (M-H, Random, 95\% CI) & $0.35[0.30,0.42]$ \\
\hline 3 Relapse: 7 to 12 months & 24 & 2669 & Risk Ratio (M-H, Random, 95\% CI) & $0.40[0.33,0.49]$ \\
\hline 4 Relapse: > 12 months & 6 & 811 & Risk Ratio (M-H, Random, 95\% CI) & $0.59[0.42,0.82]$ \\
\hline 5 Relapse: independent of duration & 62 & 6392 & Risk Ratio (M-H, Random, 95\% CI) & $0.35[0.29,0.41]$ \\
\hline $\begin{array}{l}6 \text { Leaving the study early: due to } \\
\text { any reason }\end{array}$ & 47 & 4718 & Risk Ratio (M-H, Random, 95\% CI) & $0.53[0.46,0.61]$ \\
\hline 6.1 up to 3 months & 8 & 245 & Risk Ratio (M-H, Random, 95\% CI) & $0.23[0.07,0.72]$ \\
\hline 6.24 to 6 months & 17 & 1646 & Risk Ratio (M-H, Random, 95\% CI) & $0.48[0.35,0.66]$ \\
\hline 6.37 to 12 months & 18 & 2420 & Risk Ratio (M-H, Random, 95\% CI) & $0.55[0.46,0.66]$ \\
\hline $6.4>12$ months & 4 & 407 & Risk Ratio (M-H, Random, 95\% CI) & $0.68[0.36,1.26]$ \\
\hline $\begin{array}{l}7 \text { Leaving the study early: due to } \\
\text { adverse events }\end{array}$ & 43 & 4333 & Risk Ratio (M-H, Random, 95\% CI) & $1.16[0.70,1.91]$ \\
\hline 7.1 up to 3 months & 8 & 245 & Risk Ratio (M-H, Random, 95\% CI) & $2.84[0.12,65.34]$ \\
\hline 7.24 to 6 months & 14 & 1549 & Risk Ratio (M-H, Random, 95\% CI) & $0.99[0.57,1.74]$ \\
\hline 7.37 to 12 months & 17 & 2339 & Risk Ratio (M-H, Random, 95\% CI) & $1.24[0.59,2.60]$ \\
\hline $7.4>12$ months & 4 & 200 & Risk Ratio (M-H, Random, 95\% CI) & $0.0[0.0,0.0]$ \\
\hline $\begin{array}{l}8 \text { Leaving the study early: due to } \\
\text { inefficacy }\end{array}$ & 46 & 4546 & Risk Ratio (M-H, Random, 95\% CI) & $0.37[0.31,0.44]$ \\
\hline 8.1 up to 3 months & 9 & 295 & Risk Ratio (M-H, Random, 95\% CI) & $0.23[0.07,0.79]$ \\
\hline 8.24 to 6 months & 16 & 1661 & Risk Ratio (M-H, Random, 95\% CI) & $0.41[0.31,0.54]$ \\
\hline 8.37 to 12 months & 18 & 2420 & Risk Ratio (M-H, Random, 95\% CI) & $0.36[0.28,0.45]$ \\
\hline $8.4>12$ months & 3 & 170 & Risk Ratio (M-H, Random, 95\% CI) & $0.27[0.08,0.95]$ \\
\hline $\begin{array}{c}9 \text { Global state: number of } \\
\text { participants improved }\end{array}$ & 14 & 1524 & Risk Ratio (M-H, Random, 95\% CI) & $2.34[1.68,3.26]$ \\
\hline 9.1 up to 3 months & 1 & 49 & Risk Ratio (M-H, Random, 95\% CI) & $4.61[1.22,17.40]$ \\
\hline 9.24 to 6 months & 8 & 1037 & Risk Ratio (M-H, Random, 95\% CI) & $2.33[1.69,3.21]$ \\
\hline 9.37 to 12 months & 5 & 438 & Risk Ratio (M-H, Random, 95\% CI) & $1.95[0.91,4.18]$ \\
\hline $\begin{array}{l}10 \text { Service use: number of } \\
\text { participants hospitalised }\end{array}$ & 16 & 2090 & Risk Ratio (M-H, Random, 95\% CI) & $0.38[0.27,0.55]$ \\
\hline 10.1 up to 3 months & 2 & 55 & Risk Ratio (M-H, Random, 95\% CI) & $0.42[0.04,4.06]$ \\
\hline 10.24 to 6 months & 3 & 109 & Risk Ratio (M-H, Random, 95\% CI) & $0.08[0.01,0.42]$ \\
\hline 10.37 to 12 months & 8 & 1295 & Risk Ratio (M-H, Random, 95\% CI) & $0.32[0.18,0.57]$ \\
\hline $10.4>12$ months & 3 & 631 & Risk Ratio (M-H, Random, 95\% CI) & $0.56[0.44,0.70]$ \\
\hline $\begin{array}{l}11 \text { Service use: number of } \\
\text { participants discharged }\end{array}$ & 3 & 404 & Risk Ratio (M-H, Random, 95\% CI) & $2.76[0.69,11.06]$ \\
\hline 11.14 to 6 months & 3 & 404 & Risk Ratio (M-H, Random, 95\% CI) & $2.76[0.69,11.06]$ \\
\hline 12 Death: any & 14 & 2356 & Risk Ratio (M-H, Random, 95\% CI) & $0.77[0.28,2.11]$ \\
\hline 12.1 up to 3 months & 1 & 36 & Risk Ratio (M-H, Random, 95\% CI) & $0.0[0.0,0.0]$ \\
\hline 12.24 to 6 months & 5 & 856 & Risk Ratio (M-H, Random, 95\% CI) & $2.18[0.48,9.81]$ \\
\hline 12.37 to 12 months & 8 & 1464 & Risk Ratio (M-H, Random, 95\% CI) & $0.33[0.08,1.27]$ \\
\hline 13 Death: due to natural causes & 14 & 2401 & Risk Ratio (M-H, Random, 95\% CI) & $1.24[0.39,3.97]$ \\
\hline 13.14 to 6 months & 5 & 856 & Risk Ratio (M-H, Random, 95\% CI) & $2.18[0.48,9.81]$ \\
\hline
\end{tabular}

Maintenance treatment with antipsychotic drugs for schizophrenia (Review)

Copyright $\odot 2012$ The Cochrane Collaboration. Published by John Wiley \& Sons, Ltd. 
13.27 to 12 months

14 Suicide

14.1 up to 3 months

14.24 to 6 months

14.37 to 12 months

15 Suicide attempts

15.14 to 6 months

15.27 to 12 months

16 Suicide ideation

16.1 up to 3 months

16.24 to 6 months

16.37 to 12 months

17 Violent/aggressive behaviour

17.1 up to 3 months

17.24 to 6 months

17.37 to 12 months

18 Adverse effects: at least one adverse event

18.1 up to 3 months

18.24 to 6 months

18.37 to 12 months

19 Adverse effects: movement disorders: at least one movement disorder 19.1 up to 3 months 19.24 to 6 months 19.37 to 12 months

20 Adverse effects: movement disorders: akathisia

20.1 up to 3 months

20.24 to 6 months

20.37 to 12 months

21 Adverse effects: movement disorders: akinesia

21.1 up to 3 months

22 Adverse effects: movement disorders: dyskinesia

22.1 up to 3 months

22.24 to 6 months

22.37 to 12 months

23 Adverse effects: movement disorders: dystonia

23.1 up to 3 months

23.24 to 6 months

23.37 to 12 months

24 Adverse effects: movement disorders: rigor

24.1 up to 3 months

24.24 to 6 months

24.37 to 12 months

25 Adverse effects: movement disorders: tremor 40 1468
Risk Ratio (M-H, Random, 95\% CI) Risk Ratio (M-H, Random, 95\% CI) Risk Ratio (M-H, Random, 95\% CI) Risk Ratio (M-H, Random, 95\% CI) Risk Ratio (M-H, Random, 95\% CI) Risk Ratio (M-H, Random, 95\% CI) Risk Ratio (M-H, Random, 95\% CI) Risk Ratio (M-H, Random, 95\% CI) Risk Ratio (M-H, Random, 95\% CI) Risk Ratio (M-H, Random, 95\% CI) Risk Ratio (M-H, Random, 95\% CI) Risk Ratio (M-H, Random, 95\% CI) Risk Ratio (M-H, Random, 95\% CI) Risk Ratio (M-H, Random, 95\% CI) Risk Ratio (M-H, Random, 95\% CI) Risk Ratio (M-H, Random, 95\% CI) Risk Ratio (M-H, Random, 95\% CI)

Risk Ratio (M-H, Random, 95\% CI) Risk Ratio (M-H, Random, 95\% CI) Risk Ratio (M-H, Random, 95\% CI) Risk Ratio (M-H, Random, 95\% CI)

Risk Ratio (M-H, Random, 95\% CI) Risk Ratio (M-H, Random, 95\% CI) Risk Ratio (M-H, Random, 95\% CI) Risk Ratio (M-H, Random, 95\% CI)

Risk Ratio (M-H, Random, 95\% CI) Risk Ratio (M-H, Random, 95\% CI) Risk Ratio (M-H, Random, 95\% CI) Risk Ratio (M-H, Random, 95\% CI)

Risk Ratio (M-H, Random, 95\% CI) Risk Ratio (M-H, Random, 95\% CI)

49 Risk Ratio (M-H, Random, 95\% CI) 418 Risk Ratio (M-H, Random, 95\% CI) 1353 Risk Ratio (M-H, Random, 95\% CI) 824 Risk Ratio (M-H, Random, 95\% CI)

49 Risk Ratio (M-H, Random, 95\% CI) 382 Risk Ratio (M-H, Random, 95\% CI) 393 Risk Ratio (M-H, Random, 95\% CI) 249 Risk Ratio (M-H, Random, 95\% CI)

49 Risk Ratio (M-H, Random, 95\% CI) 160 Risk Ratio (M-H, Random, 95\% CI)
Risk Ratio (M-H, Random, 95\% CI)

Risk Ratio (M-H, Random, 95\% CI)
$0.54[0.09,3.36]$

$0.34[0.04,3.28]$

$0.0[0.0,0.0]$

$0.0[0.0,0.0]$

$0.34[0.04,3.28]$

$0.47[0.10,2.33]$

$3.0[0.13,71.51]$

$0.25[0.04,1.61]$

$0.67[0.04,10.56]$

0.17 [0.01, 3.88]

$0.0[0.0,0.0]$

2.77 [0.11, 66.57]

$0.27[0.15,0.52]$

$0.33[0.01,7.50]$

$0.2[0.01,3.92]$

0.28 [0.14, 0.53]

$1.01[0.87,1.18]$

$0.53[0.30,0.93]$

$0.96[0.80,1.15]$

$1.10[0.88,1.38]$

1.55 [1.25, 1.93]

$2.42[0.70,8.33]$

$1.45[1.06,1.99]$

$1.52[1.11,2.07]$

$1.75[0.87,3.51]$

$1.94[0.24,15.97]$

$1.67[0.41,6.80]$

1.74 [0.88, 3.45]

$0.97[0.09,9.92]$

0.97 [0.09, 9.92]

$0.52[0.28,0.97]$

$1.5[0.06,34.91]$

$0.31[0.11,0.84]$

$0.68[0.30,1.58]$

1.89 [1.05, 3.41]

$2.5[0.13,49.22]$

1.75 [0.94, 3.29]

$3.97[0.44,35.54]$

$1.25[0.54,2.88]$

$0.73[0.24,2.22]$

$1.98[0.67,5.85]$

$0.0[0.0,0.0]$

1.25 [0.81, 1.93] 
25.1 up to 3 months

25.24 to 6 months

25.37 to 12 months

26 Adverse effects: movement

disorders: use of antiparkinson

medication

26.14 to 6 months

26.27 to 12 months

27 Adverse effects: sedation

27.14 to 6 months

27.27 to 12 months

28 Adverse effects: weight gain

28.14 to 6 months

28.27 to 12 months

29 Quality of life

29.1 (7 to 12) months

29.2 (> 12 ) months

30 Number of participants

employed: 7 to 12 months
Risk Ratio (M-H, Random, 95\% CI)

$1.09[0.40,3.01]$

$0.92[0.33,2.61]$

$1.41[0.82,2.43]$

$1.40[1.03,1.89]$

Risk Ratio (M-H, Random, 95\% CI)

Risk Ratio (M-H, Random, 95\% CI)

$1.53[0.90,2.61]$

$1.33[0.86,2.05]$

$1.50[1.22,1.84]$

$1.33[0.86,2.07]$

$1.72[0.90,3.31]$

$2.07[1.31,3.25]$

$1.76[0.92,3.37]$

$2.57[1.30,5.07]$

$-0.62[-1.15,-0.09]$

$-0.62[-1.26,0.01]$

$-0.61[-1.66,0.45]$

$0.96[0.75,1.23]$

Comparison 2. Subgroup analysis (relapse at 12 months)

\begin{tabular}{|c|c|c|c|c|}
\hline Outcome or subgroup title & $\begin{array}{l}\text { No. of } \\
\text { studies }\end{array}$ & $\begin{array}{c}\text { No. of } \\
\text { participants }\end{array}$ & Statistical method & Effect size \\
\hline $\begin{array}{l}1 \text { Subgroup analysis: participants } \\
\text { with a first episode }\end{array}$ & 24 & 2669 & Risk Ratio (M-H, Random, 95\% CI) & $0.40[0.33,0.48]$ \\
\hline 1.1 first episode & 8 & 528 & Risk Ratio (M-H, Random, 95\% CI) & $0.47[0.38,0.58]$ \\
\hline 1.2 not first episode & 19 & 2141 & Risk Ratio (M-H, Random, 95\% CI) & $0.39[0.31,0.49]$ \\
\hline $\begin{array}{l}2 \text { Subgroup analysis: participants } \\
\text { in remission }\end{array}$ & 24 & 2669 & Risk Ratio (M-H, Random, 95\% CI) & $0.40[0.33,0.49]$ \\
\hline 2.1 in remission & 8 & 516 & Risk Ratio (M-H, Random, 95\% CI) & $0.38[0.24,0.61]$ \\
\hline 2.2 not in remission & 16 & 2153 & Risk Ratio (M-H, Random, 95\% CI) & $0.40[0.33,0.49]$ \\
\hline $\begin{array}{l}3 \text { Subgroup analysis: various } \\
\text { durations of stability before } \\
\text { entering the study }\end{array}$ & 18 & & Risk Ratio (M-H, Random, 95\% CI) & Subtotals only \\
\hline 3.1 stable at least 1 month & 5 & 428 & Risk Ratio (M-H, Random, 95\% CI) & $0.27[0.15,0.46]$ \\
\hline 3.2 stable at least 3 months & 5 & 806 & Risk Ratio (M-H, Random, 95\% CI) & $0.30[0.21,0.44]$ \\
\hline 3.3 stable at least 6 months & 1 & 20 & Risk Ratio (M-H, Random, 95\% CI) & $0.33[0.04,2.69]$ \\
\hline 3.4 stable at least 12 months & 5 & 326 & Risk Ratio (M-H, Random, 95\% CI) & $0.31[0.17,0.57]$ \\
\hline 3.5 stable at least 3 to 6 years & 2 & 54 & Risk Ratio (M-H, Random, 95\% CI) & $0.38[0.18,0.78]$ \\
\hline $\begin{array}{l}4 \text { Subgroup analysis: abrupt } \\
\text { withdrawal versus tapering }\end{array}$ & 24 & & Risk Ratio (M-H, Random, 95\% CI) & Subtotals only \\
\hline 4.1 Abrupt withdrawal & 16 & 1946 & Risk Ratio (M-H, Random, 95\% CI) & $0.43[0.34,0.54]$ \\
\hline 4.2 Taper & 8 & 723 & Risk Ratio (M-H, Random, 95\% CI) & $0.34[0.23,0.50]$ \\
\hline $\begin{array}{l}5 \text { Subgroup analysis: single } \\
\text { antipsychotic drugs }\end{array}$ & 24 & & Risk Ratio (M-H, Random, 95\% CI) & Subtotals only \\
\hline 5.1 Chlorpromazine & 2 & 406 & Risk Ratio (M-H, Random, 95\% CI) & $0.44[0.36,0.55]$ \\
\hline 5.2 Fluphenazine depot & 6 & 296 & Risk Ratio (M-H, Random, 95\% CI) & $0.23[0.14,0.39]$ \\
\hline
\end{tabular}

Maintenance treatment with antipsychotic drugs for schizophrenia (Review)

Copyright @ 2012 The Cochrane Collaboration. Published by John Wiley \& Sons, Ltd. 
5.3 Haloperidol depot

5.4 Quetiapine

5.5 Paliperidone

5.6 Various, mixed groups of

antipsychotic drugs

5.7 Ziprasidone

6 Subgroup analysis: depot versus

oral drugs

6.1 depot

6.2 oral

7 Subgroup analysis: first-

versus second-generation

antipsychotic drugs

7.1 First-generation

antipsychotic drugs

7.2 Second-generation

antipsychotic drugs

8 Subgroup analysis: appropriate

versus unclear allocation

concealment

8.1 appropriate allocation

concealment

8.2 unclear allocation

concealment

9 Subgroup analysis: blinded

versus open trials

9.1 blinded trials

9.2 unblinded trials
43

178

617

705

424

21

7

14

24

663

1785

18

1430

6

1239

24

2669

1410

Risk Ratio (M-H, Random, 95\% CI)

1259

Risk Ratio (M-H, Random, 95\% CI)

2669

Risk Ratio (M-H, Random, 95\% CI)

2412

Risk Ratio (M-H, Random, 95\% CI)

Risk Ratio (M-H, Random, 95\% CI)
$0.14[0.04,0.55]$

$0.48[0.34,0.69]$

0.36 [0.30, 0.45]

$0.42[0.27,0.65]$

$0.52[0.43,0.64]$

Subtotals only

$0.31[0.23,0.41]$

$0.46[0.37,0.57]$

Subtotals only

$0.35[0.25,0.48]$

$0.44[0.37,0.53]$

$0.40[0.33,0.49]$

$0.41[0.33,0.52]$

$0.39[0.28,0.53]$

$0.40[0.33,0.49]$

$0.42[0.35,0.51]$

$0.26[0.17,0.39]$

\section{Comparison 3. Sensitivity analysis (relapse at 12 months)}

\begin{tabular}{|c|c|c|c|c|}
\hline Outcome or subgroup title & $\begin{array}{l}\text { No. of } \\
\text { studies }\end{array}$ & $\begin{array}{c}\text { No. of } \\
\text { participants }\end{array}$ & Statistical method & Effect size \\
\hline $\begin{array}{l}1 \text { Exclusion of studies that were } \\
\text { not explicitly described as } \\
\text { randomised }\end{array}$ & 23 & 2654 & Risk Ratio (M-H, Random, 95\% CI) & $0.40[0.33,0.49]$ \\
\hline $\begin{array}{l}2 \text { Exclusion of non-double-blind } \\
\text { studies }\end{array}$ & 22 & 2412 & Risk Ratio (M-H, Random, 95\% CI) & $0.42[0.35,0.51]$ \\
\hline 3 Fixed-effects model & 24 & 2669 & Risk Ratio (M-H, Fixed, 95\% CI) & $0.40[0.36,0.44]$ \\
\hline $\begin{array}{l}4 \text { Original authors' assumptions } \\
\text { on dropouts }\end{array}$ & 24 & 2669 & Risk Ratio (M-H, Random, 95\% CI) & $0.40[0.33,0.49]$ \\
\hline $\begin{array}{l}5 \text { Inclusion of only large studies (> } \\
200 \text { participants) }\end{array}$ & 5 & 1506 & Risk Ratio (M-H, Random, 95\% CI) & $0.39[0.32,0.48]$ \\
\hline $\begin{array}{l}6 \text { Exclusion of studies with clinical } \\
\text { diagnosis }\end{array}$ & 16 & 2325 & Risk Ratio (M-H, Random, 95\% CI) & $0.42[0.36,0.49]$ \\
\hline 7 Three months stable & 20 & 2942 & Risk Ratio (M-H, Random, 95\% CI) & $0.40[0.30,0.55]$ \\
\hline 8 Six months stable & 13 & 1382 & Risk Ratio (M-H, Random, 95\% CI) & $0.40[0.26,0.61]$ \\
\hline 9 Nine months stable & 10 & 831 & Risk Ratio (M-H, Random, 95\% CI) & $0.46[0.29,0.73]$ \\
\hline
\end{tabular}

Maintenance treatment with antipsychotic drugs for schizophrenia (Review)

Copyright @ 2012 The Cochrane Collaboration. Published by John Wiley \& Sons, Ltd. 
10 Exclusion of studies with unclear randomisation method

11 Exclusion of studies with unclear allocation concealment method

\section{Analysis I.I. Comparison I Maintenance treatment with antipsychotic drugs versus placebo/no treatment,}

Outcome I Relapse: up to 3 months.

Review: Maintenance treatment with antipsychotic drugs for schizophrenia

Comparison: I Maintenance treatment with antipsychotic drugs versus placebo/no treatment

Outcome: I Relapse: up to 3 months

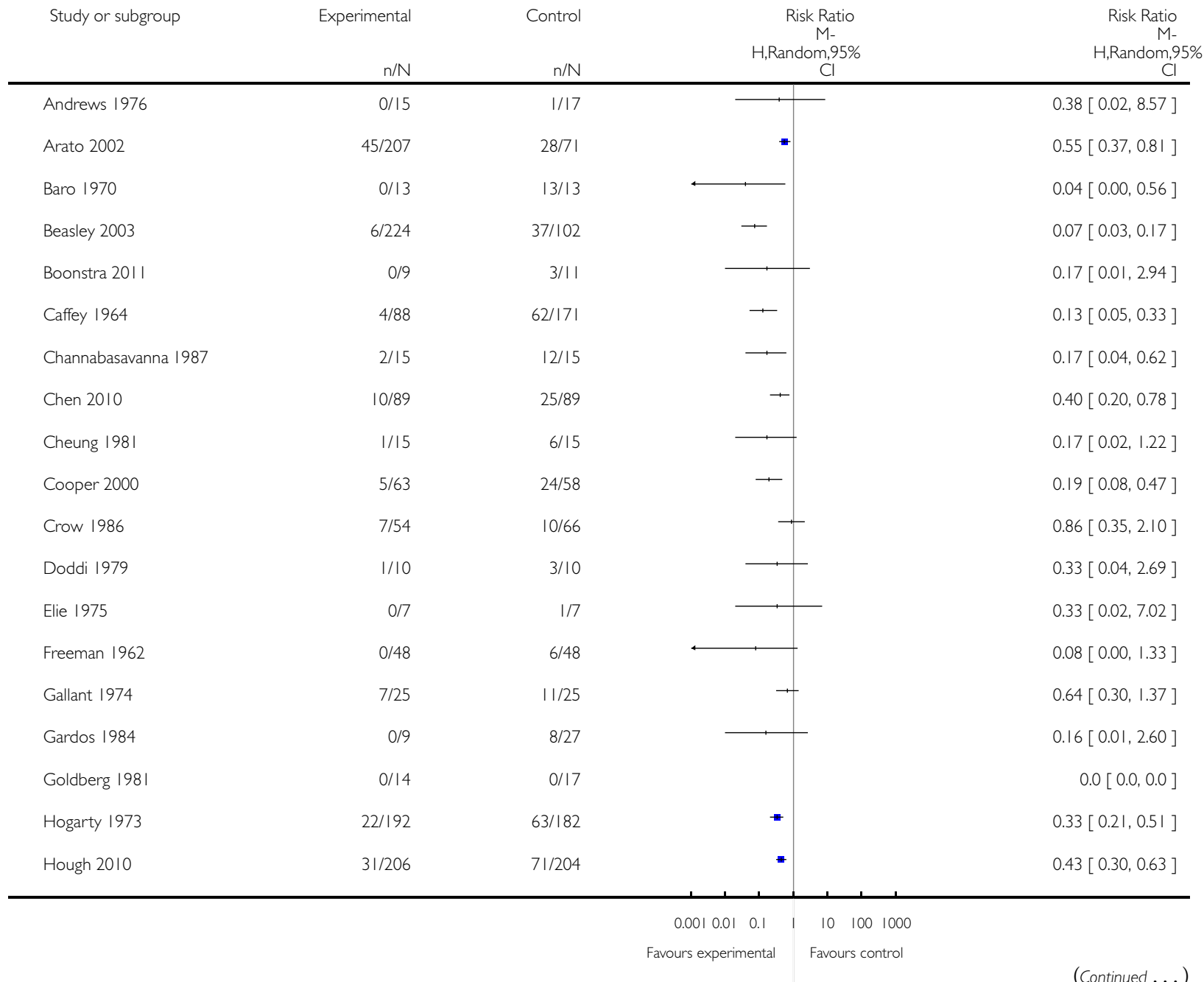




\begin{tabular}{|c|c|c|c|c|}
\hline Study or subgroup & Experimental & $\begin{array}{r}\text { Control } \\
n / N \\
\end{array}$ & $\begin{array}{c}\text { Risk Ratio } \\
\text { M- } \\
\text { H,Random,95\% } \\
\mathrm{Cl} \\
\end{array}$ & $\begin{array}{c}\text { (... Continued) } \\
\text { Risk Ratio } \\
\text { M- } \\
\text { H,Random,95\% } \\
\text { Cl } \\
\end{array}$ \\
\hline Keskiner 1968 & $3 / 13$ & $8 / 11$ & $\longrightarrow$ & $0.32[0.11,0.91]$ \\
\hline Kramer 2007 & $30 / 105$ & $64 / 102$ & $=$ & $0.46[0.32,0.64]$ \\
\hline Kurland 1975 & $0 / 18$ & $12 / 17$ & $\overline{ }$ & $0.04[0.00,0.59]$ \\
\hline Leff |97| & $2 / 20$ & $7 / 15$ & $一$ & $0.21[0.05,0.89]$ \\
\hline Melnyk 1966 & 0/20 & $10 / 20$ & - & $0.05[0.00,0.76]$ \\
\hline Nishikawa 1982 & $10 / 20$ & $8 / 10$ & - & $0.63[0.37,1.07]$ \\
\hline Olson 1962 & $0 / 30$ & $4 / 30$ & - & $0.11[0.01,1.98]$ \\
\hline Ota 1973 & 13/33 & $11 / 16$ & - & $0.57[0.33,0.98]$ \\
\hline Peuskens 2007 & 9/94 & $52 / 103$ & 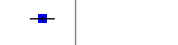 & $0.19[0.10,0.36]$ \\
\hline Pietzcker 1993 & $4 / 122$ & $15 / 115$ & 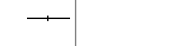 & $0.25[0.09,0.74]$ \\
\hline Sampath 1992 & $0 / 12$ & $4 / 12$ & + & $0.11[0.01,1.86]$ \\
\hline Schering Plough 2010 & $18 / 194$ & $70 / 192$ & 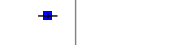 & $0.25[0.16,0.41]$ \\
\hline Spohn 1986 & $5 / 36$ & $44 / 64$ & $\leftarrow$ & $0.20[0.09,0.46]$ \\
\hline Whittaker 1963 & $1 / 13$ & $3 / 13$ & $\longrightarrow$ & $0.33[0.04,2.80]$ \\
\hline Wistedt |98| & $2 / 24$ & $6 / 17$ & 1 & $0.24[0.05,1.03]$ \\
\hline Total $(95 \%$ CI $)$ & 2057 & 1885 & - & $0.30[0.24,0.38]$ \\
\hline \multicolumn{5}{|c|}{ Total events: 238 (Experimental), 702 (Control) } \\
\hline \multicolumn{5}{|c|}{ Heterogeneity: Tau?? = 0.19; Chi?? = 69.7I, df = $32(P=0.00013) ; 1 ? ?=54 \%$} \\
\hline \multicolumn{5}{|c|}{ Test for overall effect: $Z=9.77(P<0.0000 \mathrm{I})$} \\
\hline \multicolumn{5}{|c|}{ Test for subgroup differences: Not applicable } \\
\hline
\end{tabular}


Analysis I.2. Comparison I Maintenance treatment with antipsychotic drugs versus placebo/no treatment, Outcome 2 Relapse: 4 to 6 months.

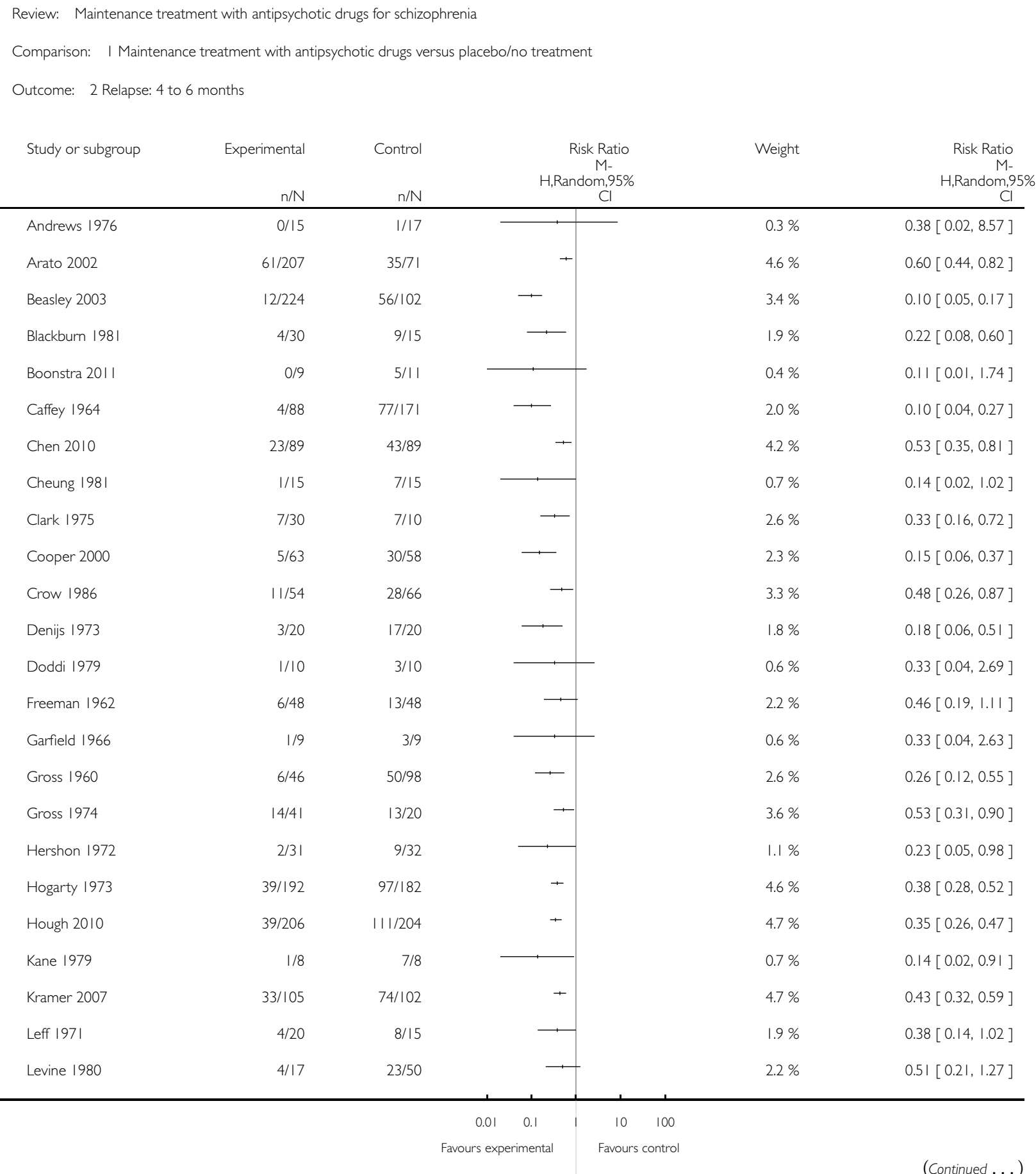




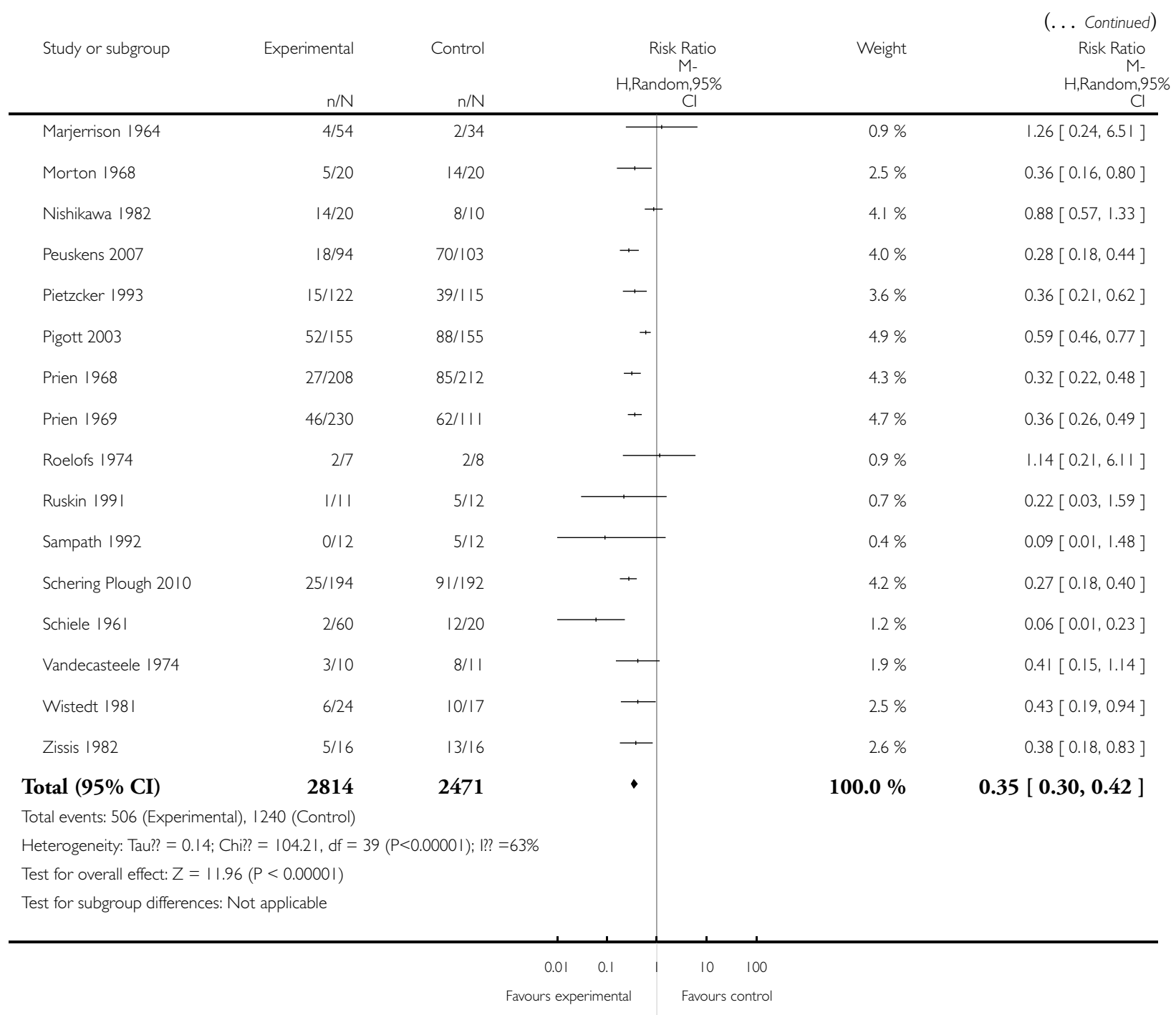


Analysis I.3. Comparison I Maintenance treatment with antipsychotic drugs versus placebo/no treatment, Outcome 3 Relapse: 7 to 12 months.

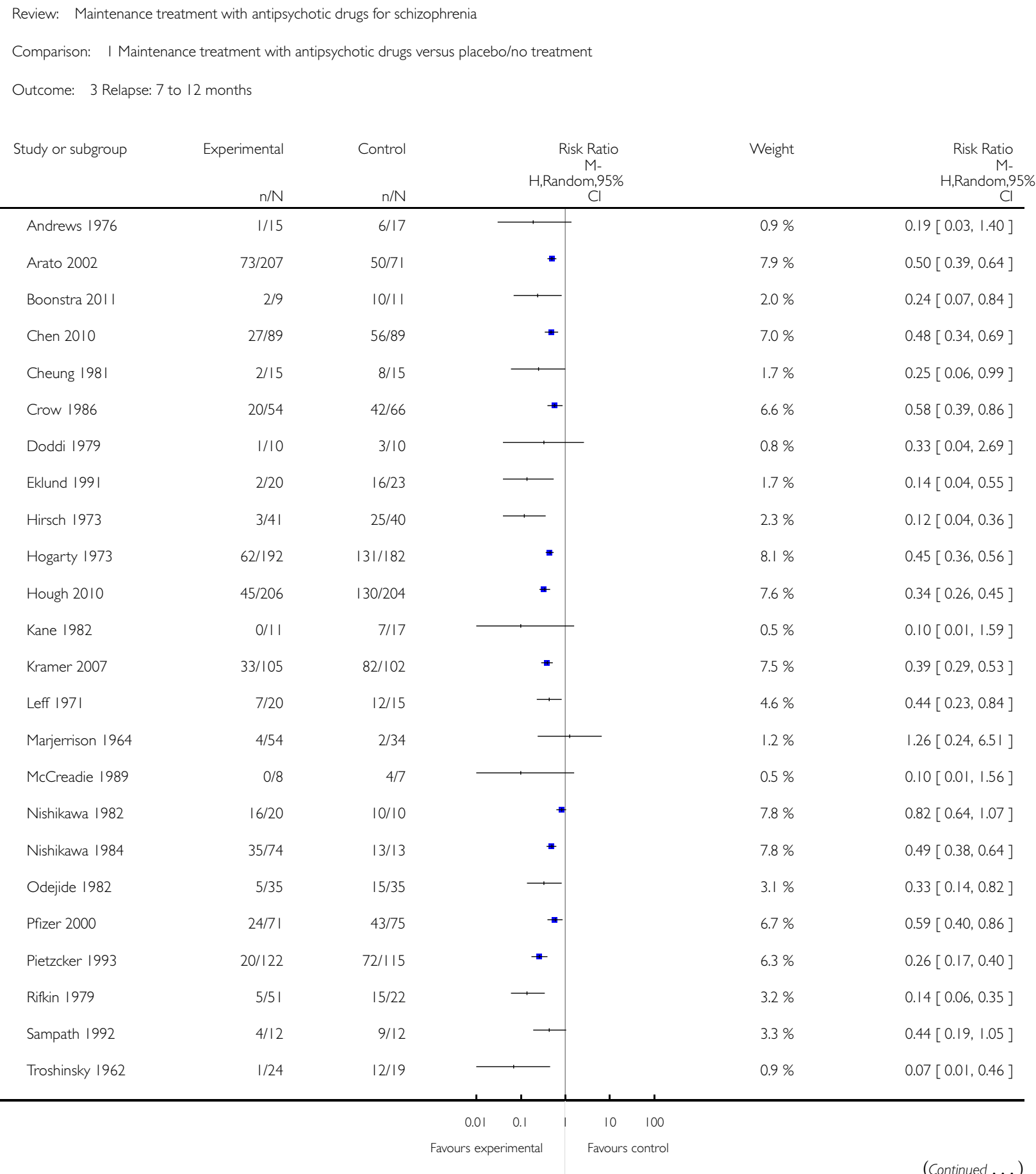




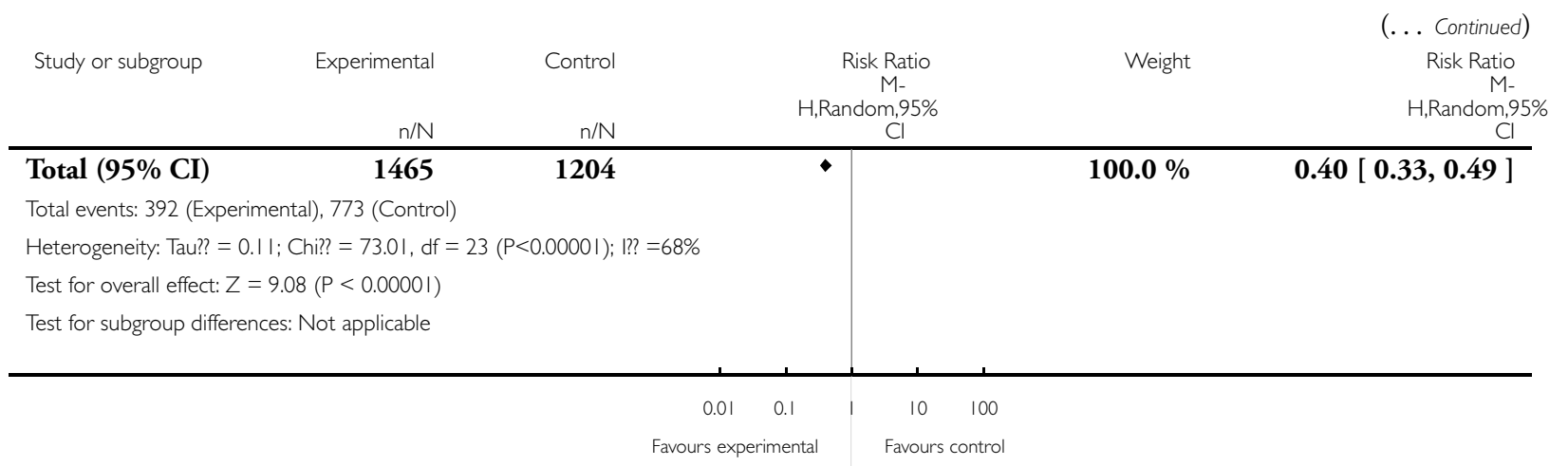

Analysis I.4. Comparison I Maintenance treatment with antipsychotic drugs versus placebo/no treatment, Outcome 4 Relapse: > 12 months.

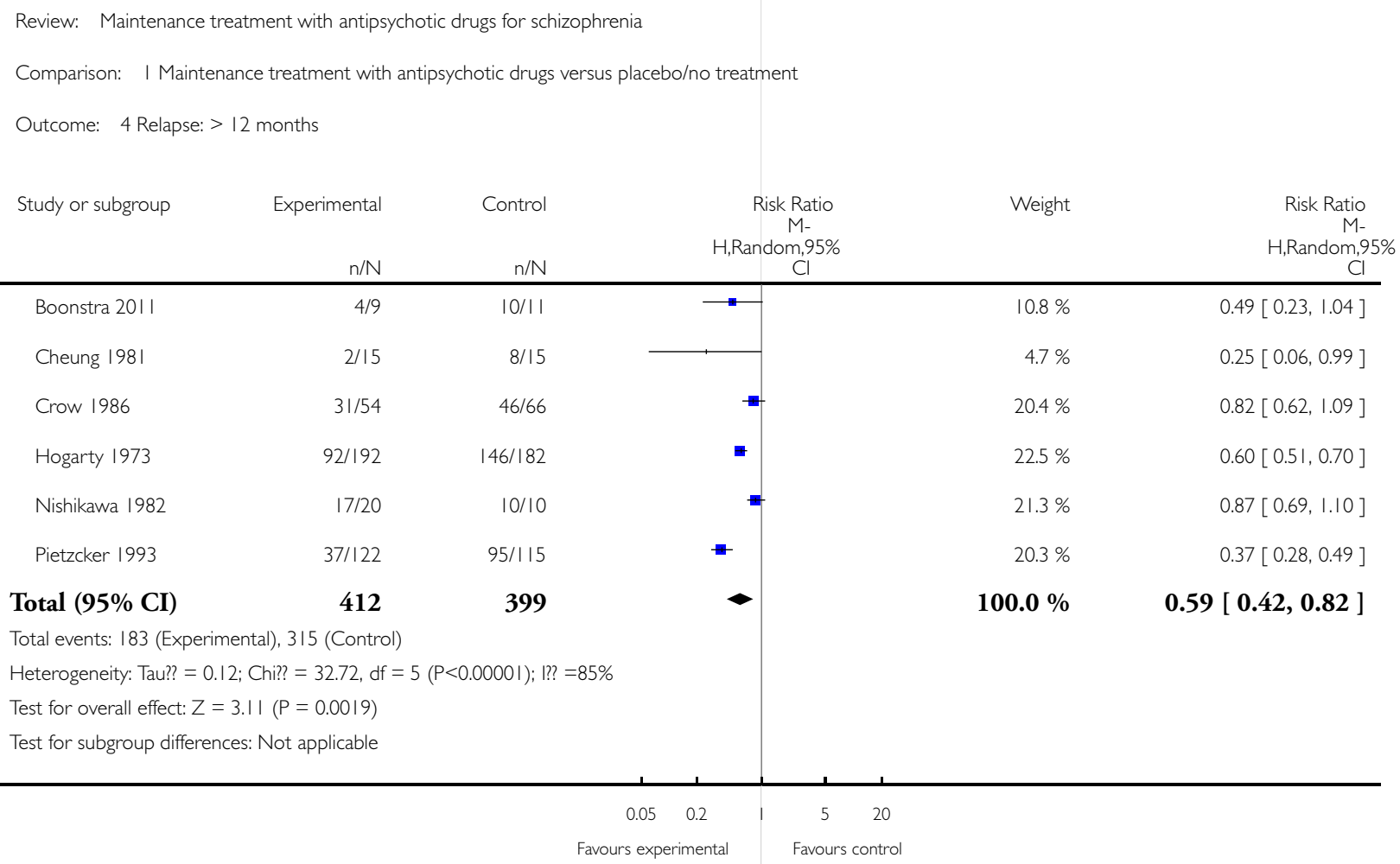


Analysis I.5. Comparison I Maintenance treatment with antipsychotic drugs versus placebo/no treatment, Outcome 5 Relapse: independent of duration.

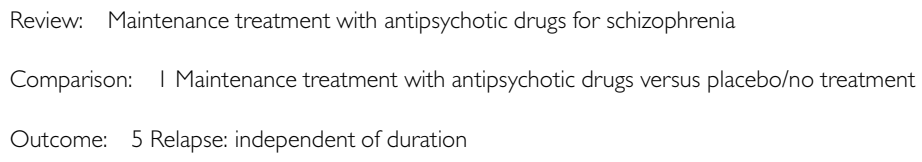

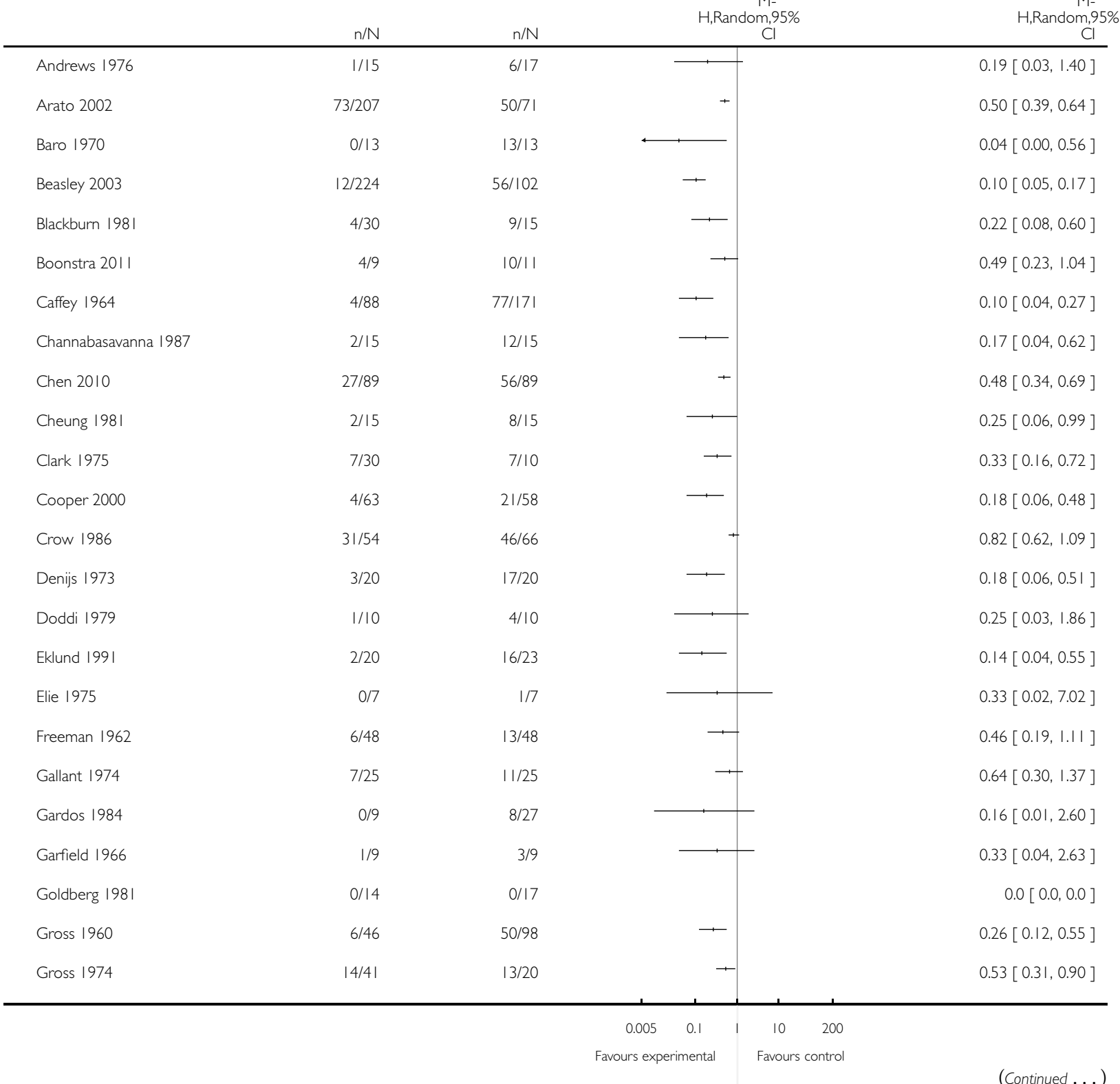




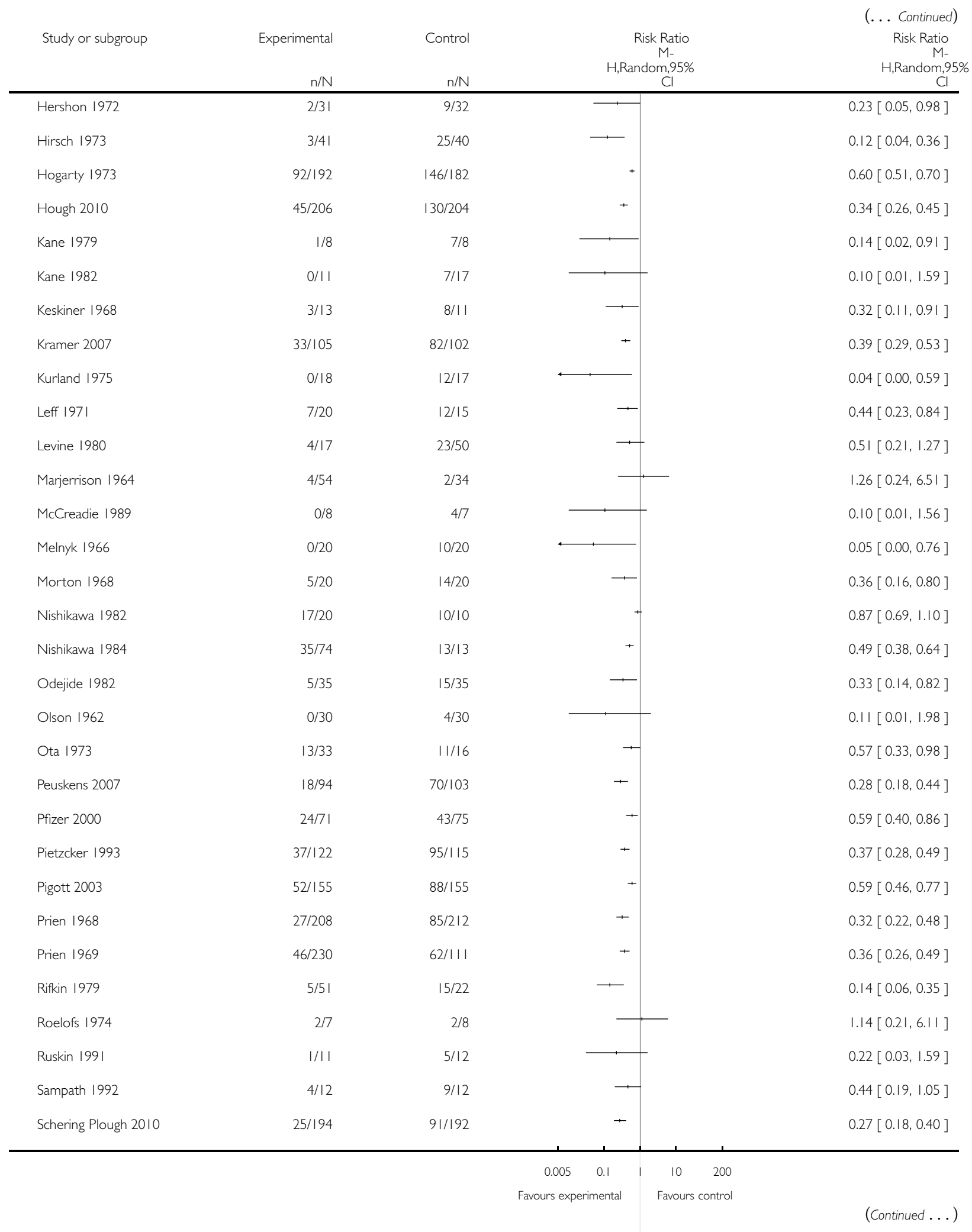

Maintenance treatment with antipsychotic drugs for schizophrenia (Review)

Copyright $\odot 2012$ The Cochrane Collaboration. Published by John Wiley \& Sons, Ltd. 


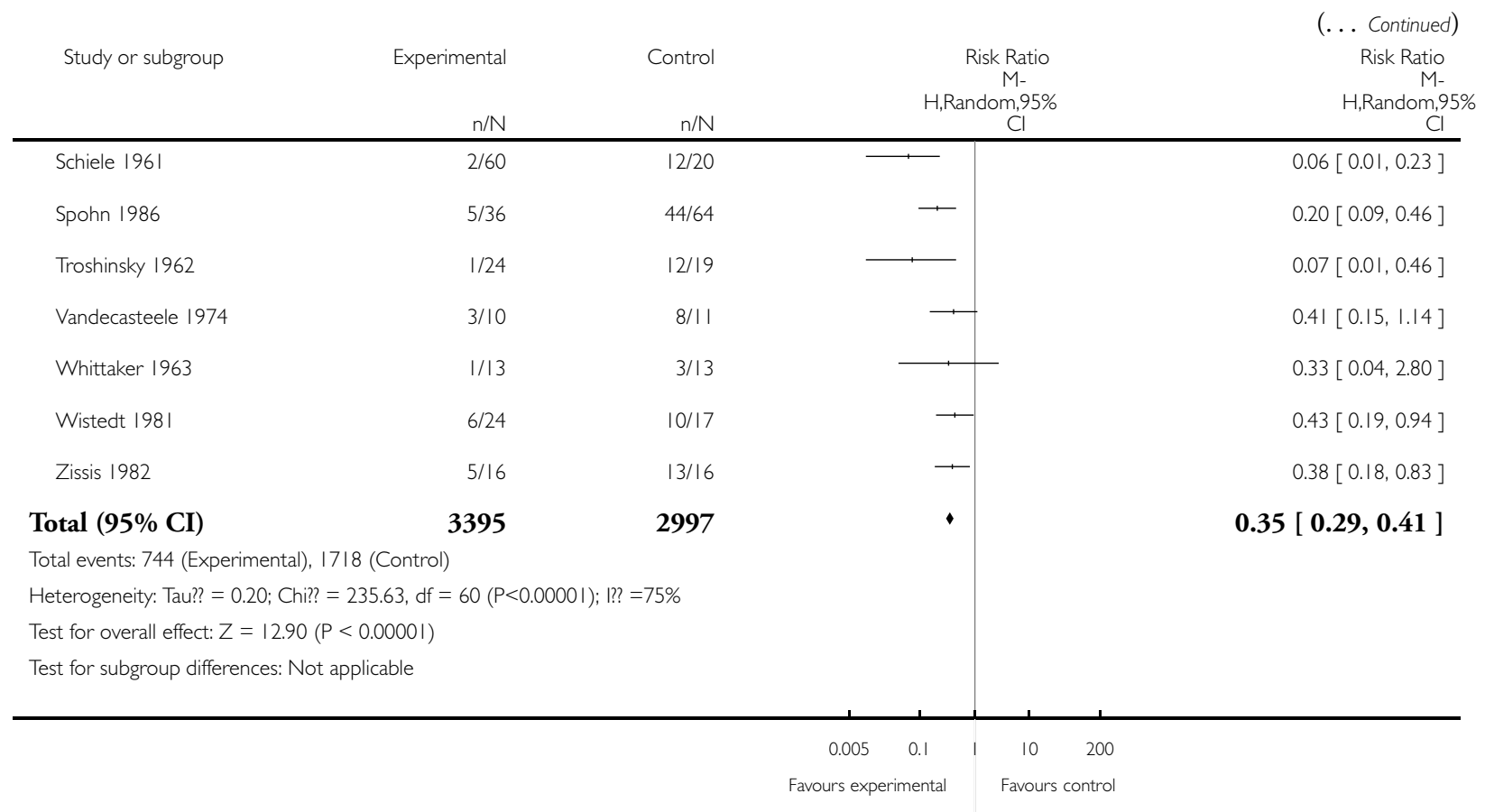


Analysis I.6. Comparison I Maintenance treatment with antipsychotic drugs versus placebo/no treatment, Outcome 6 Leaving the study early: due to any reason.

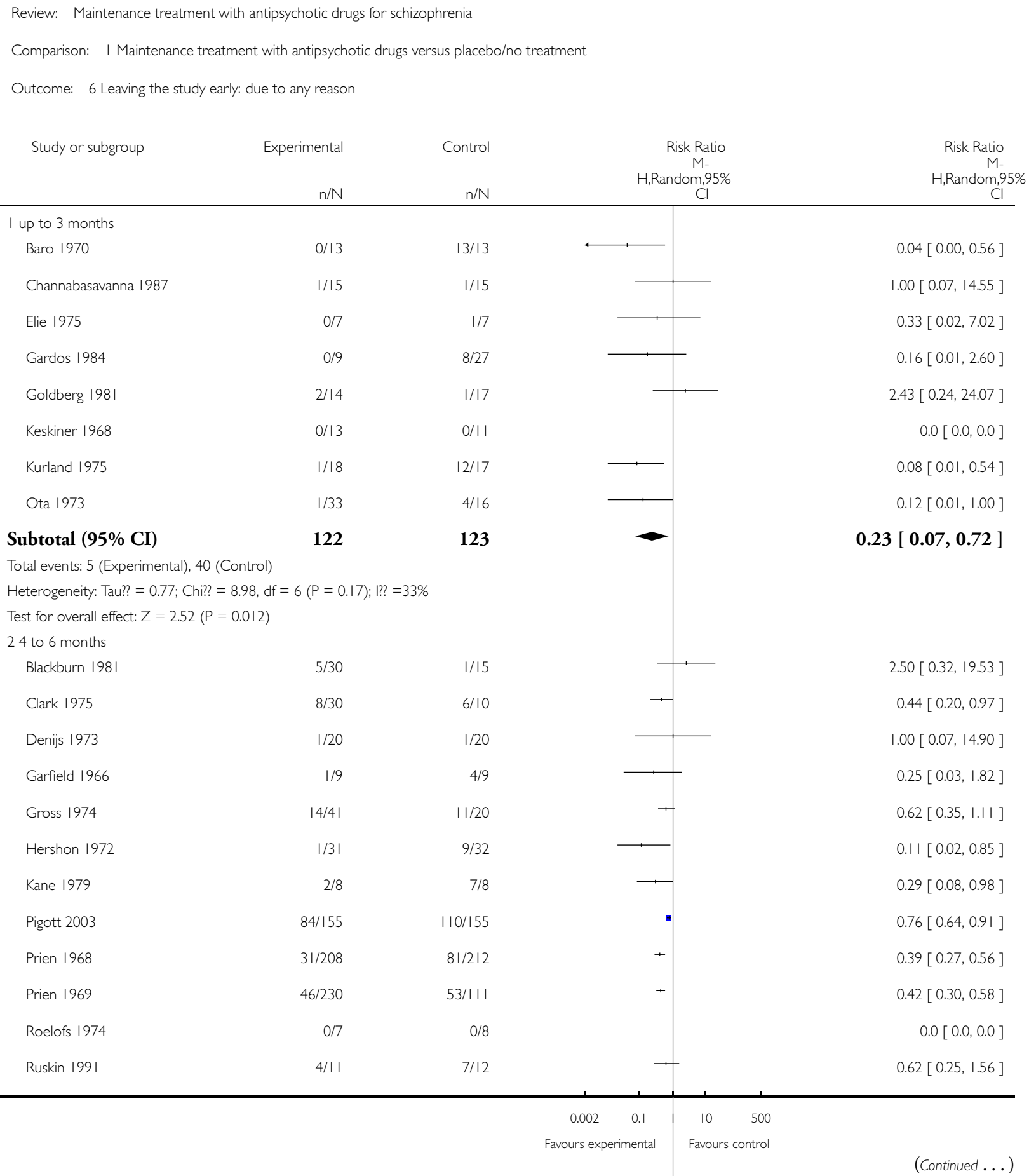




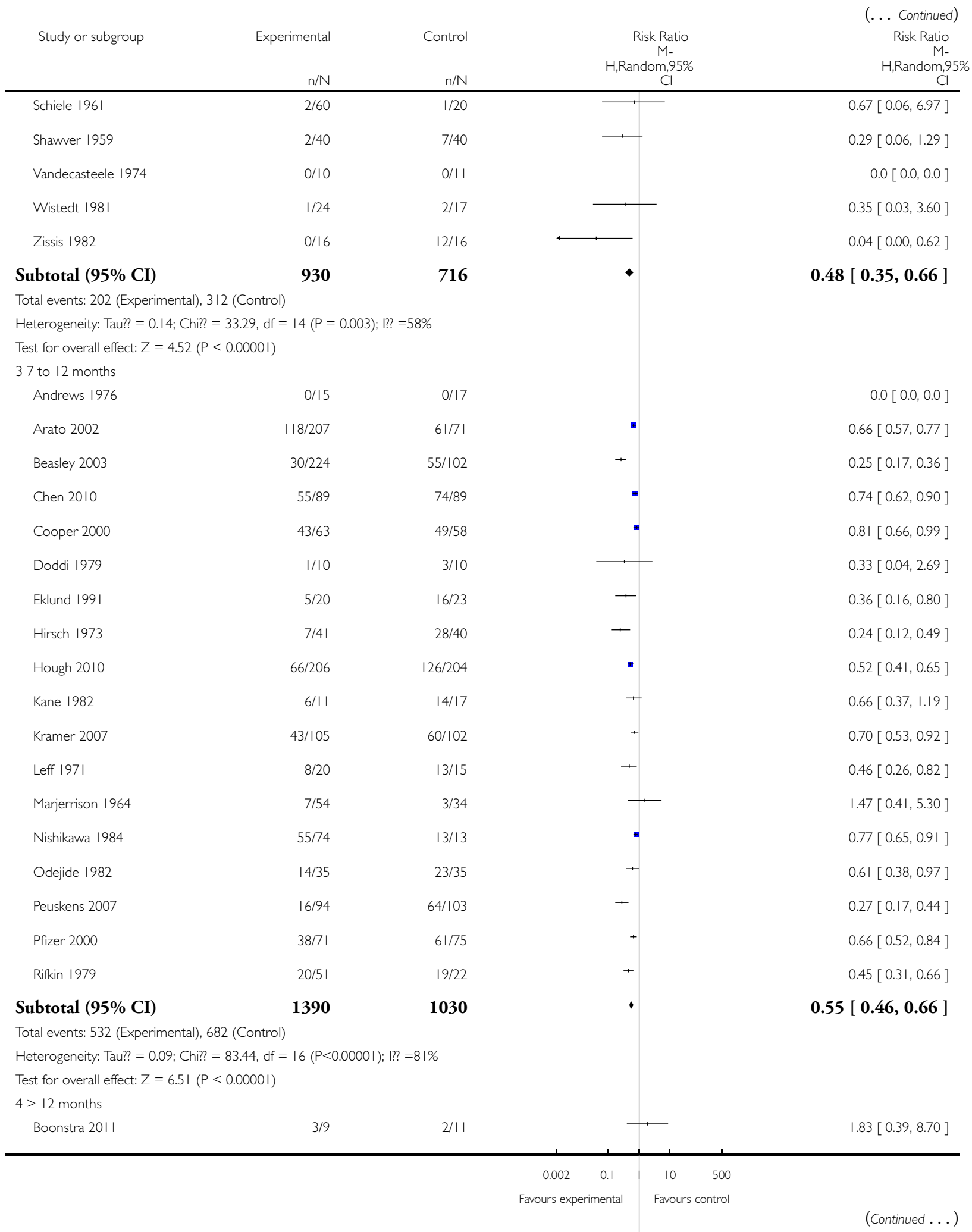

Maintenance treatment with antipsychotic drugs for schizophrenia (Review)

Copyright $\odot 2012$ The Cochrane Collaboration. Published by John Wiley \& Sons, Ltd. 


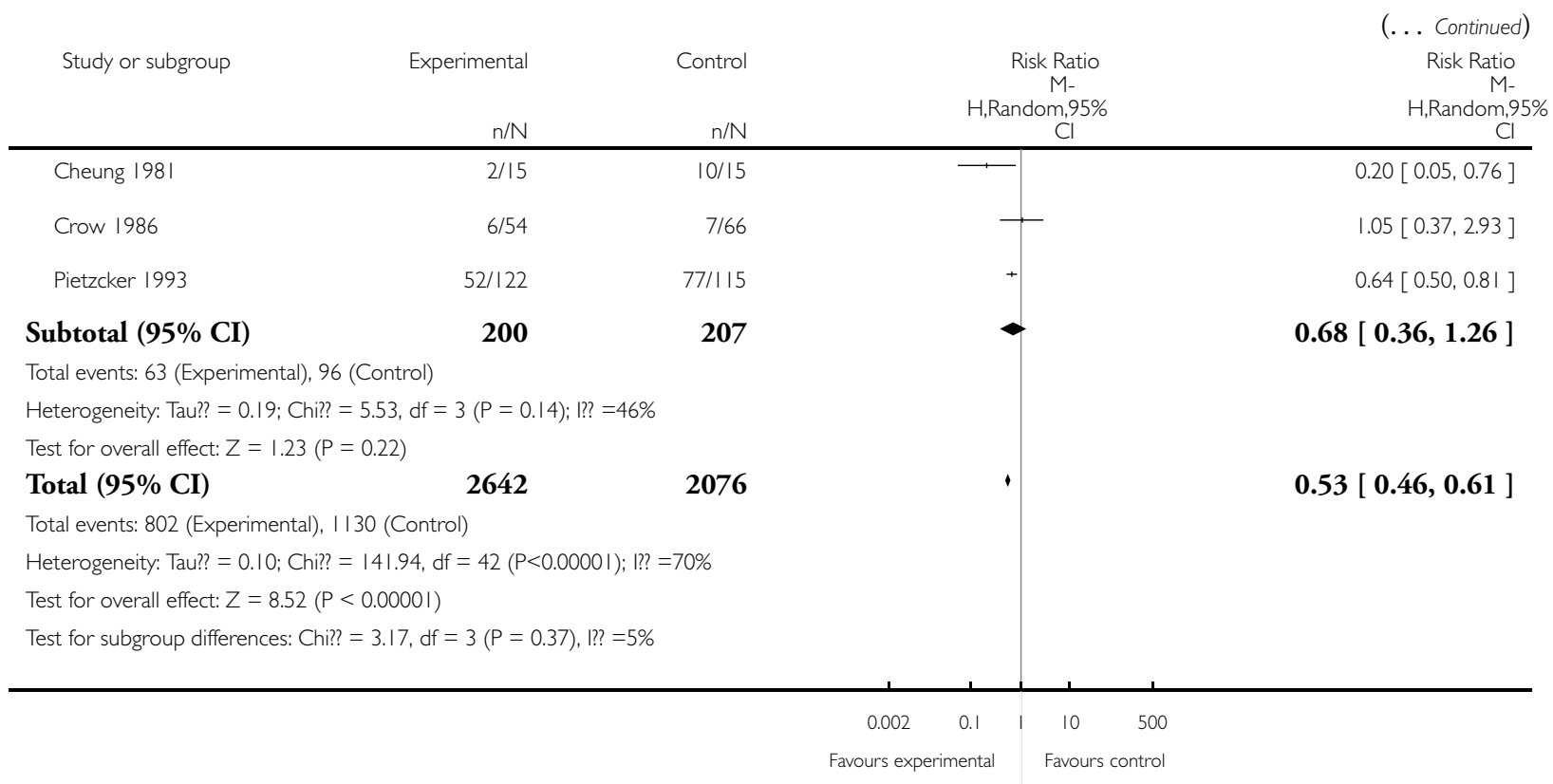


Analysis I.7. Comparison I Maintenance treatment with antipsychotic drugs versus placebo/no treatment, Outcome 7 Leaving the study early: due to adverse events.

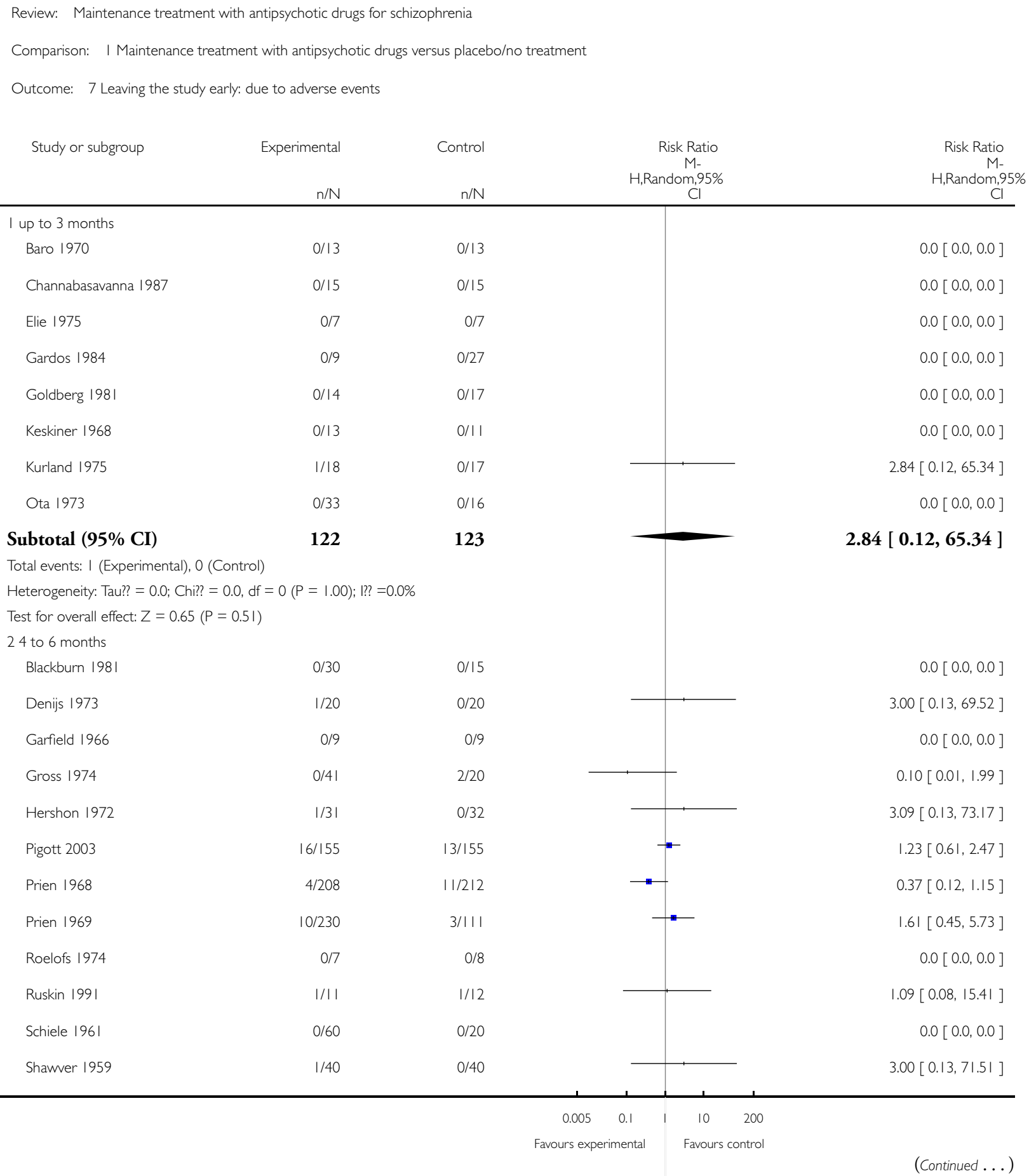




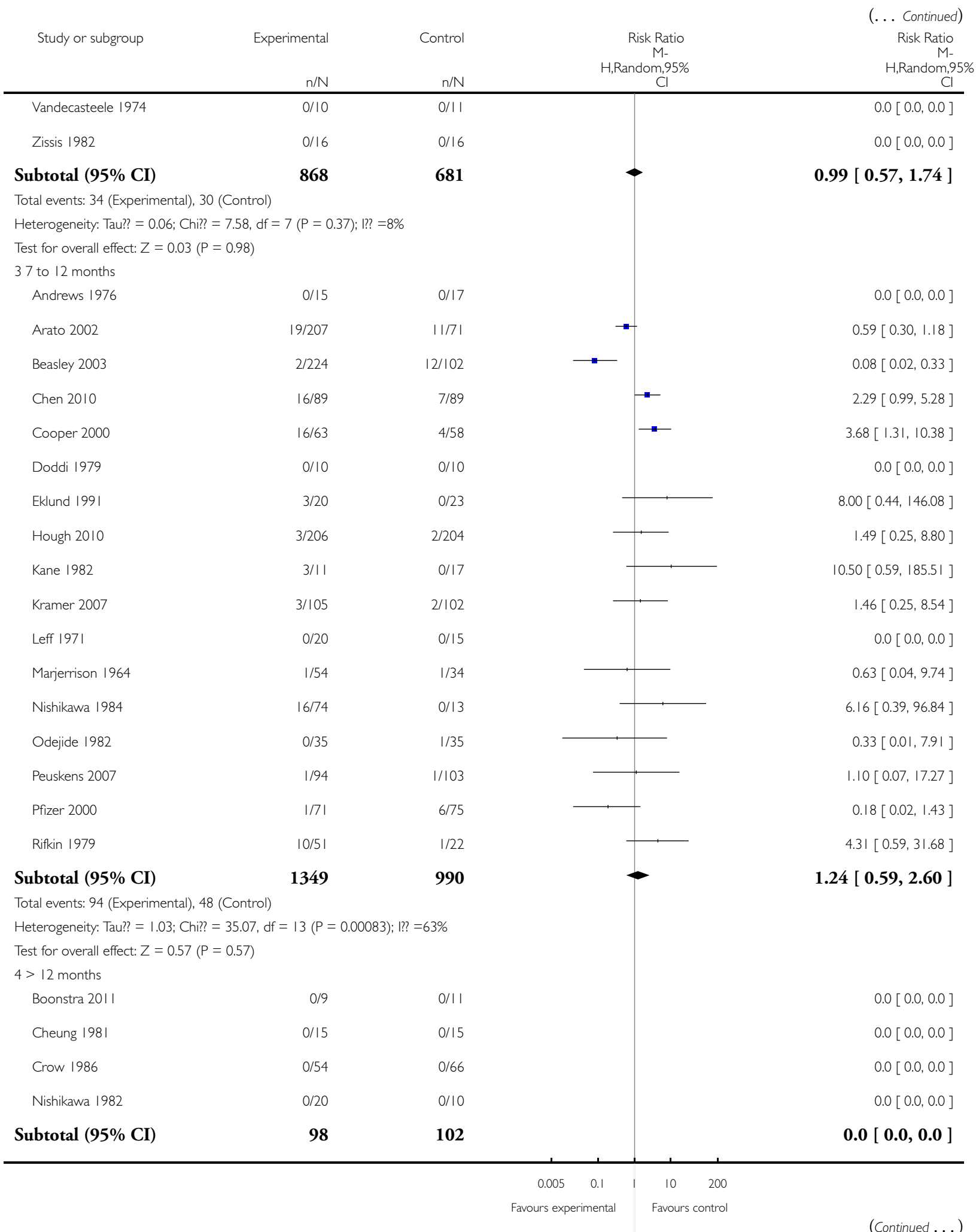




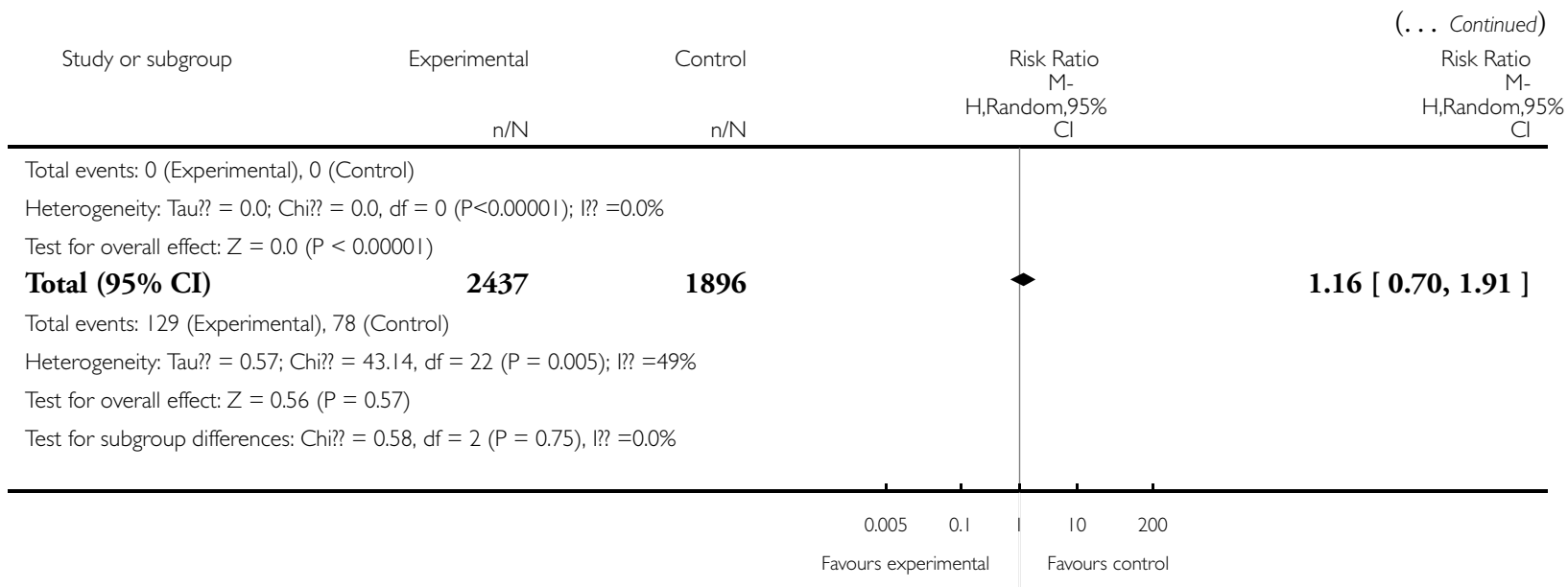

Analysis I.8. Comparison I Maintenance treatment with antipsychotic drugs versus placebo/no treatment, Outcome 8 Leaving the study early: due to inefficacy.

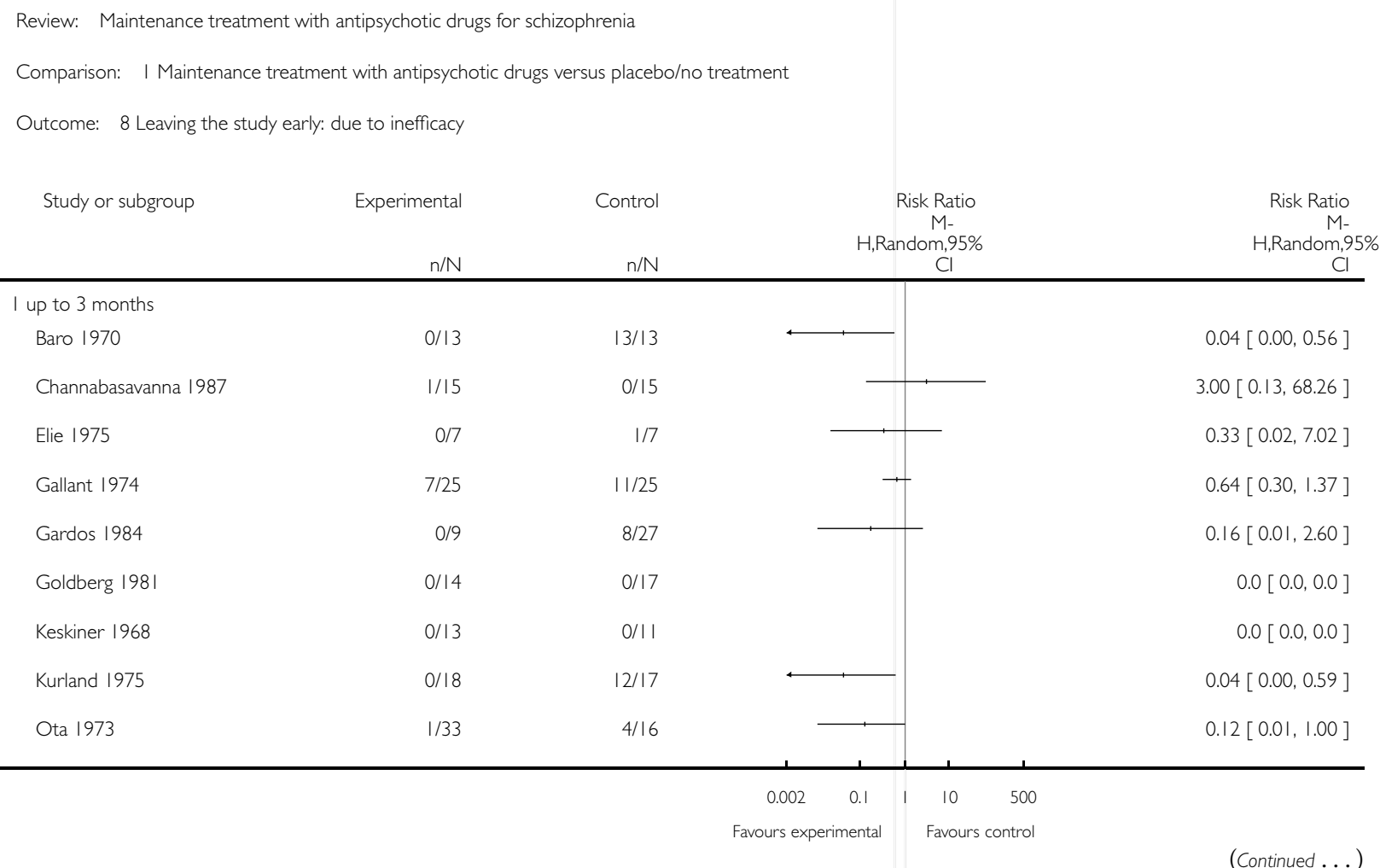




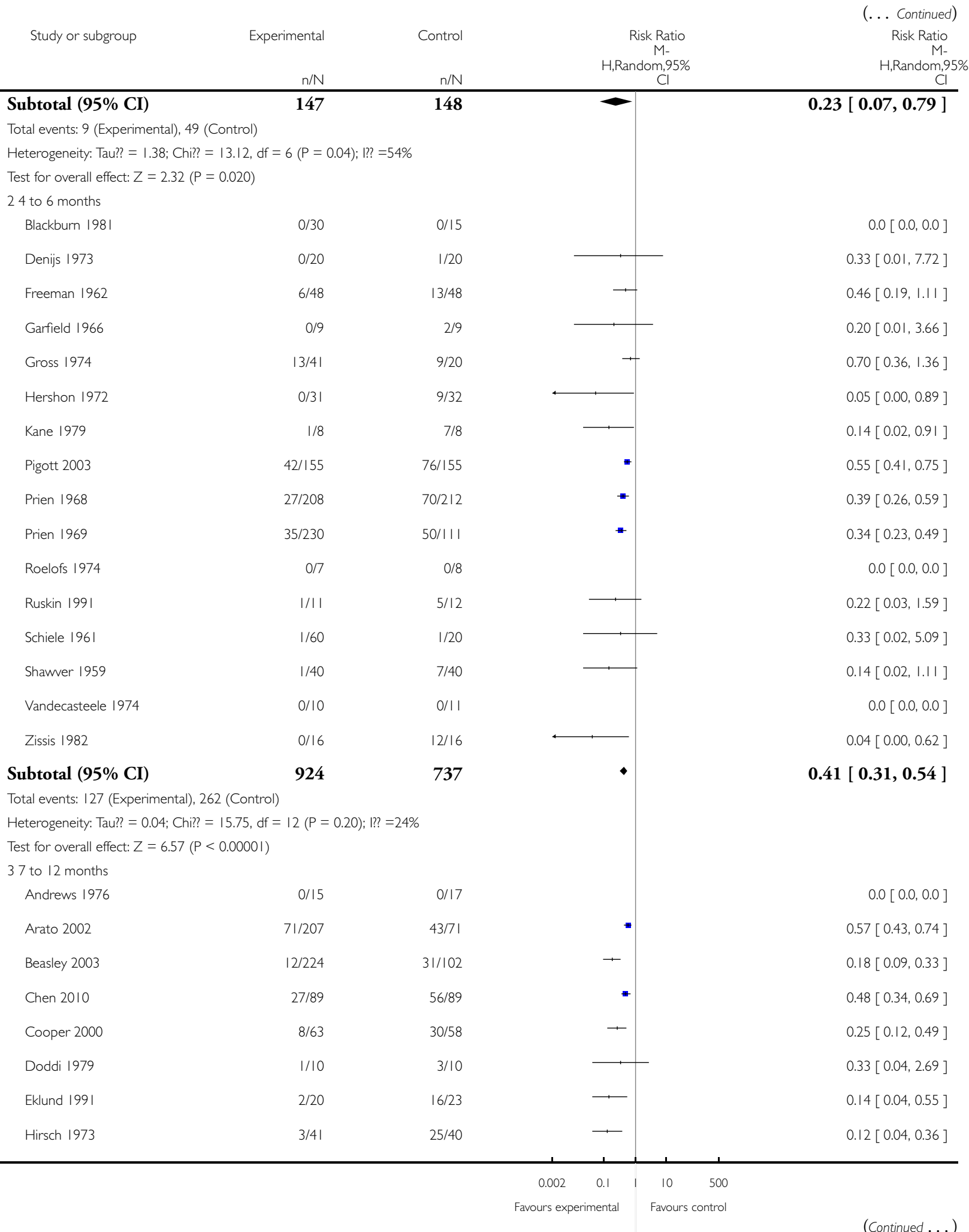




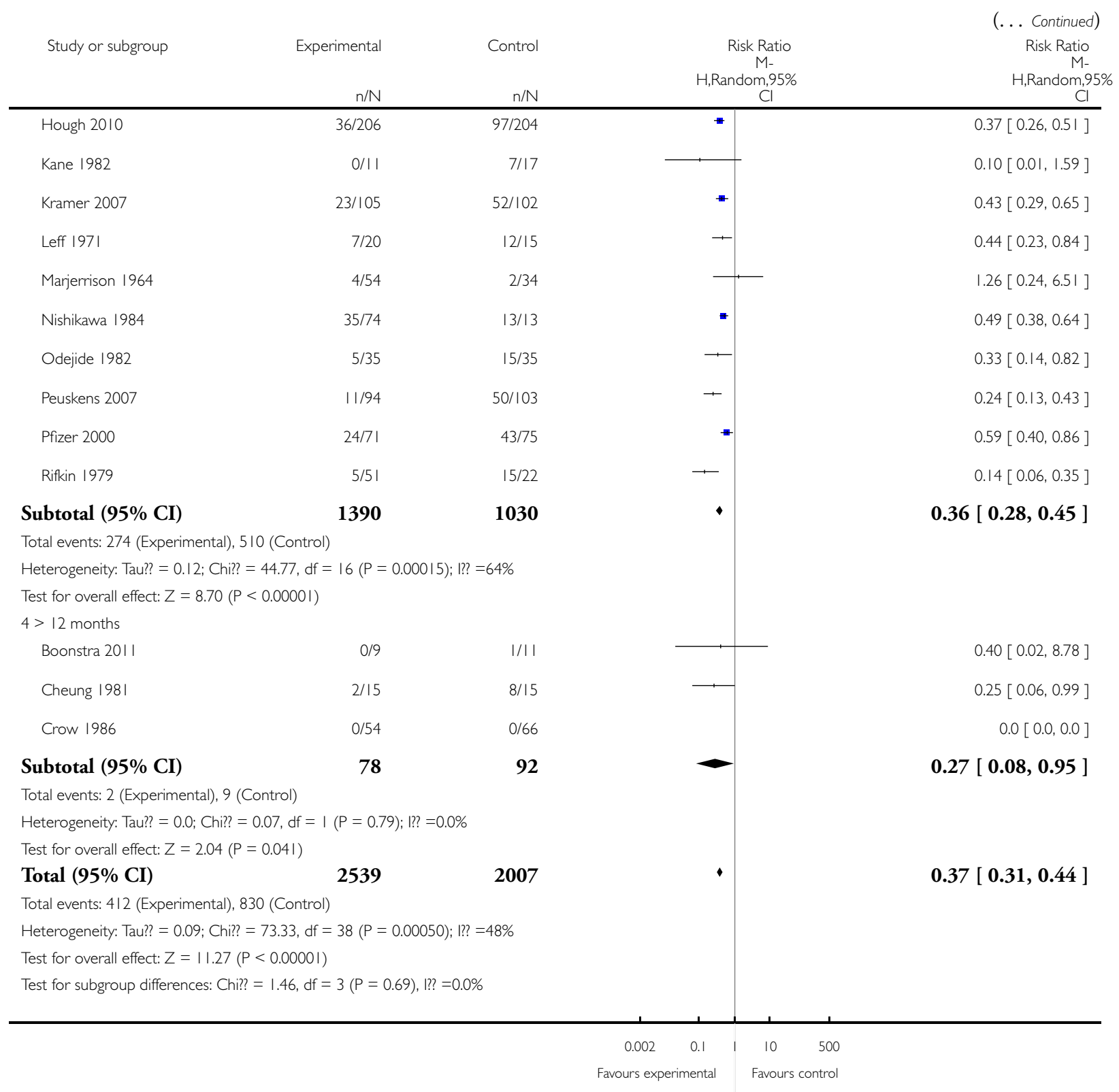


Analysis I.9. Comparison I Maintenance treatment with antipsychotic drugs versus placebo/no treatment, Outcome 9 Global state: number of participants improved.

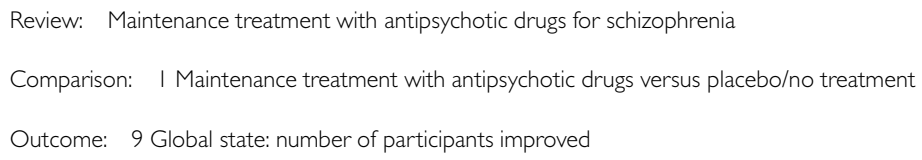

ubtotal $(95 \% \mathrm{CI})$

$38 / 208 \quad 22 / 212$

||$/||$

Total events: 189 (Experimental), 44 (Control)

Heterogeneity: Tau? $=0.00 ;$ Chi? $=7.02, \mathrm{df}=7(\mathrm{P}=0.43) ; \mathrm{l} ?=0 \%$

Test for overall effect: $Z=5.18(P<0.0000 \mathrm{I})$

37 to 12 months

Cooper 2000

Doddi 1979

Gallant 1974

$28 / 63$

$17 / 58$

Kramer 2007

$8 / 10$

$2 / 10$

$10 / 25$

0/25

Morton 1968

$12 / 105$

$7 / 102$

Subtotal (95\% CI)

223

$3 / 20$

215

Total events: 58 (Experimental), 29 (Control)

Heterogeneity: Tau?? = 0.33; Chi?? = 8.06, $\mathrm{df}=4(\mathrm{P}=0.09) ; \mathrm{l} ? \mathrm{l}=50 \%$

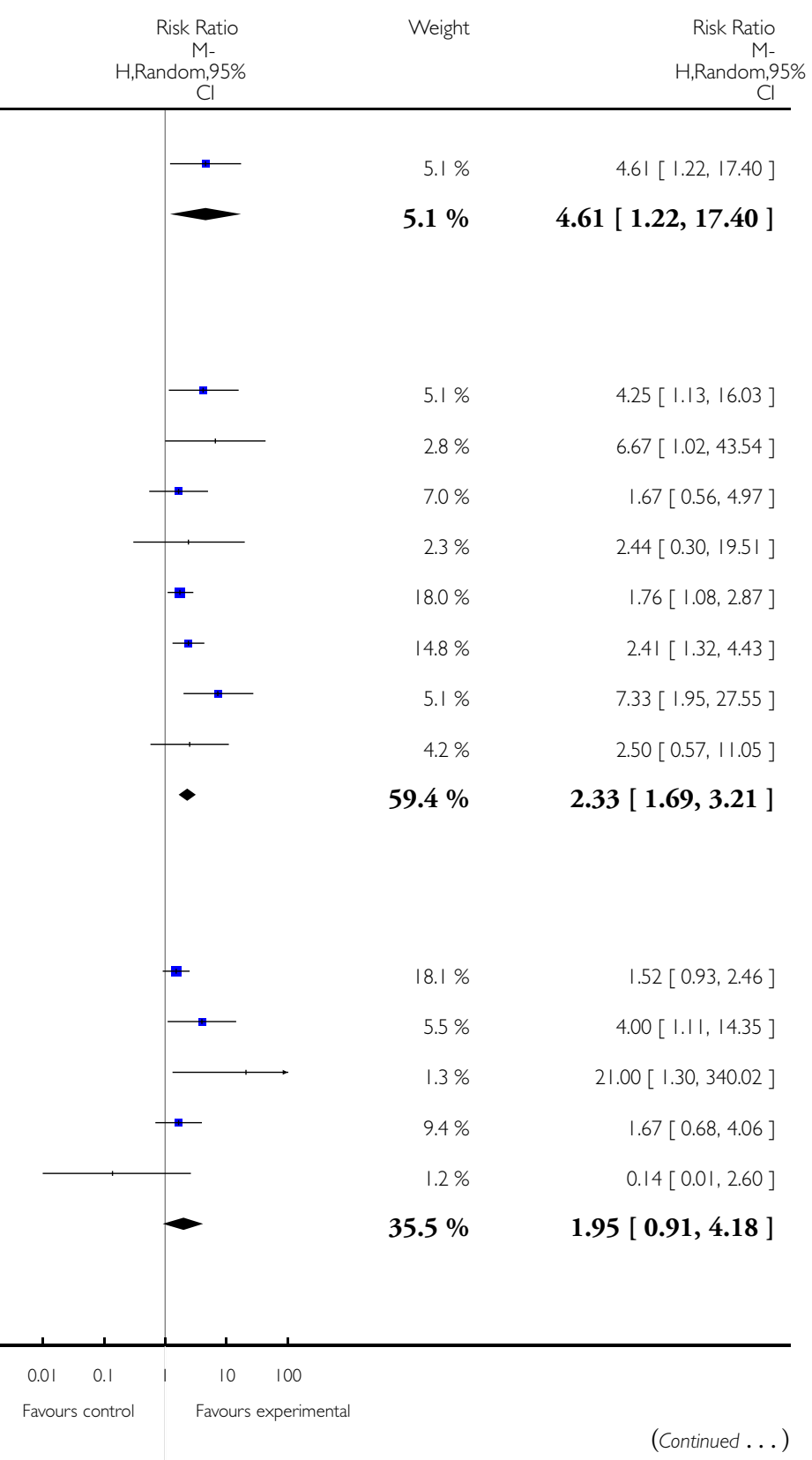




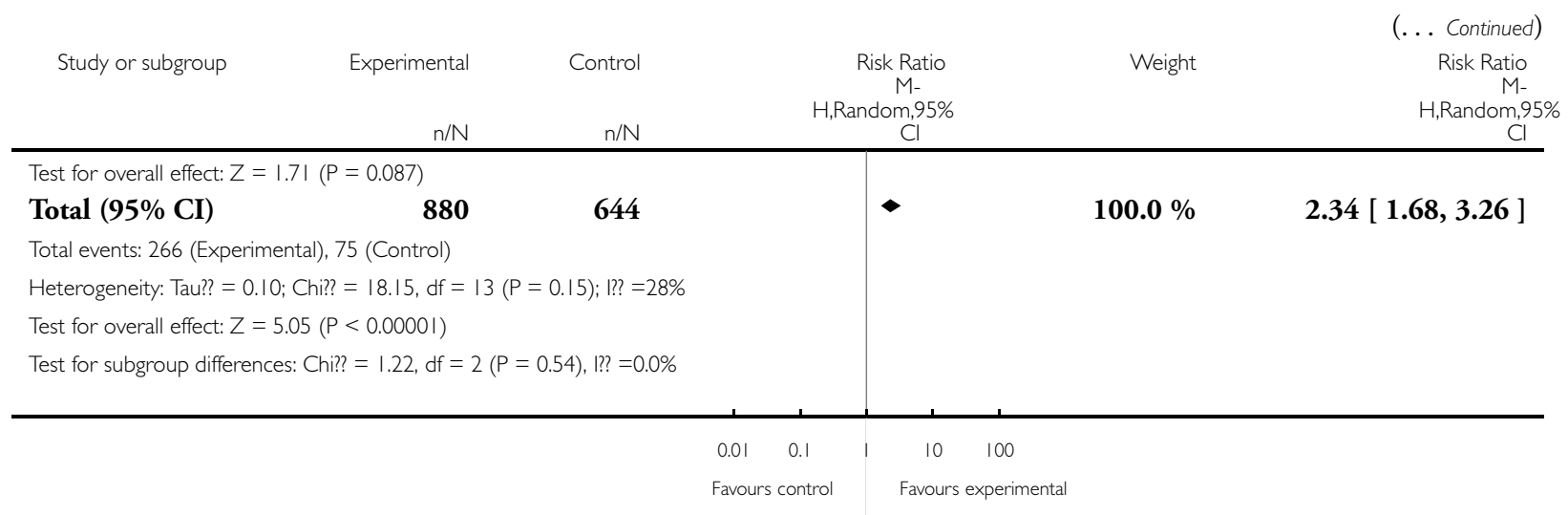

\section{Analysis I.10. Comparison I Maintenance treatment with antipsychotic drugs versus placebo/no treatment, Outcome 10 Service use: number of participants hospitalised.}

Review: Maintenance treatment with antipsychotic drugs for schizophrenia

Comparison: I Maintenance treatment with antipsychotic drugs versus placebo/no treatment

Outcome: 10 Service use: number of participants hospitalised

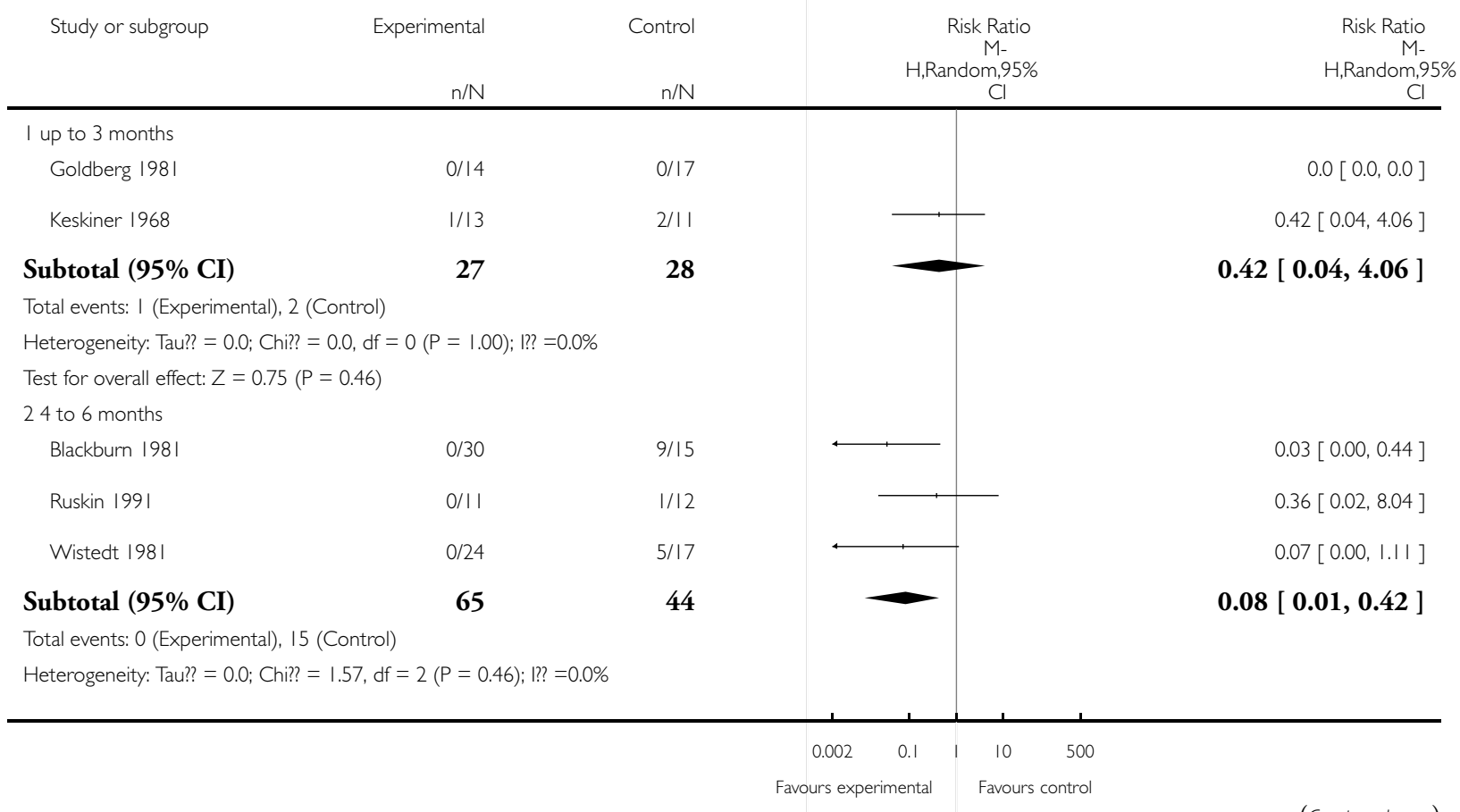




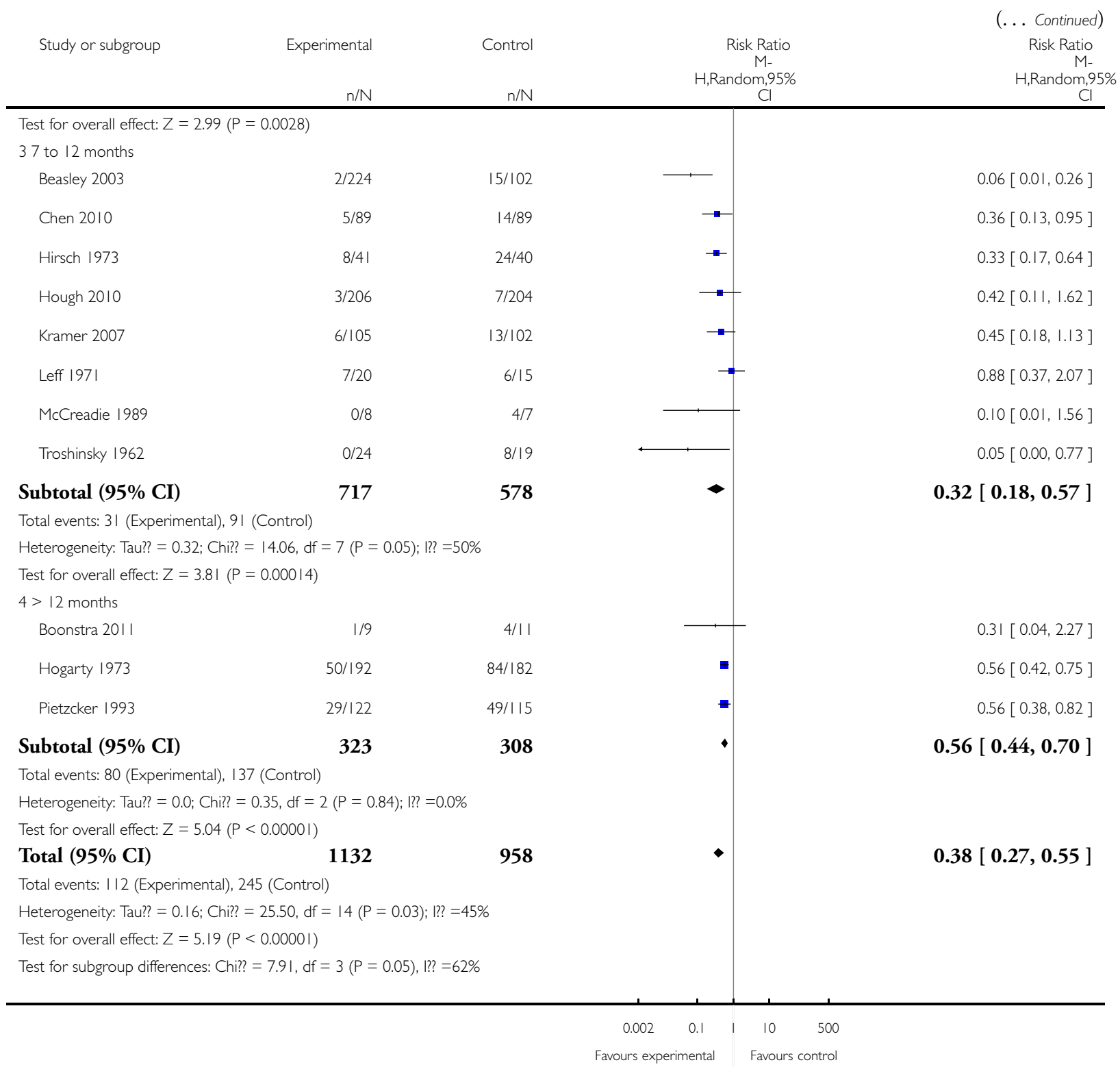


Analysis I.II. Comparison I Maintenance treatment with antipsychotic drugs versus placebo/no treatment, Outcome I I Service use: number of participants discharged.

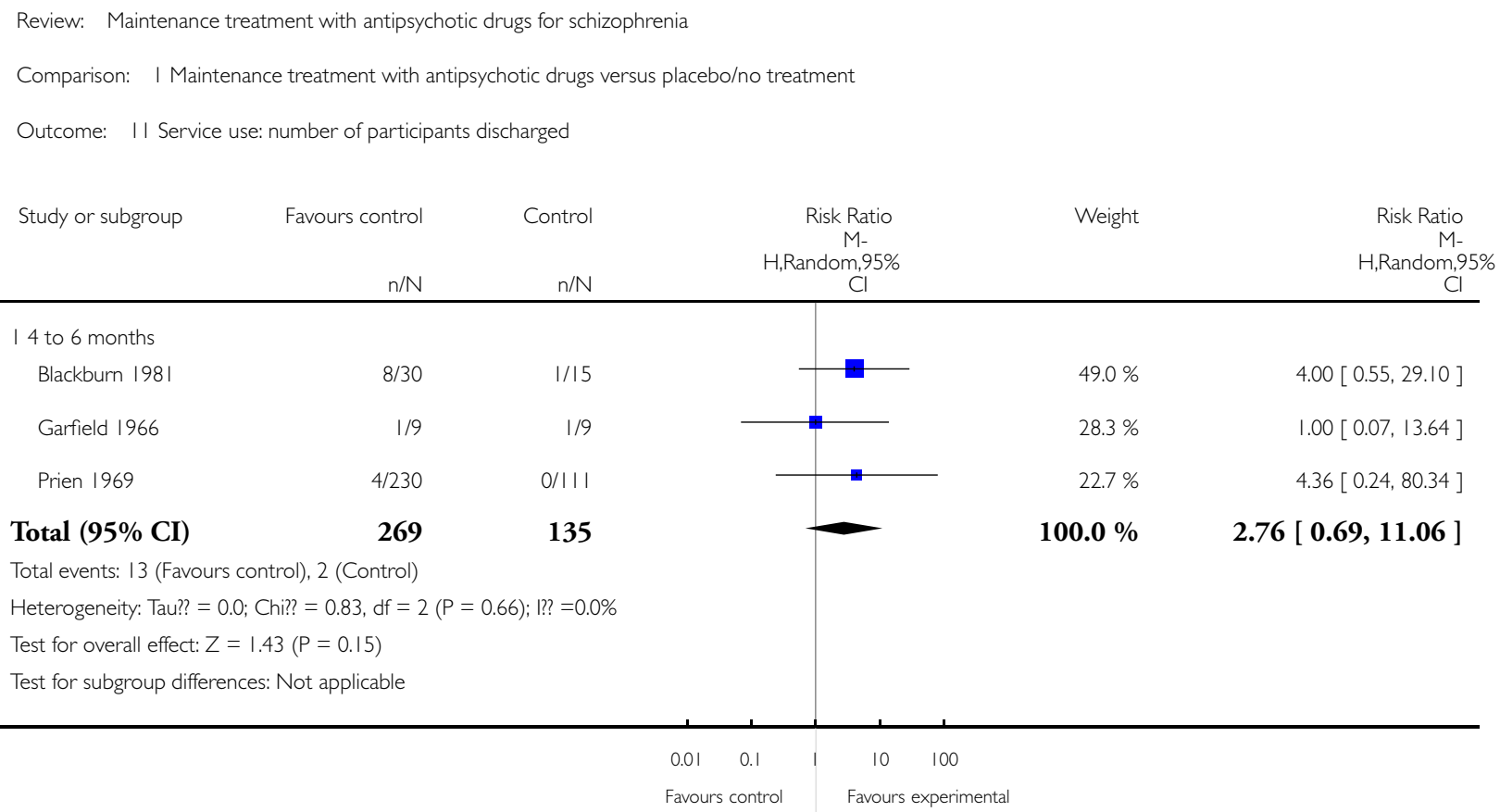


Analysis I.12. Comparison I Maintenance treatment with antipsychotic drugs versus placebo/no treatment, Outcome 12 Death: any.

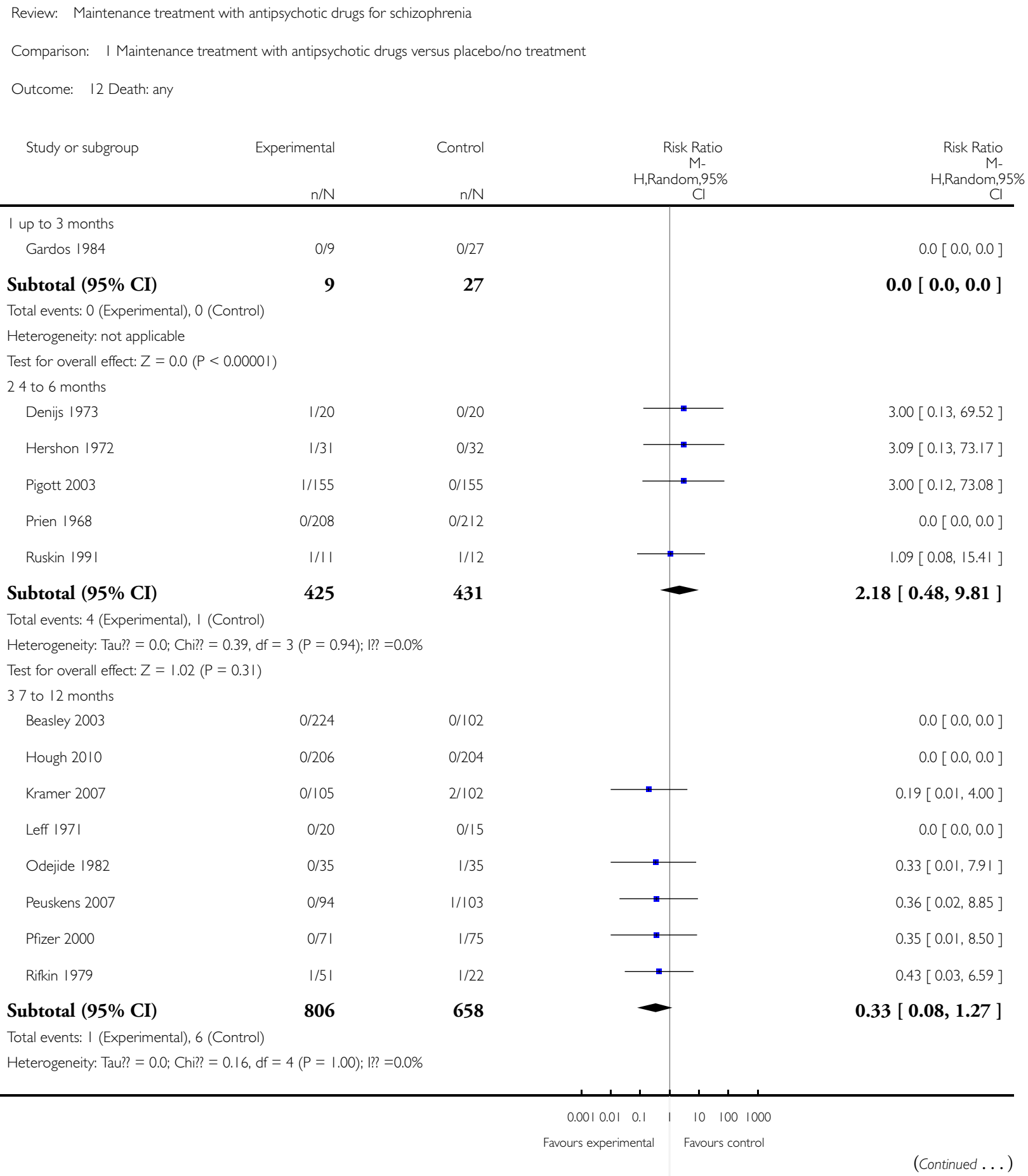




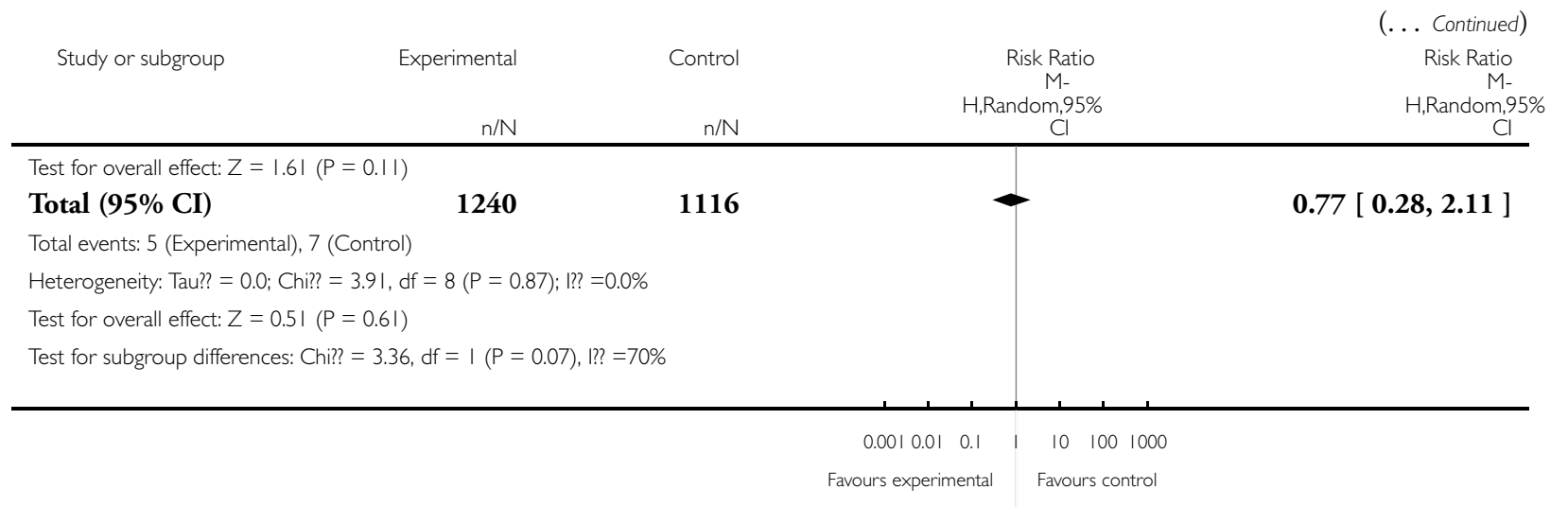

\section{Analysis I.13. Comparison I Maintenance treatment with antipsychotic drugs versus placebo/no treatment, Outcome I 3 Death: due to natural causes.}

Review: Maintenance treatment with antipsychotic drugs for schizophrenia

Comparison: I Maintenance treatment with antipsychotic drugs versus placebo/no treatment

Outcome: 13 Death: due to natural causes

Study or subgroup

Experimental Control

Risk Ratio

M-

H,Random,95\%

$\mathrm{n} / \mathrm{N}$

$\mathrm{n} / \mathrm{N}$

I 4 to 6 months

Denijs 1973

Hershon 1972

Pigott 2003

Prien 1968

Ruskin 1991

Subtotal $(95 \% \mathrm{CI})$

Total events: 4 (Experimental), I (Control)

Heterogeneity: Tau?? =0.0; Chi?? =0.39, $d f=3(P=0.94) ; ~ I ? ?=0.0 \%$

Test for overall effect: $Z=1.02(P=0.31)$

27 to 12 months

Beasley 2003

Hirsch 1973
$0 / 224$

$0 / 41$

$1 / 20$

$|/ 3|$

I/I55

0/208

|/ |

425

25

5

431

431

0/20

$0 / 32$

0/I55

$0 / 212$

$1 / 12$

31

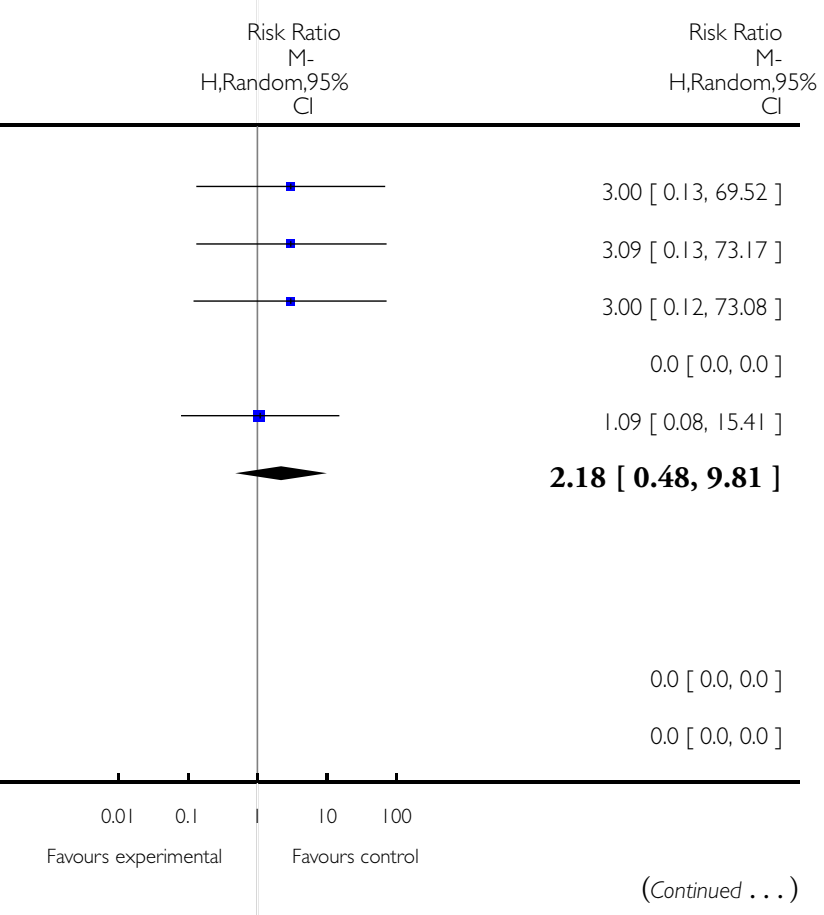

Maintenance treatment with antipsychotic drugs for schizophrenia (Review)

Copyright @ 2012 The Cochrane Collaboration. Published by John Wiley \& Sons, Ltd. 


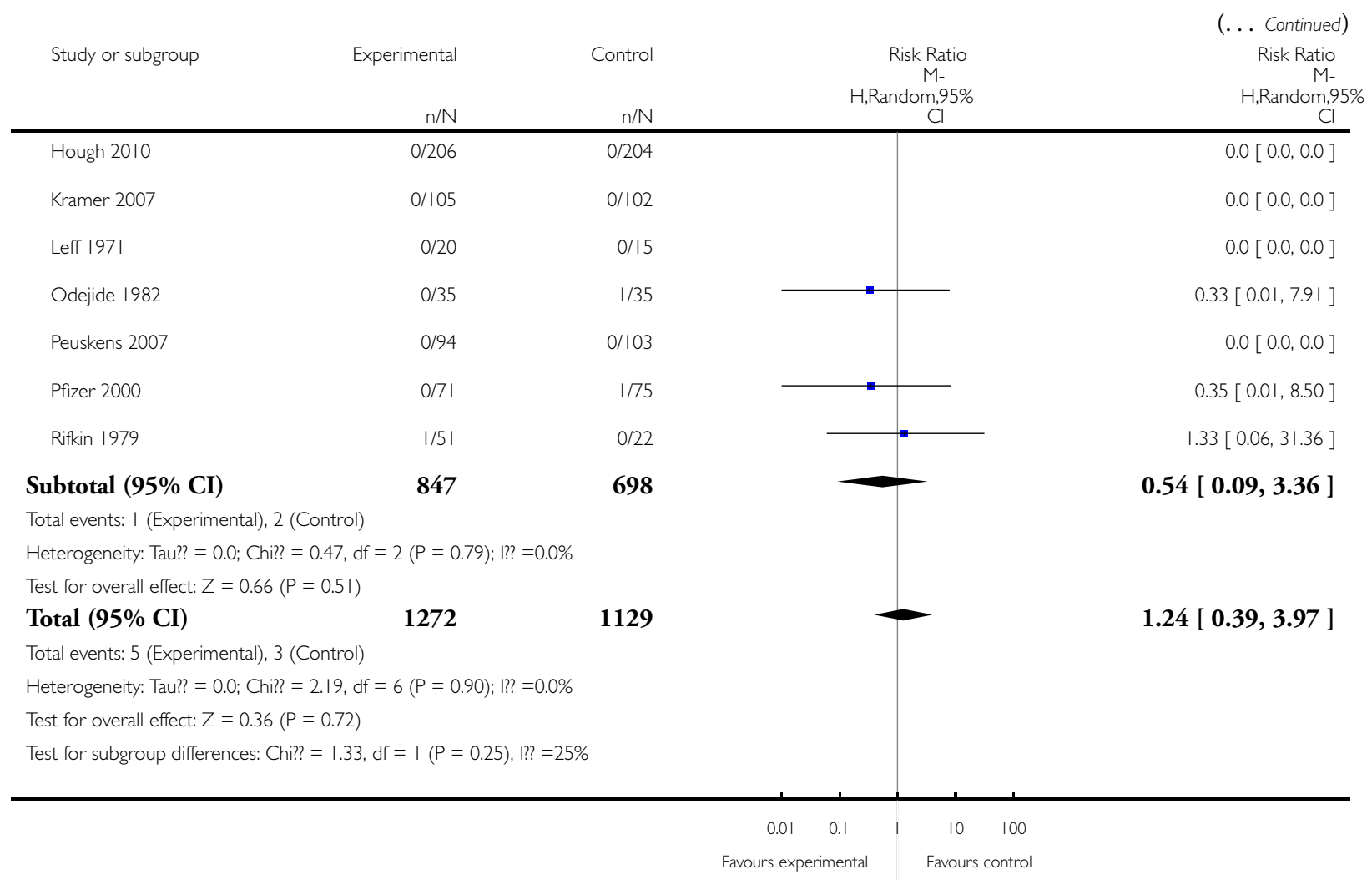


Analysis I.14. Comparison I Maintenance treatment with antipsychotic drugs versus placebo/no treatment, Outcome 14 Suicide.

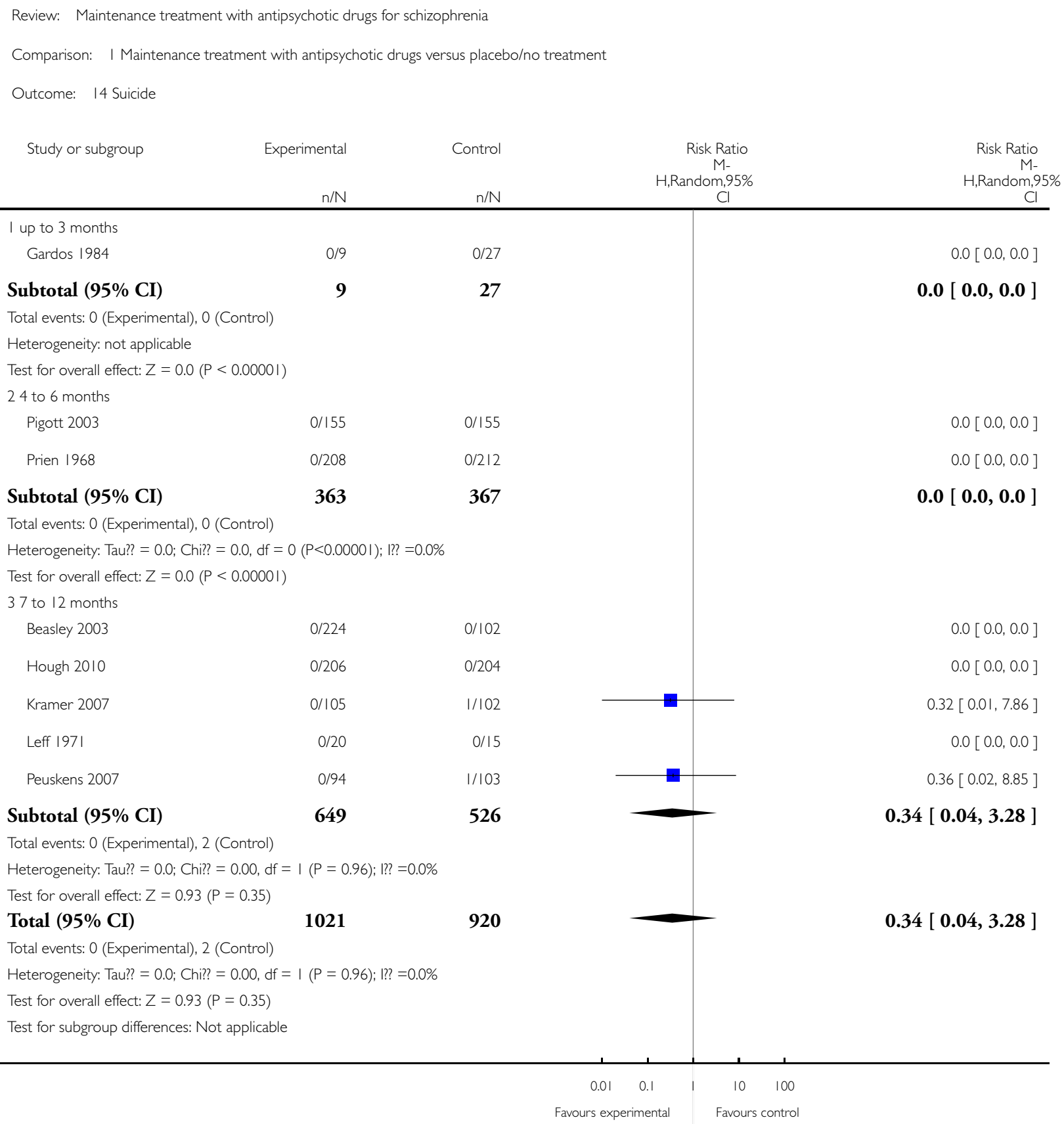


Analysis I.I5. Comparison I Maintenance treatment with antipsychotic drugs versus placebo/no treatment, Outcome 15 Suicide attempts.

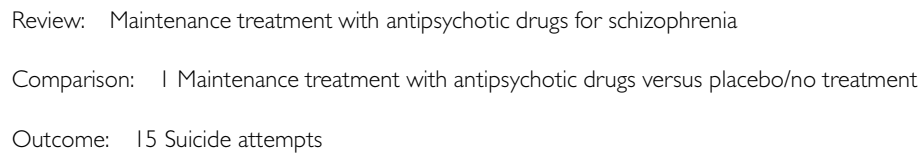

Subtotal (95\% CI)

234

232

Total events: I (Experimental), 0 (Control)

Heterogeneity: Tau?? = 0.0; Chi?? =0.0, df = $0(P=1.00) ;$ !? $=0.0 \%$

Test for overall effect: $Z=0.68(P=0.50)$

27 to 12 months

Beasley 2003

$0 / 224$

Chen 2010

$1 / 102$

Kramer 2007

$0 / 105$

Subtotal (95\% CI)

418

$1 / 102$

Total events: 0 (Experimental), 3 (Control)

Heterogeneity: Tau? = 0.0; Chi? $=0.15, \mathrm{df}=2(\mathrm{P}=0.93) ; 1 ?$ ? $=0.0 \%$

Test for overall effect: $Z=1.46(P=0.15)$

Total (95\% CI)

652

293

Total events: I (Experimental), 3 (Control)

Heterogeneity: Tau? $=0.0 ;$ Chi? $=1.89, \mathrm{df}=3(\mathrm{P}=0.60) ; \mathrm{l} ? \mathrm{l}=0.0 \%$

Test for overall effect: $Z=0.92(P=0.36)$

Test for subgroup differences: Chi?? = 1.74, $d f=1(P=0.19), 1 ?$ ? $=42 \%$

$1 / 89$

525

192

2

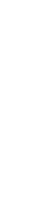

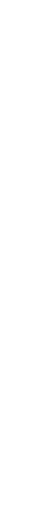

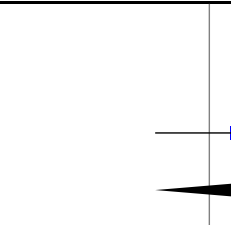

Cl

$0.15[0.01,3.71]$

$0.33[0.01,8.07]$

$0.32[0.01,7.86]$

$0.25[0.04,1.61]$

$0.47[0.10,2.33]$ 
Analysis I.16. Comparison I Maintenance treatment with antipsychotic drugs versus placebo/no treatment, Outcome 16 Suicide ideation.

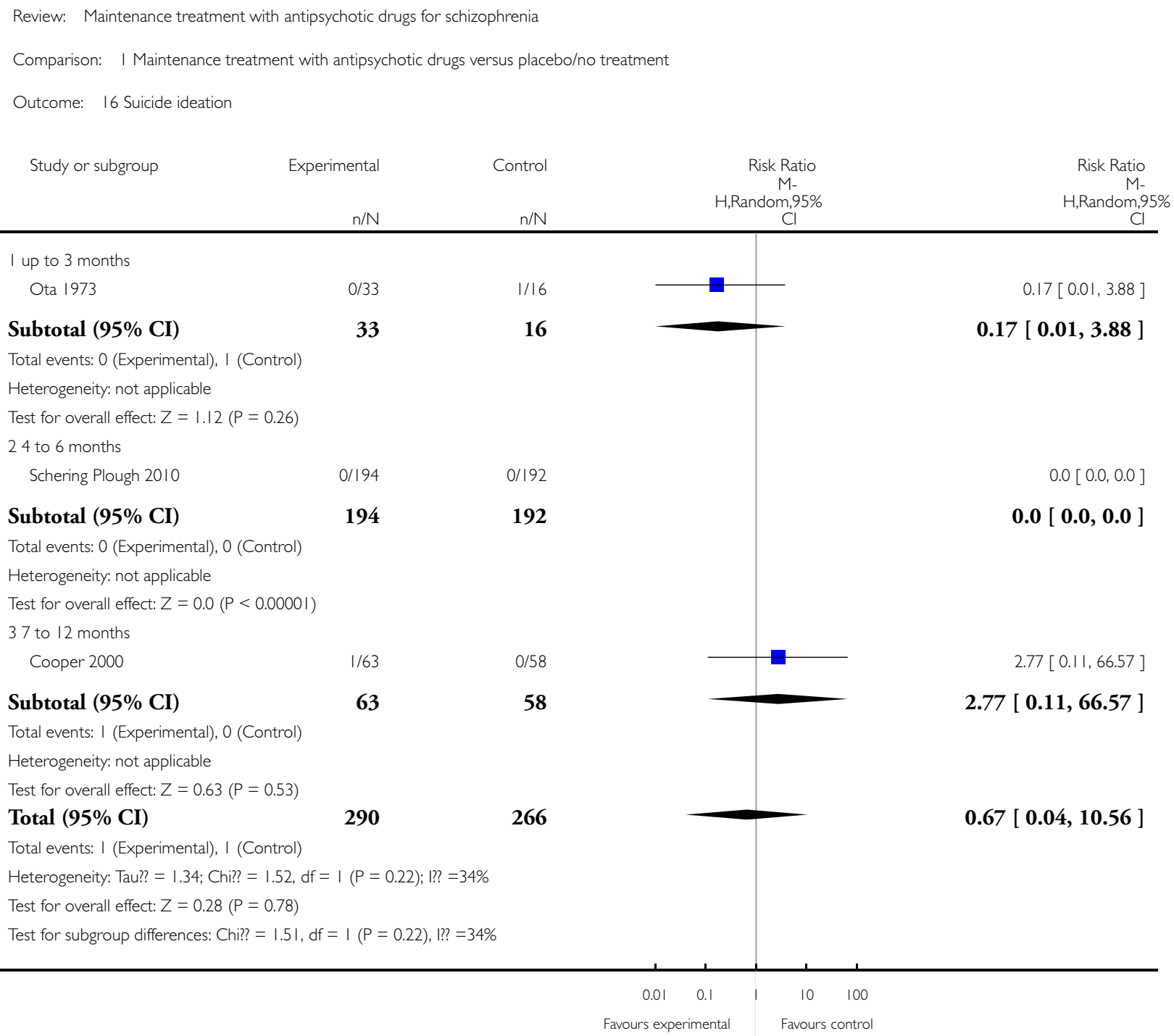


Analysis I.I7. Comparison I Maintenance treatment with antipsychotic drugs versus placebo/no treatment, Outcome 17 Violent/aggressive behaviour.

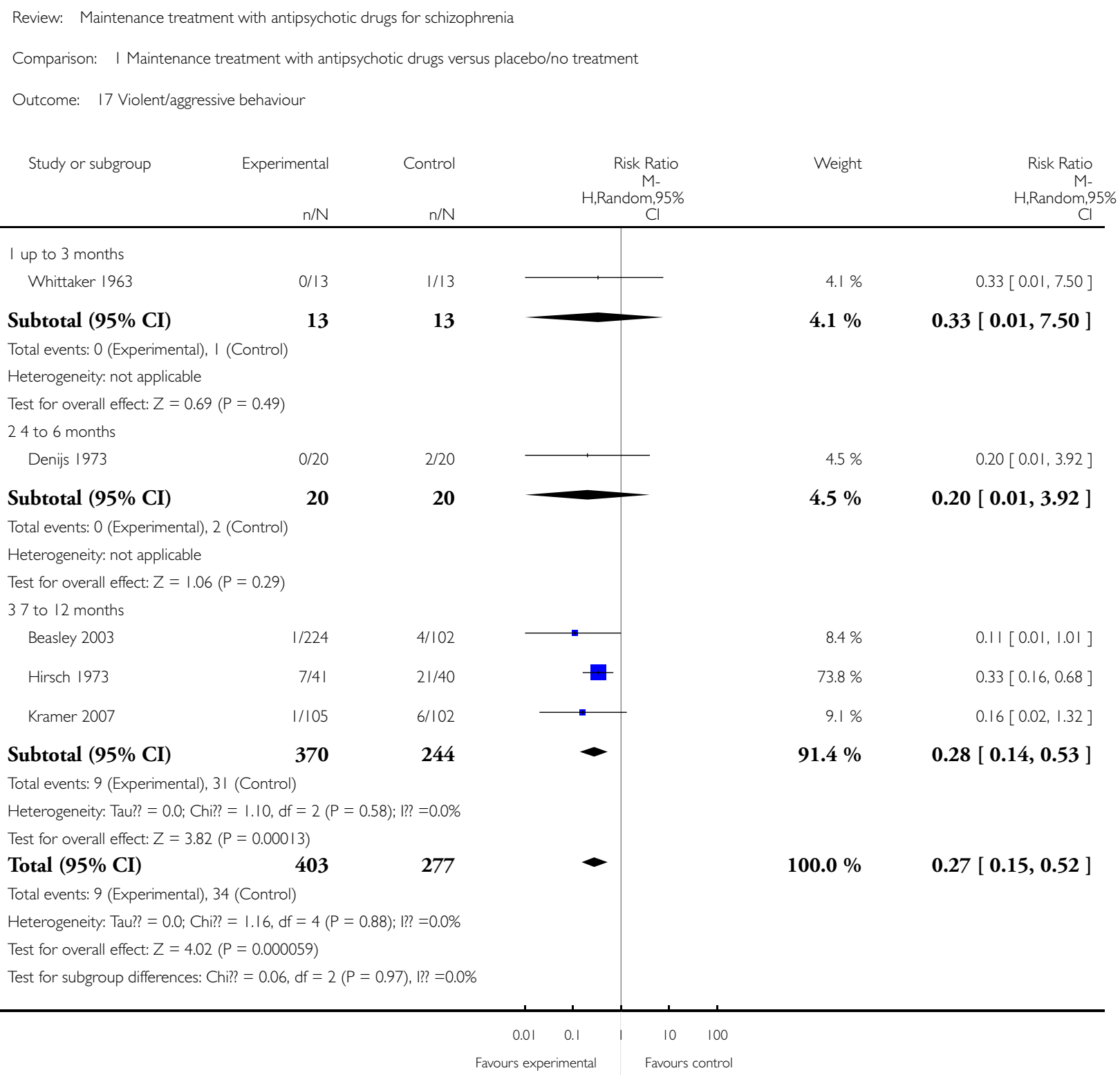


Analysis I.18. Comparison I Maintenance treatment with antipsychotic drugs versus placebo/no treatment, Outcome 18 Adverse effects: at least one adverse event.

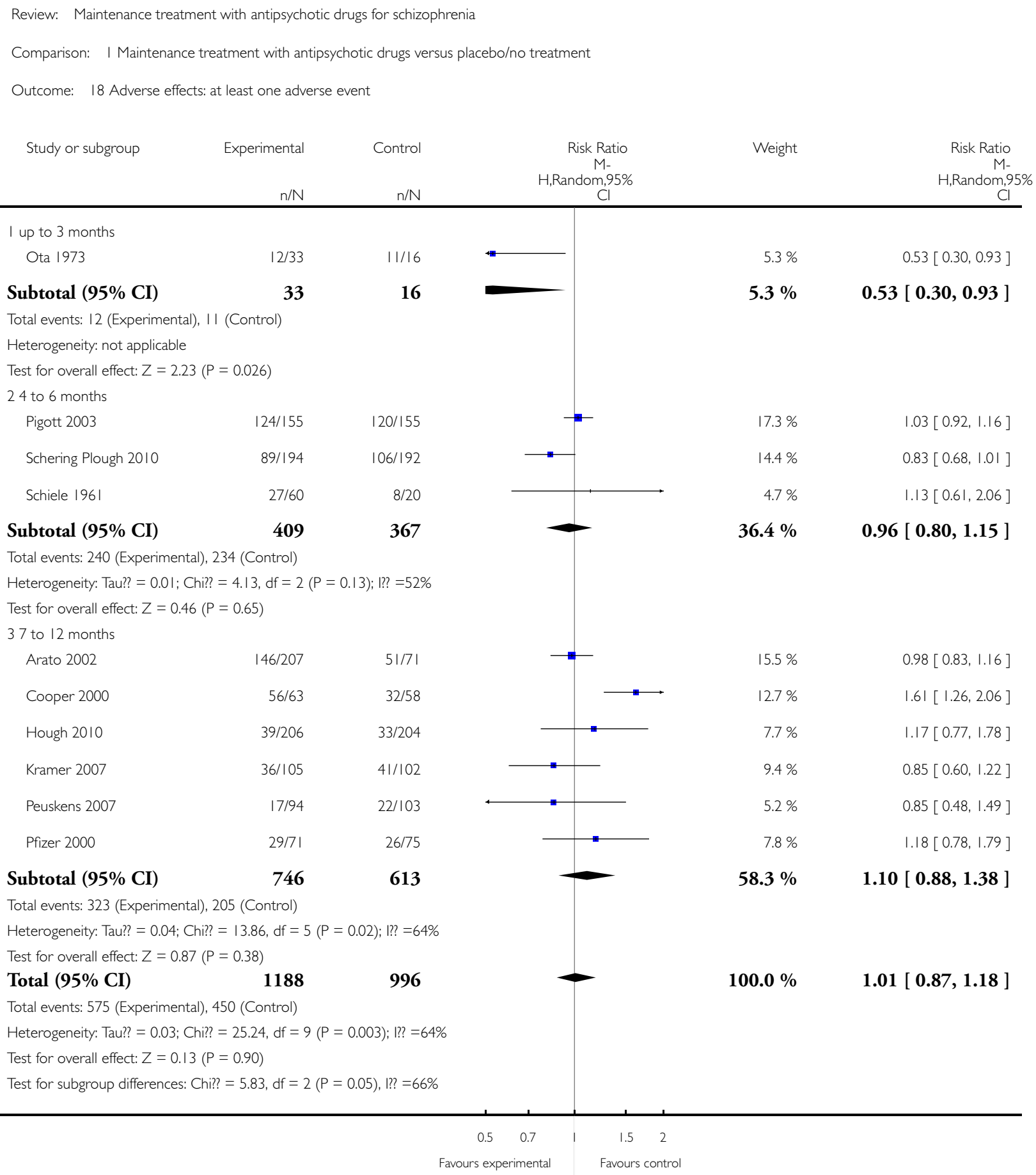


Analysis I.19. Comparison I Maintenance treatment with antipsychotic drugs versus placebo/no treatment, Outcome 19 Adverse effects: movement disorders: at least one movement disorder.

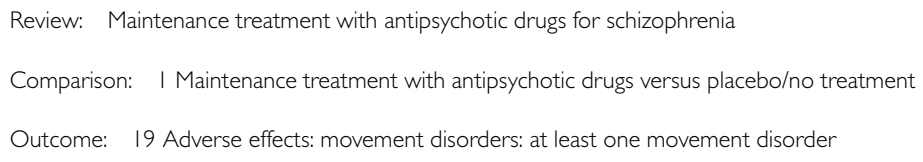

Subtotal (95\% CI)

89

69

Total events: 26 (Experimental), 7 (Control)

Heterogeneity: Tau?? = 0.62; Chi?? = 4.46, df = $2(P=0.1 \mathrm{I})$; I? $=55 \%$

Test for overall effect: $Z=1.40(P=0.16)$

24 to 6 months

Clark 1975
Denijs 1973
Pigott 2003
Prien 1968
Prien 1969
Schering Plough 2010
Schiele 1961
Wistedt 1981

Subtotal $(\mathbf{9 5 \%}$ CI)

$6 / 30 \quad 3 / 10$

$4 / 20 \quad 2 / 20$

20/155 13/155

$25 / 208 \quad 25 / 212$

$68 / 230 \quad 17 / 111$

$6 / 194 \quad 9 / 192$

$16 / 60 \quad 2 / 20$

$21 / 24$

921

737

Heterogeneity: Tau? = 0.05; Chi?? = 9.64, df= $7(P=0.21)$; I? =27\%

Test for overall effect: $Z=2.30(P=0.022)$

37 to 12 months

Arato 2002

Cooper 2000

Hough 2010

Kramer 2007

Leff 197।

$\begin{array}{rr}21 / 207 & 4 / 7 \mid \\ 7 / 63 & 4 / 58 \\ 21 / 206 & 12 / 204 \\ 7 / 105 & 3 / 102 \\ 13 / 20 & 10 / 15\end{array}$

$5.33[1.77,16.05]$

$0.0[0.0,0.0]$

$2.84[0.12,65.34]$

$1.09[0.40,3.01]$

$2.42[0.70,8.33]$

$0.67[0.20,2.18]$

$2.00[0.41,9.71]$

$1.54[0.79,2.98]$

$1.02[0.61,1.71]$

$1.93[1.19,3.12]$

$0.66[0.24,1.82]$

$2.67[0.67,10.60]$

$2.13[1.18,3.83]$

$1.45[1.06,1.99$ ]

$1.80[0.64,5.07]$

$1.61[0.50,5.22]$

$1.73[0.88,3.43]$

$2.27[0.60,8.53]$

$0.98[0.60,1.58]$

(Continued....) 


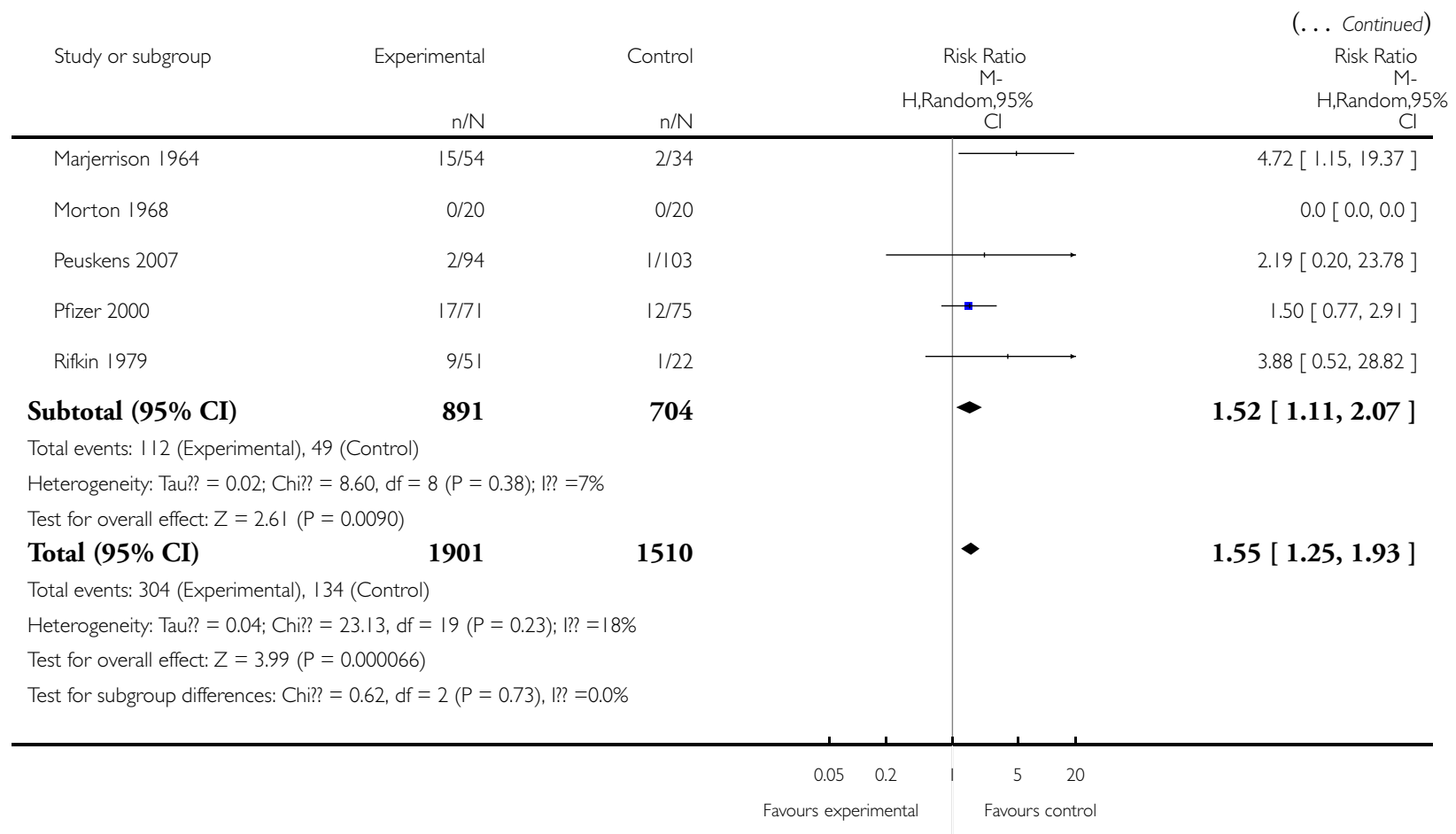


Analysis I.20. Comparison I Maintenance treatment with antipsychotic drugs versus placebo/no treatment, Outcome 20 Adverse effects: movement disorders: akathisia.

Review: Maintenance treatment with antipsychotic drugs for schizophrenia

Comparison: I Maintenance treatment with antipsychotic drugs versus placebo/no treatment

Outcome: 20 Adverse effects: movement disorders: akathisia

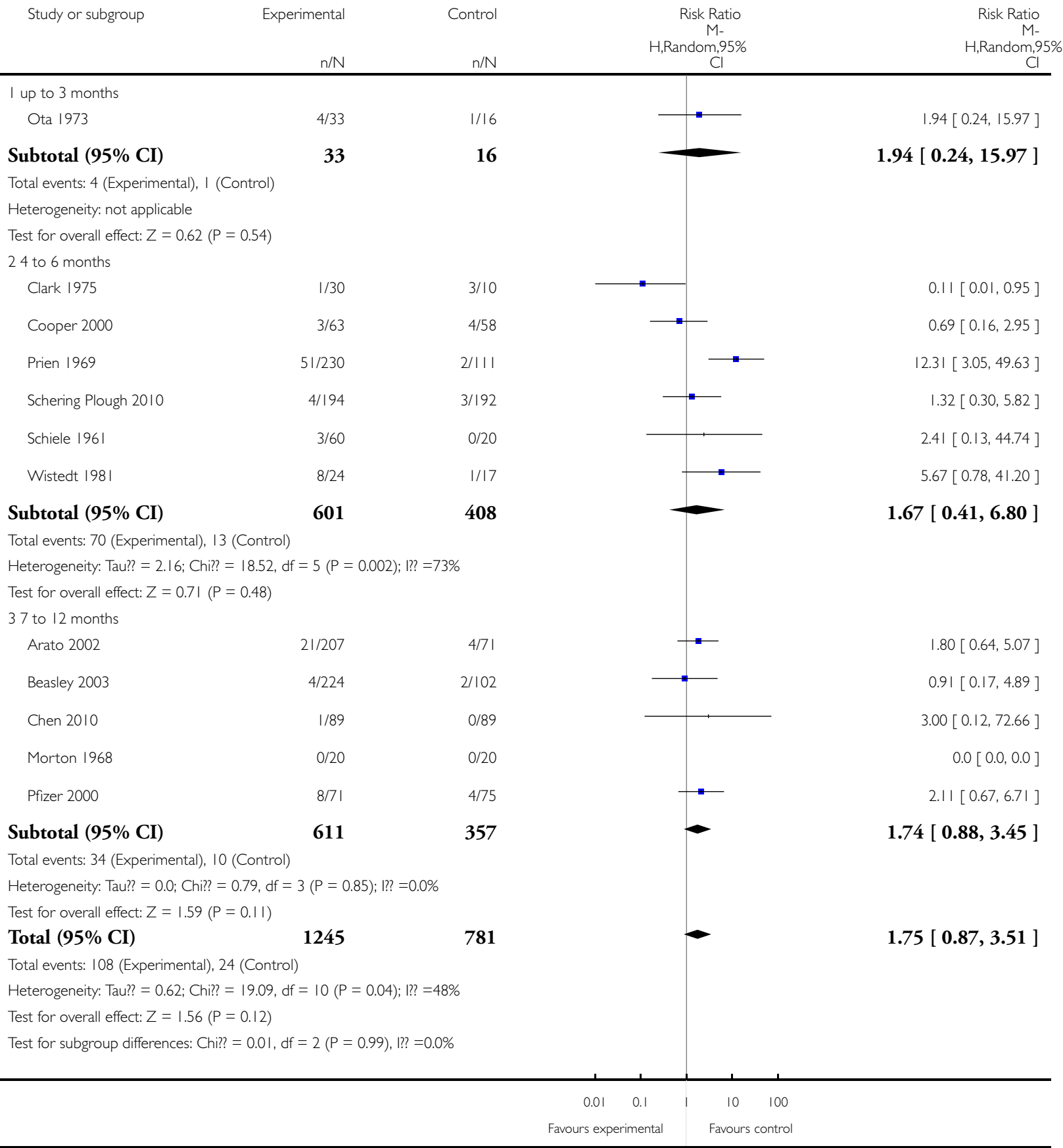

Maintenance treatment with antipsychotic drugs for schizophrenia (Review)

Copyright @ 2012 The Cochrane Collaboration. Published by John Wiley \& Sons, Ltd. 
Analysis I.2I. Comparison I Maintenance treatment with antipsychotic drugs versus placebo/no treatment, Outcome 2 I Adverse effects: movement disorders: akinesia.

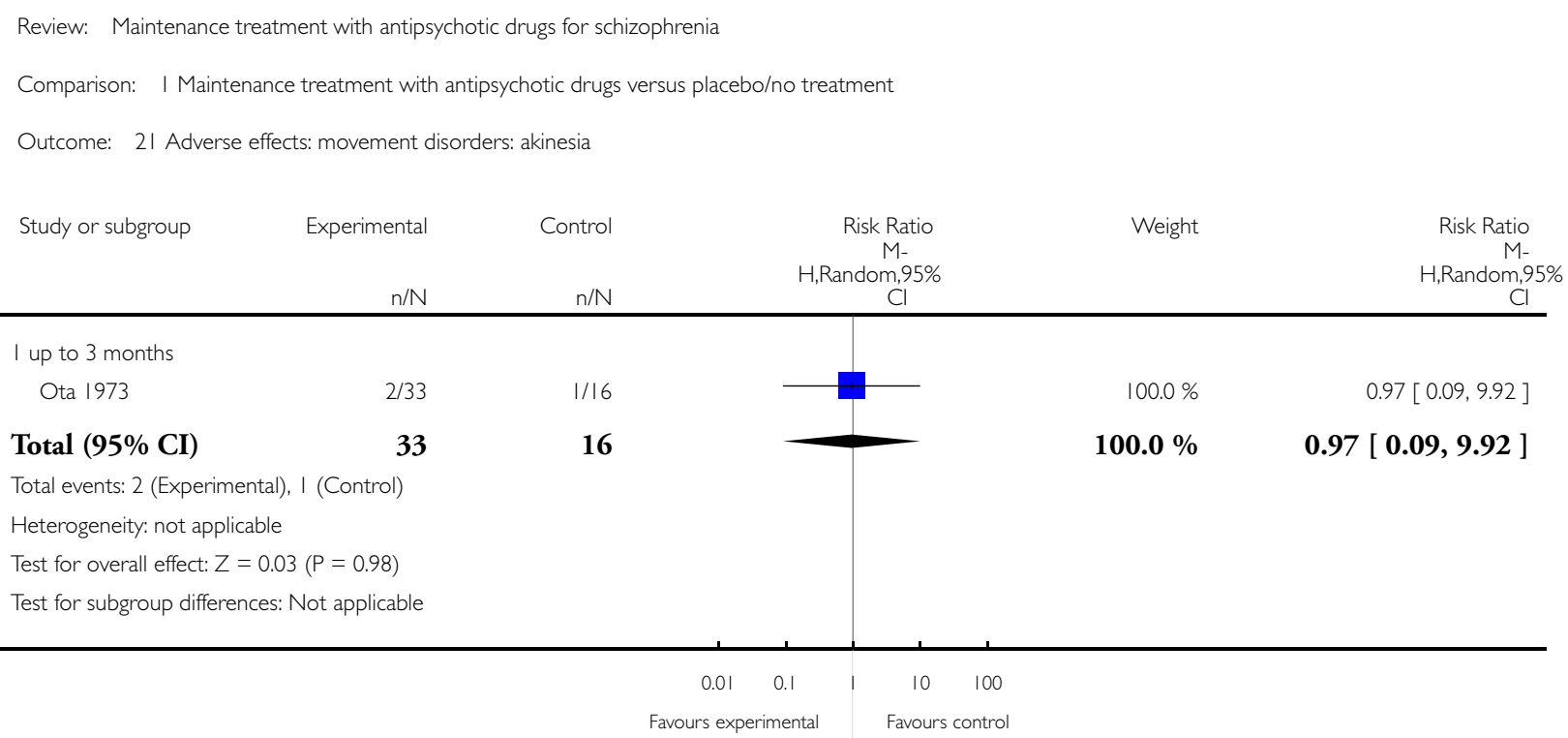


Analysis I.22. Comparison I Maintenance treatment with antipsychotic drugs versus placebo/no treatment, Outcome 22 Adverse effects: movement disorders: dyskinesia.

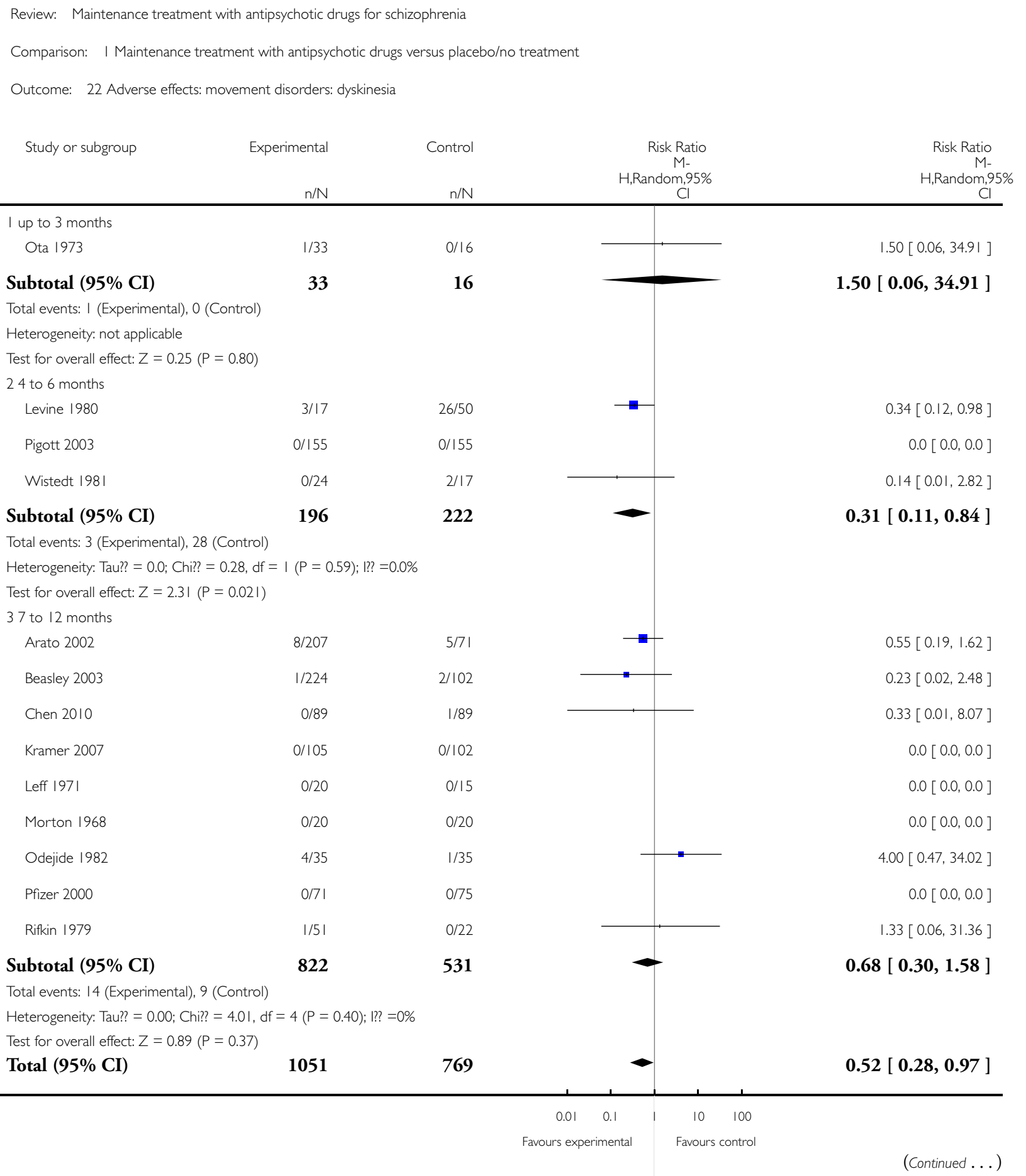


Total events: 18 (Experimental), 37 (Control)

Heterogeneity: Tau?? = 0.0; Chi?? = 6.15, df = $7(P=0.52) ; 1 ?$ ? $=0.0 \%$

Test for overall effect: $Z=2.07(P=0.038)$

Test for subgroup differences: Chi?? = 1.91, $\mathrm{df}=2(\mathrm{P}=0.39), \mathrm{l} ? \mathrm{?}=0.0 \%$

\section{$\begin{array}{ccccc}0.01 & 0.1 & 1 & 10 & 100 \\ \text { Favours experimental } & & \text { Favours control }\end{array}$}

\section{Analysis I.23. Comparison I Maintenance treatment with antipsychotic drugs versus placebo/no treatment, Outcome 23 Adverse effects: movement disorders: dystonia.}

\footnotetext{
Review: Maintenance treatment with antipsychotic drugs for schizophrenia

Comparison: I Maintenance treatment with antipsychotic drugs versus placebo/no treatment

Outcome: 23 Adverse effects: movement disorders: dystonia
}

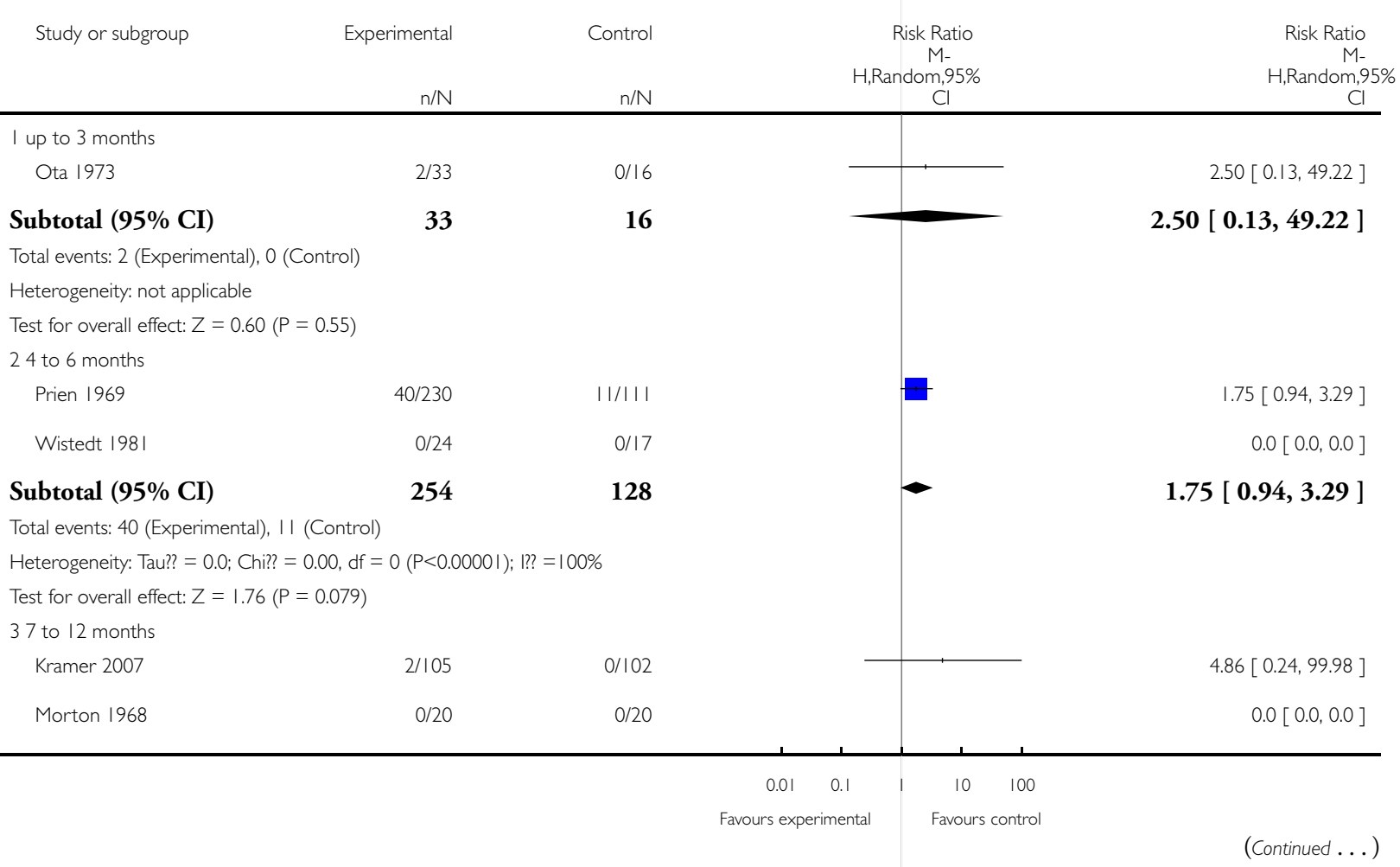




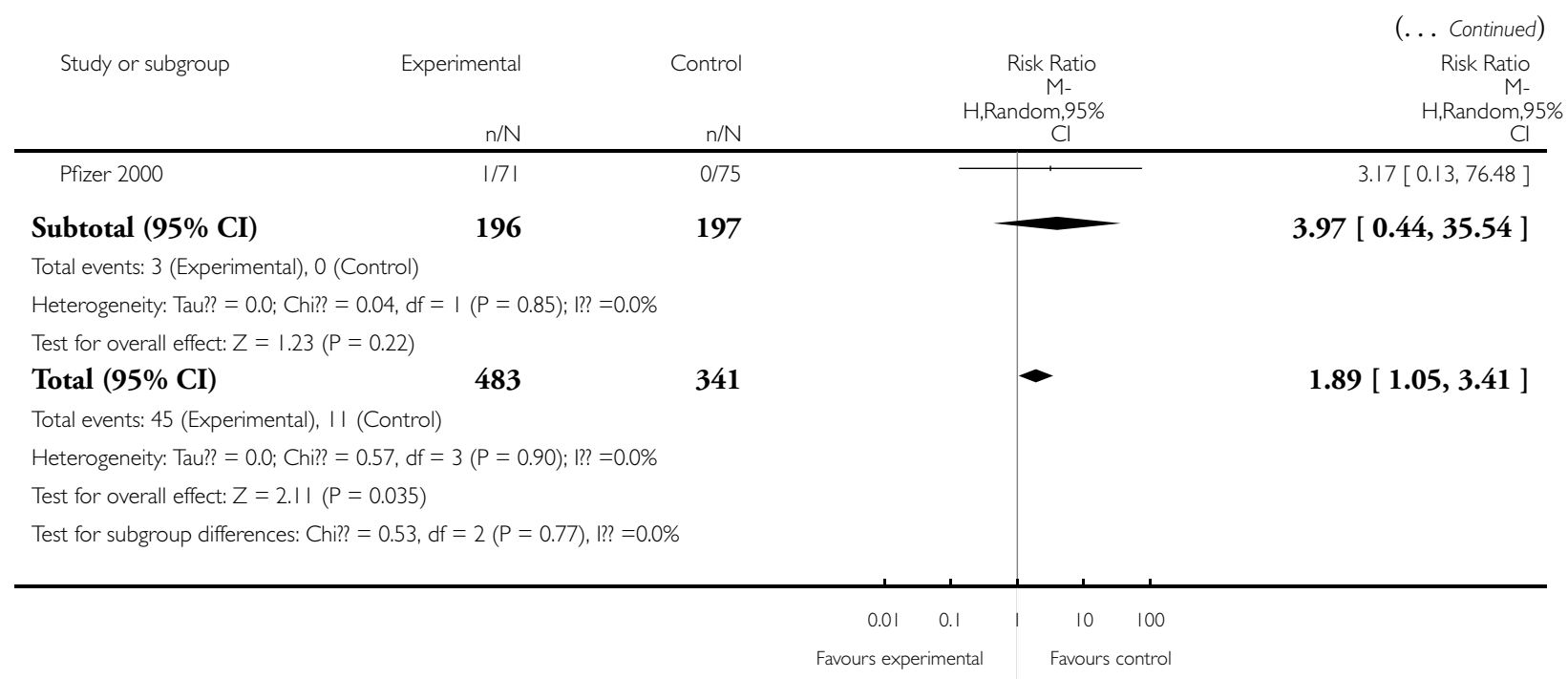

\section{Analysis I.24. Comparison I Maintenance treatment with antipsychotic drugs versus placebo/no treatment, Outcome 24 Adverse effects: movement disorders: rigor.}

Review: Maintenance treatment with antipsychotic drugs for schizophrenia

Comparison: I Maintenance treatment with antipsychotic drugs versus placebo/no treatment

Outcome: 24 Adverse effects: movement disorders: rigor

$\begin{array}{lll}\text { Study or subgroup } & \text { Cxperimental } & \text { Control Ratio }\end{array}$

M-

H,Random, $95 \%$

$\mathrm{n} / \mathrm{N}$

Cl

H,Random,95\%

I up to 3 months
Ota 1973

Subtotal (95\% CI)

$\mathrm{n} / \mathrm{N}$

(n)

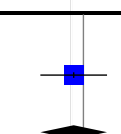

$0.73[0.24,2.22]$

Total events: 6 (Experimental), 4 (Control)

33

16

Heterogeneity: not applicable

Test for overall effect: $Z=0.56(P=0.58)$

24 to 6 months

Clark 1975

Denijs 1973

Schiele 1961

$6 / 33$

$4 / 16$

$0.73[0.24,2.22]$

(

3316


Subtotal (95\% CI)

$\mathrm{n} / \mathrm{N}$

50

$\longrightarrow$

Total events: 19 (Experimental), 4 (Control)

110

Heterogeneity: Tau? = 0.0; Chi?? = I.55, df = $2(P=0.46) ;$ l? $=0.0 \%$

Test for overall effect: $Z=1.23(P=0.22)$

37 to 12 months

Morton 1968

Subtotal (95\% CI)

20

20

Total events: 0 (Experimental), 0 (Control)

Heterogeneity: not applicable

Test for overall effect: $Z=0.0(P<0.0000$ I)

Total (95\% CI)

163

86

0
0
86

(... Continued) Risk Ratio H,Random, $95 \%$

Total events: 25 (Experimental), 8 (Control)

Heterogeneity: Tau? = 0.07; Chi?? = 3.31, df = $3(P=0.35) ;$ l? =9\%

Test for overall effect: $Z=0.52(P=0.60)$

Test for subgroup differences: Chi?? $=1.59, \mathrm{df}=1(P=0.21), 1 ? ?=37 \%$

$1.98[0.67,5.85]$

$0.0[0.0,0.0]$

$0.0[0.0,0.0]$

$1.25[0.54,2.88]$ 
Analysis I.25. Comparison I Maintenance treatment with antipsychotic drugs versus placebo/no treatment, Outcome 25 Adverse effects: movement disorders: tremor.

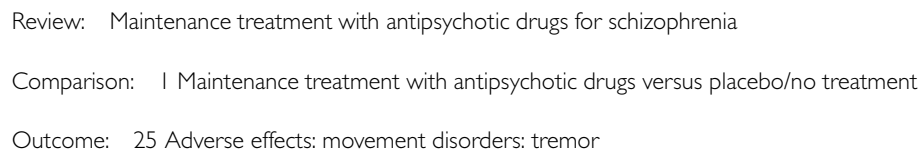

$9 / 33 \quad 4 / 16$

Subtotal (95\% CI)

33

16

Total events: 9 (Experimental), 4 (Control)

Heterogeneity: not applicable

Test for overall effect: $Z=0.17(P=0.87)$

24 to 6 months

Clark 1975

6/30 2/10

Denijs 1973

$3 / 20$

Schiele 1961

$0 / 60$

$2 / 20$

$1 / 20$

Subtotal $(95 \% \mathrm{CI})$

110

50

Total events: 9 (Experimental), 5 (Control)

Heterogeneity: Tau?? = 0.0 I; Chi?? = 2.02, df = $2(P=0.36) ; 1 ?$ ? = $1 \%$

Test for overall effect: $Z=0.15(P=0.88)$

37 to 12 months

Arato 2002
Chen 2010
Hough 2010
Kramer 2007
Porton 1968

Subtotal $(95 \%$ CI)

$8 / 207$

$16 / 89 \quad 13 / 89$

4/206 I/204

$1 / 105$

$0 / 20$

$4 / 71$

$0 / 20$

2/75

Total events: 33 (Experimental), 19 (Control)

Heterogeneity: Tau? = 0.0; Chi? = I.33, df = $4(P=0.86) ;$ l? $=0.0 \%$

Test for overall effect: $Z=1.23(P=0.22)$

Total (95\% CI)

841

627

561

Total events: 5 I (Experimental), 28 (Control)

Heterogeneity: Tau? = 0.0; Chi?? = 3.91, df = $8(P=0.87) ;$ l? $=0.0 \%$

Test for overall effect: $Z=0.99(P=0.32)$

Test for subgroup differences: Chi?? $=0.58, d f=2(P=0.75), \mathrm{I} ? ?=0.0 \%$

6

$1.09[0.40,3.01]$

$1.09[0.40,3.01]$

$1.00[0.24,4.18]$

$1.50[0.28,8.04]$

$0.11[0.00,2.71]$

$0.92[0.33,2.61]$

$1.37[0.30,6.31]$

$1.23[0.63,2.41]$

$3.96[0.45,35.14]$

$0.97[0.06,15.32]$

$0.0[0.0,0.0]$

$2.11[0.40,11.18]$

$1.41[0.82,2.43]$

$1.25[0.81,1.93]$ 
Analysis I.26. Comparison I Maintenance treatment with antipsychotic drugs versus placebo/no treatment, Outcome 26 Adverse effects: movement disorders: use of antiparkinson medication.

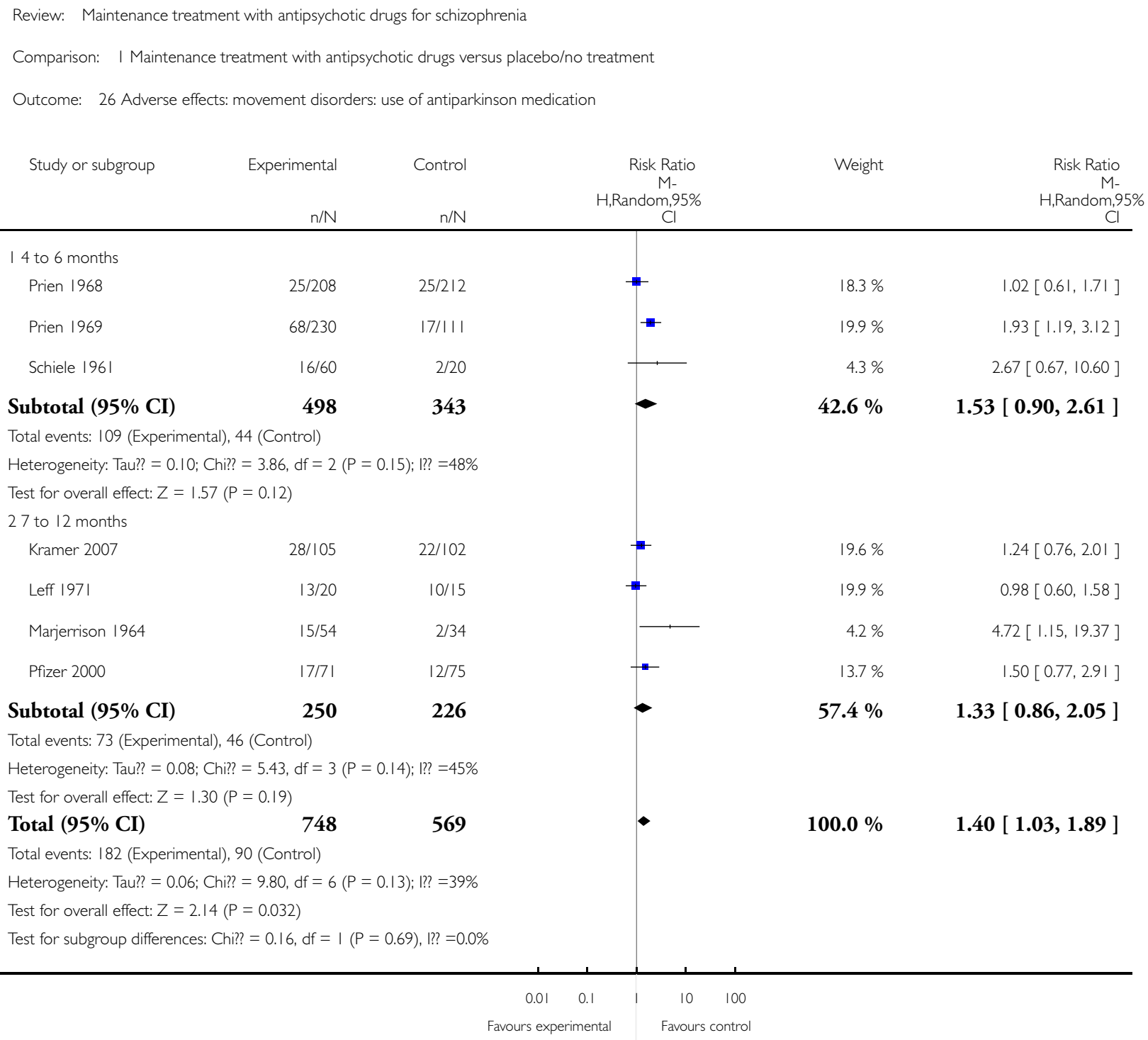


Analysis I.27. Comparison I Maintenance treatment with antipsychotic drugs versus placebo/no treatment, Outcome 27 Adverse effects: sedation.

\begin{tabular}{|c|c|c|c|c|c|}
\hline \multicolumn{6}{|c|}{ Comparison: I Maintenance treatment with antipsychotic drugs versus placebo/no treatment } \\
\hline \multicolumn{6}{|c|}{ Outcome: 27 Adverse effects: sedation } \\
\hline Study or subgroup & Experimental & $\mathrm{n} / \mathrm{N}$ & $\begin{array}{c}\text { Risk Ratio } \\
\text { M- } \\
\text { H,Random,95\% } \\
\text { Cl }\end{array}$ & Weight & $\begin{array}{c}\text { Risk Ratio } \\
\text { M- } \\
\text { H,Random,95\% } \\
\mathrm{Cl} \\
\end{array}$ \\
\hline \multicolumn{6}{|l|}{ I 4 to 6 months } \\
\hline Clark 1975 & $10 / 30$ & $2 / 10$ & $\longrightarrow$ & $2.3 \%$ & $1.67[0.44,6.36]$ \\
\hline Pigott 2003 & $5 / 155$ & $3 / 155$ & $\longrightarrow$ & $2.1 \%$ & $1.67[0.41,6.85]$ \\
\hline Prien 1968 & $14 / 208$ & $13 / 212$ & $\rightarrow$ & $7.8 \%$ & $1.10[0.53,2.28]$ \\
\hline Prien 1969 & $20 / 230$ & $6 / 111$ & - & $5.4 \%$ & $1.61[0.66,3.89]$ \\
\hline Schering Plough 2010 & $1 / 194$ & $2 / 192$ & \begin{tabular}{l|l} 
\\
\end{tabular} & $0.7 \%$ & $0.49[0.05,5.41]$ \\
\hline Schiele 1961 & $13 / 60$ & $3 / 20$ & $\longrightarrow$ & $3.2 \%$ & $1.44[0.46,4.56]$ \\
\hline Subtotal $(95 \% \mathrm{CI})$ & 877 & 700 & - & $21.5 \%$ & $1.33[0.86,2.07]$ \\
\hline \multicolumn{6}{|c|}{ Total events: 63 (Experimental), 29 (Control) } \\
\hline \multicolumn{6}{|c|}{ Heterogeneity: Tau? $=0.0 ;$ Chi?? = 1.33, $\mathrm{df}=5(\mathrm{P}=0.93) ; \mathrm{l} ?=0.0 \%$} \\
\hline \multicolumn{6}{|c|}{ Test for overall effect: $Z=1.28(P=0.20)$} \\
\hline \multicolumn{6}{|c|}{27 to 12 months } \\
\hline Chen 2010 & $62 / 89$ & $44 / 89$ & 由 & $66.5 \%$ & $1.41[1.10,1.81]$ \\
\hline Cooper 2000 & $32 / 63$ & $10 / 58$ & $\rightarrow$ & $11.1 \%$ & $2.95[1.59,5.44]$ \\
\hline Peuskens 2007 & $0 / 94$ & $2 / 103$ & - & $0.5 \%$ & $0.22[0.01,4.50]$ \\
\hline Rifkin 1979 & $1 / 51$ & $0 / 22$ & & $0.4 \%$ & $1.33[0.06,31.36]$ \\
\hline Subtotal $(95 \% \mathrm{CI})$ & 297 & 272 & - & $78.5 \%$ & $1.72[0.90,3.31]$ \\
\hline \multicolumn{6}{|c|}{ Total events: 95 (Experimental), 56 (Control) } \\
\hline \multicolumn{6}{|c|}{ Heterogeneity: Tau? $=0.19 ;$ Chi? $=6.61, d f=3(P=0.09) ; 1 ? ?=55 \%$} \\
\hline \multicolumn{6}{|c|}{ Test for overall effect: $Z=1.63(P=0.10)$} \\
\hline Total $(95 \% \mathrm{CI})$ & 1174 & 972 & $\bullet$ & $100.0 \%$ & $1.50[1.22,1.84]$ \\
\hline \multicolumn{6}{|c|}{ Total events: I58 (Experimental), 85 (Control) } \\
\hline \multicolumn{6}{|c|}{ Heterogeneity: Tau?? = 0.0; Chi?? = 8.07, $\mathrm{df}=9(\mathrm{P}=0.53) ; \mathrm{l} ?=0.0 \%$} \\
\hline \multicolumn{6}{|c|}{ Test for overall effect: $Z=3.87(P=0.00011)$} \\
\hline Test for subgroup differen & $? ?=0.40, \mathrm{df}=1$ & 3), $1 ? ?=0.0 \%$ & & & \\
\hline
\end{tabular}


Analysis I.28. Comparison I Maintenance treatment with antipsychotic drugs versus placebo/no treatment, Outcome 28 Adverse effects: weight gain.

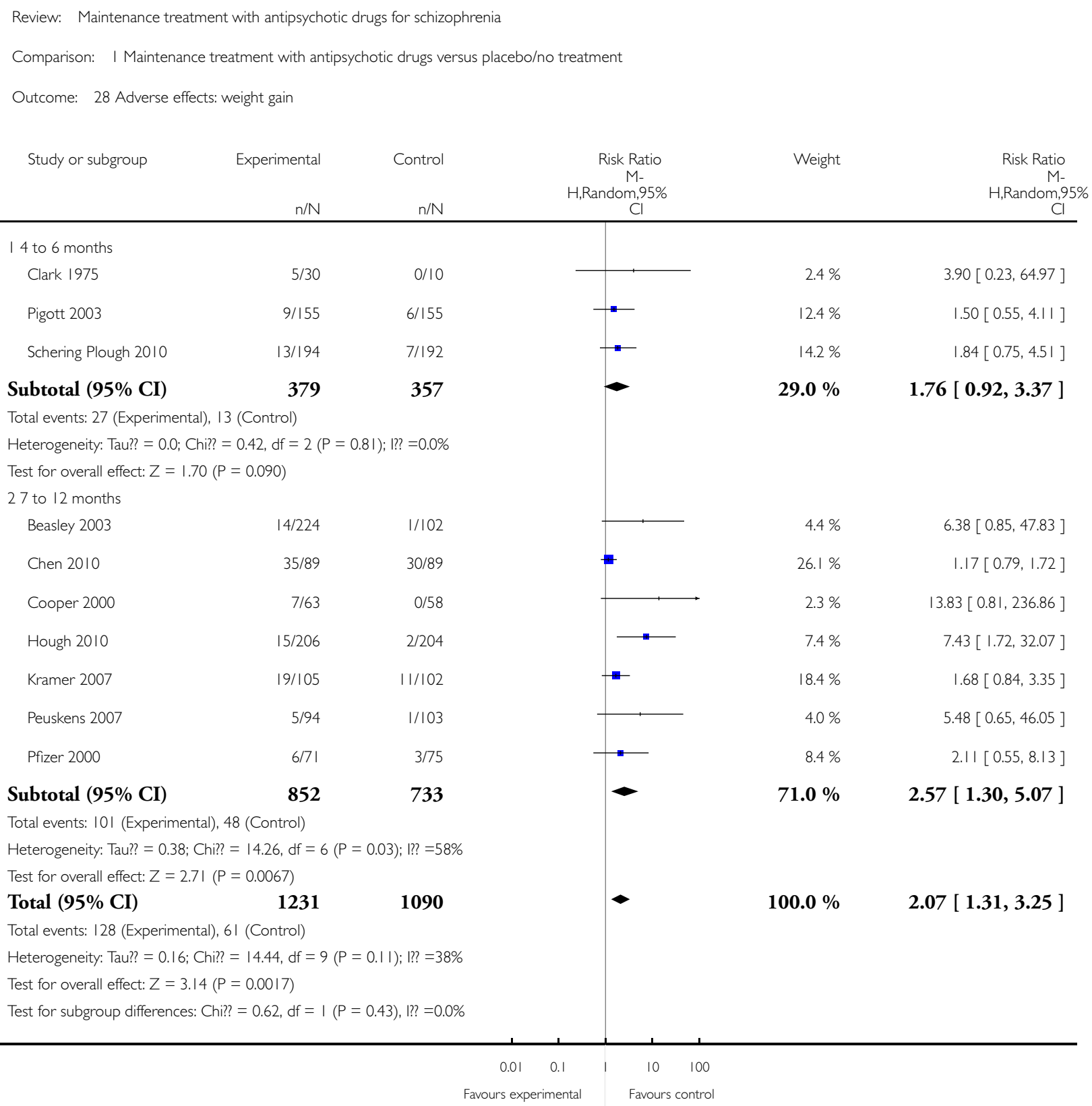


Analysis I.29. Comparison I Maintenance treatment with antipsychotic drugs versus placebo/no treatment, Outcome 29 Quality of life.

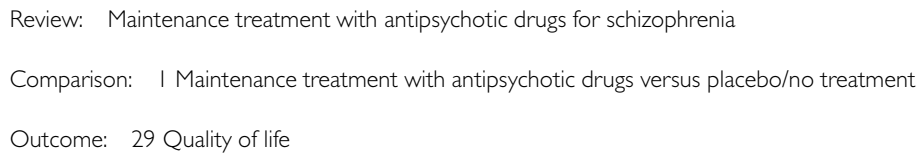

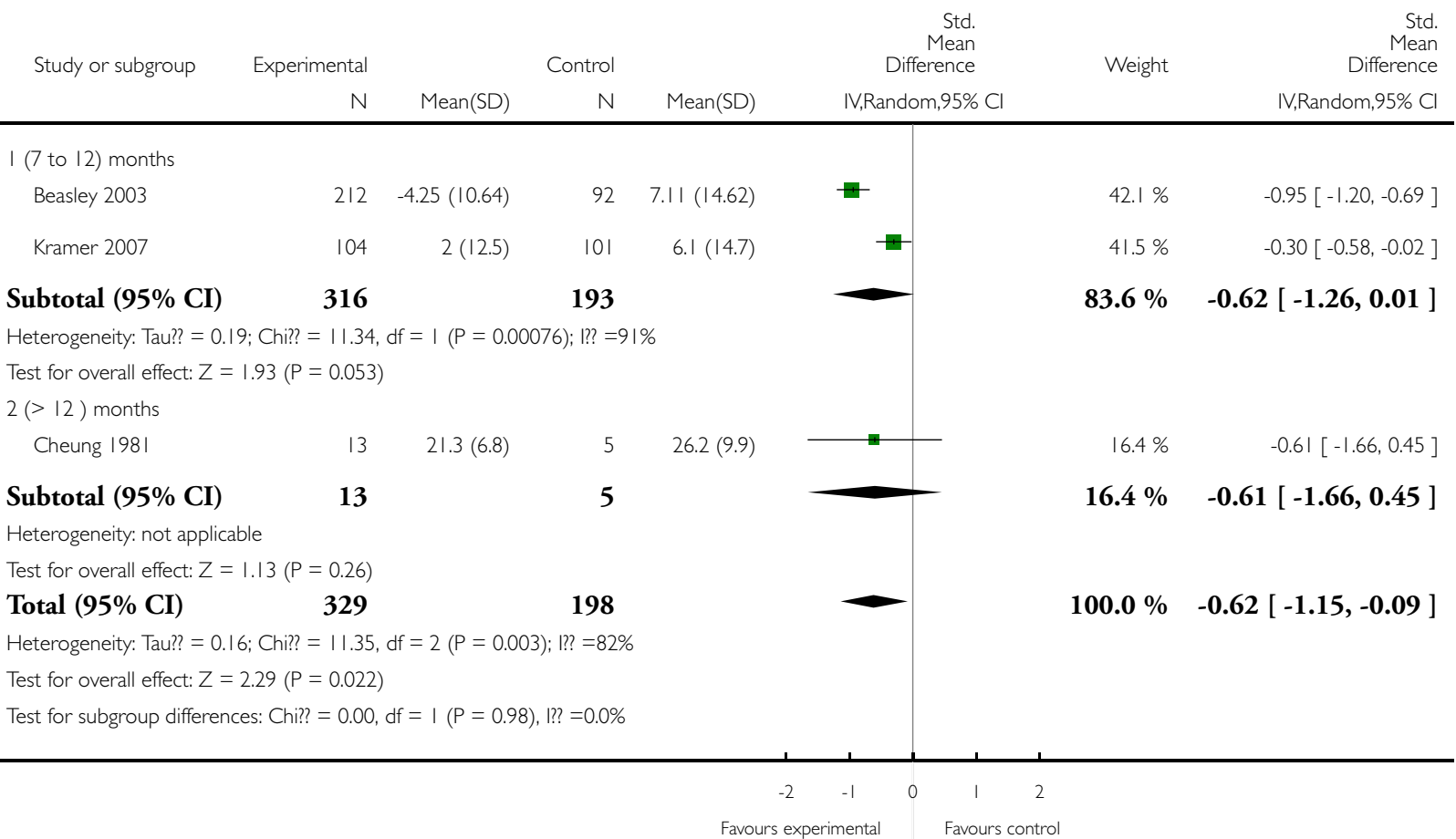


Analysis I.30. Comparison I Maintenance treatment with antipsychotic drugs versus placebo/no treatment, Outcome 30 Number of participants employed: 7 to 12 months.

\begin{tabular}{|c|c|c|c|c|c|}
\hline \multicolumn{6}{|c|}{ Comparison: I Maintenance treatment with antipsychotic drugs versus placebo/no treatment } \\
\hline \multicolumn{6}{|c|}{ Outcome: 30 Number of participants employed: 7 to 12 months } \\
\hline Study or subgroup & Experimental & $\begin{array}{r}\text { Control } \\
n / N \\
\end{array}$ & $\begin{array}{c}\text { Risk Ratio } \\
\text { M- } \\
\text { H,Random,95\% } \\
\text { Cl }\end{array}$ & Weight & $\begin{array}{c}\text { Risk Ratio } \\
\text { M- } \\
\text { H,Random,95\% } \\
\text { Cl } \\
\end{array}$ \\
\hline Chen 2010 & $45 / 89$ & $44 / 89$ & E & $70.5 \%$ & $1.02[0.76,1.37]$ \\
\hline Hirsch 1973 & $|8 / 4|$ & $21 / 40$ & - & $29.5 \%$ & $0.84[0.53,1.32]$ \\
\hline Total $(95 \%$ CI $)$ & 130 & 129 & $\bullet$ & $100.0 \%$ & $0.96[0.75,1.23]$ \\
\hline \multicolumn{6}{|c|}{ Total events: 63 (Experimental), 65 (Control) } \\
\hline \multicolumn{6}{|c|}{ Heterogeneity: Tau?? = 0.0; Chi?? = 0.53, df = I $(P=0.47) ; 1 ? ?=0.0 \%$} \\
\hline \multicolumn{6}{|c|}{ Test for overall effect: $Z=0.29(P=0.77)$} \\
\hline \multicolumn{6}{|c|}{ Test for subgroup differences: Not applicable } \\
\hline
\end{tabular}


Analysis 2.I. Comparison 2 Subgroup analysis (relapse at 12 months), Outcome I Subgroup analysis: participants with a first episode.

Review: Maintenance treatment with antipsychotic drugs for schizophrenia

Comparison: 2 Subgroup analysis (relapse at 12 months)

Outcome: I Subgroup analysis: participants with a first episode

Study or subgroup

Favours experimental

Control

Risk Ratio

H,Random $95 \%$

$n / N \quad n / N$

I first episode

Boonstra 201।

2/9 10/11

Chen 2010

$27 / 89 \quad 56 / 89$

Crow 1986

$20 / 54 \quad 42 / 66$

Hogarty 1973

$10 / 36$

$24 / 39$

Kane 1982

$0 / 11$

McCreadie 1989

0/8

Pietzcker 1993

$7 / 36$

$7 / 17$

$1 / 12$

$4 / 7$

Rifkin 1979

255

$1 / 4$

Subtotal (95\% CI)

273

Total events: 67 (Favours experimental), 167 (Control)

Heterogeneity: Tau?? = 0.0; Chi?? = 5.85, $\mathrm{df}=7(\mathrm{P}=0.56) ;$ I? $=0.0 \%$

Test for overall effect: $Z=6.72(P<0.00001)$

2 not first episode

Andrews 1976

Arato 2002

Cheung 1981

Doddi 1979

Eklund 1991

Hirsch 1973

Hogarty 1973

Hough 2010

Kramer 2007

Leff 197।

Marjerrison 1964

Nishikawa 1982

$1 / 15$

$73 / 207$

2/15

$1 / 10$

$2 / 20$

$3 / 41$

$52 / 156$

$45 / 206$

33/105

$7 / 20$

$4 / 54$

$16 / 20$
, $95 \%$

Weight

Risk Ratio

H,Random,95\%

$\mathrm{Cl}$

1

$1.8 \%$

$0.24[0.07,0.84]$

$6.5 \%$

$0.48[0.34,0.69]$

$6.1 \%$

$0.58[0.39,0.86]$

$4.6 \%$

$0.4 \%$

$0.45[0.25,0.81]$

$0.4 \%$

$3.7 \%$

$0.5 \%$

$0.10[0.01,1.59]$

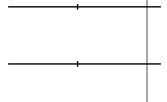

$0.10[0.01,1.56]$

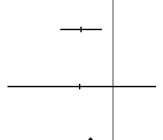

$0.34[0.17,0.69]$

$0.33[0.03,4.19]$

$24.1 \%$

0.47 [ $0.38,0.58$ ]

$0.8 \%$

$0.19[0.03,1.40]$

$7.4 \%$

$0.50[0.39,0.64]$

$1.5 \%$

$0.25[0.06,0.99]$

$0.7 \%$

$0.33[0.04,2.69]$

$1.6 \%$

$0.14[0.04,0.55]$

$2.1 \%$

$0.12[0.04,0.36]$

$7.4 \%$

$0.45[0.35,0.57]$

$7.1 \%$

$0.34[0.26,0.45]$

$6.9 \%$

$0.39[0.29,0.53]$

$4.2 \%$

$0.44[0.23,0.84]$

$1.1 \%$

$1.26[0.24,6.51]$

$7.3 \%$

$0.82[0.64,1.07]$

$10 / 10$ 


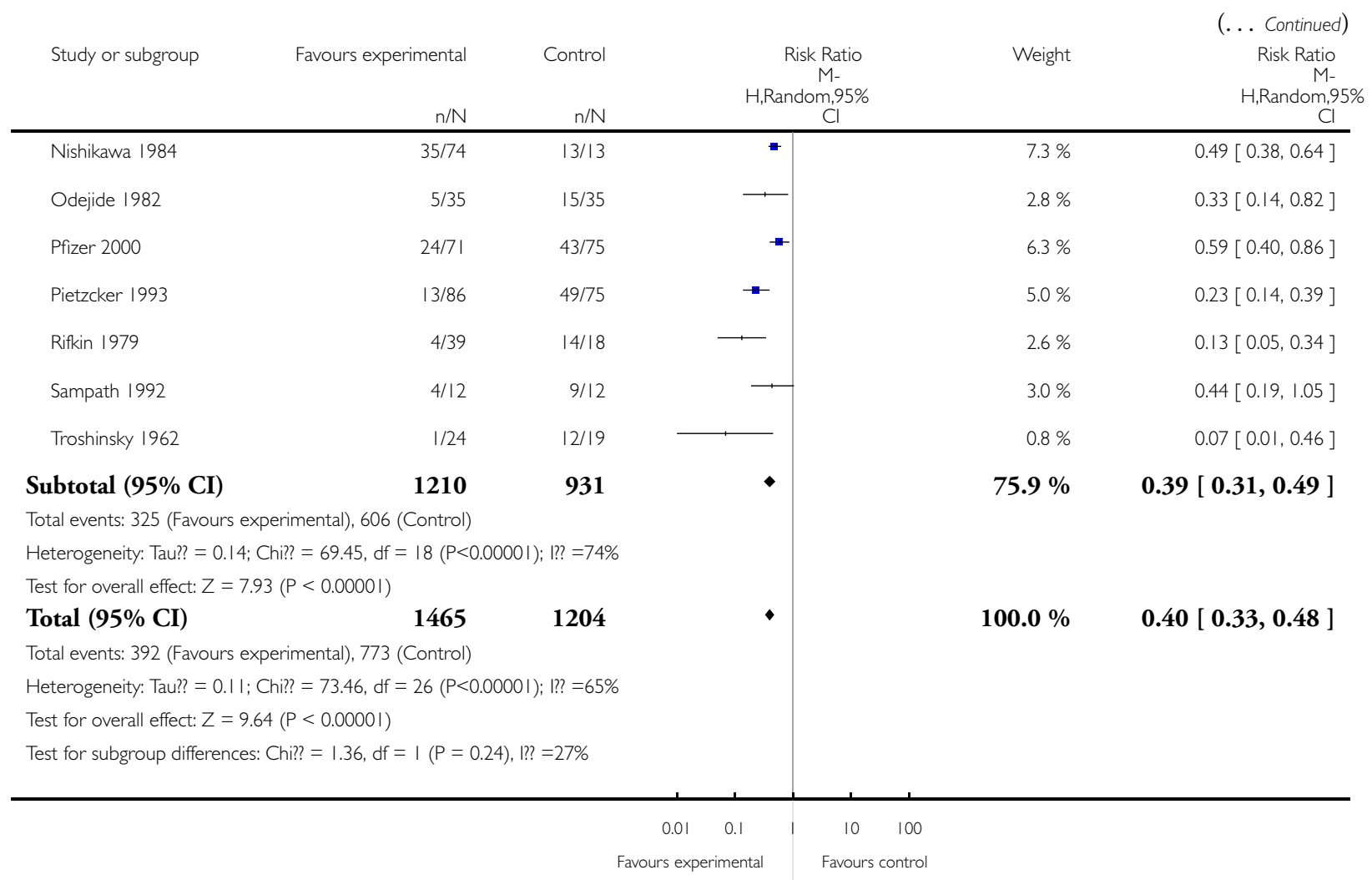


Analysis 2.2. Comparison 2 Subgroup analysis (relapse at 12 months), Outcome 2 Subgroup analysis: participants in remission.

Review: Maintenance treatment with antipsychotic drugs for schizophrenia

Comparison: 2 Subgroup analysis (relapse at 12 months)

Outcome: 2 Subgroup analysis: participants in remission

Study or subgroup

Experimental Control

Risk Ratio

M-

$\mathrm{n} / \mathrm{N}$

H.Random,95\%

$n / N$

$\mathrm{Cl}$

Weight

Risk Ratio

H,Random, $95 \%$

I in remission

Boonstra 201।

$2 / 9 \quad 10 / 11$

Chen 2010

$27 / 89$

$56 / 89$

Cheung 1981

$2 / 15$

Kane 1982

$0 / 11$

Nishikawa 1982

$16 / 20$

$8 / 15$

Nishikawa 1984

$35 / 74$

$7 / 17$

Odejide 1982

5/35

Rifkin 1979

$5 / 51$

$304 \quad 212$

$10 / 10$

$13 / 13$

15/35

15/22

Subtotal (95\% CI)

212

Total events: 92 (Experimental), 134 (Control)

Heterogeneity: Tau?? = 0.28; Chi?? = 38.22, df = 7 (P<0.0000 I); I? =82\%

Test for overall effect: $Z=4.00(P=0.000064)$

2 not in remission

Andrews 1976

$1 / 15$

$6 / 17$

Arato 2002

$73 / 207$

$50 / 71$

Crow 1986

20/54

$42 / 66$

Doddi 1979

$1 / 10$

$3 / 10$

Eklund 1991

$2 / 20$

$16 / 23$

Hirsch 1973

$3 / 41$

$25 / 40$

Hogarty 1973

$62 / 192$

$131 / 182$

Hough 2010

$45 / 206$

130/204

Kramer 2007

33/105

$82 / 102$

Leff 197|

$7 / 20$

$12 / 15$

Marjerrison 1964

$4 / 54$

2/34

McCreadie 1989

$0 / 8$

$4 / 7$

$0.9 \%$

$0.19[0.03,1.40]$

$7.9 \%$

$0.50[0.39,0.64]$

$6.6 \%$

$0.58[0.39,0.86]$

$0.8 \%$

$0.33[0.04,2.69]$

$1.7 \%$

$0.14[0.04,0.55]$

$2.3 \%$

$0.12[0.04,0.36]$

$8.1 \%$

$0.45[0.36,0.56]$

$7.6 \%$

$0.34[0.26,0.45]$

$7.5 \%$

$0.39[0.29,0.53]$

$4.6 \%$

$0.44[0.23,0.84]$

$1.2 \%$

$1.26[0.24,6.51]$

$0.5 \%$

$0.10[0.01,1.56]$

(Continued ... ) 


\begin{tabular}{|c|c|c|c|c|c|}
\hline Study or subgroup & Experimental & $n / N$ & $\begin{array}{c}\text { Risk Ratio } \\
\text { M- } \\
\text { H,Random, } 95 \% \\
\mathrm{Cl}\end{array}$ & Weight & $\begin{array}{c}\text { (... Continued) } \\
\text { Risk Ratio } \\
\text { M- } \\
\text { H,Random,95\% } \\
\text { Cl }\end{array}$ \\
\hline Pfizer 2000 & $24 / 71$ & $43 / 75$ & - & $6.7 \%$ & $0.59[0.40,0.86]$ \\
\hline Pietzcker 1993 & $20 / 122$ & $72 / 115$ & $\mp$ & $6.3 \%$ & $0.26[0.17,0.40]$ \\
\hline Sampath 1992 & $4 / 12$ & $9 / 12$ & $\longrightarrow$ & $3.3 \%$ & $0.44[0.19,1.05]$ \\
\hline Troshinsky 1962 & $1 / 24$ & $12 / 19$ & - & $0.9 \%$ & $0.07[0.01,0.46]$ \\
\hline Subtotal $(95 \% \mathrm{CI})$ & 1161 & 992 & - & $67.0 \%$ & $0.40[0.33,0.49]$ \\
\hline \multicolumn{6}{|c|}{ Total events: 300 (Experimental), 639 (Control) } \\
\hline \multicolumn{6}{|c|}{ Heterogeneity: Tau? $=0.06 ;$ Chi?? $=31.53, d f=15(P=0.01) ; 1 ? ?=52 \%$} \\
\hline \multicolumn{6}{|c|}{ Test for overall effect: $Z=9.21(P<0.00001)$} \\
\hline Total $(95 \% \mathrm{CI})$ & 1465 & 1204 & - & $100.0 \%$ & $0.40[0.33,0.49]$ \\
\hline \multicolumn{6}{|c|}{ Total events: 392 (Experimental), 773 (Control) } \\
\hline \multicolumn{6}{|c|}{ Heterogeneity: Tau? = 0.11; Chi?? = 73.01, df = 23 (P<0.0000 I); 1 ? =68\% } \\
\hline \multicolumn{6}{|c|}{ Test for overall effect: $Z=9.08(P<0.0000 \mathrm{I})$} \\
\hline \multicolumn{6}{|c|}{ Test for subgroup differences: Chi?? $=0.03, \mathrm{df}=\mathrm{I}(\mathrm{P}=0.87), 1 ? ?=0.0 \%$} \\
\hline
\end{tabular}


Analysis 2.3. Comparison 2 Subgroup analysis (relapse at 12 months), Outcome 3 Subgroup analysis: various durations of stability before entering the study.

Review: Maintenance treatment with antipsychotic drugs for schizophrenia

Comparison: 2 Subgroup analysis (relapse at 12 months)

Outcome: 3 Subgroup analysis: various durations of stability before entering the study

Study or subgroup

Experimental

Control

Risk Ratio

H.

$\mathrm{n} / \mathrm{N} \quad \mathrm{n} / \mathrm{N}$

Cl

| stable at least | month

$3 / 41$

Hirsch 1973

$25 / 40$

Rifkin 1979

$5 / 51$

$15 / 22$

Andrews 1976

I/15

$6 / 17$

Kramer 2007

33/105

$82 / 102$

Leff 197|

$7 / 20$

$12 / 15$

Subtotal (95\% CI)

232

196

Total events: 49 (Experimental), 140 (Control)

Heterogeneity: Tau?? = 0.19; Chi?? = 9.65, df = 4 ( $P=0.05) ;$ l? =59\%

Test for overall effect: $Z=4.80(P<0.0000$ I)

2 stable at least 3 months

$\begin{array}{lrr}\text { Kane 1982 } & \text { 0/II } & \text { 7/17 } \\ \text { Eklund 1991 } & 2 / 20 & 16 / 23 \\ \text { Pietzcker 1993 } & 20 / 122 & 72 / 115 \\ \text { Hough 2010 } & 45 / 206 & 130 / 204 \\ \text { Marjerrison 1964 } & 4 / 54 & 2 / 34\end{array}$

Subtotal (95\% CI)

413

393

Total events: 7I (Experimental), 227 (Control)

Heterogeneity: Tau?? = 0.05; Chi?? = 5.84, df= $4(P=0.21) ;$ l? $=31 \%$

Test for overall effect: $Z=6.28(P<0.00001)$

3 stable at least 6 months

Doddi 1979

$$
1 / 10
$$

10

$3 / 10$

10

$\longrightarrow$
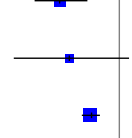

$-$

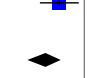

$<$

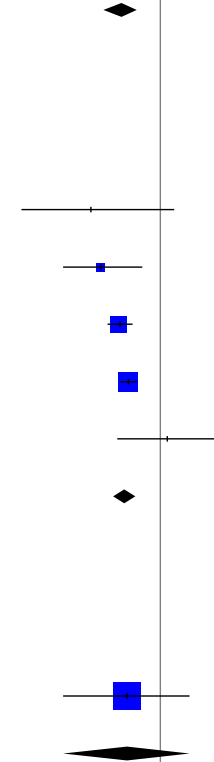

Subtotal (95\% CI)

Total events: I (Experimental), 3 (Control)

Heterogeneity: not applicable

Test for overall effect: $Z=1.03(P=0.30)$

4 stable at least 12 months

Troshinsky 1962

McCreadie 1989
$12 / 19$

$4 / 7$
Weight

Risk Ratio

H,Random,95\%

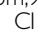

$$
14.7 \%
$$

$0.12[0.04,0.36]$

$19.2 \%$

$0.14[0.06,0.35]$

$6.2 \%$

$34.9 \%$

$25.0 \%$

$0.19[0.03,1.40]$

$0.39[0.29,0.53]$

$0.44[0.23,0.84]$

$100.0 \%$

0.27 [ $0.15,0.46$ ]

$1.7 \%$

$0.10[0.01,1.59]$

$6.9 \%$

$0.14[0.04,0.55]$

$36.5 \%$

$50.2 \%$

$0.26[0.17,0.40]$

$0.34[0.26,0.45]$

$4.7 \%$

$1.26[0.24,6.51]$

$100.0 \%$

$0.30[0.21,0.44$ ]

$100.0 \%$

$0.33[0.04,2.69]$

$100.0 \%$

0.33 [ 0.04, 2.69]

$8.3 \%$

0.07 [ $0.01,0.46$ ]

$4.5 \%$

$0.10[0.01,1.56]$

(Continued ....) 


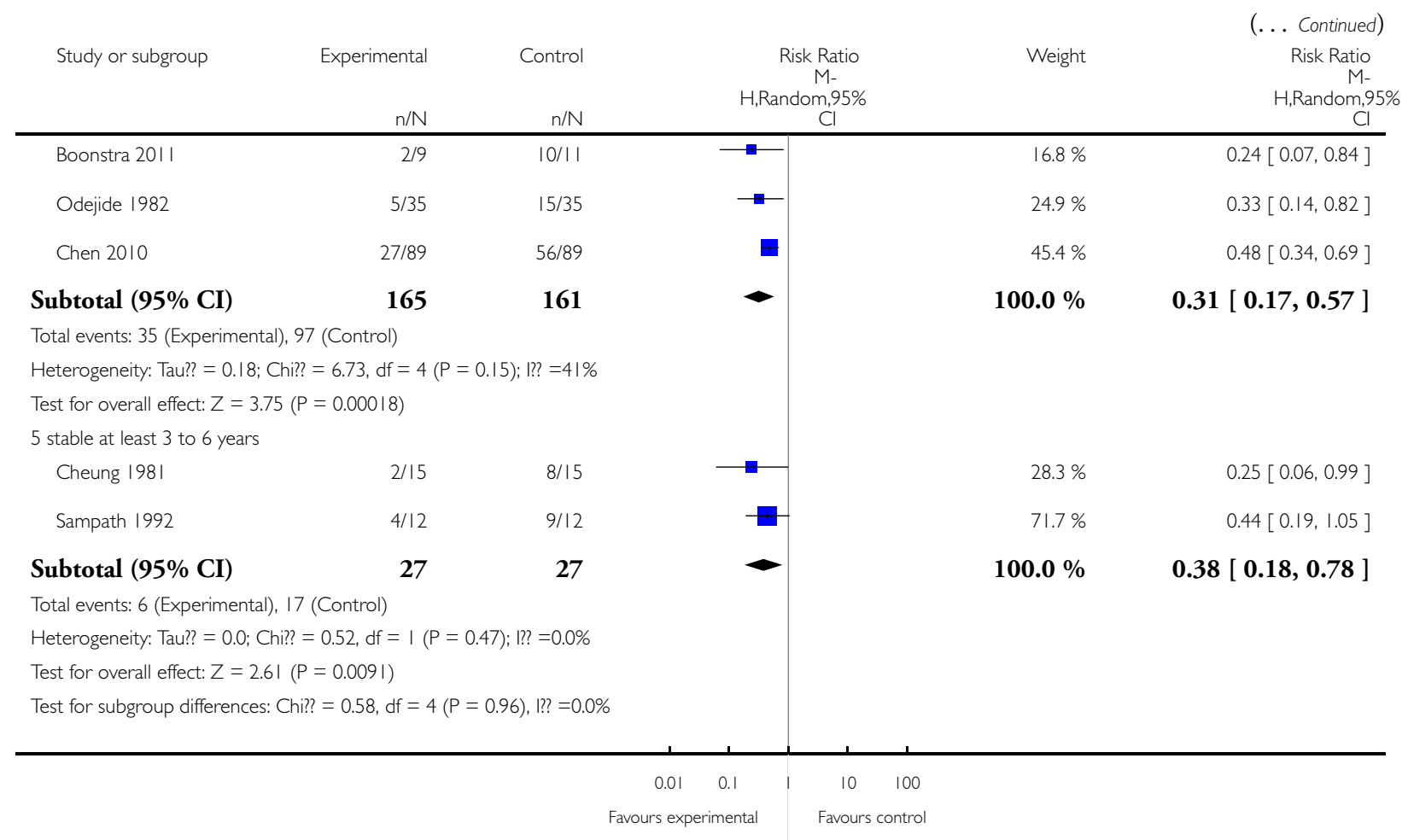


Analysis 2.4. Comparison 2 Subgroup analysis (relapse at 12 months), Outcome 4 Subgroup analysis: abrupt withdrawal versus tapering.

Review: Maintenance treatment with antipsychotic drugs for schizophrenia

Comparison: 2 Subgroup analysis (relapse at 12 months)

Outcome: 4 Subgroup analysis: abrupt withdrawal versus tapering

Study or subgroup

Experimental Control

Risk Ratio

M-

$\mathrm{n} / \mathrm{N} \quad \mathrm{n} / \mathrm{N}$

I Abrupt withdrawal

Andrews 1976

Arato 2002

$73 / 207$

Cheung 1981

Hogarty 1973

$62 / 192$

Hough 2010

$45 / 206$

Kane 1982

$0 / 11$

Kramer 2007

33/105

Leff 197।

$7 / 20$

Marjerrison 1964

$4 / 54$

McCreadie 1989

Nishikawa 1982

Nishikawa 1984

$35 / 74$

Odejide 1982

$5 / 35$

Pfizer 2000

$24 / 71$

Rifkin 1979

Troshinsky 1962

$5 / 51$

1108

Subtotal (95\% CI)

Risk Ratio
M-
H,Random,95\%
Cl

Weight

Risk Ratio

H,Random,95\%

$\mathrm{Cl}$

Total events: 313 (Experimental), 540 (Control)

Heterogeneity: Tau?? = 0.10; Chi?? = 51.47, $d f=15(P<0.00001) ; 1$ ? =71\%

Test for overall effect: $Z=7.21(P<0.00001)$

2 Taper

Boonstra 20I

Chen 2010

$27 / 89$

Crow 1986

$20 / 54$

Doddi 1979

$1 / 15$

$6 / 17$

2/15

$50 / 71$

$8 / 15$

$131 / 182$

130/204

$7 / 17$

$82 / 102$

$0 / 8$

$16 / 20$

$12 / 15$

I/24

$2 / 34$

$4 / 7$

$10 / 10$

$13 / 13$

15/35

$43 / 75$

15/22

$12 / 19$

838

$10 / 11$

$56 / 89$

$42 / 66$

$1 / 10$

$3 / 10$

+
$\square$
$\square$
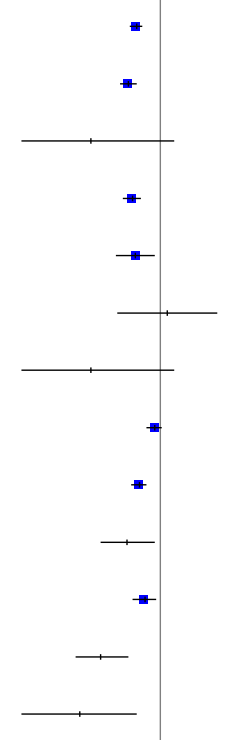

$\bullet$
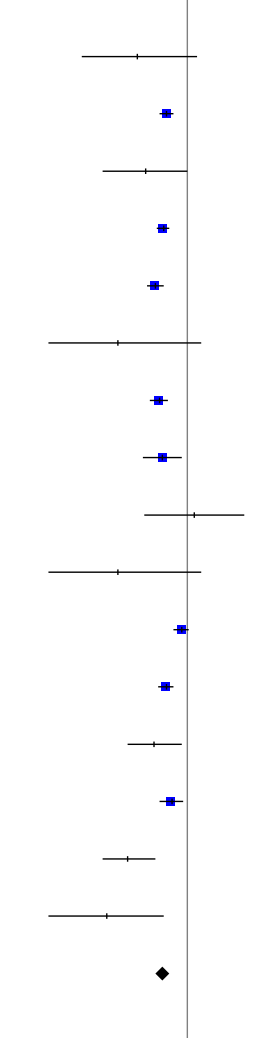

$1.2 \%$

$11.5 \%$

$2.3 \%$

$11.7 \%$

$11.0 \%$

$0.7 \%$

$10.7 \%$

$6.4 \%$

$1.7 \%$

$0.7 \%$

$11.2 \%$

$11.2 \%$

$4.4 \%$

$9.6 \%$

$4.5 \%$

$1.3 \%$

$100.0 \%$

$0.43[0.34,0.54]$

$0.19[0.03,1.40]$

$0.50[0.39,0.64]$

$0.25[0.06,0.99]$

$0.45[0.36,0.56]$

$0.34[0.26,0.45]$

$0.10[0.01,1.59]$

$0.39[0.29,0.53]$

$0.44[0.23,0.84]$

$.26[0.24,6.51]$

$0.10[0.01,1.56]$

$0.82[0.64,1.07]$

$0.49[0.38,0.64]$

$0.33[0.14,0.82]$

$0.59[0.40,0.86]$

$0.14[0.06,0.35]$

$0.07[0.01,0.46]$
$7.3 \%$

$21.9 \%$

$21.0 \%$

$3.1 \%$
$0.24[0.07,0.84]$

$0.48[0.34,0.69]$

$0.58[0.39,0.86]$

$0.33[0.04,2.69]$

(Continued....) 


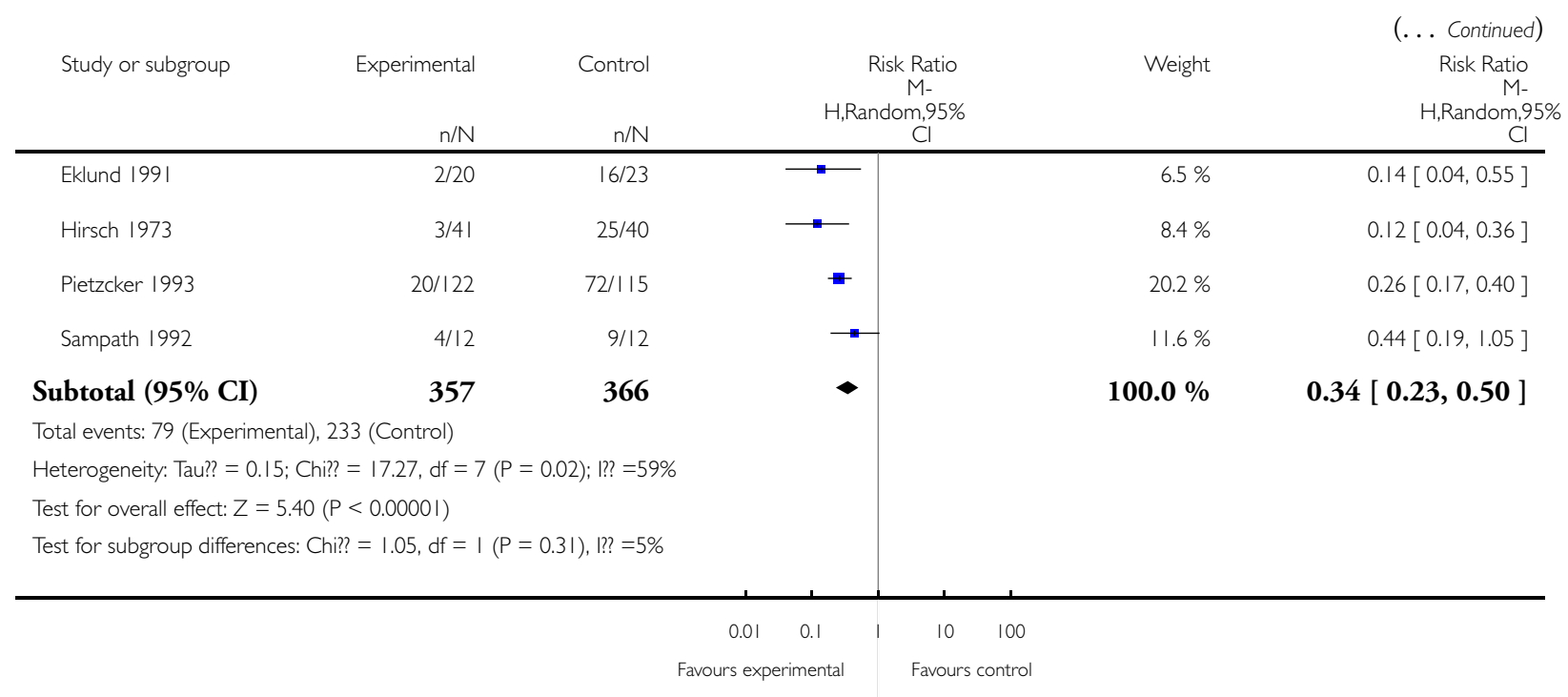

\section{Analysis 2.5. Comparison 2 Subgroup analysis (relapse at 12 months), Outcome 5 Subgroup analysis: single antipsychotic drugs.}

Review: Maintenance treatment with antipsychotic drugs for schizophrenia

Comparison: 2 Subgroup analysis (relapse at 12 months)

Outcome: 5 Subgroup analysis: single antipsychotic drugs

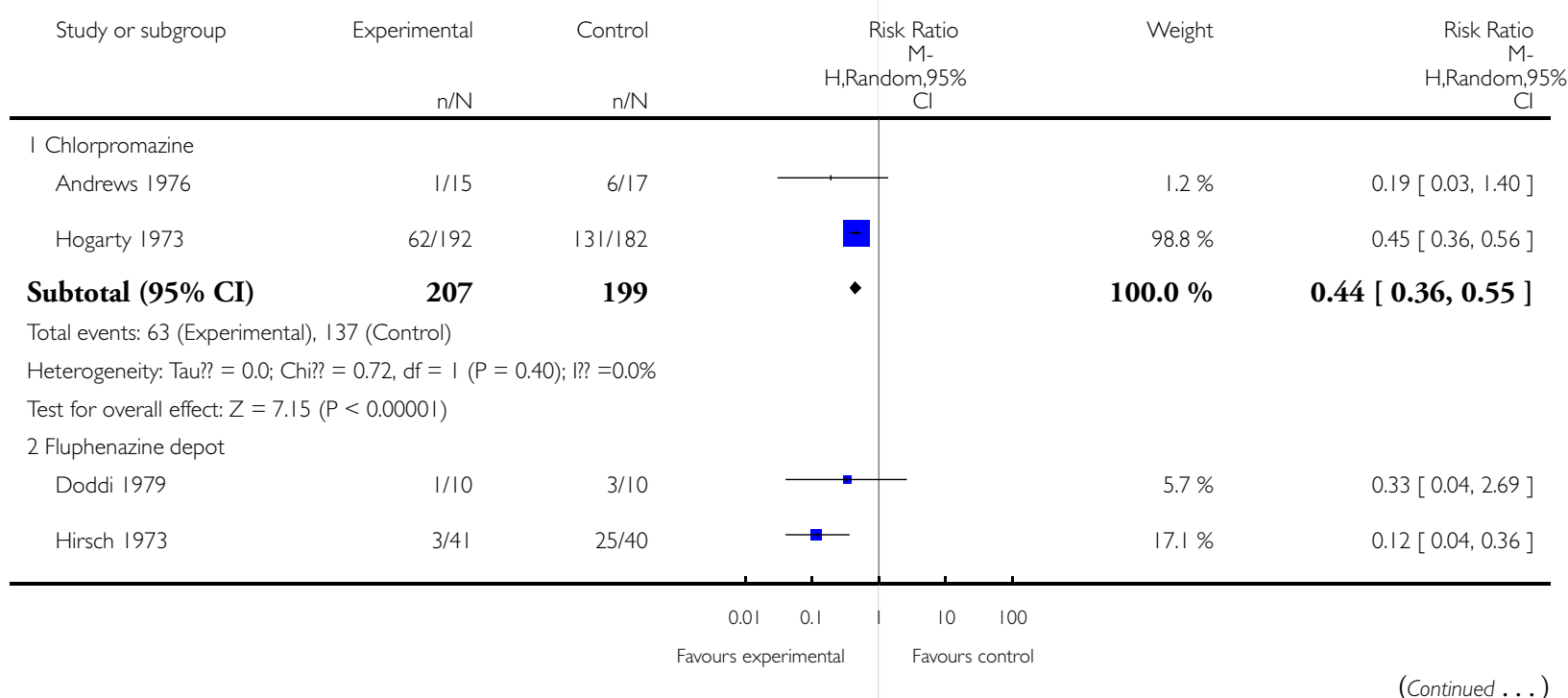




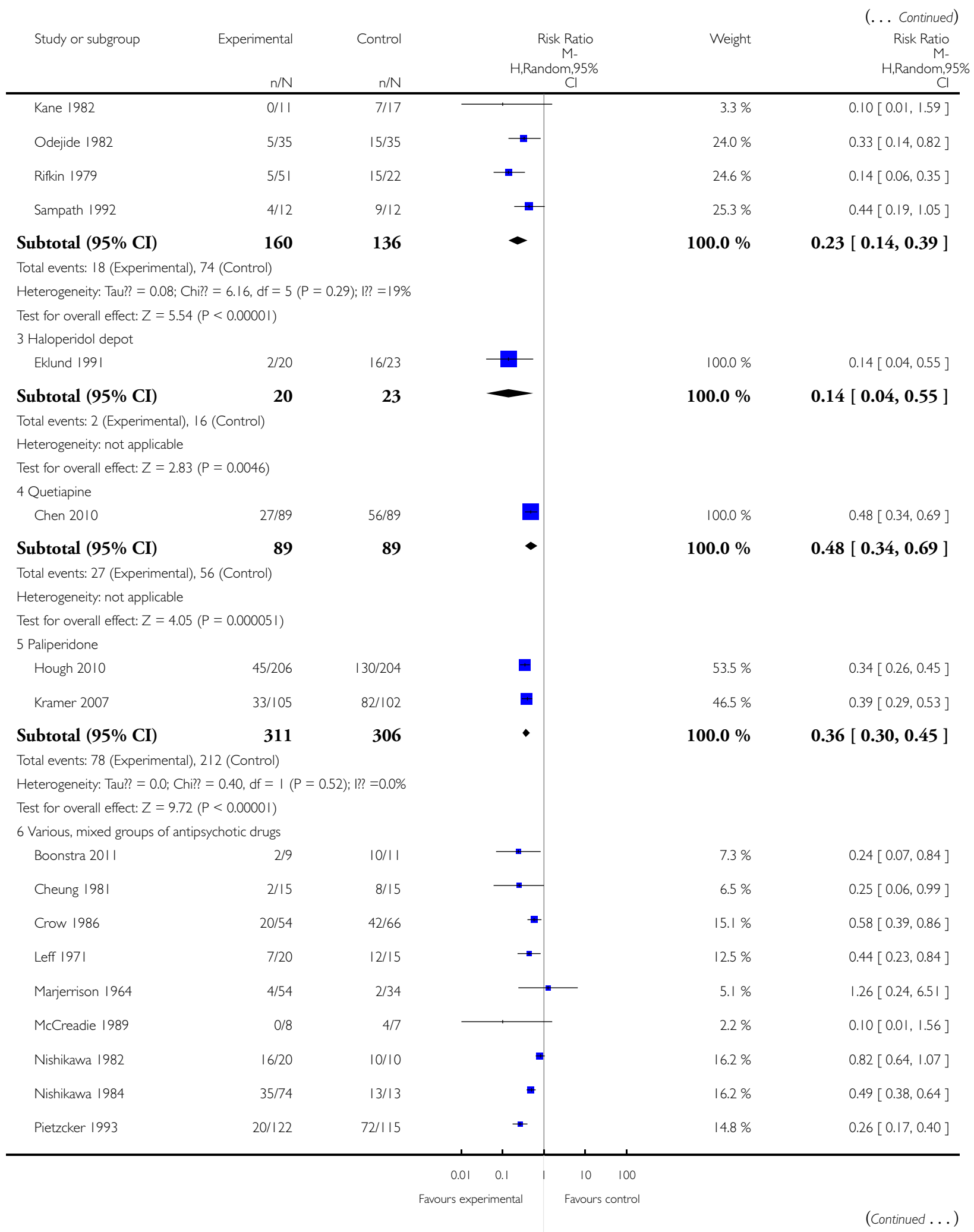

Maintenance treatment with antipsychotic drugs for schizophrenia (Review)

Copyright $\odot 2012$ The Cochrane Collaboration. Published by John Wiley \& Sons, Ltd. 


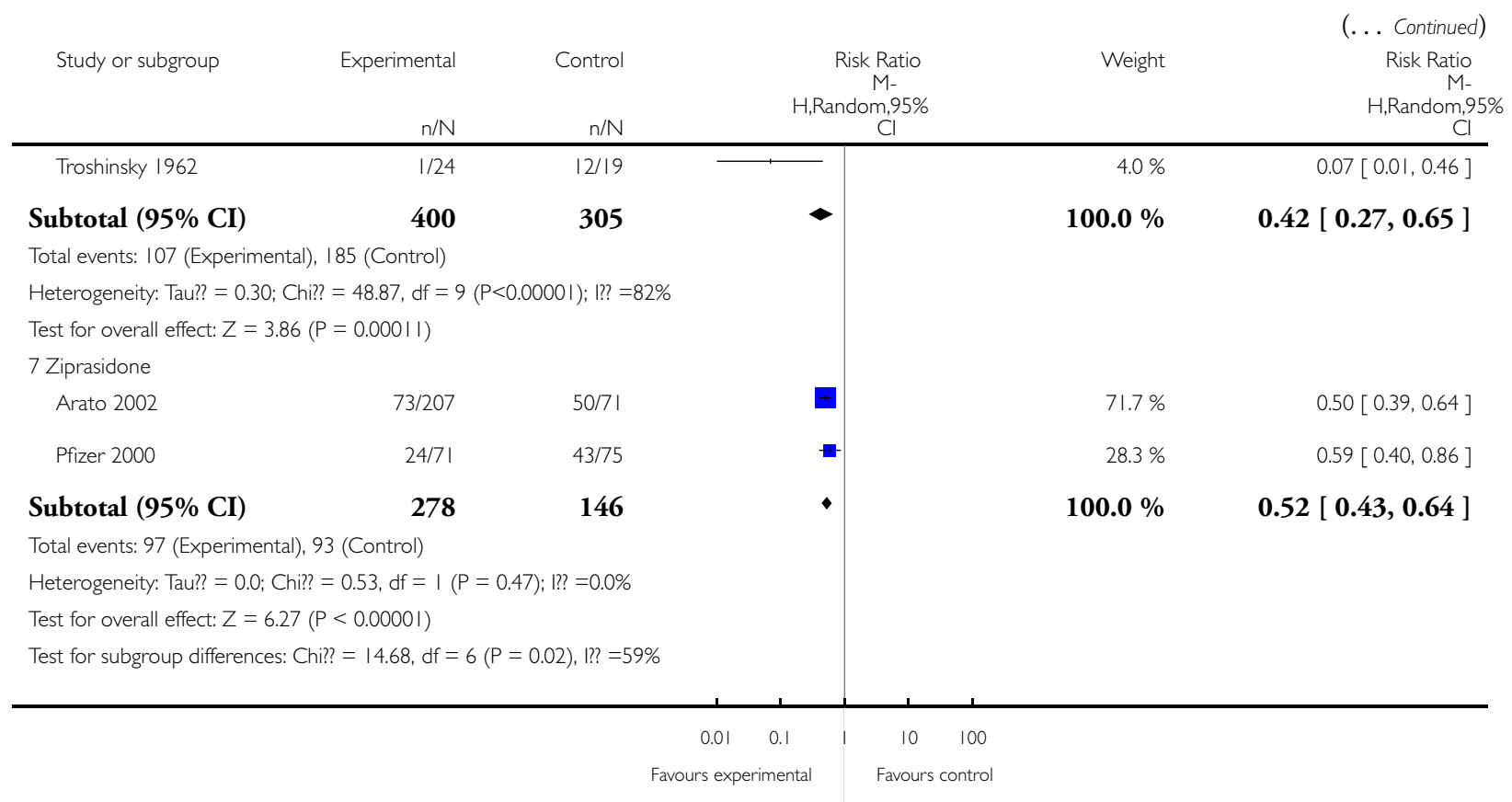


Analysis 2.6. Comparison 2 Subgroup analysis (relapse at 12 months), Outcome 6 Subgroup analysis: depot versus oral drugs.

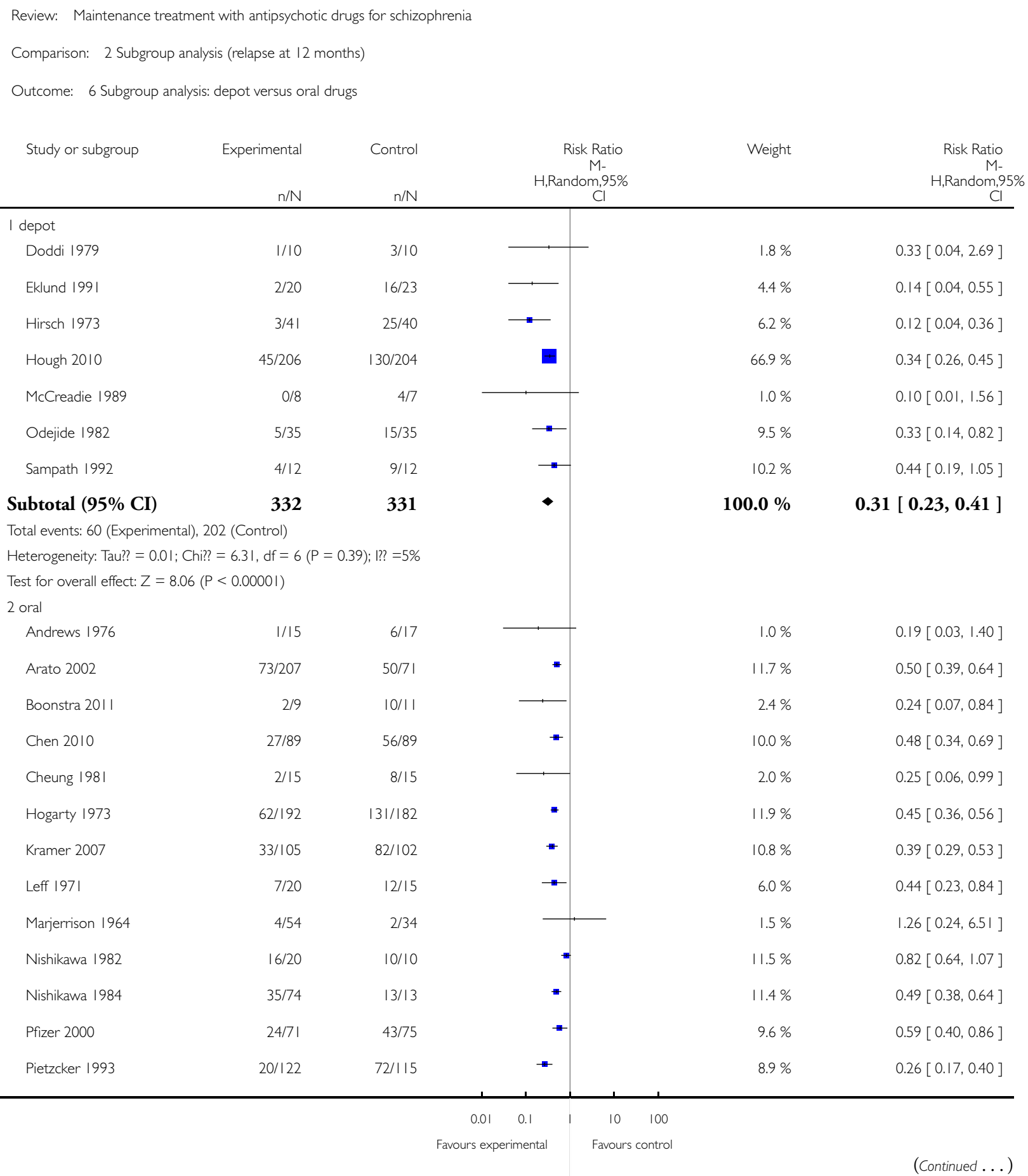




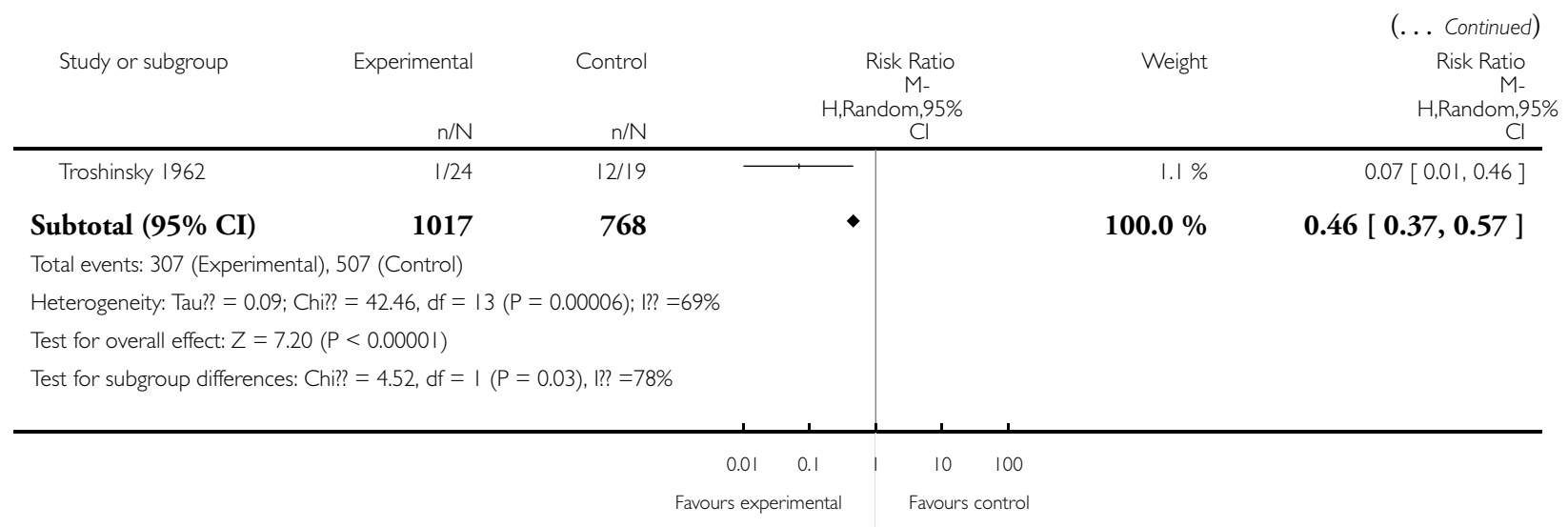

Analysis 2.7. Comparison 2 Subgroup analysis (relapse at 12 months), Outcome 7 Subgroup analysis: firstversus second-generation antipsychotic drugs.

Review: Maintenance treatment with antipsychotic drugs for schizophrenia

Comparison: 2 Subgroup analysis (relapse at 12 months)

Outcome: 7 Subgroup analysis: first- versus second-generation antipsychotic drugs

$\begin{array}{llll}\text { Study or subgroup } & \text { Experimental } & \text { Control } & \text { Risk Ratio }\end{array}$

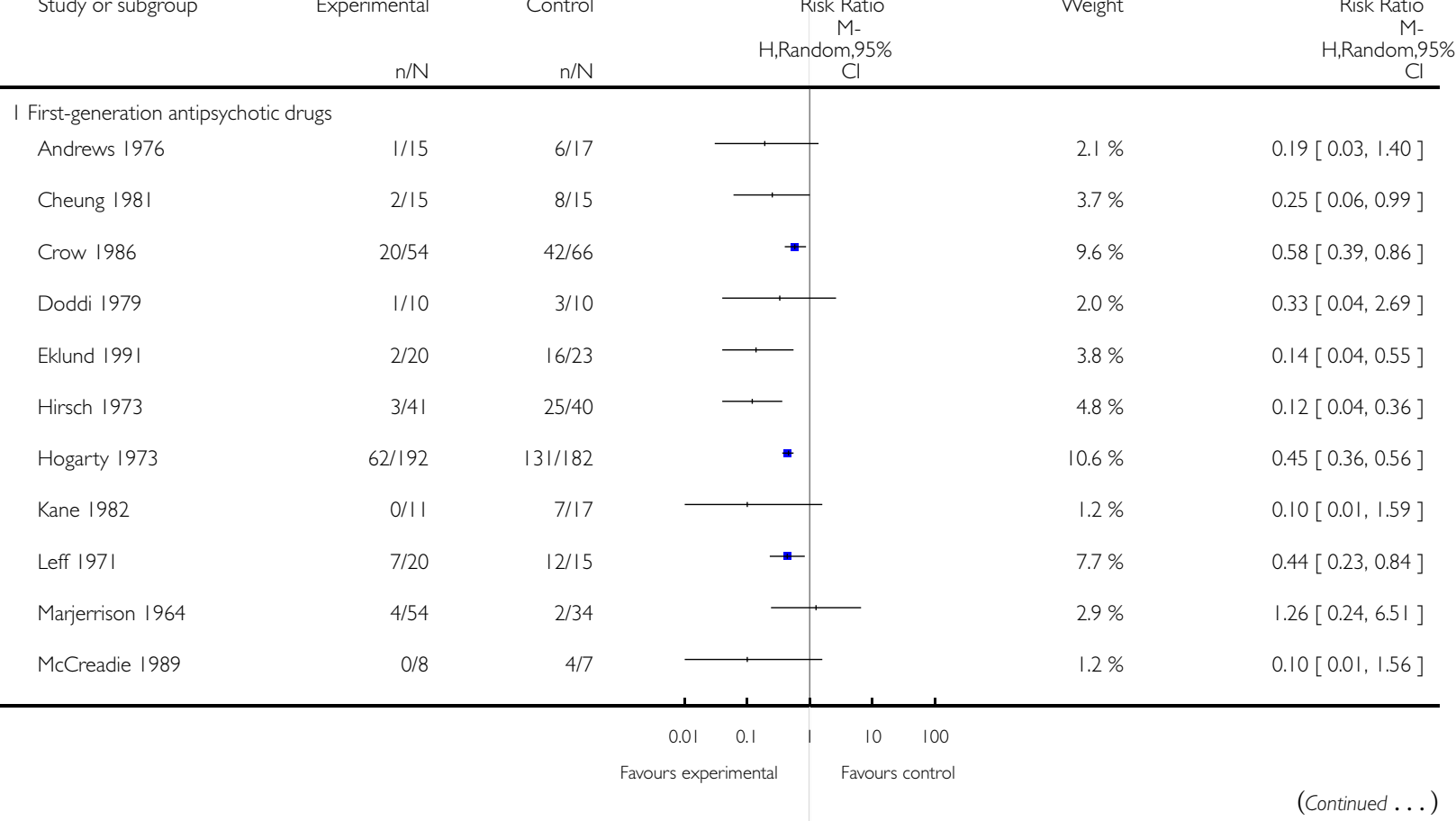




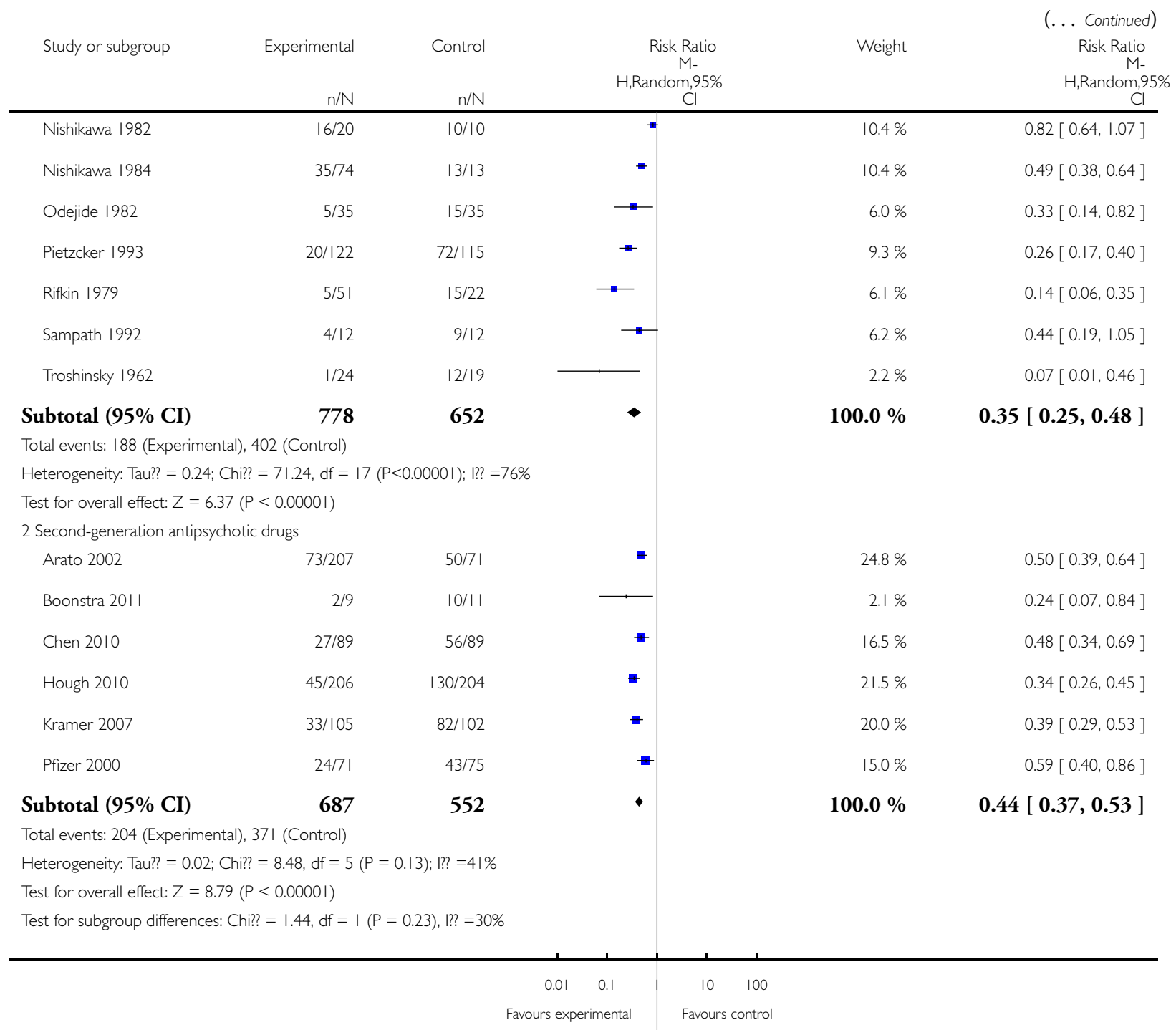


Analysis 2.8. Comparison 2 Subgroup analysis (relapse at 12 months), Outcome 8 Subgroup analysis: appropriate versus unclear allocation concealment.

Review: Maintenance treatment with antipsychotic drugs for schizophrenia

Comparison: 2 Subgroup analysis (relapse at 12 months)

Outcome: 8 Subgroup analysis: appropriate versus unclear allocation concealment

Study or subgroup

Experimental Control

Risk Ratio

M-

Weight

Risk Ratio

H,Random,95\%

$\mathrm{n} / \mathrm{N} \quad \mathrm{n} / \mathrm{N}$

, $95 \%$

I appropriate allocation concealment

Andrews 1976

$1 / 15$

$6 / 17$

Arato 2002

$73 / 207$

$50 / 71$

Chen 2010

$27 / 89$

$56 / 89$

Hirsch 1973

$3 / 41$

$25 / 40$

Hough 2010

$45 / 206$

130/204

Kramer 2007

33/105

$82 / 102$

Leff 197|

$7 / 20$

$12 / 15$

Pfizer 2000

24/7।

$43 / 75$

Troshinsky 1962

I/24

$12 / 19$

Subtotal (95\% CI)

778

632

$+$

Total events: 214 (Experimental), 416 (Control)

Heterogeneity: Tau?? = 0.06; Chi?? = 18.37, $d f=8(P=0.02) ;$ l? $=56 \%$

Test for overall effect: $Z=7.57(P<0.0000 \mathrm{I})$

2 unclear allocation concealment

Boonstra 201 I

$2 / 9$

Cheung 1981

$2 / 15$

Crow 1986

20/54

Doddi 1979

$1 / 10$

Eklund 1991

$2 / 20$

$10 / 11$

$8 / 15$

Hogarty 1973

$62 / 192$

Kane 1982

Marjerrison 1964

McCreadie 1989

0/II

$4 / 54$

0/8

Nishikawa 1982

$16 / 20$

Nishikawa 1984

$35 / 74$

$42 / 66$

$3 / 10$

16/23

$131 / 182$

$7 / 17$

2/34

$4 / 7$

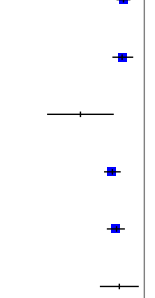

$0.9 \%$

$7.9 \%$

$7.0 \%$

$2.3 \%$

$7.6 \%$

$7.5 \%$

$4.6 \%$

$6.7 \%$

$0.9 \%$

$45.4 \%$

$0.41[0.33,0.52]$

$2.0 \%$

$0.24[0.07,0.84]$

$1.7 \%$

$0.25[0.06,0.99]$

$6.6 \%$

$0.58[0.39,0.86]$

$0.8 \%$

$0.33[0.04,2.69]$

$1.7 \%$

$0.14[0.04,0.55]$

$8.1 \%$

$0.45[0.36,0.56]$

$0.5 \%$

$0.10[0.01,1.59]$

$1.2 \%$

$1.26[0.24,6.51]$

$0.5 \%$

$0.10[0.01,1.56]$

$7.8 \%$

$0.82[0.64,1.07]$

$10 / 10$

$7.8 \%$

$0.49[0.38,0.64]$

$13 / 13$ 


\begin{tabular}{|c|c|c|c|c|c|}
\hline Study or subgroup & Experimental & $\mathrm{n} / \mathrm{N}$ & $\begin{array}{c}\text { Risk Ratio } \\
\text { M- } \\
\text { H,Random,95\% } \\
\text { Cl }\end{array}$ & Weight & $\begin{array}{c}\text { (... Continued) } \\
\text { Risk Ratio } \\
\text { M- } \\
\text { H,Random,95\% } \\
\text { Cl }\end{array}$ \\
\hline Odejide 1982 & $5 / 35$ & $15 / 35$ & $\longrightarrow$ & $3.1 \%$ & $0.33[0.14,0.82]$ \\
\hline Pietzcker 1993 & $20 / 122$ & $72 / 115$ & - & $6.3 \%$ & $0.26[0.17,0.40]$ \\
\hline Rifkin 1979 & $5 / 51$ & $15 / 22$ & 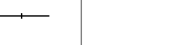 & $3.2 \%$ & $0.14[0.06,0.35]$ \\
\hline Sampath 1992 & $4 / 12$ & $9 / 12$ & $\longrightarrow$ & $3.3 \%$ & $0.44[0.19,1.05]$ \\
\hline Subtotal $(95 \% \mathrm{CI})$ & 687 & 572 & $\bullet$ & $54.6 \%$ & $0.39[0.28,0.53]$ \\
\hline \multicolumn{6}{|c|}{ Total events: 178 (Experimental), 357 (Control) } \\
\hline \multicolumn{6}{|c|}{ Heterogeneity: Tau? $=0.20 ;$ Chi? $?=55.30, d f=14(P<0.00001) ; 1 ? ?=75 \%$} \\
\hline \multicolumn{6}{|c|}{ Test for overall effect: $Z=5.80(P<0.0000 I)$} \\
\hline Total $(95 \% \mathrm{CI})$ & 1465 & 1204 & - & $100.0 \%$ & $0.40[0.33,0.49]$ \\
\hline \multicolumn{6}{|c|}{ Total events: 392 (Experimental), 773 (Control) } \\
\hline \multicolumn{6}{|c|}{ Heterogeneity: Tau? = 0.11; Chi?? = 73.01, df = 23 (P<0.0000 I); 1 ? =68\% } \\
\hline \multicolumn{6}{|c|}{ Test for overall effect: $Z=9.08(P<0.0000 \mathrm{I})$} \\
\hline \multicolumn{6}{|c|}{ Test for subgroup differences: Chi?? $=0.09, \mathrm{df}=\mathrm{I}(\mathrm{P}=0.76), 1 ? ?=0.0 \%$} \\
\hline
\end{tabular}


Analysis 2.9. Comparison 2 Subgroup analysis (relapse at 12 months), Outcome 9 Subgroup analysis: blinded versus open trials.

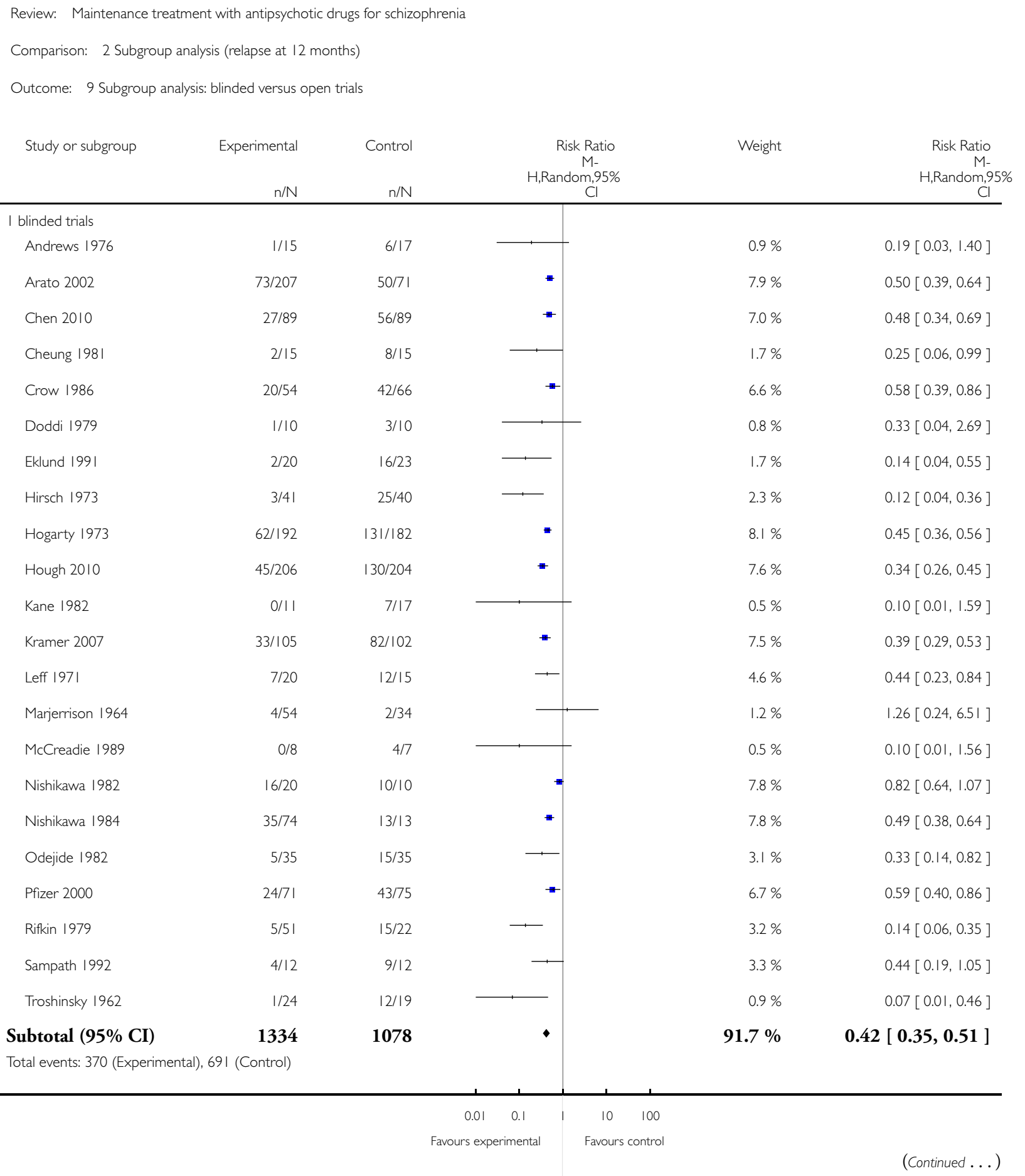




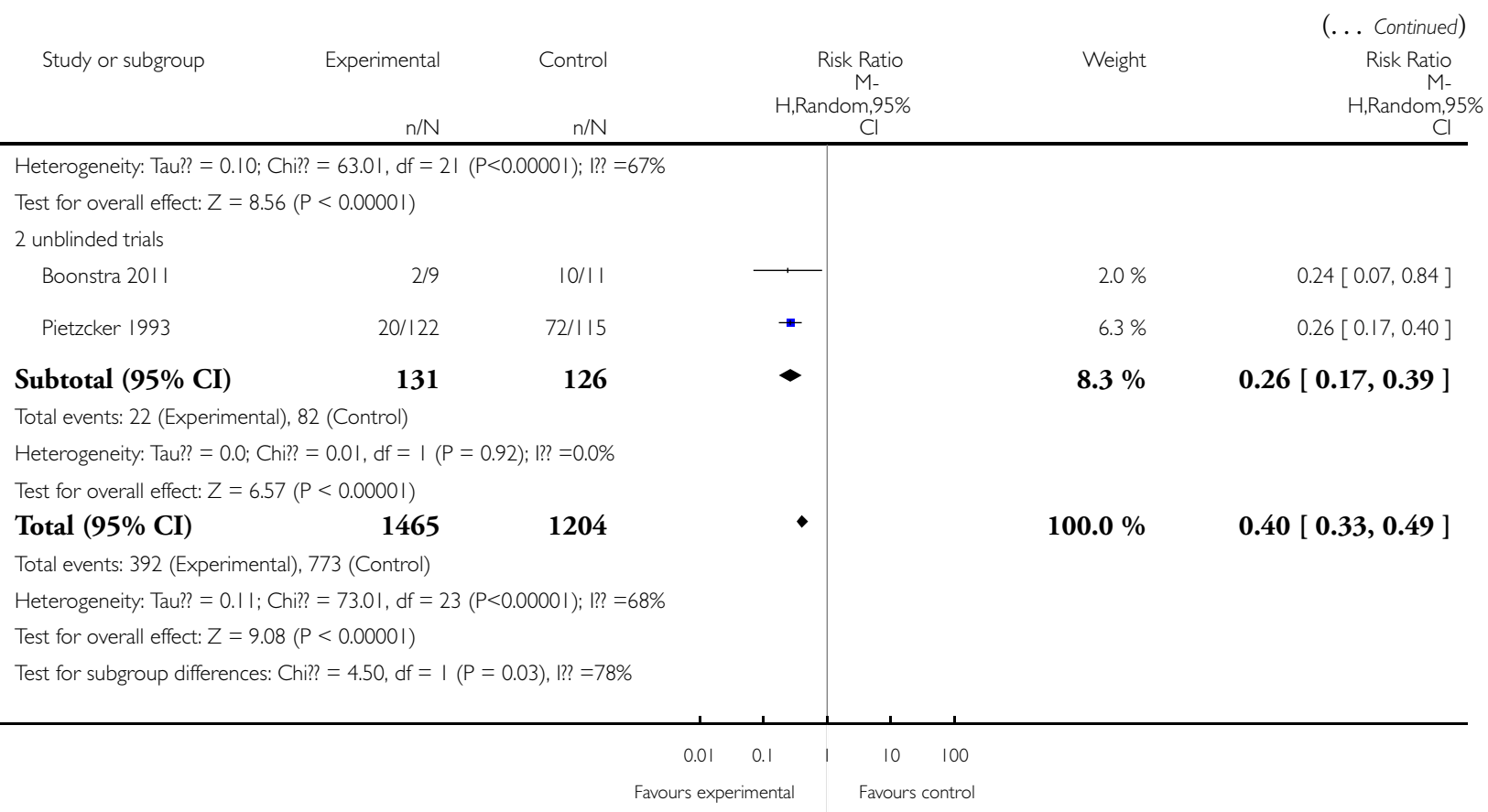


Analysis 3.I. Comparison 3 Sensitivity analysis (relapse at 12 months), Outcome I Exclusion of studies that were not explicitly described as randomised.

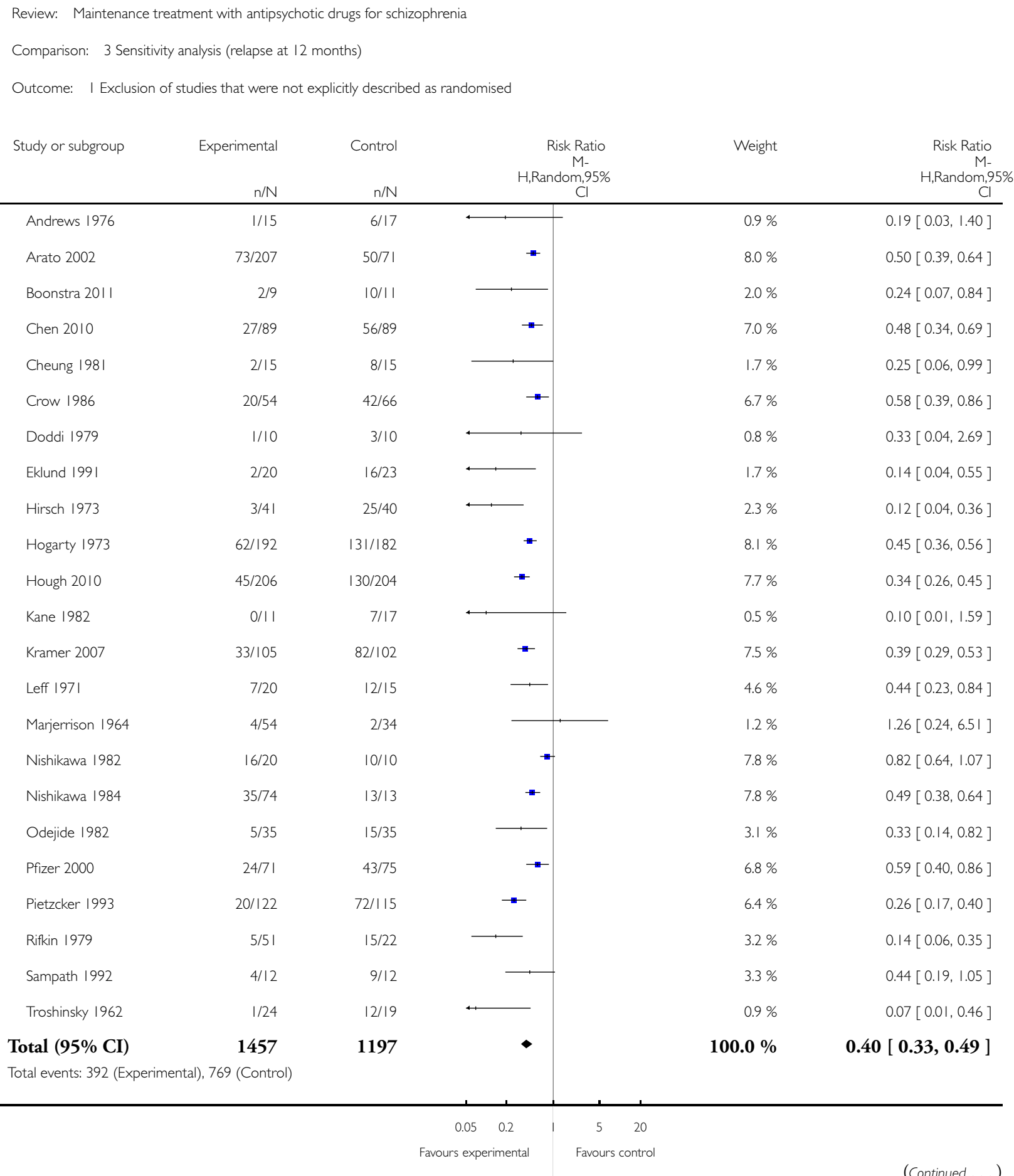

(Continued ...) 


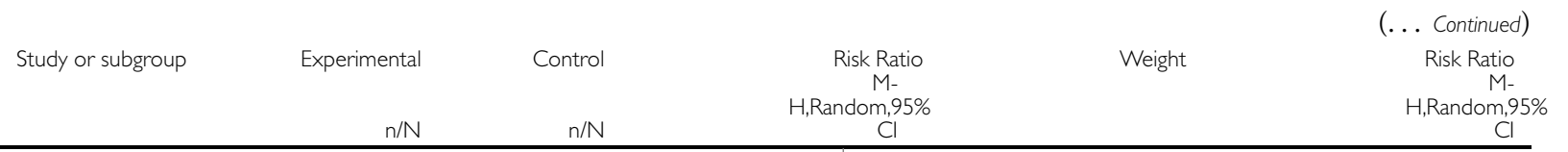

Heterogeneity: Tau?? = 0.1 I; Chi?? = 71.39, $\mathrm{df}=22(\mathrm{P}<0.0000 \mathrm{I}) ; \mathrm{l} ? \mathrm{l}=69 \%$

Test for overall effect: $Z=9.02(P<0.00001)$

Test for subgroup differences: Not applicable

\section{$\begin{array}{lllll}0.05 & 0.2 & 1 & 5 & 20\end{array}$ \\ Favours experimental Favours control}

Analysis 3.2. Comparison 3 Sensitivity analysis (relapse at 12 months), Outcome 2 Exclusion of non-doubleblind studies.

Review: Maintenance treatment with antipsychotic drugs for schizophrenia

Comparison: 3 Sensitivity analysis (relapse at 12 months)

Outcome: 2 Exclusion of non-double-blind studies

Study or subgroup Experimental Control

Experimental Control Risk Ratio

Weight

H,Random, $95 \%$

Risk Ratio

H,Random, $95 \%$

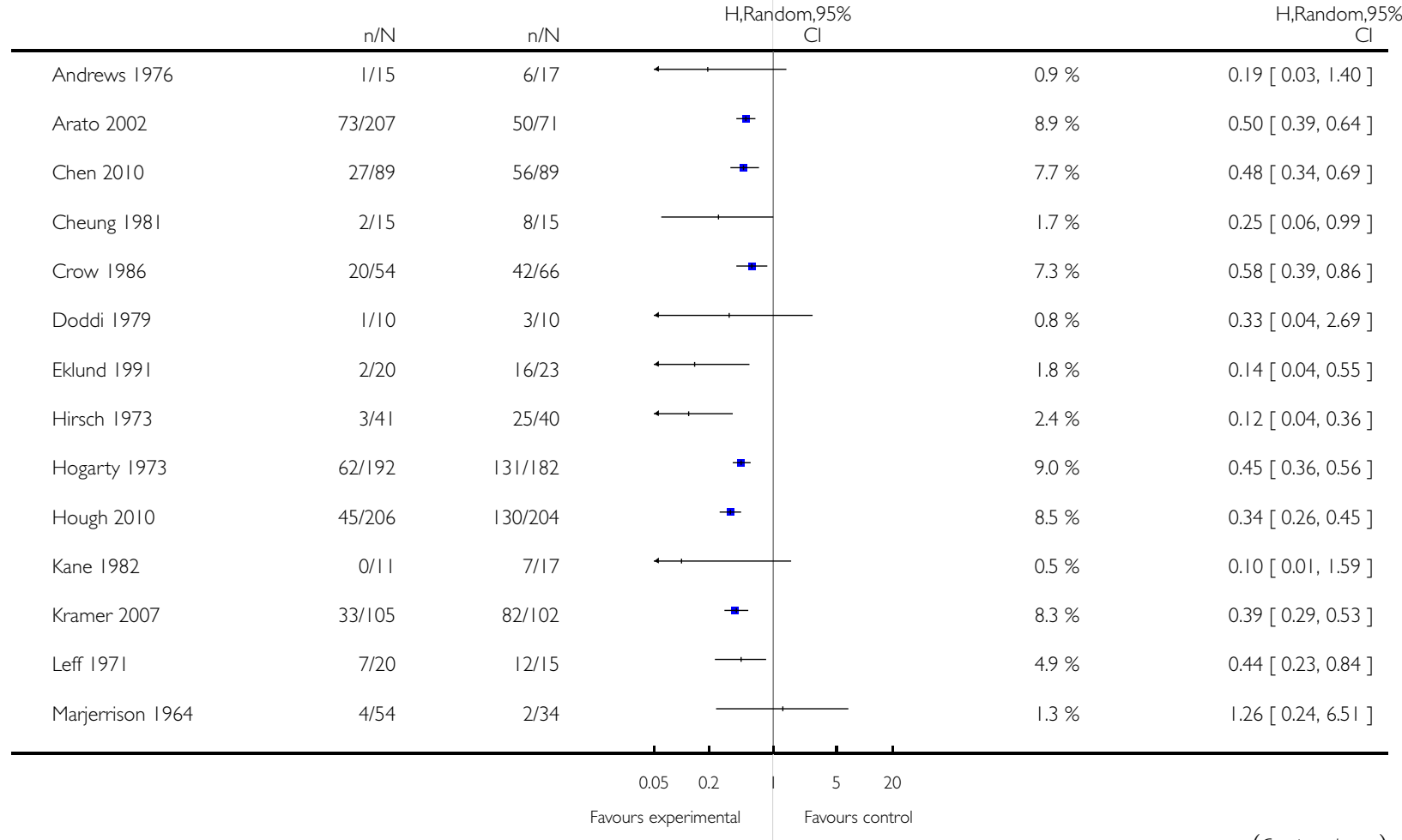

(Continued....) 


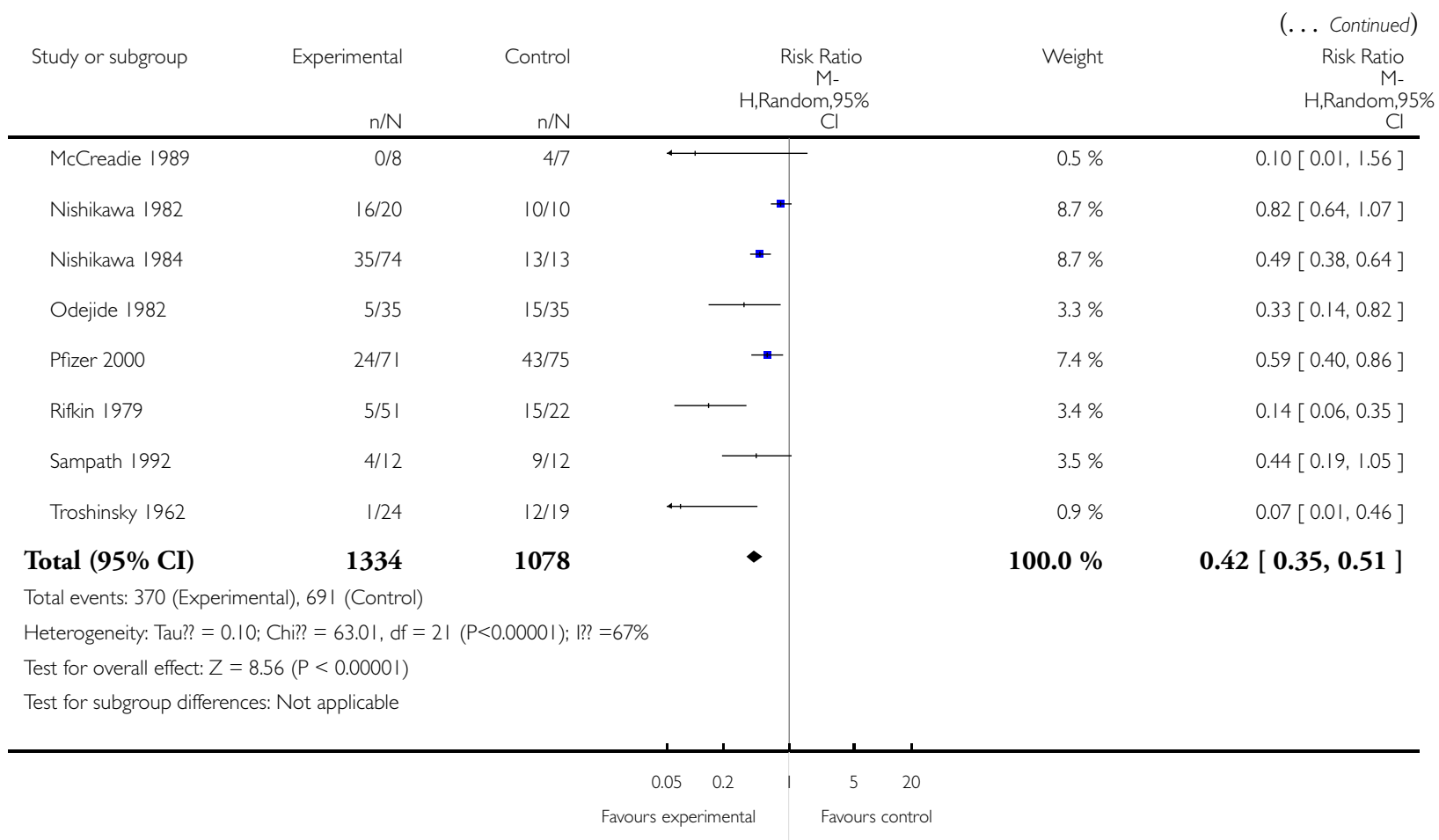




\section{Analysis 3.3. Comparison 3 Sensitivity analysis (relapse at 12 months), Outcome 3 Fixed-effects model.}

Review: Maintenance treatment with antipsychotic drugs for schizophrenia

Comparison: 3 Sensitivity analysis (relapse at 12 months)

Outcome: 3 Fixed-effects model

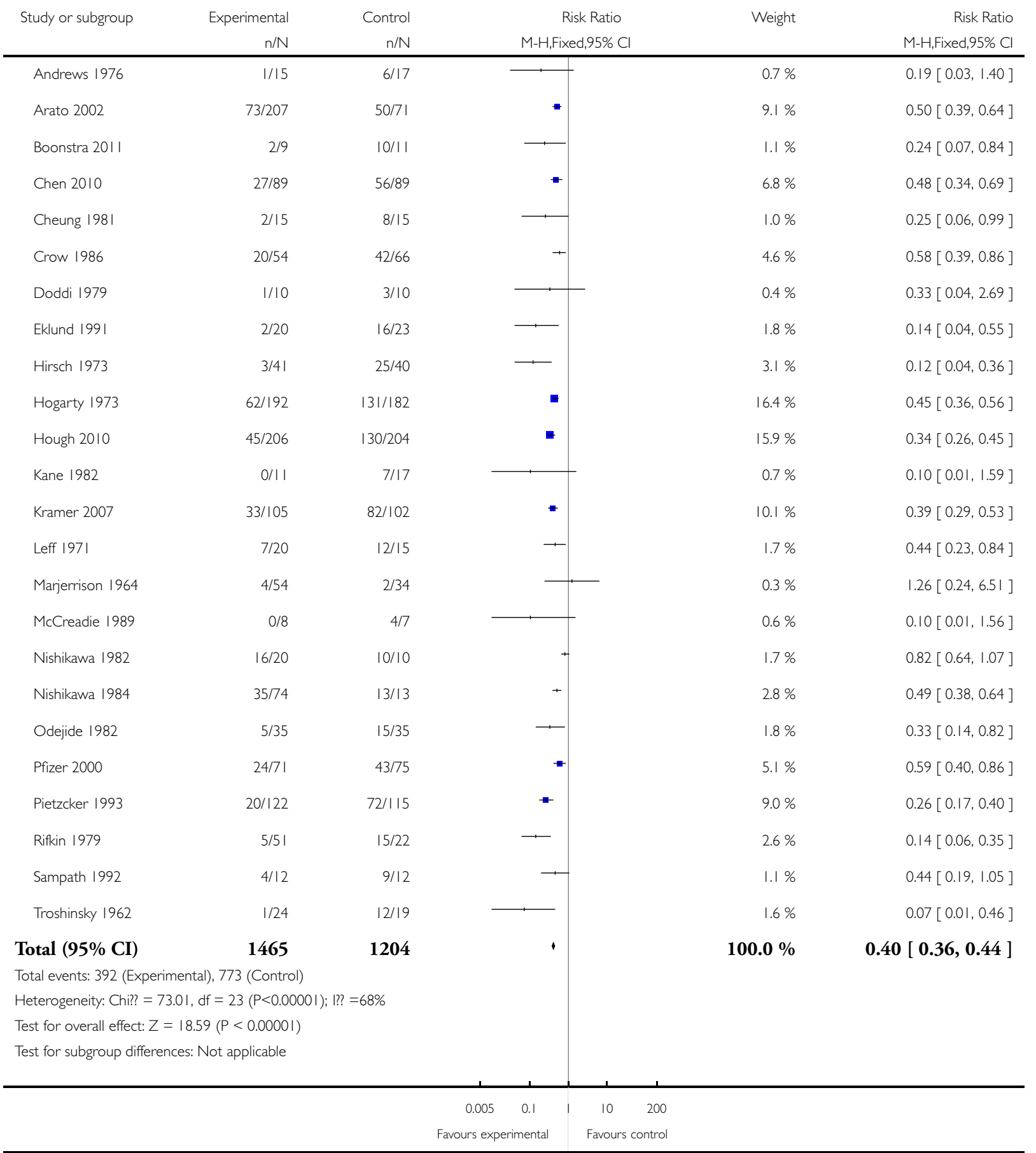

Maintenance treatment with antipsychotic drugs for schizophrenia (Review)

Copyright @ 2012 The Cochrane Collaboration. Published by John Wiley \& Sons, Ltd. 


\section{Analysis 3.4. Comparison 3 Sensitivity analysis (relapse at I 2 months), Outcome 4 Original authors' assumptions on dropouts.}

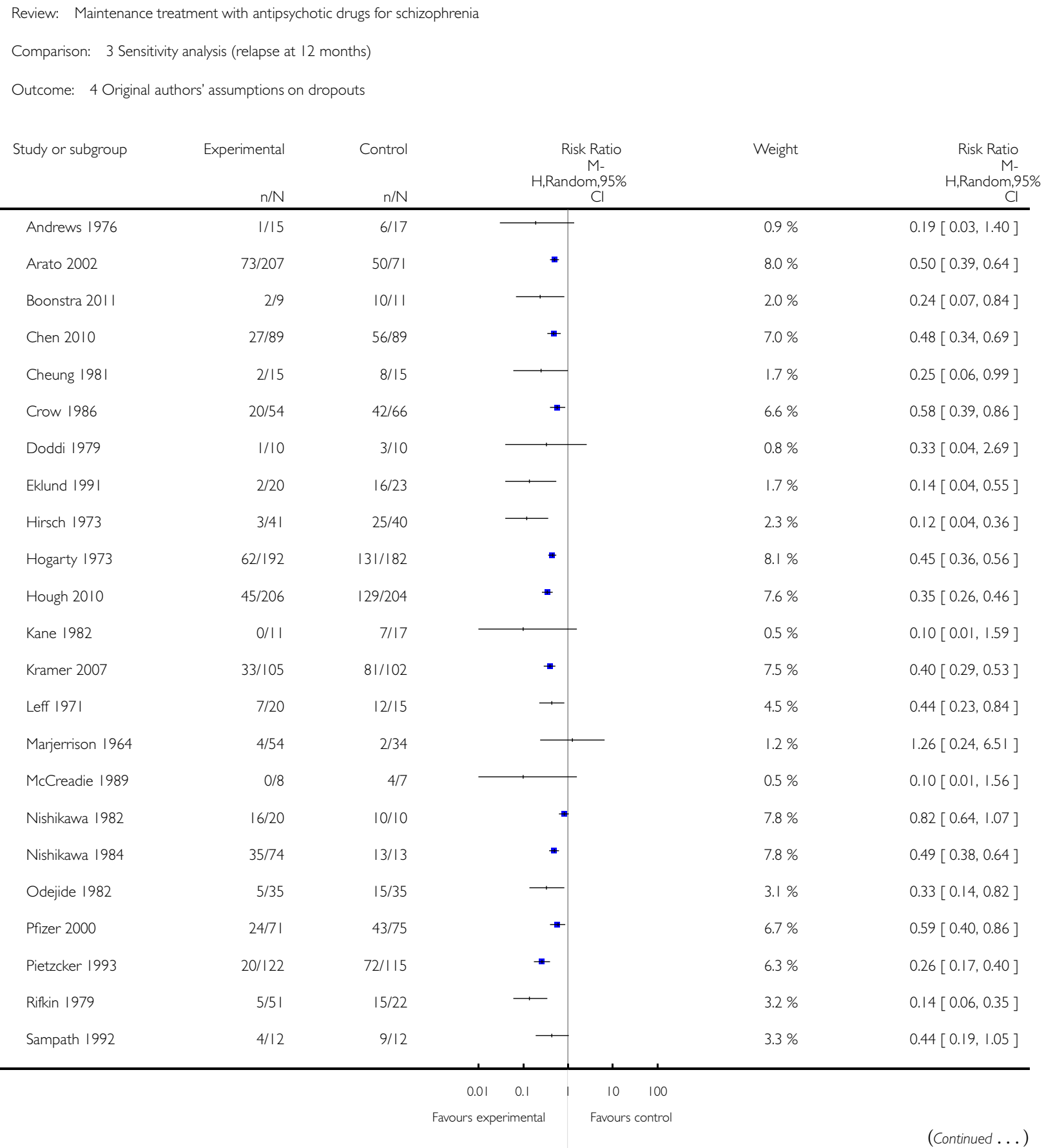




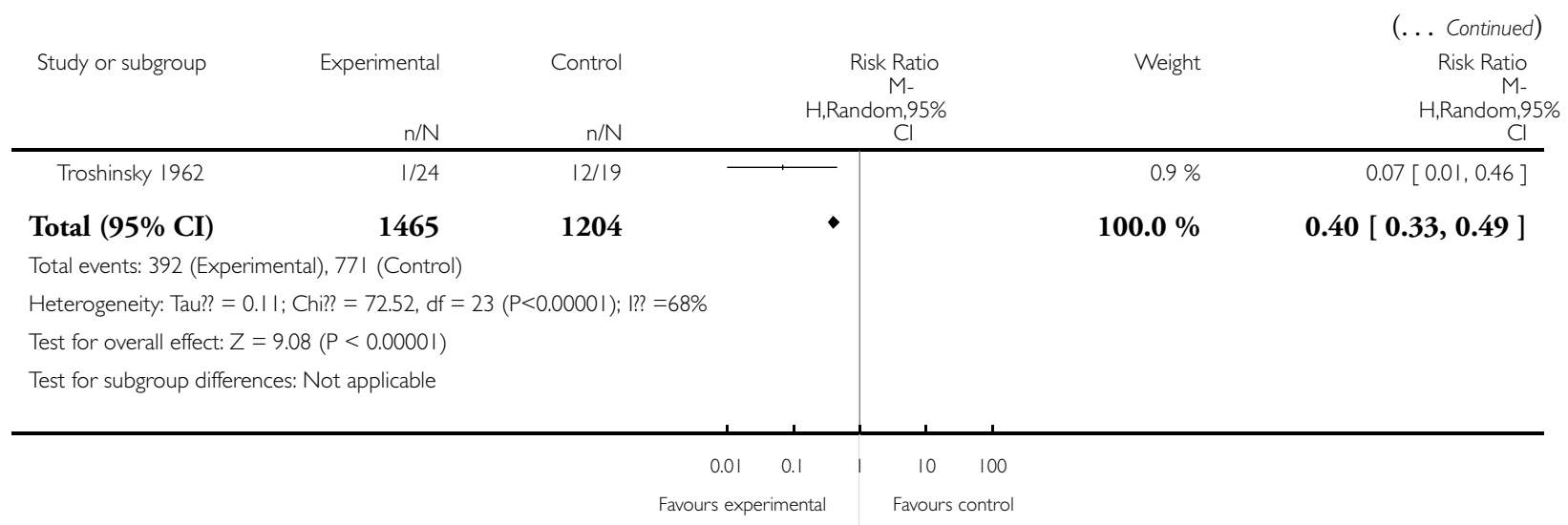

\section{Analysis 3.5. Comparison 3 Sensitivity analysis (relapse at 12 months), Outcome 5 Inclusion of only large} studies (> 200 participants).

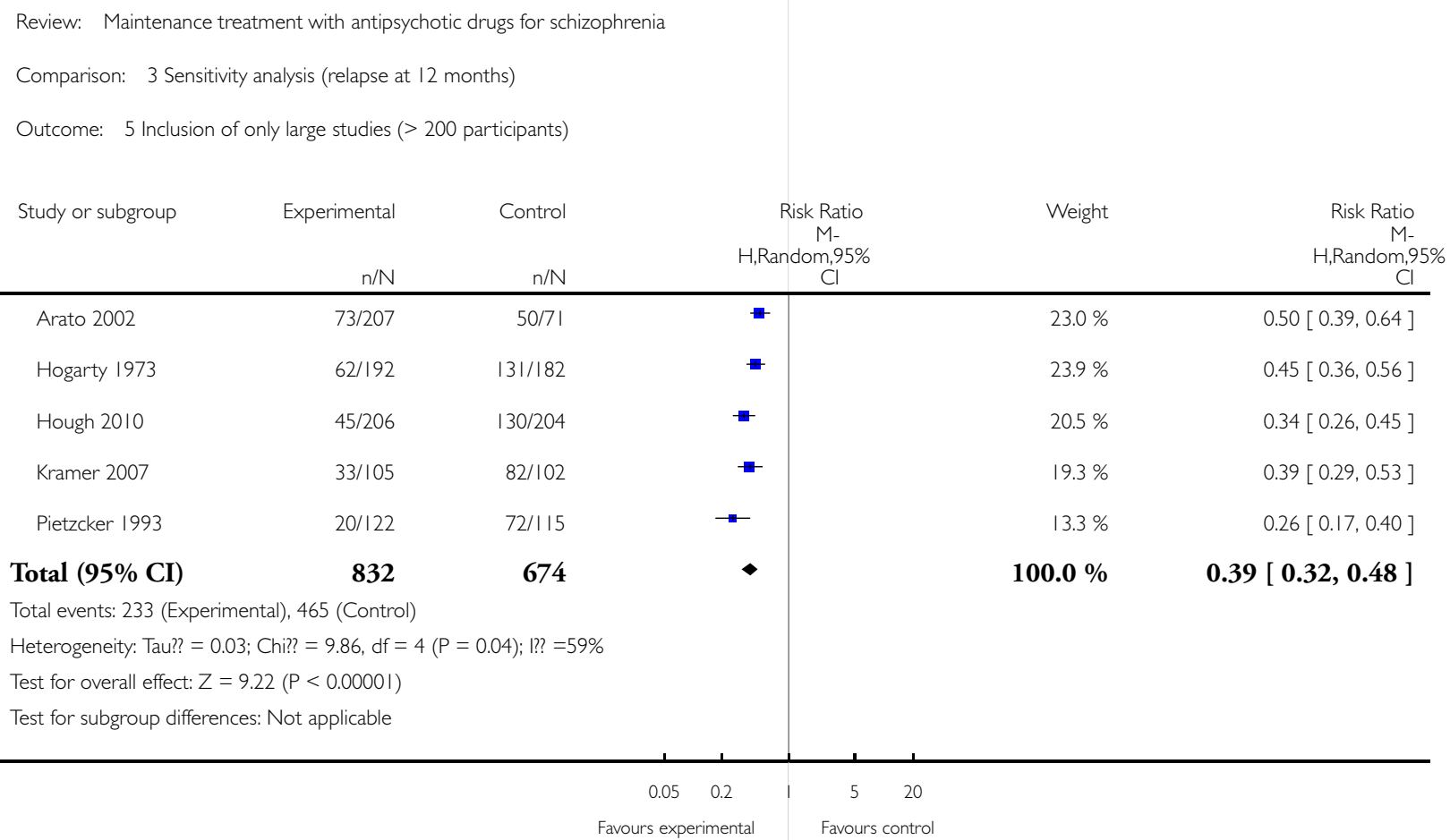


Analysis 3.6. Comparison 3 Sensitivity analysis (relapse at 12 months), Outcome 6 Exclusion of studies with clinical diagnosis.

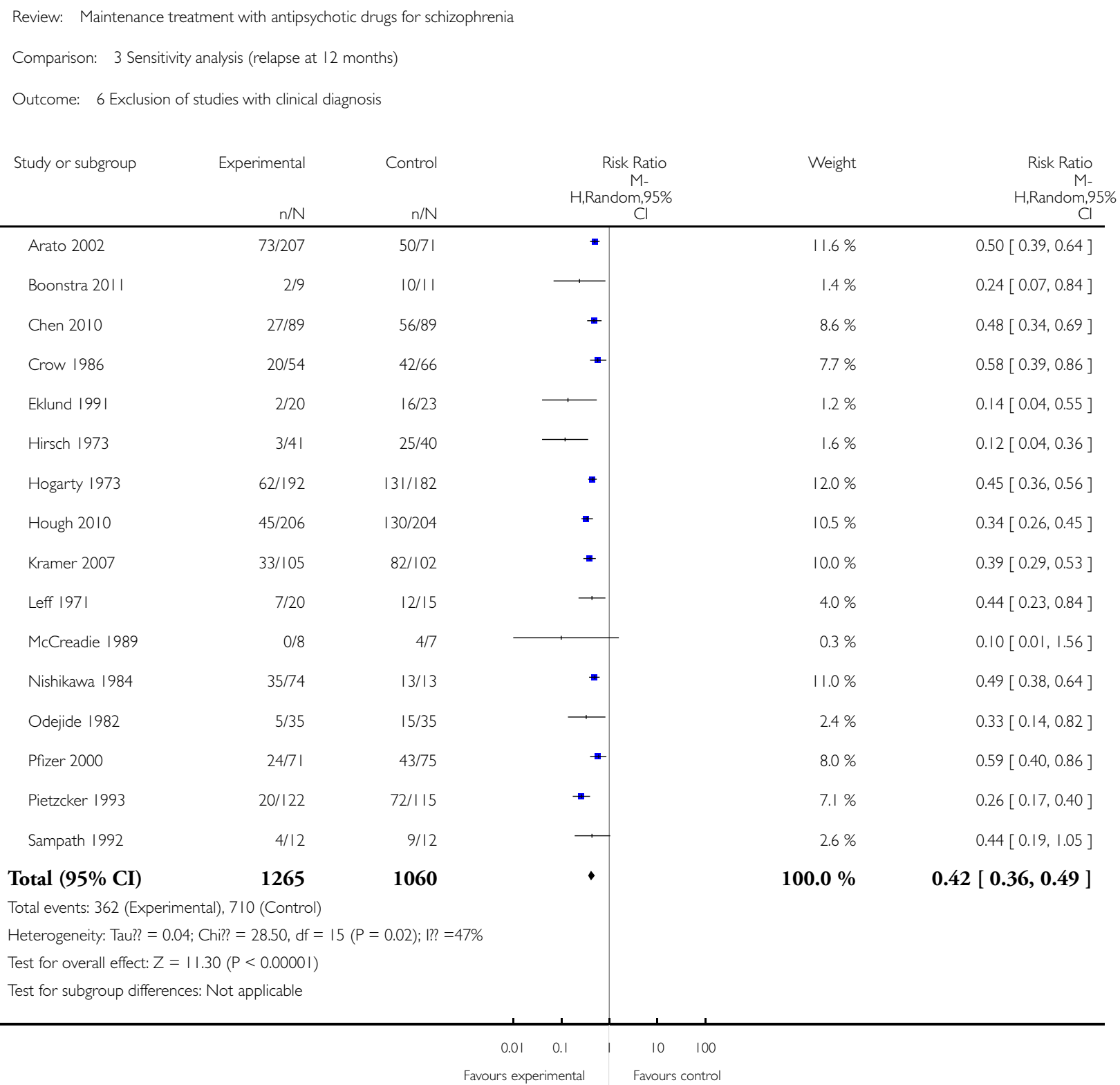




\section{Analysis 3.7. Comparison 3 Sensitivity analysis (relapse at 12 months), Outcome 7 Three months stable.}

Review: Maintenance treatment with antipsychotic drugs for schizophrenia

Comparison: 3 Sensitivity analysis (relapse at 12 months)

Outcome: 7 Three months stable

Study or subgroup

Experimental Control

Risk Ratio

$M$ -

Weight

Risk Ratio

Andrews 1976

$n / N \quad n / N$

Arato 2002

28/179

$5 / 16$

Beasley 2003

$6 / 220$

$22 / 56$

Boonstra 2011

$4 / 9$

19/81

Caffey 1964

$0 / 86$

$7 / 9$

Chen 2010

$17 / 79$

15/136

Cheung 1981

1/15

$31 / 76$

Cooper 2000

$0 / 58$

2/9

Crow 1986

Freeman 1962

$24 / 48$

$6 / 39$

Hogarty 1973

$6 / 48$

$36 / 62$

Hough 2010

$70 / 192$

$7 / 48$

Kramer 2007

$14 / 188$

$83 / 182$

Leff 197|

$3 / 83$

$59 / 157$

Nishikawa 1982

$5 / 18$

$18 / 50$

Peuskens 2007

$7 / 12$

$5 / 8$

Pietzcker 1993

9/92

$2 / 2$

$33 / 120$

$18 / 64$

$80 / 110$

Sampath 1992

Schering Plough 2010

$4 / 12$

Wistedt 1981

$7 / 182$

$4 / 22$

1678

$5 / 10$

$21 / 136$

$4 / 13$

Total (95\% CI)

1264

Total events: 243 (Experimental), 445 (Control)

Heterogeneity: Tau?? = 0.27; Chi?? = 73.60, df = 19 (P<0.0000I); I? =74\%

Test for overall effect: $Z=5.85(P<0.0000$ I $)$

Test for subgroup differences: Not applicable
H,Random, $95 \%$

H,Random $95 \%$

$\mathrm{H}$, Random,95\%
$\mathrm{Cl}$ $\begin{array}{r}\mathrm{H}, \mathrm{Random}, 95 \% \\ \mathrm{Cl}\end{array}$

$1.8 \% \quad 0.21[0.03,1.62]$

$7.3 \% \quad 0.40[0.25,0.64]$

$5.1 \% \quad 0.12[0.05,0.28]$

$5.4 \% \quad 0.57[0.25,1.28]$

$1.0 \% \quad 0.05[0.00,0.84]$

$7.1 \% \quad 0.53[0.32,0.87]$

$1.5 \% \quad 0.30[0.03,2.86]$

$1.0 \% \quad 0.05[0.00,0.90]$

$7.9 \% \quad 0.86[0.60,1.23]$

$4.5 \% \quad 0.86[0.31,2.36]$

$8.3 \% \quad 0.80[0.63,1.02]$

$6.9 \% \quad 0.20[0.12,0.34]$

$3.8 \% \quad 0.10[0.03,0.32]$

$4.9 \% \quad 0.44[0.18,1.11]$

$6.1 \% \quad 0.69[0.35,1.38]$

$5.8 \% \quad 0.35[0.17,0.72]$

$8.1 \% \quad 0.38[0.28,0.52]$

$4.5 \% \quad 0.67[0.24,1.83]$

$5.3 \% \quad 0.25[0.11,0.57]$

$3.7 \% \quad 0.59[0.18,1.97]$

$100.0 \% \quad 0.40[0.30,0.55]$ 


\section{Analysis 3.8. Comparison 3 Sensitivity analysis (relapse at 12 months), Outcome 8 Six months stable.}

Review: Maintenance treatment with antipsychotic drugs for schizophrenia

Comparison: 3 Sensitivity analysis (relapse at 12 months)

Outcome: 8 Six months stable

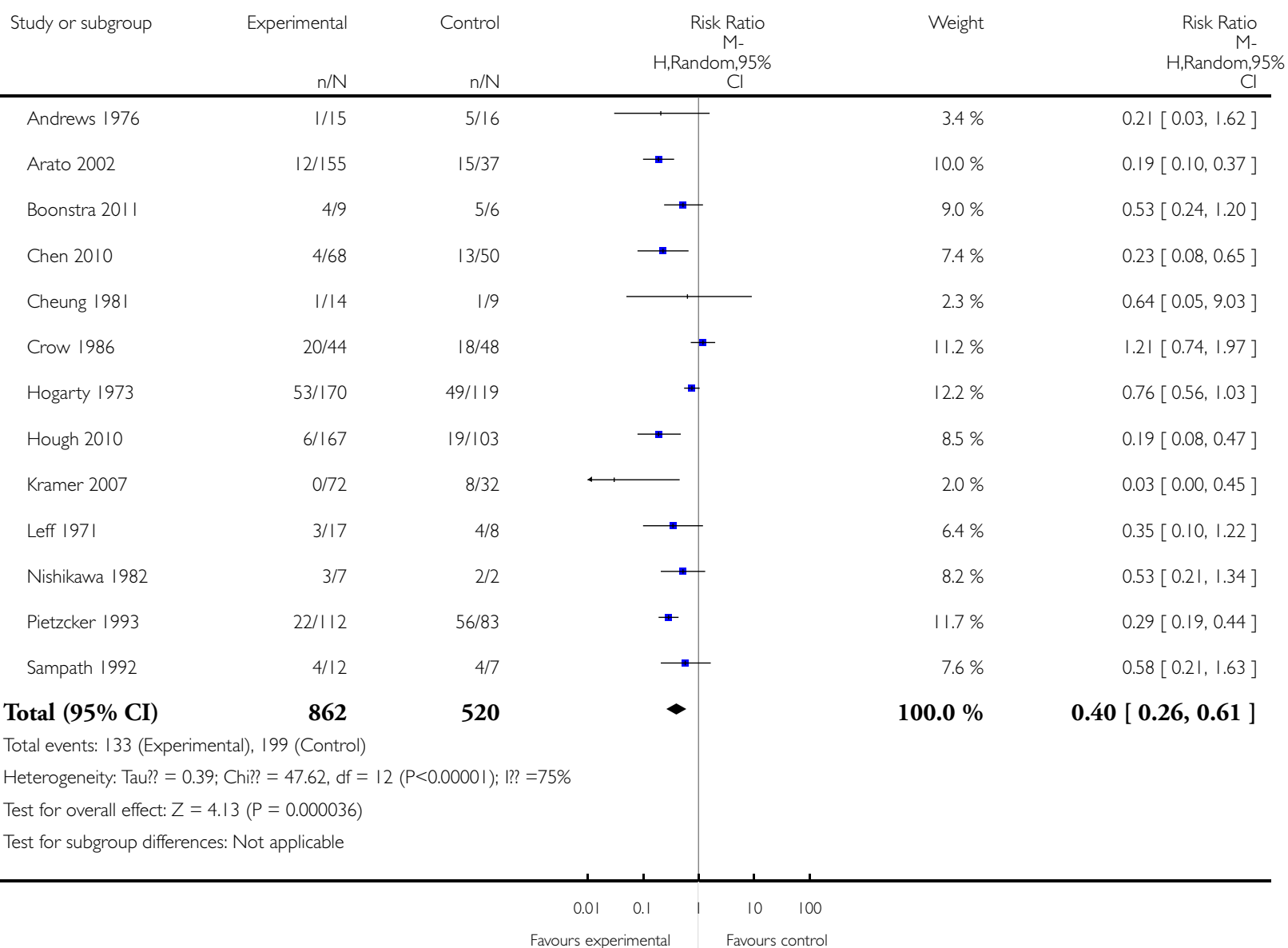




\section{Analysis 3.9. Comparison 3 Sensitivity analysis (relapse at 12 months), Outcome 9 Nine months stable.}

Review: Maintenance treatment with antipsychotic drugs for schizophrenia

Comparison: 3 Sensitivity analysis (relapse at 12 months)

Outcome: 9 Nine months stable

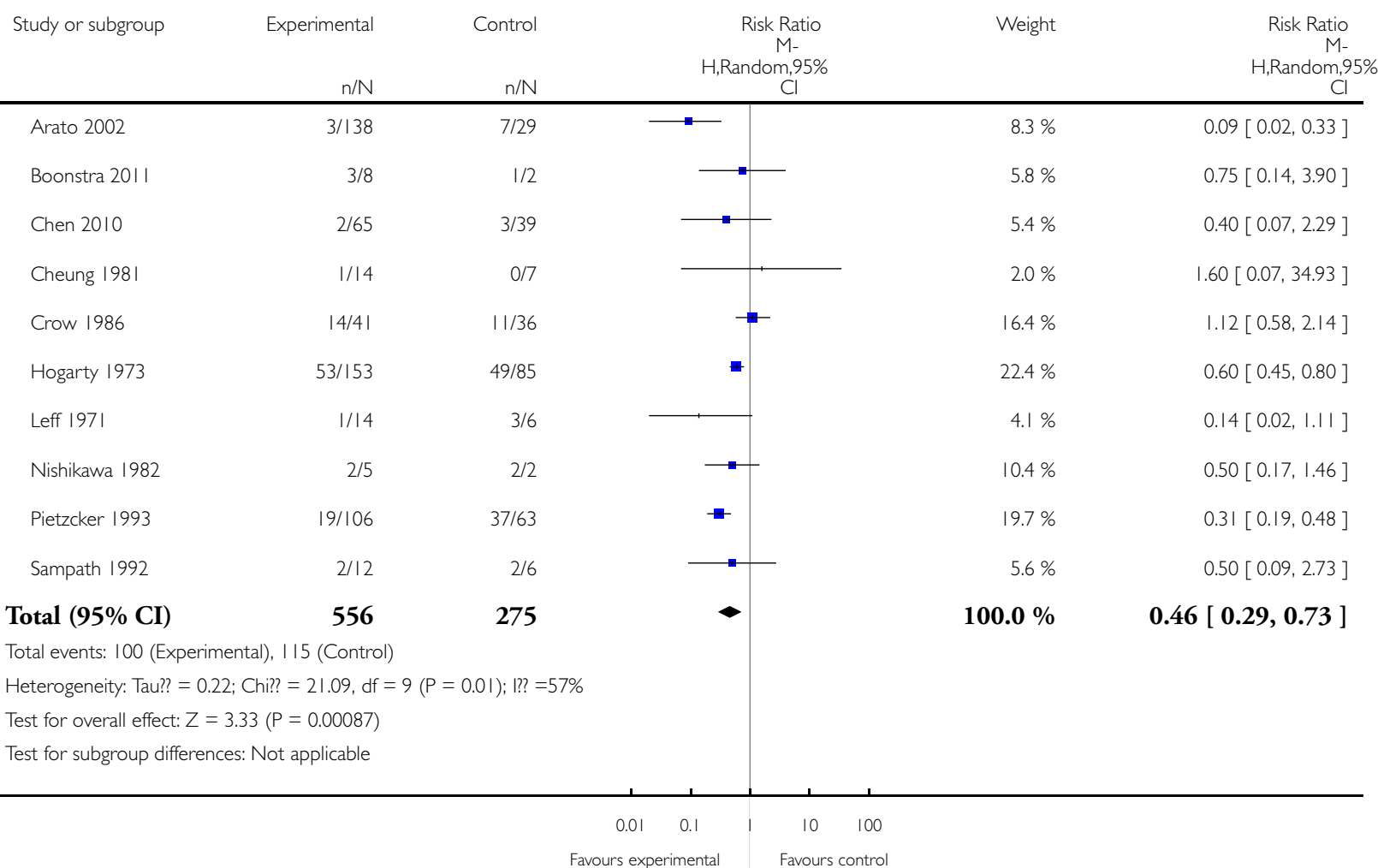


Analysis 3.10. Comparison 3 Sensitivity analysis (relapse at 12 months), Outcome 10 Exclusion of studies with unclear randomisation method.

Review: Maintenance treatment with antipsychotic drugs for schizophrenia

Comparison: 3 Sensitivity analysis (relapse at 12 months)

Outcome: 10 Exclusion of studies with unclear randomisation method

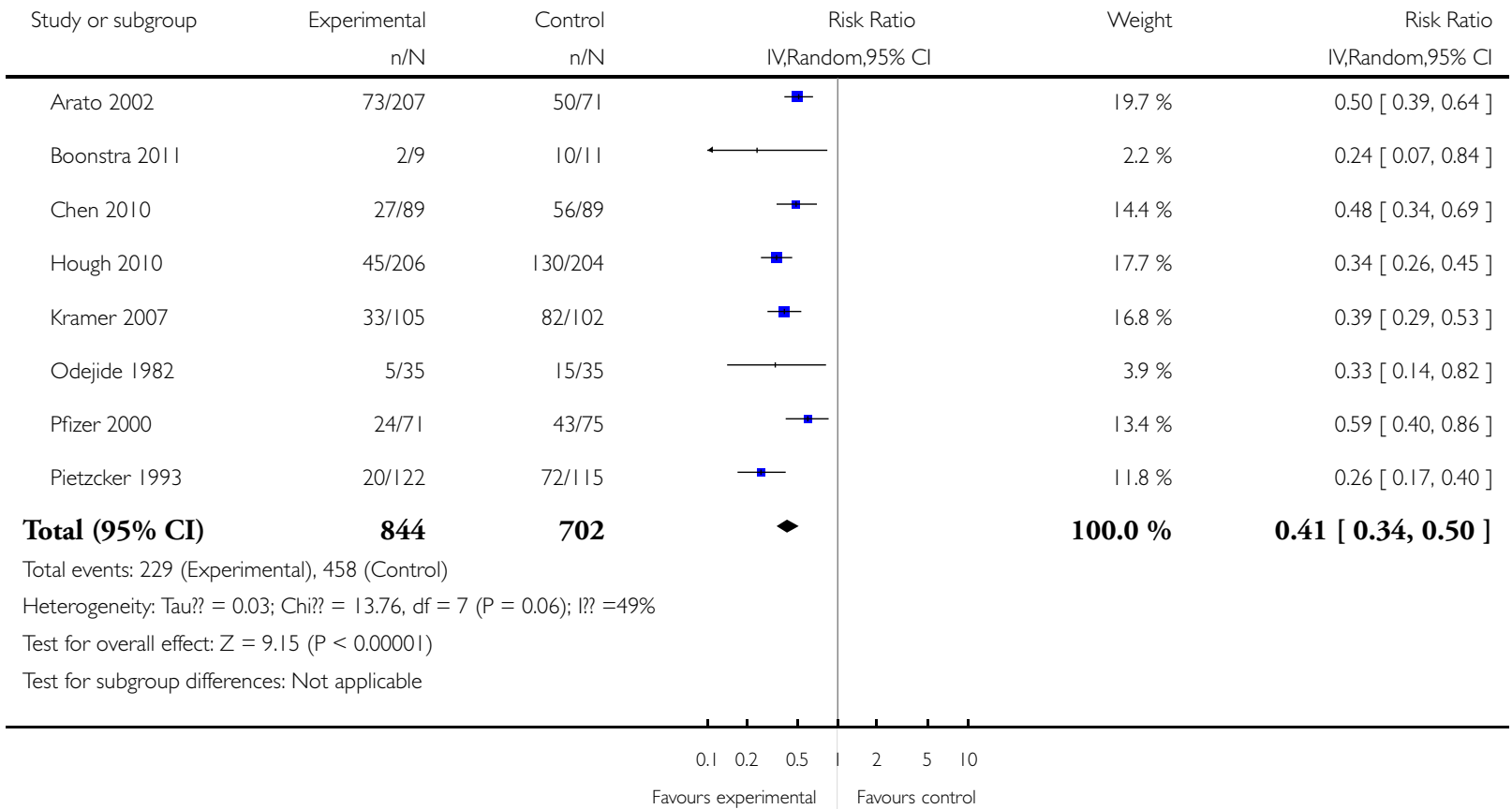


Analysis 3.I I. Comparison 3 Sensitivity analysis (relapse at I 2 months), Outcome I I Exclusion of studies with unclear allocation concealment method.

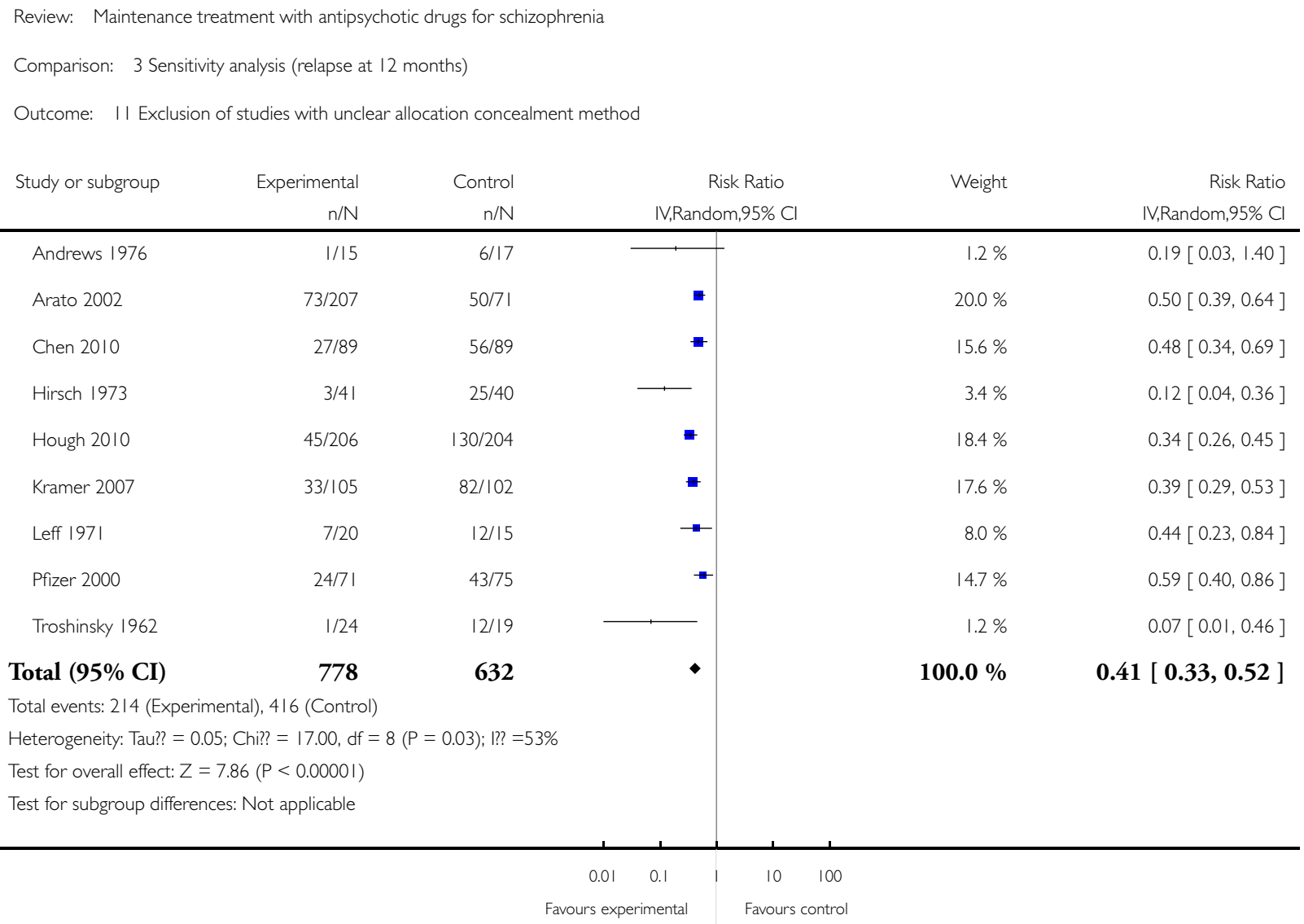

\section{ADDITIONAL TABLES}

Table 1. Design of a future study

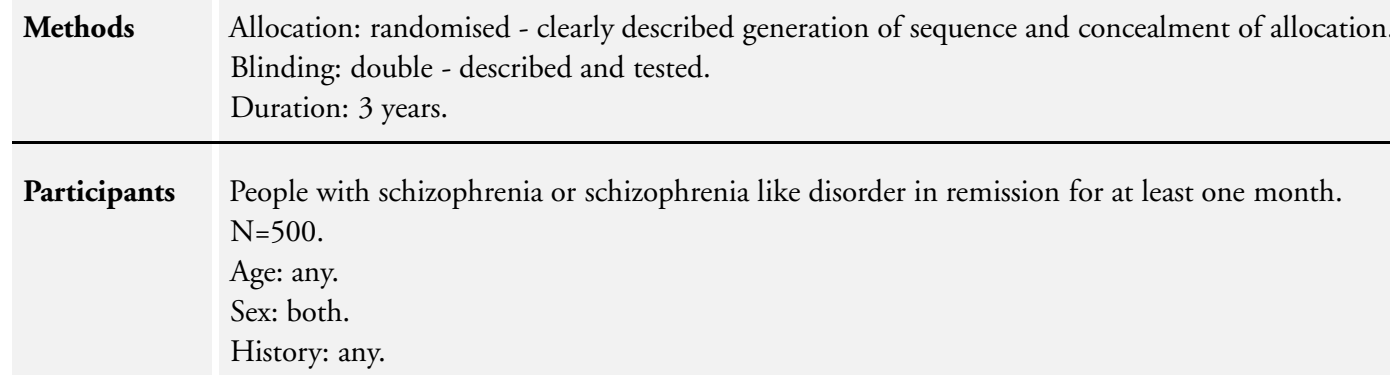

Methods Allocation: randomised - clearly described generation of sequence and concealment of allocation.

Blinding: double - described and tested.

Duration: 3 years.
Participants People with schizophrenia or schizophrenia like disorder in remission for at least one month.
$\mathrm{N}=500$.
Age: any.
Sex: both.
History: any.

Interventions 1. Any antipsychotic drug (flexible dose within appropriate range)

2. Placebo (after gradual withdrawal of the previous antipsychotic drug) 
Table 1. Design of a future study (Continued)

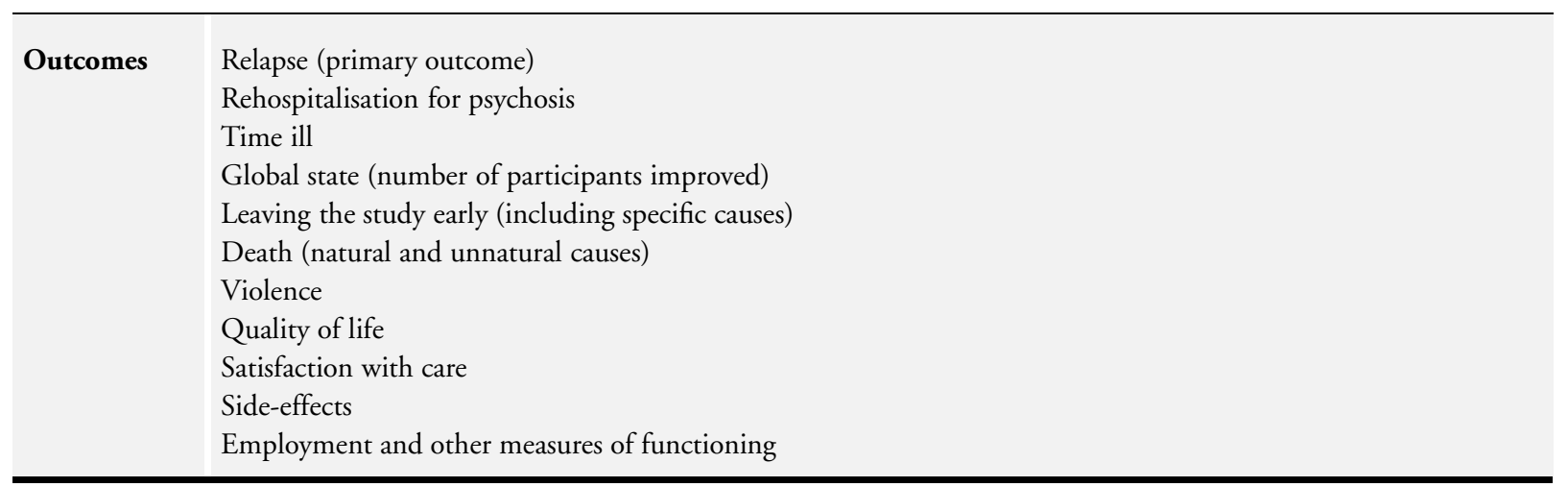

\section{AP PENDICES}

\section{Appendix I. MEDLINE search}

MEDLINE 6 June 2011

(((cessation* or withdraw* or discontinu* or halt* or stop* or drop-out* or dropout* or drop out or rehospitalis* ${ }^{*}$ or relaps* ${ }^{*}$ or maintain* $^{*}$ or maintenance* or recur*) and schizophr*) or schizoaff*).mp. [mp=title, abstract, subject headings, heading word, drug trade name, original title, device manufacturer, drug manufacturer, device trade name, keyword]

\section{Appendix 2. EMBASE search}

EMBASE 06-06-2011

("search”[All Fields] AND Term[All Fields]) AND ((cessation[All Fields] OR cessation/avoidance[All Fields] OR cessation/depletion[All Fields] OR cessation/hypercholesterolemia[All Fields] OR cessation/legislation[All Fields] OR cessation/lifestyle[All Fields] OR cessation/prevention[All Fields] OR cessation/prohibition[All Fields] OR cessation/reduction[All Fields] OR cessation/relapse[All Fields] OR cessation/reperfusion[All Fields] OR cessation/retardation[All Fields] OR cessation/smoking[All Fields] OR cessation/stabilization[All Fields] OR cessation/to[All Fields] OR cessation'[All Fields] OR cessation's[All Fields] OR cessationof[All Fields] OR cessations[All Fields] OR cessations'[All Fields] OR cessationsof[All Fields]) OR (withdraw[All Fields] OR withdraw/limit[All Fields] OR withdraw/pause/advance[All Fields] OR withdraw/retire[All Fields] OR withdraw/withhold[All Fields] OR withdraw'[All Fields] OR withdrawal[All Fields] OR withdrawal/abstinence[All Fields] OR withdrawal/ach[All Fields] OR withdrawal/adaptation[All Fields] OR withdrawal/addition[All Fields] OR withdrawal/advancement[All Fields] OR withdrawal/anhedonia[All Fields] OR withdrawal/ anxiety[All Fields] OR withdrawal/apathy/lack[All Fields] OR withdrawal/asocial[All Fields] OR withdrawal/avoidance[All Fields] OR withdrawal/bacteraemia[All Fields] OR withdrawal/challenge[All Fields] OR withdrawal/chronic[All Fields] OR withdrawal/continuation[All Fields] OR withdrawal/conversion[All Fields] OR withdrawal/craving[All Fields] OR withdrawal/decondensation[All Fields] OR withdrawal/delayed[All Fields] OR withdrawal/dependence[All Fields] OR withdrawal/depression[All Fields] OR withdrawal/discontinuation[All Fields] OR withdrawal/disinterest[All Fields] OR withdrawal/dropouts[All Fields] OR withdrawal/failure[All Fields] OR withdrawal/fear[All Fields] OR withdrawal/high[All Fields] OR withdrawal/hospitalisation[All Fields] OR withdrawal/infusion[All Fields] OR withdrawal/inhibition[All Fields] OR withdrawal/intoxication[All Fields] OR withdrawal/isolation[All Fields] OR withdrawal/lethargy[All Fields] OR withdrawal/limitation[All Fields] OR withdrawal/losses[All Fields] OR withdrawal/ masking[All Fields] OR withdrawal/minimization[All Fields] OR withdrawal/minipump[All Fields] OR withdrawal/motor[All Fields] OR withdrawal/negative[All Fields] OR withdrawal/no[All Fields] OR withdrawal/numbing[All Fields] OR withdrawal/overcompensation[All Fields] OR withdrawal/periodic[All Fields] OR withdrawal/placebo[All Fields] OR withdrawal/protection[All Fields] OR

Maintenance treatment with antipsychotic drugs for schizophrenia (Review)

Copyright $\odot 2012$ The Cochrane Collaboration. Published by John Wiley \& Sons, Ltd. 
withdrawal/rebound[All Fields] OR withdrawal/recovery[All Fields] OR withdrawal/refusal[All Fields] OR withdrawal/regulation[All Fields] OR withdrawal/reinfusion[All Fields] OR withdrawal/reinsertion[All Fields] OR withdrawal/reintroduction[All Fields] OR withdrawal/removal[All Fields] OR withdrawal/reperfusion[All Fields] OR withdrawal/replacement[All Fields] OR withdrawal/resistance[All Fields] OR withdrawal/responsiveness[All Fields] OR withdrawal/retardation[All Fields] OR withdrawal/reversal[All Fields] OR withdrawal/rhythm[All Fields] OR withdrawal/ri[All Fields] OR withdrawal/screaming[All Fields] OR withdrawal/social[All Fields] OR withdrawal/stereotypy[All Fields] OR withdrawal/stimulation[All Fields] OR withdrawal/study[All Fields] OR withdrawal/tolerance[All Fields] OR withdrawal/toxic[All Fields] OR withdrawal/transfusion[All Fields] OR withdrawal/uremia[All Fields] OR withdrawal/warnings[All Fields] OR withdrawal/withholding[All Fields] OR withdrawal'[All Fields] OR withdrawal's[All Fields] OR withdrawall[All Fields] OR withdrawallike[All Fields] OR withdrawally[All Fields] OR withdrawalpolicy[All Fields] OR withdrawalpolicyv[All Fields] OR withdrawals[All Fields] OR withdrawals/dropouts[All Fields] OR withdrawan[All Fields] OR withdrawas[All Fields] OR withdrawed[All Fields] OR withdrawel[All Fields] OR withdrawen[All Fields] OR withdrawer[All Fields] OR withdrawers[All Fields] OR withdrawers'[All Fields] OR withdrawial[All Fields] OR withdrawing[All Fields] OR withdrawing/accepting[All Fields] OR withdrawing/donating[All Fields] OR withdrawing/electron[All Fields] OR withdrawing/withholding[All Fields] OR withdrawing'[All Fields] OR withdrawings[All Fields] OR withdrawl[All Fields] OR withdrawls[All Fields] OR withdrawn[All Fields] OR withdrawn/ acceptor[All Fields] OR withdrawn/anxious[All Fields] OR withdrawn/black[All Fields] OR withdrawn/depressed[All Fields] OR withdrawn/depression[All Fields] OR withdrawn/depressive[All Fields] OR withdrawn/dysphoric[All Fields] OR withdrawn/inhibited[All Fields] OR withdrawn/ltfu[All Fields] OR withdrawn/not[All Fields] OR withdrawn/psychotic[All Fields] OR withdrawn/timid[All Fields] OR withdrawn/uncommunicative[All Fields] OR withdrawn/uncooperative[All Fields] OR withdrawn/withheld[All Fields] OR withdrawn'[All Fields] OR withdrawness[All Fields] OR withdrawning[All Fields] OR withdrawnn[All Fields] OR withdrawnness[All Fields] OR withdrawol[All Fields] OR withdraws[All Fields]) OR (discontinu[All Fields] OR discontinua[All Fields] OR discontinuacion[All Fields] OR discontinual[All Fields] OR discontinualis[All Fields] OR discontinually[All Fields] OR discontinuance[All Fields] OR discontinuances[All Fields] OR discontinuante[All Fields] OR discontinuanti[All Fields] OR discontinuate[All Fields] OR discontinuated[All Fields] OR discontinuating[All Fields] OR discontinuation[All Fields] OR discontinuation/change[All Fields] OR discontinuation/completion[All Fields] OR discontinuation/continuation[All Fields] OR discontinuation/delay[All Fields] OR discontinuation/dose[All Fields] OR discontinuation/interruption[All Fields] OR discontinuation/interruption/reduction[All Fields] OR discontinuation/reduction[All Fields] OR discontinuation/reintroduction[All Fields] OR discontinuation/retreatment[All Fields] OR discontinuation/safety[All Fields] OR discontinuation/substitution[All Fields] OR discontinuation/switch[All Fields] OR discontinuation/switching[All Fields] OR discontinuation/tapering[All Fields] OR discontinuation/unevaluable[All Fields] OR discontinuation/ withdrawal[All Fields] OR discontinuation'[All Fields] OR discontinuations[All Fields] OR discontinuations/bortezomib[All Fields] OR discontinuations/dose[All Fields] OR discontinuations/first[All Fields] OR discontinue[All Fields] OR discontinue/change[All Fields] OR discontinue/reduce[All Fields] OR discontinue/renewal[All Fields] OR discontinue/switch[All Fields] OR discontinued[All Fields] OR discontinued/avoided[All Fields] OR discontinued/switched[All Fields] OR discontinued'[All Fields] OR discontinuence[All Fields] OR discontinueous[All Fields] OR discontinuer[All Fields] OR discontinuer/augmenter/maintainer[All Fields] OR discontinuerlig[All Fields] OR discontinuerlige[All Fields] OR discontinuers[All Fields] OR discontinuers/maintainers/augmenters[All Fields] OR discontinuers'[All Fields] OR discontinues[All Fields] OR discontinuidades[All Fields] OR discontinuing[All Fields] OR discontinuining[All Fields] OR discontinuist[All Fields] OR discontinuist'[All Fields] OR discontinuita[All Fields] OR discontinuite[All Fields] OR discontinuiteit[All Fields] OR discontinuites[All Fields] OR discontinuities[All Fields] OR discontinuities/edges[All Fields] OR discontinuities/line[All Fields] OR discontinuities/splits[All Fields] OR discontinuities'[All Fields] OR discontinuiting[All Fields] OR discontinuity[All Fields] OR discontinuity/fatigue[All Fields] OR discontinuity/occlusion[All Fields] OR discontinuity/ otosclerosis[All Fields] OR discontinuity'[All Fields] OR discontinuo[All Fields] OR discontinuos[All Fields] OR discontinuosly[All Fields] OR discontinuosus[All Fields] OR discontinuous[All Fields] OR discontinuous/absent[All Fields] OR discontinuous/conformational[All Fields] OR discontinuous/continuous[All Fields] OR discontinuous/insular[All Fields] OR discontinuous/jumping[All Fields] OR discontinuous/satellite[All Fields] OR discontinuous/sequencing[All Fields] OR discontinuous'[All Fields] OR discontinuously[All Fields] OR discontinuousness[All Fields] OR discontinus[All Fields] OR discontinutation[All Fields] OR discontinute[All Fields] OR discontinuties[All Fields] OR discontinution[All Fields] OR discontinuty[All Fields] OR discontinuum[All Fields]) OR (halt[All Fields] OR halt/moderate[All Fields] OR halt/regress[All Fields] OR halt/reverse[All Fields] OR halt/slow[All Fields] OR halt/standstill[All Fields] OR halt'[All Fields] OR halt's[All Fields] OR halt1[All Fields] OR halt2[All Fields] OR halt3[All Fields] OR halta[All Fields] OR haltafall[All Fields] OR haltagning[All Fields] OR haltai[All Fields] OR haltalin[All Fields] OR haltam[All Fields] OR haltamshire[All Fields] OR haltan[All Fields] OR haltande[All Fields] OR haltas[All Fields] OR haltatari[All Fields] OR haltaufderheide[All Fields] OR haltaufderhyde[All Fields] OR haltbakk[All Fields] OR haltbar[All Fields] OR haltbare[All Fields] OR haltbaren[All Fields] OR haltbarer[All Fields] OR haltbares[All Fields] OR haltbargemachte[All Fields] OR haltbarkeit[All Fields] OR haltbarkeitsberechnung[All Fields] OR haltbarkeitsberechungen[All Fields] OR haltbarkeitsfrist[All Fields] OR haltbarkeitsprufung[All Fields] OR haltbarkeitsspezifische[All Fields] OR haltbarkeitsstudien[All Fields] OR haltbarkeitsverminderung[All Fields] 
OR haltbarkeitsversuche[All Fields] OR haltbarketi[All Fields] OR haltbarmachung[All Fields] OR haltbestamning[All Fields] OR haltcpbd4dbkgcj3[All Fields] OR halte[All Fields] OR halteapparat[All Fields] OR halteapparates[All Fields] OR haltearbeit[All Fields] OR haltearms[All Fields] OR haltebourg[All Fields] OR haltechnologies[All Fields] OR halted[All Fields] OR haltedon[All Fields] OR halteelement[All Fields] OR halteelemente[All Fields] OR halteelementen[All Fields] OR halteelements[All Fields] OR haltefaden[All Fields] OR haltefeder[All Fields] OR haltefunktion[All Fields] OR haltegerat[All Fields] OR haltegriff[All Fields] OR halteh[All Fields] OR haltehilfe[All Fields] OR halteklemme[All Fields] OR haltekraft[All Fields] OR haltelasten[All Fields] OR halteleistung[All Fields] OR halteleistungsfahigkeit[All Fields] OR haltelement[All Fields] OR halteman[All Fields] OR haltemechanismen[All Fields] OR haltemomentes[All Fields] OR halten[All Fields] OR haltenbanken[All Fields] OR haltende[All Fields] OR haltenden[All Fields] OR haltenhof[All Fields] OR haltenhoff[All Fields] OR haltenhoffstr[All Fields] OR haltenhoffstrasse[All Fields] OR haltenhofstrasse[All Fields] OR halteosen[All Fields] OR haltepersonals[All Fields] OR haltepersonen[All Fields] OR haltequote[All Fields] OR halter[All Fields] OR halter/lead[All Fields] OR halter/wing[All Fields] OR halter's[All Fields] OR halterahmen[All Fields] OR halterapis[All Fields] OR halterata[All Fields] OR haltere[All Fields] OR haltere's[All Fields] OR haltered[All Fields] OR haltereflexe[All Fields] OR halteren[All Fields] OR halterenfrage[All Fields] OR halterenscheibe[All Fields] OR halteres[All Fields] OR halteresassociates[All Fields] OR halterhohung[All Fields] OR halteria[All Fields] OR halteridial[All Fields] OR halteridium[All Fields] OR halteriia[All Fields] OR halteriid[All Fields] OR halteriids[All Fields] OR haltering[All Fields] OR halterj[All Fields] OR halterman[All Fields] OR haltern[All Fields] OR halterna[All Fields] OR halterner[All Fields] OR halternung[All Fields] OR halteromyces[All Fields] OR halterophile[All Fields] OR halterophilus[All Fields] OR halters[All Fields] OR halterung[All Fields] OR halterungstemperatur[All Fields] OR halterwohl[All Fields] OR haltes[All Fields] OR haltestellen[All Fields] OR haltestifte[All Fields] OR haltetechnik[All Fields] OR haltetonus[All Fields] OR haltevorrichtung[All Fields] OR haltevorrichtungen[All Fields] OR haltezange[All Fields] OR haltezeit[All Fields] OR haltfax[All Fields] OR halth[All Fields] OR halthane[All Fields] OR halthcare[All Fields] OR halthon[All Fields] OR halthore[All Fields] OR halthur[All Fields] OR halthy[All Fields] OR halti001[All Fields] OR haltia[All Fields] OR haltiala[All Fields] OR haltialle[All Fields] OR haltiavaara[All Fields] OR haltica[All Fields] OR halticae[All Fields] OR halticella[All Fields] OR haltichella[All Fields] OR halticinae[All Fields] OR halticine[All Fields] OR halticus[All Fields] OR haltigan[All Fields] OR haltige[All Fields] OR haltigem[All Fields] OR haltigen[All Fields] OR haltiger[All Fields] OR haltiges[All Fields] OR haltija[All Fields] OR haltin[All Fields] OR haltiner[All Fields] OR halting[All Fields] OR haltingly[All Fields] OR haltinner[All Fields] OR haltiok[All Fields] OR haltiti[All Fields] OR haltiwanger[All Fields] OR haltli[All Fields] OR haltlib[All Fields] OR haltlichem[All Fields] OR haltlos[All Fields] OR haltm[All Fields] OR haltman[All Fields] OR haltmar[All Fields] OR haltmayer[All Fields] OR haltmayers[All Fields] OR haltmeier[All Fields] OR haltmeyer[All Fields] OR haltmeyr[All Fields] OR haltner[All Fields] OR haltof[All Fields] OR haltohane[All Fields] OR haltom[All Fields] OR halton[All Fields] OR halton's[All Fields] OR haltonhealthcare[All Fields] OR haltore[All Fields] OR haltrabolsi[All Fields] OR haltrecht[All Fields] OR haltrich[All Fields] OR haltrin[All Fields] OR halts[All Fields] OR halts/delays[All Fields] OR halts'[All Fields] OR haltsonen[All Fields] OR halttula[All Fields] OR halttunen[All Fields] OR haltuch[All Fields] OR haltun[All Fields] OR haltundal[All Fields] OR haltunen[All Fields] OR haltung[All Fields] OR haltungen[All Fields] OR haltungs[All Fields] OR haltungsabhangig[All Fields] OR haltungsabhangiger[All Fields] OR haltungsanalyse[All Fields] OR haltungsanalytische[All Fields] OR haltungsanderung[All Fields] OR haltungsanomalien[All Fields] OR haltungsarbeit[All Fields] OR haltungsasymmetrie[All Fields] OR haltungsauffalligkeiten[All Fields] OR haltungsbedigungen[All Fields] OR haltungsbedingte[All Fields] OR haltungsbedingten[All Fields] OR haltungsbedingungen[All Fields] OR haltungsbereich[All Fields] OR haltungsbestimmungen[All Fields] OR haltungsbiofeedback[All Fields] OR haltungsbiologie[All Fields] OR haltungsdauer[All Fields] OR haltungsentwicklung[All Fields] OR haltungsfaktoren[All Fields] OR haltungsfehler[All Fields] OR haltungsfehlern[All Fields] OR haltungsform[All Fields] OR haltungsformen[All Fields] OR haltungsforschung[All Fields] OR haltungsgeschadigten[All Fields] OR haltungsgeschadigter[All Fields] OR haltungshygiene[All Fields] OR haltungsintensitat[All Fields] OR haltungskontrolle[All Fields] OR haltungskorrektur[All Fields] OR haltungslage[All Fields] OR haltungsmangeln[All Fields] OR haltungsmethodik[All Fields] OR haltungsnormalen[All Fields] OR haltungsproblem[All Fields] OR haltungsproblematik[All Fields] OR haltungsprobleme[All Fields] OR haltungsprogrammen[All Fields] OR haltungsreflexe[All Fields] OR haltungsregulation[All Fields] OR haltungsschablone[All Fields] OR haltungsschaden[All Fields] OR haltungsschaeden[All Fields] OR haltungsschwache[All Fields] OR haltungsschwachen[All Fields] OR haltungsschwacher[All Fields] OR haltungssituation[All Fields] OR haltungsspannung[All Fields] OR haltungsstorung[All Fields] OR haltungsstorungen[All Fields] OR haltungssysteme[All Fields] OR haltungssystemen[All Fields] OR haltungssystems[All Fields] OR haltungsszintimyelographie[All Fields] OR haltungstechnik[All Fields] OR haltungstechnische[All Fields] OR haltungstemperaturen[All Fields] OR haltungstherapie[All Fields] OR haltungsturnen[All Fields] OR haltungsturnens[All Fields] OR haltungsumstellung[All Fields] OR haltungsuntersuchung[All Fields] OR haltungsuntersuchungen[All Fields] OR haltungsvariable[All Fields] OR haltungsvarianten[All Fields] OR haltungsverfahren[All Fields] OR haltungsverfall[All Fields] OR haltungsverschleiss[All Fields] OR haltungsvorrichtung[All Fields] OR haltunhan[All Fields] OR haltunkaya[All Fields] OR haltuun[All Fields] OR haltverbesserung[All Fields] OR haltx[All Fields] OR halty[All Fields] OR haltzman[All Fields]) OR (stop[All Fields] OR stop/2[All Fields] OR stop/centering[All Fields] OR stop/centrifugation[All Fields] OR stop/continuancy[All Fields] OR stop/continue[All Fields] OR stop/decrease[All 
Fields] OR stop/flex[All Fields] OR stop/flow[All Fields] OR stop/free[All Fields] OR stop/fricative[All Fields] OR stop/glide[All Fields] OR stop/go[All Fields] OR stop/hyperperfusion[All Fields] OR stop/increase[All Fields] OR stop/kakapo[All Fields] OR stop/ I[All Fields] OR stop/linear[All Fields] OR stop/map6[All Fields] OR stop/nasal[All Fields] OR stop/ndei[All Fields] OR stop/not[All Fields] OR stop/p/in[All Fields] OR stop/pass[All Fields] OR stop/polyadenylation[All Fields] OR stop/q106r[All Fields] OR stop/r[All Fields] OR stop/r262q[All Fields] OR stop/reduce[All Fields] OR stop/repress[All Fields] OR stop/reset[All Fields] OR stop/reverse[All Fields] OR stop/s[All Fields] OR stop/s/sequences[All Fields] OR stop/stall[All Fields] OR stop/start[All Fields] OR stop/stop[All Fields] OR stop/switch[All Fields] OR stop/taper[All Fields] OR stop/tgc972[All Fields] OR stop/trading[All Fields] OR stop/trap[All Fields] OR stop/vowel[All Fields] OR stop/y[All Fields] OR stop'[All Fields] OR stop"[All Fields] OR stop's[All Fields] OR stop1[All Fields] OR stop111c[All Fields] OR stop115031[All Fields] OR stop126[All Fields] OR stop145[All Fields] OR stop148[All Fields] OR stop152arg[All Fields] OR stop155[All Fields] OR stop160[All Fields] OR stop1p[All Fields] OR stop2[All Fields] OR stop220[All Fields] OR stop221[All Fields] OR stop259taa[All Fields] OR stop28[All Fields] OR stop305[All Fields] OR stop306[All Fields] OR stop330[All Fields] OR stop331[All Fields] OR stop337[All Fields] OR stop351a[All Fields] OR stop373c[All Fields] OR stop373c/ e142k[All Fields] OR stop39[All Fields] OR stop398[All Fields] OR stop446[All Fields] OR stop447[All Fields] OR stop45[All Fields] OR stop454[All Fields] OR stop491[All Fields] OR stop523[All Fields] OR stop65[All Fields] OR stop657[All Fields] OR stop660[All Fields] OR stop693[All Fields] OR stop74[All Fields] OR stop78arg[All Fields] OR stop78gly[All Fields] OR stop838[All Fields] OR stop838/nr2a[All Fields] OR stop8546[All Fields] OR stop905[All Fields] OR stopa[All Fields] OR stopac[All Fields] OR stopacciaro[All Fields] OR stopach[All Fields] OR stopadesate[All Fields] OR stopadesatemu[All Fields] OR stopadesatileta[All Fields] OR stopadvies[All Fields] OR stopage[All Fields] OR stopajnik[All Fields] OR stopak[All Fields] OR stopala[All Fields] OR stopali1[All Fields] OR stopalo[All Fields] OR stopalu[All Fields] OR stopalz[All Fields] OR stopami[All Fields] OR stopangin[All Fields] OR stopani[All Fields] OR stopanska[All Fields] OR stopansko[All Fields] OR stopanstva[All Fields] OR stopanstvo[All Fields] OR stopanstvoto[All Fields] OR stopar[All Fields] OR stopard[All Fields] OR stoparic[All Fields] OR stopat[All Fields] OR stopatsams[All Fields] OR stopatschinskaja[All Fields] OR stopatschinskaya[All Fields] OR stopayne[All Fields] OR stopazzoni[All Fields] OR stopband[All Fields] OR stopband/structure[All Fields] OR stopbands[All Fields] OR stopbas[All Fields] OR stopbowitzi[All Fields] OR stopbreastcancer[All Fields] OR stopc[All Fields] OR stopce[All Fields] OR stopchanska[All Fields] OR stopchanskaia[All Fields] OR stopchanskaya[All Fields] OR stopchatuiu[All Fields] OR stopchik[All Fields] OR stopcna[All Fields] OR stopcna1[All Fields] OR stopcna123[All Fields] OR stopcna2[All Fields] OR stopcna3[All Fields] OR stopcna323[All Fields] OR stopcnas[All Fields] OR stopcock[All Fields] OR stopcock'[All Fields] OR stopcocks[All Fields] OR stopcodon[All Fields] OR stopcodons[All Fields] OR stopcoks[All Fields] OR stopcold[All Fields] OR stopcs[All Fields] OR stopcuoglu[All Fields] OR stopczanski[All Fields] OR stopczk[All Fields] OR stopczyk[All Fields] OR stopczyka[All Fields] OR stopczynska[All Fields] OR stopczynski[All Fields] OR stopd[All Fields] OR stopdomesticabuse[All Fields] OR stope[All Fields] OR stopeck[All Fields] OR stoped[All Fields] OR stopedectomy[All Fields] OR stopedeseta[All Fields] OR stopedesetgodisnjica[All Fields] OR stopehylem[All Fields] OR stopek[All Fields] OR stopekova[All Fields] OR stopel[All Fields] OR stopelegeringer[All Fields] OR stopeleire[All Fields] OR stopen[All Fields] OR stopen'[All Fields] OR stopenjska[All Fields] OR stoper[All Fields] OR stopera[All Fields] OR stoperative[All Fields] OR stoperator[All Fields] OR stoperator'[All Fields] OR stopers[All Fields] OR stopes[All Fields] OR stopes's[All Fields] OR stopeskjeen[All Fields] OR stopeteknikk[All Fields] OR stopethyl[All Fields] OR stopethylem[All Fields] OR stopethyloveho[All Fields] OR stopetie[All Fields] OR stopetiniaia[All Fields] OR stopetylove[All Fields] OR stopetylu[All Fields] OR stopf[All Fields] OR stopfbarer[All Fields] OR stopfdruck[All Fields] OR stopfdrucke[All Fields] OR stopfel[All Fields] OR stopfen[All Fields] OR stopfer[All Fields] OR stopferm[All Fields] OR stopfgold[All Fields] OR stopfgoldfullung[All Fields] OR stopfkuchen[All Fields] OR stopflow[All Fields] OR stopflu[All Fields] OR stopfmethode[All Fields] OR stopfnadel[All Fields] OR stopford[All Fields] OR stopfordb[All Fields] OR stopforth[All Fields] OR stopftechniken[All Fields] OR stopgap[All Fields] OR stopgap/solution[All Fields] OR stopgap's[All Fields] OR stopgaps[All Fields] OR stopgo[All Fields] OR stoph[All Fields] OR stophanthidin[All Fields] OR stophantine[All Fields] OR stophanyl[All Fields] OR stophasius[All Fields] OR stophel[All Fields] OR stopher[All Fields] OR stophila[All Fields] OR stophiv[All Fields] OR stophlee[All Fields] OR stophylococcus[All Fields] OR stopi[All Fields] OR stopic[All Fields] OR stopie[All Fields] OR stopie'n[All Fields] OR stopien[All Fields] OR stopiglia[All Fields] OR stopik[All Fields] OR stopikowska[All Fields] OR stopimt[All Fields] OR stopin[All Fields] OR stoping[All Fields] OR stopiniska[All Fields] OR stopinsek[All Fields] OR stopinska[All Fields] OR stopinski[All Fields] OR stopinsky[All Fields] OR stopit[All Fields] OR stopk[All Fields] OR stopk8[All Fields] OR stopka[All Fields] OR stopkan[All Fields] OR stopkan'[All Fields] OR stopkat'e[All Fields] OR stopkatou[All Fields] OR stopkaty[All Fields] OR stopkatym[All Fields] OR stopke[All Fields] OR stopki[All Fields] OR stopkie[All Fields] OR stopkoobraznykh[All Fields] OR stopkou[All Fields] OR stopkova[All Fields] OR stopkovaneho[All Fields] OR stopkowicz[All Fields] OR stopky[All Fields] OR stopler[All Fields] OR stopless[All Fields] OR stoplicht[All Fields] OR stoplicht'[All Fields] OR stoplight[All Fields] OR stoplights[All Fields] OR stoplu[All Fields] OR stopn[All Fields] OR stopni[All Fields] OR stopnia[All Fields] OR stopniach[All Fields] OR stopniau[All Fields] OR stopnicka[All Fields] OR stopnie[All Fields] OR stopniem[All Fields] OR stopning[All Fields] OR stopniowa[All Fields] OR stopniowanego[All Fields] OR stopniowanej[All Fields] OR stopniowanie[All Fields] OR stopniowanych[All Fields] OR stopniowego[All Fields] OR 
stopniowo[All Fields] OR stopniowy[All Fields] OR stopniowym[All Fields] OR stopnisek[All Fields] OR stopniu[All Fields] OR stopnje[All Fields] OR stopnjo[All Fields] OR stopnogo[All Fields] OR stopnom[All Fields] OR stopochnykh[All Fields] OR stopoi[All Fields] OR stopoiu[All Fields] OR stopol[All Fields] OR stopolianskaia[All Fields] OR stopolyanskij[All Fields] OR stopolyanskiy[All Fields] OR stopom[All Fields] OR stopomer[All Fields] OR stopometriia[All Fields] OR stopopani[All Fields] OR stoporev[All Fields] OR stopornymi[All Fields] OR stoporov[All Fields] OR stopout[All Fields] OR stopov'ych[All Fields] OR stopove[All Fields] OR stopover[All Fields] OR stopover/foraging[All Fields] OR stopovers[All Fields] OR stopovers'[All Fields] OR stopovy[All Fields] OR stopovych[All Fields] OR stopovymi[All Fields] OR stopow[All Fields] OR stopoytch[All Fields] OR stopp[All Fields] OR stopp/ start[All Fields] OR stopp'a[All Fields] OR stoppa[All Fields] OR stoppa’s[All Fields] OR stoppable[All Fields] OR stoppacciaro[All Fields] OR stoppacher[All Fields] OR stoppaciaro[All Fields] OR stoppad[All Fields] OR stoppade[All Fields] OR stoppage[All Fields] OR stoppage/change[All Fields] OR stoppage/occupational[All Fields] OR stoppages[All Fields] OR stoppain[All Fields] OR stoppalyonnet[All Fields] OR stoppani[All Fields] OR stoppany[All Fields] OR stoppany's[All Fields] OR stoppanys[All Fields] OR stoppar[All Fields] OR stoppard[All Fields] OR stoppard's[All Fields] OR stoppas[All Fields] OR stoppat[All Fields] OR stoppato[All Fields] OR stoppato's[All Fields] OR stoppcodon[All Fields] OR stoppe[All Fields] OR stopped[All Fields] OR stopped/reduced[All Fields] OR stopped/reinitiated[All Fields] OR stopped/released[All Fields] OR stopped/slowed[All Fields] OR stopped/withheld[All Fields] OR stopped'[All Fields] OR stoppee[All Fields] OR stoppeed[All Fields] OR stoppel[All Fields] OR stoppelaar[All Fields] OR stoppelaire[All Fields] OR stoppelbein[All Fields] OR stoppelenburg[All Fields] OR stoppeler[All Fields] OR stoppelhaar[All Fields] OR stoppelhutung[All Fields] OR stoppelkamp[All Fields] OR stoppelli[All Fields] OR stoppelman[All Fields] OR stoppelmann[All Fields] OR stoppels[All Fields] OR stoppen[All Fields] OR stoppenbach[All Fields] OR stoppenbrink[All Fields] OR stoppende[All Fields] OR stoppende'[All Fields] OR stoppenhagen[All Fields] OR stopper[All Fields] OR stopper/glass[All Fields] OR stopper'[All Fields] OR stopperan[All Fields] OR stoppered[All Fields] OR stopperegler[All Fields] OR stopperich[All Fields] OR stoppering[All Fields] OR stoppers[All Fields] OR stoppers/plungers[All Fields] OR stoppers'[All Fields] OR stoppersystem[All Fields] OR stoppes[All Fields] OR stoppet[All Fields] OR stoppia[All Fields] OR stoppicking[All Fields] OR stoppie[All Fields] OR stoppiglia[All Fields] OR stoppin[All Fields] OR stopping[All Fields] OR stopping/continuation[All Fields] OR stopping/continuing[All Fields] OR stopping/crossing[All Fields] OR stopping/decrease[All Fields] OR stopping/decreasing[All Fields] OR stopping/floating[All Fields] OR stopping/keeping[All Fields] OR stopping/limiting[All Fields] OR stopping/reducing[All Fields] OR stopping/release[All Fields] OR stopping/restarting[All Fields] OR stopping/reversing[All Fields] OR stopping/slowing[All Fields] OR stopping/stalling[All Fields] OR stopping/starting[All Fields] OR stopping/switching[All Fields] OR stopping/tapering[All Fields] OR stopping/trying[All Fields] OR stopping'[All Fields] OR stoppings[All Fields] OR stoppini[All Fields] OR stoppinni[All Fields] OR stoppino[All Fields] OR stoppioni[All Fields] OR stoppit[All Fields] OR stoppkotte[All Fields] OR stopple[All Fields] OR stoppler[All Fields] OR stopples[All Fields] OR stoppliquors[All Fields] OR stoppmanns[All Fields] OR stoppo[All Fields] OR stoppok[All Fields] OR stoppoloni[All Fields] OR stopponi[All Fields] OR stoppped[All Fields] OR stopps[All Fields] OR stoppt[All Fields] OR stoppur[All Fields] OR stoppy[All Fields] OR stopr[All Fields] OR stopr3[All Fields] OR stopric[All Fields] OR stoprotsentnykh[All Fields] OR stops[All Fields] OR stops/inconvenience[All Fields] OR stops/market[All Fields] OR stops'[All Fields] OR stops1[All Fields] OR stopsack[All Fields] OR stopschinski[All Fields] OR stopsel[All Fields] OR stopsida[All Fields] OR stopsignal[All Fields] OR stopsinc[All Fields] OR stopsite[All Fields] OR stopsleven[All Fields] OR stopsley[All Fields] OR stopsmokingcenter[All Fields] OR stopstroke[All Fields] OR stopszabaly[All Fields] OR stopt[All Fields] OR stoptb[All Fields] OR stopterapy[All Fields] OR stopti[All Fields] OR stoptik[All Fields] OR stoptrade[All Fields] OR stopu[All Fields] OR stopul[All Fields] OR stopurilor[All Fields] OR stopus[All Fields] OR stopver[All Fields] OR stopwatch[All Fields] OR stopwatch/calculator[All Fields] OR stopwatch'[All Fields] OR stopwatches[All Fields] OR stopwatchesreality[All Fields] OR stopwise[All Fields] OR stopword[All Fields] OR stopwords[All Fields] OR stopwork[All Fields] OR stopy[All Fields] OR stopyouthsuicide[All Fields] OR stopyra[All Fields] OR stopyrowa[All Fields] OR stopzetten[All Fields] OR stopzetting[All Fields] OR stopzyk[All Fields]) OR (drop out[All Fields] OR drop out/new[All Fields] OR drop outline[All Fields] OR drop outmanship[All Fields] OR drop outs[All Fields]) OR (dropout[All Fields] OR dropout/death[All Fields] OR dropout/participation[All Fields] OR dropout/withdrawal[All Fields] OR dropout'[All Fields] OR dropout's[All Fields] OR dropouts[All Fields] OR dropouts/decliners[All Fields] OR dropouts/disciplinary[All Fields] OR dropouts/nonusers[All Fields] OR dropouts/withdrawals[All Fields] OR dropouts' [All Fields]) OR (drop[All Fields] AND out[All Fields]) OR (rehospitalisation[All Fields] OR rehospitalisations[All Fields] OR rehospitalised[All Fields] OR rehospitalisiert[All Fields] OR rehospitalisierung[All Fields] OR rehospitalisierungsfreie[All Fields] OR rehospitalisierungsquote[All Fields] OR rehospitalisierungsrate[All Fields] OR rehospitalisierungsrisiko[All Fields] OR rehospitalisierungszeiten[All Fields]) OR (relaps[All Fields] OR relapsable[All Fields] OR relapsans[All Fields] OR relapsation[All Fields] OR relapsd[All Fields] OR relapse[All Fields] OR relapse/5[All Fields] OR relapse/abstinence[All Fields] OR relapse/breakthrough[All Fields] OR relapse/colectomy[All Fields] OR relapse/continued[All Fields] OR relapse/death[All Fields] OR relapse/defect[All Fields] OR relapse/delivery[All Fields] OR relapse/disease[All Fields] OR relapse/drug[All Fields] OR relapse/exacerbation[All Fields] OR relapse/extrapulmonary[All Fields] OR relapse/failure[All Fields] OR relapse/impending[All Fields] OR relapse/ir[All Fields] OR relapse/ loss[All Fields] OR relapse/marked[All Fields] OR relapse/metastasis[All Fields] OR relapse/month[All Fields] OR relapse/no[All Fields] 
OR relapse/nonrelapse[All Fields] OR relapse/nonresponse[All Fields] OR relapse/outcome[All Fields] OR relapse/patient[All Fields] OR relapse/patient/year[All Fields] OR relapse/persistence[All Fields] OR relapse/persistent[All Fields] OR relapse/person/year[All Fields] OR relapse/pick[All Fields] OR relapse/primary[All Fields] OR relapse/probable[All Fields] OR relapse/progress[All Fields] OR relapse/progression[All Fields] OR relapse/progressive[All Fields] OR relapse/rate[All Fields] OR relapse/reactivation[All Fields] OR relapse/readmission[All Fields] OR relapse/rebound[All Fields] OR relapse/recrudescence[All Fields] OR relapse/recur[All Fields] OR relapse/recurrence[All Fields] OR relapse/reduction[All Fields] OR relapse/refractoriness[All Fields] OR relapse/refractory[All Fields] OR relapse/rehospitalisation[All Fields] OR relapse/rehospitalisation[All Fields] OR relapse/reinfection[All Fields] OR relapse/reinstatement[All Fields] OR relapse/relapses[All Fields] OR relapse/remission[All Fields] OR relapse/remit[All Fields] OR relapse/remitting[All Fields] OR relapse/residual[All Fields] OR relapse/resistance[All Fields] OR relapse/resistant[All Fields] OR relapse/response[All Fields] OR relapse/rising[All Fields] OR relapse/settling[All Fields] OR relapse/shub[All Fields] OR relapse/sustained[All Fields] OR relapse/ transformation[All Fields] OR relapse/transformed[All Fields] OR relapse/treatment[All Fields] OR relapse/tumour[All Fields] OR relapse/uncontrolled[All Fields] OR relapse/worsening[All Fields] OR relapse/year[All Fields] OR relapse'[All Fields] OR relapse”[All Fields] OR relapse's[All Fields] OR relapse1[All Fields] OR relapsec[All Fields] OR relapsed[All Fields] OR relapsed/advanced[All Fields] OR relapsed/chemoresistant[All Fields] OR relapsed/metastatic[All Fields] OR relapsed/or[All Fields] OR relapsed/persistent[All Fields] OR relapsed/primary[All Fields] OR relapsed/progressed[All Fields] OR relapsed/progressive[All Fields] OR relapsed/recurrent[All Fields] OR relapsed/refactory[All Fields] OR relapsed/refractor[All Fields] OR relapsed/refractory[All Fields] OR relapsed/ relapsed[All Fields] OR relapsed/resistant[All Fields] OR relapsed/secondary[All Fields] OR relapsed'[All Fields] OR relapsefree[All Fields] OR relapseless[All Fields] OR relapselike[All Fields] OR relapsem[All Fields] OR relapsen[All Fields] OR relapser[All Fields] OR relapsers[All Fields] OR relapsers/breakthroughs[All Fields] OR relapsers/incomplete[All Fields] OR relapsers/nonresponders[All Fields] OR relapsers'[All Fields] OR relapses[All Fields] OR relapses/16[All Fields] OR relapses/23[All Fields] OR relapses/28[All Fields] OR relapses/breast[All Fields] OR relapses/chronicity[All Fields] OR relapses/disease[All Fields] OR relapses/exacerbation[All Fields] OR relapses/failures[All Fields] OR relapses/increases[All Fields] OR relapses/metastases[All Fields] OR relapses/metastasis[All Fields] OR relapses/patient[All Fields] OR relapses/patient/month[All Fields] OR relapses/patient/year[All Fields] OR relapses/person/ year[All Fields] OR relapses/progressions[All Fields] OR relapses/recurrences[All Fields] OR relapses/recurrent[All Fields] OR relapses/ reinfections[All Fields] OR relapses/the[All Fields] OR relapses/woman/year[All Fields] OR relapses/y[All Fields] OR relapses/year[All Fields] OR relapses/yr[All Fields] OR relapses'[All Fields] OR relapset[All Fields] OR relapsf[All Fields] OR relapsi[All Fields] OR relapsin[All Fields] OR relapsing[All Fields] OR relapsing/445[All Fields] OR relapsing/chronic[All Fields] OR relapsing/malignant[All Fields] OR relapsing/non[All Fields] OR relapsing/persistent[All Fields] OR relapsing/persisting[All Fields] OR relapsing/progressing[All Fields] OR relapsing/progressive[All Fields] OR relapsing/refractory[All Fields] OR relapsing/remission[All Fields] OR relapsing/remittent[All Fields] OR relapsing/remitting[All Fields] OR relapsing/residual[All Fields] OR relapsing/resistant[All Fields] OR relapsing/resisting[All Fields] OR relapsing/starting[All Fields] OR relapsing'[All Fields] OR relapsinginflammatory[All Fields] OR relapsingremitting[All Fields] OR relapsingwegener's[All Fields] OR relapsion[All Fields] OR relapsive[All Fields] OR relapsmg[All Fields] OR relapsom[All Fields] OR relapsong[All Fields] OR relapsrate[All Fields] OR relapsu[All Fields] OR relapsujici[All Fields] OR relapsus[All Fields] OR relapsusa[All Fields] OR relapsy[All Fields] OR relapszus[All Fields]) OR (maintain[All Fields] OR maintain/ attain[All Fields] OR maintain/avoid[All Fields] OR maintain/elongate[All Fields] OR maintain/expand[All Fields] OR maintain/ form[All Fields] OR maintain/improve[All Fields] OR maintain/modulate[All Fields] OR maintain/obtain[All Fields] OR maintain/ optimise[All Fields] OR maintain/promote[All Fields] OR maintain/regain[All Fields] OR maintain/regulate[All Fields] OR maintain/remove[All Fields] OR maintain/repair[All Fields] OR maintain/restore[All Fields] OR maintain'[All Fields] OR maintaina[All Fields] OR maintainability[All Fields] OR maintainability'[All Fields] OR maintainable[All Fields] OR maintainace[All Fields] OR maintainance[All Fields] OR maintainat[All Fields] OR maintaince[All Fields] OR maintaind[All Fields] OR maintaine[All Fields] OR maintained[All Fields] OR maintained/altered[All Fields] OR maintained/discontinued[All Fields] OR maintained/enhanced[All Fields] OR maintained/exercised[All Fields] OR maintained/expanded[All Fields] OR maintained/improved[All Fields] OR maintained/increased[All Fields] OR maintained/intermittent[All Fields] OR maintained/modified[All Fields] OR maintained/raised[All Fields] OR maintained/reduced[All Fields] OR maintained'[All Fields] OR maintainedover[All Fields] OR maintainedpto[All Fields] OR maintainement[All Fields] OR maintainenance[All Fields] OR maintainence[All Fields] OR maintainer[All Fields] OR maintainer'[All Fields] OR maintainer's[All Fields] OR maintainers[All Fields] OR maintainers/augmenters[All Fields] OR maintainers'[All Fields] OR maintaines[All Fields] OR maintaing[All Fields] OR maintainig[All Fields] OR maintainindependent[All Fields] OR maintainine[All Fields] OR maintaininf[All Fields] OR maintaining[All Fields] OR maintaining/adjusting[All Fields] OR maintaining/ controlling[All Fields] OR maintaining/creating[All Fields] OR maintaining/elongating[All Fields] OR maintaining/expanding[All Fields] OR maintaining/generating[All Fields] OR maintaining/improving[All Fields] OR maintaining/inducing[All Fields] OR maintaining/obtaining/returning[All Fields] OR maintaining/preserving[All Fields] OR maintaining/producing[All Fields] OR maintaining/promoting[All Fields] OR maintaining/publishing[All Fields] OR maintaining/recovering[All Fields] OR maintaining/regular[All Fields] OR maintaining/regulating[All Fields] OR maintaining/restoring[All Fields] OR maintaining/restoring/inducing[All Fields] OR 
maintaining/spreading[All Fields] OR maintaining/stimulating[All Fields] OR maintaining'[All Fields] OR maintainingthe[All Fields] OR maintainly[All Fields] OR maintainment[All Fields] OR maintainng[All Fields] OR maintainnormal[All Fields] OR maintainremission[All Fields] OR maintains[All Fields] OR maintains/stabilizes[All Fields] OR maintaintained[All Fields] OR maintainted[All Fields] OR maintainually[All Fields]) OR (maintenance[All Fields] OR maintenance/activation[All Fields] OR maintenance/affective[All Fields] OR maintenance/assembly[All Fields] OR maintenance/assembly/differentiation[All Fields] OR maintenance/audit[All Fields] OR maintenance/biogenesis[All Fields] OR maintenance/classification[All Fields] OR maintenance/collision[All Fields] OR maintenance/consolidation[All Fields] OR maintenance/continuation[All Fields] OR maintenance/contraceptive[All Fields] OR maintenance/creation[All Fields] OR maintenance/cue[All Fields] OR maintenance/cyclosporine[All Fields] OR maintenance/d[All Fields] OR maintenance/deployment[All Fields] OR maintenance/depreciation[All Fields] OR maintenance/detergent[All Fields] OR maintenance/detoxification[All Fields] OR maintenance/development[All Fields] OR maintenance/differentiation[All Fields] OR maintenance/discontinuation[All Fields] OR maintenance/disruption[All Fields] OR maintenance/dna[All Fields] OR maintenance/economics[All Fields] OR maintenance/education[All Fields] OR maintenance/efficiency[All Fields] OR maintenance/efforts[All Fields] OR maintenance/efforts/year/patients[All Fields] OR maintenance/elongation[All Fields] OR maintenance/emergence[All Fields] OR maintenance/engineering[All Fields] OR maintenance/environmental[All Fields] OR maintenance/equipment[All Fields] OR maintenance/establishment[All Fields] OR maintenance/ethics[All Fields] OR maintenance/exacerbation[All Fields] OR maintenance/expansion[All Fields] OR maintenance/exportin[All Fields] OR maintenance/exportin1[All Fields] OR maintenance/extended[All Fields] OR maintenance/fat[All Fields] OR maintenance/function[All Fields] OR maintenance/gain[All Fields] OR maintenance/gardening[All Fields] OR maintenance/growth[All Fields] OR maintenance/health[All Fields] OR maintenance/homeostasis[All Fields] OR maintenance/hypertrophy[All Fields] OR maintenance/improvement[All Fields] OR maintenance/induction[All Fields] OR maintenance/ inept[All Fields] OR maintenance/inhibition[All Fields] OR maintenance/inspiration[All Fields] OR maintenance/integrity[All Fields] OR maintenance/intensification[All Fields] OR maintenance/interruption[All Fields] OR maintenance/jurisprudence[All Fields] OR maintenance/lifestyle[All Fields] OR maintenance/manpower[All Fields] OR maintenance/mechanical[All Fields] OR maintenance/ metabolism[All Fields] OR maintenance/methods[All Fields] OR maintenance/mixed[All Fields] OR maintenance/nutrition[All Fields] OR maintenance/observation[All Fields] OR maintenance/operation[All Fields] OR maintenance/output[All Fields] OR maintenance/ periodic[All Fields] OR maintenance/prevention[All Fields] OR maintenance/progression[All Fields] OR maintenance/proliferation[All Fields] OR maintenance/promotion[All Fields] OR maintenance/protection[All Fields] OR maintenance/protective[All Fields] OR maintenance/quality[All Fields] OR maintenance/rebound[All Fields] OR maintenance/reconstitution[All Fields] OR maintenance/ reconstruction[All Fields] OR maintenance/recovery[All Fields] OR maintenance/regain[All Fields] OR maintenance/regeneration[All Fields] OR maintenance/regression[All Fields] OR maintenance/regulation[All Fields] OR maintenance/rehearsal[All Fields] OR maintenance/relapse[All Fields] OR maintenance/reliability[All Fields] OR maintenance/remodeling[All Fields] OR maintenance/remodelling[All Fields] OR maintenance/renovation[All Fields] OR maintenance/renovators[All Fields] OR maintenance/repair[All Fields] OR maintenance/replenishment[All Fields] OR maintenance/rescue[All Fields] OR maintenance/resolution[All Fields] OR maintenance/restoration[All Fields] OR maintenance/retrieval[All Fields] OR maintenance/reverberation[All Fields] OR maintenance/segregation[All Fields] OR maintenance/sequential[All Fields] OR maintenance/standards[All Fields] OR maintenance/support[All Fields] OR maintenance/survival[All Fields] OR maintenance/sustainability[All Fields] OR maintenance/system[All Fields] OR maintenance/ targeting[All Fields] OR maintenance/transport[All Fields] OR maintenance/treatment[All Fields] OR maintenance/trends[All Fields] OR maintenance/use[All Fields] OR maintenance/utilization[All Fields] OR maintenance/waste[All Fields] OR maintenance/with[All Fields] OR maintenance'[All Fields] OR maintenance's[All Fields] OR maintenance1[All Fields] OR maintenancefed[All Fields] OR maintenancein[All Fields] OR maintenances[All Fields]) OR (recur[All Fields] OR recur/progress[All Fields] OR recur/regrow[All Fields] OR recur'[All Fields] OR recur31a[All Fields] OR recur71a[All Fields] OR recuraresierung[All Fields] OR recurarisation[All Fields] OR recurarisation'[All Fields] OR recurarised[All Fields] OR recurarisierung[All Fields] OR recurarizacao[All Fields] OR recurarizaci'on[All Fields] OR recurarization[All Fields] OR recurarization'[All Fields] OR recurated[All Fields] OR recurculating[All Fields] OR recurdescence[All Fields] OR recurdescences[All Fields] OR recure[All Fields] OR recured[All Fields] OR recureded[All Fields] OR recureence[All Fields] OR recuren[All Fields] OR recurence[All Fields] OR recurences[All Fields] OR recurency[All Fields] OR recurens[All Fields] OR recurensive[All Fields] OR recurent[All Fields] OR recurenta[All Fields] OR recurente[All Fields] OR recurentei[All Fields] OR recurentelor[All Fields] OR recurential[All Fields] OR recurentiala[All Fields] OR recurentis[All Fields] OR recurento[All Fields] OR recurer[All Fields] OR recurerence[All Fields] OR recurerences[All Fields] OR recurerrent[All Fields] OR recures[All Fields] OR recuretage[All Fields] OR recurettage[All Fields] OR recurgitation[All Fields] OR recuriential[All Fields] OR recuriertos[All Fields] OR recuring[All Fields] OR recurit[All Fields] OR recurited[All Fields] OR recuriting[All Fields] OR recuritment[All Fields] OR recurits[All Fields] OR recuronium[All Fields] OR recuronium/hour[All Fields] OR recuroniums[All Fields] OR recuros[All Fields] OR recurr[All Fields] OR recurralo[All Fields] OR recurrance[All Fields] OR recurrances[All Fields] OR recurrancy[All Fields] OR recurrant[All Fields] OR recurrants[All Fields] OR recurre[All Fields] OR recurreat[All Fields] OR recurrebt[All Fields] OR recurrece[All Fields] OR recurrect[All Fields] OR recurred[All Fields] OR recurred/metastasized[All Fields] OR recurred/ 
persisted[All Fields] OR recurred/remnant[All Fields] OR recurred'[All Fields] OR recurren[All Fields] OR recurrenc[All Fields] OR recurrenc/month[All Fields] OR recurrence[All Fields] OR recurrence/100[All Fields] OR recurrence/additional[All Fields] OR recurrence/appearance[All Fields] OR recurrence/cancer[All Fields] OR recurrence/cbc[All Fields] OR recurrence/clearance[All Fields] OR recurrence/complication[All Fields] OR recurrence/death[All Fields] OR recurrence/deterioration[All Fields] OR recurrence/development[All Fields] OR recurrence/diagnosis[All Fields] OR recurrence/disease[All Fields] OR recurrence/distance[All Fields] OR recurrence/distant[All Fields] OR recurrence/economics[All Fields] OR recurrence/enlargement[All Fields] OR recurrence/epidemiology[All Fields] OR recurrence/etiology[All Fields] OR recurrence/excellent[All Fields] OR recurrence/extension[All Fields] OR recurrence/ foveal[All Fields] OR recurrence/frank[All Fields] OR recurrence/growth[All Fields] OR recurrence/icd[All Fields] OR recurrence/immunology[All Fields] OR recurrence/incomplete[All Fields] OR recurrence/increased[All Fields] OR recurrence/malignant[All Fields] OR recurrence/marginal[All Fields] OR recurrence/metachronous[All Fields] OR recurrence/metastases[All Fields] OR recurrence/ metastasis[All Fields] OR recurrence/metastasis/death[All Fields] OR recurrence/metastatic[All Fields] OR recurrence/methastasis[All Fields] OR recurrence/month[All Fields] OR recurrence/mortality[All Fields] OR recurrence/new[All Fields] OR recurrence/occurrence[All Fields] OR recurrence/pathology[All Fields] OR recurrence/patient[All Fields] OR recurrence/persistence[All Fields] OR recurrence/persistent[All Fields] OR recurrence/pfs[All Fields] OR recurrence/post[All Fields] OR recurrence/prevention[All Fields] OR recurrence/progress[All Fields] OR recurrence/progression[All Fields] OR recurrence/progressions[All Fields] OR recurrence/ progressive[All Fields] OR recurrence/prosthesis[All Fields] OR recurrence/radiography[All Fields] OR recurrence/recrudescence[All Fields] OR recurrence/regrowing[All Fields] OR recurrence/regrowth[All Fields] OR recurrence/reinfection[All Fields] OR recurrence/ relapse[All Fields] OR recurrence/remission[All Fields] OR recurrence/reoperation[All Fields] OR recurrence/residual[All Fields] OR recurrence/residue[All Fields] OR recurrence/resistance[All Fields] OR recurrence/rest[All Fields] OR recurrence/restaging[All Fields] OR recurrence/second[All Fields] OR recurrence/splenic[All Fields] OR recurrence/spread[All Fields] OR recurrence/spt[All Fields] OR recurrence/stability[All Fields] OR recurrence/stable[All Fields] OR recurrence/stroke[All Fields] OR recurrence/surgery[All Fields] OR recurrence/surgical[All Fields] OR recurrence/survival[All Fields] OR recurrence/therapy[All Fields] OR recurrence/time[All Fields] OR recurrence/transience[All Fields] OR recurrence/treatment[All Fields] OR recurrence/vital[All Fields] OR recurrence/withdrawal[All Fields] OR recurrence/worsening[All Fields] OR recurrence/wrap[All Fields] OR recurrence/year[All Fields] OR recurrence'[All Fields] OR recurrence's[All Fields] OR recurrenced[All Fields] OR recurrencee[All Fields] OR recurrencefree[All Fields] OR recurrencel[All Fields] OR recurrenceless[All Fields] OR recurrenceonline[All Fields] OR recurrencerate[All Fields] OR recurrencerates[All Fields] OR recurrenceree[All Fields] OR recurrences[All Fields] OR recurrences/100[All Fields] OR recurrences/1000[All Fields] OR recurrences/ extensions[All Fields] OR recurrences/infections[All Fields] OR recurrences/marginal[All Fields] OR recurrences/metastases[All Fields] OR recurrences/metastatic[All Fields] OR recurrences/month[All Fields] OR recurrences/nonsatisfactory[All Fields] OR recurrences/ number[All Fields] OR recurrences/patient[All Fields] OR recurrences/persistent[All Fields] OR recurrences/progressions[All Fields] OR recurrences/reinfections[All Fields] OR recurrences/relapses[All Fields] OR recurrences/residual[All Fields] OR recurrences/tumour[All Fields] OR recurrences/y[All Fields] OR recurrences/year[All Fields] OR recurrences/year/girl[All Fields] OR recurrences/ yr[All Fields] OR recurrences'[All Fields] OR recurrencesed[All Fields] OR recurrenceses[All Fields] OR recurrencess[All Fields] OR recurrencewithout[All Fields] OR recurrencia[All Fields] OR recurrencial[All Fields] OR recurrencias[All Fields] OR recurrencies[All Fields] OR recurrenct[All Fields] OR recurrency[All Fields] OR recurrency/reinfection[All Fields] OR recurrencys[All Fields] OR recurrend[All Fields] OR recurrende[All Fields] OR recurrene[All Fields] OR recurreness[All Fields] OR recurrens[All Fields] OR recurrens'[All Fields] OR recurrensa[All Fields] OR recurrensbenulas[All Fields] OR recurrensdurchtrennung[All Fields] OR recurrensidentifizierung[All Fields] OR recurrensinfektion[All Fields] OR recurrenslahmung[All Fields] OR recurrenslahmungen[All Fields] OR recurrensmonitoring[All Fields] OR recurrensparalyse[All Fields] OR recurrensparalysen[All Fields] OR recurrenspares[All Fields] OR recurrensparese[All Fields] OR recurrensparesen[All Fields] OR recurrenspareserate[All Fields] OR recurrensparsen[All Fields] OR recurrensreizung[All Fields] OR recurrensschadigungen[All Fields] OR recurrenstam3[All Fields] OR recurrensund[All Fields] OR recurrensutfall[All Fields] OR recurrensverlamming[All Fields] OR recurrent[All Fields] OR recurrent/advanced[All Fields] OR recurrent/aggressive[All Fields] OR recurrent/chronic[All Fields] OR recurrent/complicated[All Fields] OR recurrent/continued[All Fields] OR recurrent/continuous[All Fields] OR recurrent/cyclic[All Fields] OR recurrent/disseminated[All Fields] OR recurrent/extended[All Fields] OR recurrent/external[All Fields] OR recurrent/feedback[All Fields] OR recurrent/feedforward[All Fields] OR recurrent/founder[All Fields] OR recurrent/habitual[All Fields] OR recurrent/ineffective[All Fields] OR recurrent/infiltrative[All Fields] OR recurrent/inoperable[All Fields] OR recurrent/larger[All Fields] OR recurrent/latent[All Fields] OR recurrent/locally[All Fields] OR recurrent/loculated[All Fields] OR recurrent/metastasized[All Fields] OR recurrent/metastatic[All Fields] OR recurrent/metastic[All Fields] OR recurrent/multifocal[All Fields] OR recurrent/new[All Fields] OR recurrent/nonhealing[All Fields] OR recurrent/nonresponsive[All Fields] OR recurrent/overlapping[All Fields] OR recurrent/persistent[All Fields] OR recurrent/persistent/metastatic[All Fields] OR recurrent/platinum[All Fields] OR recurrent/poor[All Fields] OR recurrent/primary[All Fields] OR recurrent/progressing[All Fields] OR recurrent/progression[All Fields] OR recurrent/progressive[All Fields] OR recurrent/prolonged[All Fields] OR recurrent/protracted[All Fields] OR recurrent/reactivated[All Fields] OR recurrent/recalcitrant[All Fields] OR recurrent/refractory[All 
Fields] OR recurrent/refractory/poor[All Fields] OR recurrent/regrown[All Fields] OR recurrent/regrowth[All Fields] OR recurrent/ relapsed[All Fields] OR recurrent/remaining[All Fields] OR recurrent/residual[All Fields] OR recurrent/resistant[All Fields] OR recurrent/resistant/persistent[All Fields] OR recurrent/retained[All Fields] OR recurrent/second[All Fields] OR recurrent/secondary[All Fields] OR recurrent/severe[All Fields] OR recurrent/stuttering[All Fields] OR recurrent/superior[All Fields] OR recurrent/terminal[All Fields] OR recurrent/unresectable[All Fields] OR recurrent/worsening[All Fields] OR recurrent'[All Fields] OR recurrentbladder[All Fields] OR recurrente[All Fields] OR recurrented[All Fields] OR recurrentes[All Fields] OR recurrential[All Fields] OR recurrentiel[All Fields] OR recurrentielle[All Fields] OR recurrentielles[All Fields] OR recurrentiels[All Fields] OR recurrentis[All Fields] OR recurrentis/b[All Fields] OR recurrentis/species[All Fields] OR recurrently[All Fields] OR recurrentnasal[All Fields] OR recurrents[All Fields] OR recurrenttumors[All Fields] OR recurrentvte[All Fields] OR recurrenty[All Fields] OR recurrenz[All Fields] OR recurrernt[All Fields] OR recurrers[All Fields] OR recurres[All Fields] OR recurretage[All Fields] OR recurretaged[All Fields] OR recurreuce[All Fields] OR recurrey[All Fields] OR recurriculating[All Fields] OR recurrid[All Fields] OR recurring[All Fields] OR recurring/lasting[All Fields] OR recurring/refractory[All Fields] OR recurring/rising[All Fields] OR recurring/terminating[All Fields] OR recurring'[All Fields] OR recurringly[All Fields] OR recurrings[All Fields] OR recurrnet[All Fields] OR recurroids[All Fields] OR recurrrence[All Fields] OR recurrrent[All Fields] OR recurrs[All Fields] OR recurs[All Fields] OR recursa[All Fields] OR recursing[All Fields] OR recursion[All Fields] OR recursions[All Fields] OR recursive[All Fields] OR recursive'[All Fields] OR recursiveclustering[All Fields] OR recursively[All Fields] OR recursiveness[All Fields] OR recursividad[All Fields] OR recursivite[All Fields] OR recursivities[All Fields] OR recursivity[All Fields] OR recurso[All Fields] OR recursor[All Fields] OR recursors[All Fields] OR recursos[All Fields] OR recursosnaturales[All Fields] OR recurt[All Fields] OR recurva[All Fields] OR recurvalis[All Fields] OR recurvartum[All Fields] OR recurvata[All Fields] OR recurvate[All Fields] OR recurvated[All Fields] OR recurvatiane[All Fields] OR recurvatianes[All Fields] OR recurvation[All Fields] OR recurvation/antecurvation[All Fields] OR recurvatios[All Fields] OR recurvatis[All Fields] OR recurvato[All Fields] OR recurvatum[All Fields] OR recurvatum'[All Fields] OR recurvature[All Fields] OR recurvatus[All Fields] OR recurvaum[All Fields] OR recurvazione[All Fields] OR recurve[All Fields] OR recurved[All Fields] OR recurves[All Fields] OR recurvifolia[All Fields] OR recurving[All Fields] OR recurving'[All Fields] OR recurvirostra[All Fields] OR recurvirostrae[All Fields] OR recurvirostridae[All Fields] OR recurvirostrids[All Fields] OR recurvirostrinae[All Fields] OR recurvirostris[All Fields] OR recurvisepala[All Fields] OR recurvispinis[All Fields] OR recurvomyces[All Fields] OR recurvum[All Fields] OR recurvus[All Fields])) AND (schizophr[All Fields] OR schizophr'ene[All Fields] OR schizophr'enes[All Fields] OR schizophr'enie[All Fields] OR schizophr'enies[All Fields] OR schizophr'eniforme[All Fields] OR schizophr'eniformes[All Fields] OR schizophr'enique[All Fields] OR schizophr'eniques[All Fields] OR schizophragma[All Fields] OR schizophrania[All Fields] OR schizophreania[All Fields] OR schizophrehic[All Fields] OR schizophreia[All Fields] OR schizophreie[All Fields] OR schizophreina[All Fields] OR schizophreinia[All Fields] OR schizophreinic[All Fields] OR schizophreken[All Fields] OR schizophrema[All Fields] OR schizophremia[All Fields] OR schizophremic[All Fields] OR schizophremie[All Fields] OR schizophren[All Fields] OR schizophrena[All Fields] OR schizophrenc[All Fields] OR schizophrenci[All Fields] OR schizophrencis[All Fields] OR schizophrencs[All Fields] OR schizophrene[All Fields] OR schizophrene’s[All Fields] OR schizophrenek[All Fields] OR schizophrenem[All Fields] OR schizophrenen[All Fields] OR schizophrenengruppe[All Fields] OR schizophrenenproblem[All Fields] OR schizophrener[All Fields] OR schizophrenes[All Fields] OR schizophrenese[All Fields] OR schizophreni[All Fields] OR schizophreni'as[All Fields] OR schizophrenia[All Fields] OR schizophrenia/adhd[All Fields] OR schizophrenia/affective[All Fields] OR schizophrenia/alzheimer's/multiple[All Fields] OR schizophrenia/art[All Fields] OR schizophrenia/autism[All Fields] OR schizophrenia/autistic[All Fields] OR schizophrenia/bacteriological[All Fields] OR schizophrenia/bipolar[All Fields] OR schizophrenia/blood[All Fields] OR schizophrenia/bp[All Fields] OR schizophrenia/cannabis[All Fields] OR schizophrenia/ case[All Fields] OR schizophrenia/catatonic[All Fields] OR schizophrenia/cerebrospinal[All Fields] OR schizophrenia/chemistry[All Fields] OR schizophrenia/chronic[All Fields] OR schizophrenia/classification[All Fields] OR schizophrenia/complications[All Fields] OR schizophrenia/control[All Fields] OR schizophrenia/cyclothymia[All Fields] OR schizophrenia/delusion[All Fields] OR schizophrenia/delusional[All Fields] OR schizophrenia/depression[All Fields] OR schizophrenia/diabetes[All Fields] OR schizophrenia/diagnosis[All Fields] OR schizophrenia/differential[All Fields] OR schizophrenia/drugs[All Fields] OR schizophrenia/early[All Fields] OR schizophrenia/economics[All Fields] OR schizophrenia/endocrine[All Fields] OR schizophrenia/enzymology[All Fields] OR schizophrenia/epidemiology[All Fields] OR schizophrenia/ethnology[All Fields] OR schizophrenia/etiology[All Fields] OR schizophrenia/experimental[All Fields] OR schizophrenia/flocculation[All Fields] OR schizophrenia/genetics[All Fields] OR schizophrenia/heredity[All Fields] OR schizophrenia/history[All Fields] OR schizophrenia/hyperglycemic[All Fields] OR schizophrenia/hypothyroidism[All Fields] OR schizophrenia/immunology[All Fields] OR schizophrenia/in[All Fields] OR schizophrenia/insulin[All Fields] OR schizophrenia/ jurisprudence[All Fields] OR schizophrenia/learning[All Fields] OR schizophrenia/major[All Fields] OR schizophrenia/manifestations[All Fields] OR schizophrenia/mao[All Fields] OR schizophrenia/mdp[All Fields] OR schizophrenia/metabolism[All Fields] OR schizophrenia/meth[All Fields] OR schizophrenia/microbiology[All Fields] OR schizophrenia/mood[All Fields] OR schizophrenia/ mortality[All Fields] OR schizophrenia/no[All Fields] OR schizophrenia/nonsuicide[All Fields] OR schizophrenia/normal[All Fields] OR schizophrenia/nursing[All Fields] OR schizophrenia/nutrition[All Fields] OR schizophrenia/obesity[All Fields] OR schizophre- 
nia/obstetric[All Fields] OR schizophrenia/ocd[All Fields] OR schizophrenia/other[All Fields] OR schizophrenia/others[All Fields] OR schizophrenia/paranoid[All Fields] OR schizophrenia/parasitology[All Fields] OR schizophrenia/pathogenesis[All Fields] OR schizophrenia/pathology[All Fields] OR schizophrenia/pet[All Fields] OR schizophrenia/pharmacological[All Fields] OR schizophrenia/physiology[All Fields] OR schizophrenia/physiopathology[All Fields] OR schizophrenia/prevention[All Fields] OR schizophrenia/prognosis[All Fields] OR schizophrenia/psychology[All Fields] OR schizophrenia/psychoses[All Fields] OR schizophrenia/psychosis[All Fields] OR schizophrenia/psychotherapy[All Fields] OR schizophrenia/psychotic[All Fields] OR schizophrenia/radiography[All Fields] OR schizophrenia/rehabilitation[All Fields] OR schizophrenia/research[All Fields] OR schizophrenia/retinitis[All Fields] OR schizophrenia/schizoaffective[All Fields] OR schizophrenia/schizophrenia[All Fields] OR schizophrenia/schizophrenic[All Fields] OR schizophrenia/schizophreniform[All Fields] OR schizophrenia/schizotypal[All Fields] OR schizophrenia/schizotypy[All Fields] OR schizophrenia/shock[All Fields] OR schizophrenia/sociology[All Fields] OR schizophrenia/spectrum[All Fields] OR schizophrenia/ speech[All Fields] OR schizophrenia/spinal[All Fields] OR schizophrenia/ssd[All Fields] OR schizophrenia/statistics[All Fields] OR schizophrenia/substance[All Fields] OR schizophrenia/suicide[All Fields] OR schizophrenia/surgery[All Fields] OR schizophrenia/therapy[All Fields] OR schizophrenia/ultrasonography[All Fields] OR schizophrenia/urine[All Fields] OR schizophrenia/vasospasm[All Fields] OR schizophrenia/virology[All Fields] OR schizophrenia'[All Fields] OR schizophrenia's[All Fields] OR schizophrenia1[All Fields] OR schizophreniaban[All Fields] OR schizophreniac[All Fields] OR schizophreniacs[All Fields] OR schizophreniaes[All Fields] OR schizophreniaforum[All Fields] OR schizophreniagene[All Fields] OR schizophreniai[All Fields] OR schizophreniak[All Fields] OR schizophrenial[All Fields] OR schizophrenialike[All Fields] OR schizophreniaor[All Fields] OR schizophreniara[All Fields] OR schizophreniaresearch[All Fields] OR schizophreniaresearchforum[All Fields] OR schizophreniarol[All Fields] OR schizophrenias[All Fields] OR schizophrenias'[All Fields] OR schizophreniay[All Fields] OR schizophrenic[All Fields] OR schizophrenic/ cocaine[All Fields] OR schizophrenic/control[All Fields] OR schizophrenic/nonparanoid[All Fields] OR schizophrenic/normal[All Fields] OR schizophrenic/paranoid[All Fields] OR schizophrenic/psychotic[All Fields] OR schizophrenic/schizoaffective[All Fields] OR schizophrenic/schizophreniform[All Fields] OR schizophrenic/schizotypal[All Fields] OR schizophrenic/vocational[All Fields] OR schizophrenic'[All Fields] OR schizophrenic's[All Fields] OR schizophrenical[All Fields] OR schizophrenically[All Fields] OR schizophrenices[All Fields] OR schizophrenicity[All Fields] OR schizophreniclike[All Fields] OR schizophrenicpatients[All Fields] OR schizophrenics[All Fields] OR schizophrenics/controls[All Fields] OR schizophrenics/s[All Fields] OR schizophrenics'[All Fields] OR schizophrenicss[All Fields] OR schizophrenie[All Fields] OR schizophrenie'[All Fields] OR schizophrenieaehnlichen[All Fields] OR schizophrenieahnliche[All Fields] OR schizophrenieahnlichen[All Fields] OR schizophrenieahnlicher[All Fields] OR schizophrenieartige[All Fields] OR schizophrenieartigen[All Fields] OR schizophrenieartiger[All Fields] OR schizophreniebeggriffs[All Fields] OR schizophreniebegriff[All Fields] OR schizophreniebegriffes[All Fields] OR schizophreniebegriffs[All Fields] OR schizophreniebehandlung[All Fields] OR schizophreniebehandlungen[All Fields] OR schizophreniediagnose[All Fields] OR schizophrenieerkrankten[All Fields] OR schizophrenieerkrankter[All Fields] OR schizophreniefalle[All Fields] OR schizophreniefallen[All Fields] OR schizophrenieform[All Fields] OR schizophrenieforme[All Fields] OR schizophrenieformen[All Fields] OR schizophrenieformer[All Fields] OR schizophrenieforschung[All Fields] OR schizophreniefrage[All Fields] OR schizophreniegenese[All Fields] OR schizophreniekonzepte[All Fields] OR schizophreniekonzepten[All Fields] OR schizophreniekranke[All Fields] OR schizophreniekranken[All Fields] OR schizophreniekranker[All Fields] OR schizophreniekreises[All Fields] OR schizophrenielehre[All Fields] OR schizophrenien[All Fields] OR schizophrenienahe[All Fields] OR schizophreniepatienten[All Fields] OR schizophreniepatientinnen[All Fields] OR schizophrenieproblem[All Fields] OR schizophrenieproblems[All Fields] OR schizophrenierisiko[All Fields] OR schizophrenieritoriality[All Fields] OR schizophrenies[All Fields] OR schizophreniespektrums[All Fields] OR schizophreniespezifitat[All Fields] OR schizophreniestudie[All Fields] OR schizophreniesymptomen[All Fields] OR schizophrenietheorie[All Fields] OR schizophrenietherapie[All Fields] OR schizophrenietypologie[All Fields] OR schizophrenieverlauf[All Fields] OR schizophrenieverlaufe[All Fields] OR schizophrenieverlaufs[All Fields] OR schizophrenieverstandnis[All Fields] OR schizophrenifallen[All Fields] OR schizophreniforems[All Fields] OR schizophreniform[All Fields] OR schizophreniform/paranoid[All Fields] OR schizophreniform/schizoaffective[All Fields] OR schizophreniform'[All Fields] OR schizophreniforme[All Fields] OR schizophreniformen[All Fields] OR schizophreniformes[All Fields] OR schizophreniformic[All Fields] OR schizophreniforms[All Fields] OR schizophrenigenesis[All Fields] OR schizophreniics[All Fields] OR schizophrenikern[All Fields] OR schizophrenine[All Fields] OR schizophreniologists[All Fields] OR schizophreniphorm[All Fields] OR schizophrenique[All Fields] OR schizophreniques[All Fields] OR schizophrenis[All Fields] OR schizophrenisation[All Fields] OR schizophrenism[All Fields] OR schizophreniucs[All Fields] OR schizophrenix[All Fields] OR schizophrenix's[All Fields] OR schizophreniz[All Fields] OR schizophrenization[All Fields] OR schizophrenized[All Fields] OR schizophrenjeforschung[All Fields] OR schizophrenlcs[All Fields] OR schizophrenle[All Fields] OR schizophreno[All Fields] OR schizophrenoform[All Fields] OR schizophrenogenesis[All Fields] OR schizophrenogenic[All Fields] OR schizophrenoid[All Fields] OR schizophrenomimetic[All Fields] OR schizophrenomimetics[All Fields] OR schizophrenosimilar[All Fields] OR schizophrens[All Fields] OR schizophrenuc[All Fields] OR schizophreny[All Fields] OR schizophrerines[All Fields] OR schizophrinic[All Fields] OR schizophrinie[All Fields] OR schizophrnia[All Fields] OR schizophrniekreises[All Fields]) OR (schizoaffecive[All Fields] OR schizoaffectieve[All Fields] OR schizoaf- 
fectif[All Fields] OR schizoaffectifs[All Fields] OR schizoaffective[All Fields] OR schizoaffective/bipolar[All Fields] OR schizoaffective/ bipolars[All Fields] OR schizoaffective/mania[All Fields] OR schizoaffective/mood[All Fields] OR schizoaffective/schizoaffective[All Fields] OR schizoaffective/unipolars[All Fields] OR schizoaffective'[All Fields] OR schizoaffectives[All Fields] OR schizoaffectives'[All Fields] OR schizoaffectivity[All Fields] OR schizoaffektive[All Fields] OR schizoaffektiven[All Fields] OR schizoaffektiver[All Fields] OR schizoaffettiva[All Fields] OR schizoaffettive[All Fields] OR schizoaffettivo[All Fields]) AND (Randomized Controlled Trial[ptyp] AND (“2008”[PDAT] : “2011”[PDAT]))

\section{Appendix 3. Clinicaltrials.gov search}

Clinicaltrials.gov 8 June 2011

We searched clinicaltrials.gov with the names of 13 second-generation antipsychotics (amisulpride, aripiprazole, clozapine, iloperidone, lurasidone, olanzapine, quetiapine, risperidone, paliperidone, sertindole, ziprasidone, zotepine)

\section{H I S T O R Y}

Protocol first published: Issue 4, 2009

Review first published: Issue 5, 2012

\section{CONTRIBUTIONSOFAUTHORS}

Stefan Leucht: designing the review, study selection, data extraction, statistical analysis and writing of the report.

Magdolna Tardy: designing the review, study selection, data extraction, statistical analysis and writing of the report.

Katja Komossa: designing the study, study selection, data extraction and writing of the report.

Stephan Heres: designing the study, data extraction and writing of the report.

Werner Kissling: designing the study, data extraction and writing of the report.

John Davis: designing the study, data extraction, statistical analysis and writing of the report.

All authors have agreed to a co-publication of this review in the Lancet (Leucht 2012).

\section{DECLARATIONSOF INTEREST}

Stefan Leucht: has received honoraria for consulting/advisory boards from Alkermes, Bristol-Myers Squibb, Eli Lilly, Janssen, Johnson \& Johnson, Medavante and Roche; lecture honoraria from AstraZeneca, Bristol-Myers Squibb, Eli Lilly, Essex Pharma, Janssen, Johnson \& Johnson, Lundbeck Institute, Pfizer and Sanofi-Aventis; and Eli Lilly has provided medication for a trial with SL as the primary investigator.

Magdolna Tardy: none to declare.

Katja Komossa: none to declare.

Stephan Heres: received honoraria from Janssen-Cilag, Sanofi-Aventis and Johnson \& Johnson. SH has accepted travel or hospitality payment from Janssen-Cilag, Sanofi-Aventis, Johnson \& Johnson, Pfizer, Bristol-Myers Squibb, AstraZeneca, Lundbeck, Novartis and Eli Lilly.

Werner Kissling: has received honoraria for board memberships, consulting and lectures from Janssen and Eli Lilly; honoraria for development of educational materials from Janssen; grant support from Janssen and AstraZeneca; and travel/accommodation expenses from AstraZeneca, Eli Lilly and Janssen.

John M Davis: none to declare.

Maintenance treatment with antipsychotic drugs for schizophrenia (Review)

Copyright () 2012 The Cochrane Collaboration. Published by John Wiley \& Sons, Ltd. 


\section{SOURCES OF SUPPORT}

\section{Internal sources}

- Freistaat Bayern, Germany.

- Psychiatric Institute, University of Chicago at Illinois, USA.

\section{External sources}

- Bundesministerium für Bildung und Forschung Grant number 01KG0816 88166528, Germany.

\section{DIFFERENCES BETWEEN PROTOCOLANDREVIEW}

Instead of Stata 2002 we used Comprehensive Meta-analysis Version 2 (Borenstein 2006) for the meta-regression, but both programs use the same formulae. NNTB and NNTH were calculated as the inverse of the risk difference rather than using Visual Rx. Various subgroup and meta-regression analyses were added and the method section on the investigation of heterogeneity changed to reflect this. Post-hoc analyses were clearly marked as such using an asterisk*.

We only contacted the manufacturers of so-called second-generation antipsychotic drugs for further trials (Sanofi-Aventis, Astellas, Bristol-Myers Squibb, Novartis, Eli Lilly, AstraZeneca, Janssen-Cilag, Lundbeck and Pfizer; asenapine, iloperidone and lurasidone were not available at the time of our first search and therefore not contacted). Our attempts to contact the manufacturers of old "firstgeneration antipsychotic drugs" had not been successful and most of these trials had been published more than 15 years ago (the official time trial documents must be stored in many countries).

\section{NDEX TERMS}

\section{Medical Subject Headings (MeSH)}

Antipsychotic Agents [*therapeutic use]; Dopamine Antagonists [therapeutic use]; Maintenance Chemotherapy [ ${ }^{*}$ methods]; Quality of Life; Randomized Controlled Trials as Topic; Recurrence [prevention \& control]; Schizophrenia [drug therapy; ${ }^{*}$ prevention \& control]

\section{MeSH check words}

Humans 